SYLVIO HENRIQUE NETO

\title{
DEMOCRACIA E TECNOLOGIA DA INFORMAÇÃO: O TRÍPLICE CONFLITO ENTRE CRIPTOGRAFIA, VIGILÂNCIA E PRIVACIDADE NOS ESTADOS UNIDOS
}

SÃO PAULO

2019, v.1.1, versão corrigida. 



\section{ENTREGA DO EXEMPLAR CORRIGIDO DA DISSERTAÇÃO/TESE}

\section{Termo de Ciência e Concordância do (a) orientador (a)}

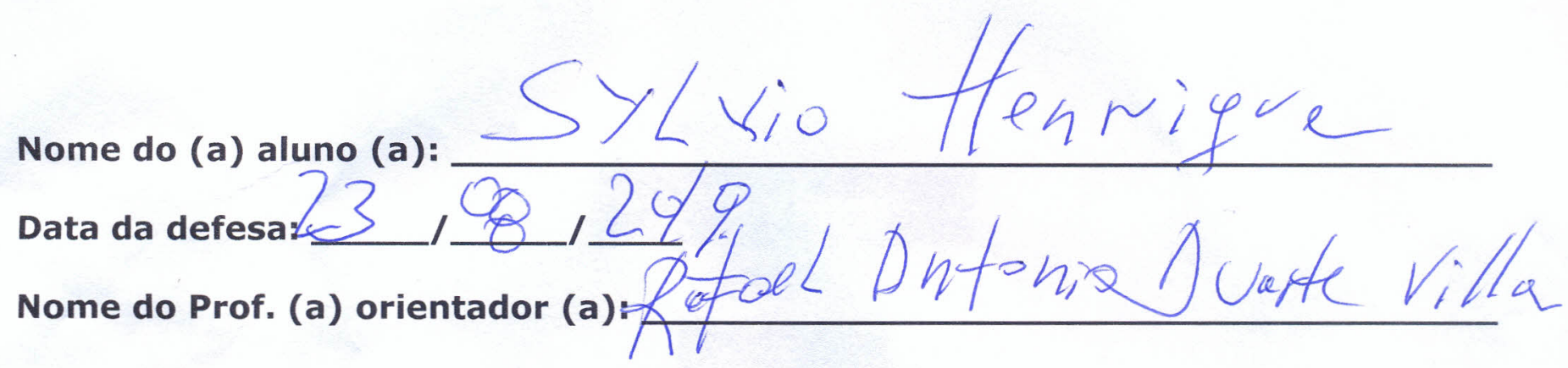

Nos termos da legislação vigente, declaro ESTAR CIENTE do conteúdo deste EXEMPLAR CORRIGIDO elaborado em atenção às sugestões dos membros da comissão Julgadora na sessão de defesa do trabalho, manifestando-me plenamente favorável ao seu encaminhamento e publicação no Portal Digital de Teses da USP.
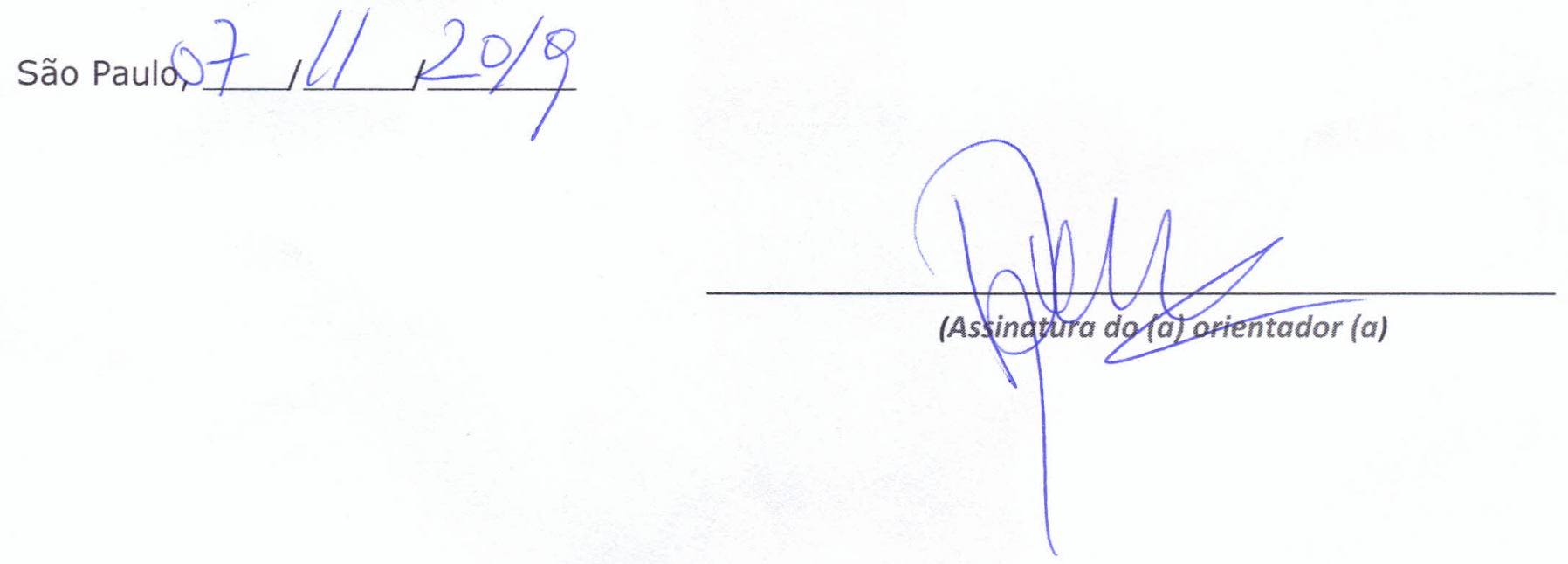
SYLVIO HENRIQUE NETO

\title{
DEMOCRACIA E TECNOLOGIA DA INFORMAÇÃO: O TRÍPLICE CONFLITO ENTRE CRIPTOGRAFIA, VIGILÂNCIA E PRIVACIDADE NOS ESTADOS UNIDOS
}

Tese de Doutorado apresentada para o Programa de Pós-Graduação em Ciência Política da Universidade de São Paulo.

\author{
Universidade de São Paulo - USP \\ Faculdade de Filosofia e Ciências Humanas \\ Programa de Pós-Graduação em Ciência Política
}

Orientador: Rafael Antônio Duarte Villa

$$
\text { SÃO PAULO }
$$

2019, v.1.1, versão corrigida. 
Autorizo a reprodução e divulgação total ou parcial deste trabalho, por qualquer meio convencional ou eletrônico, para fins de estudo e pesquisa, desde que citada a fonte.

Catalogação na Publicação

Serviço de Biblioteca e Documentação

Faculdade de Filosofia, Letras e Ciências Humanas da Universidade de São Paulo

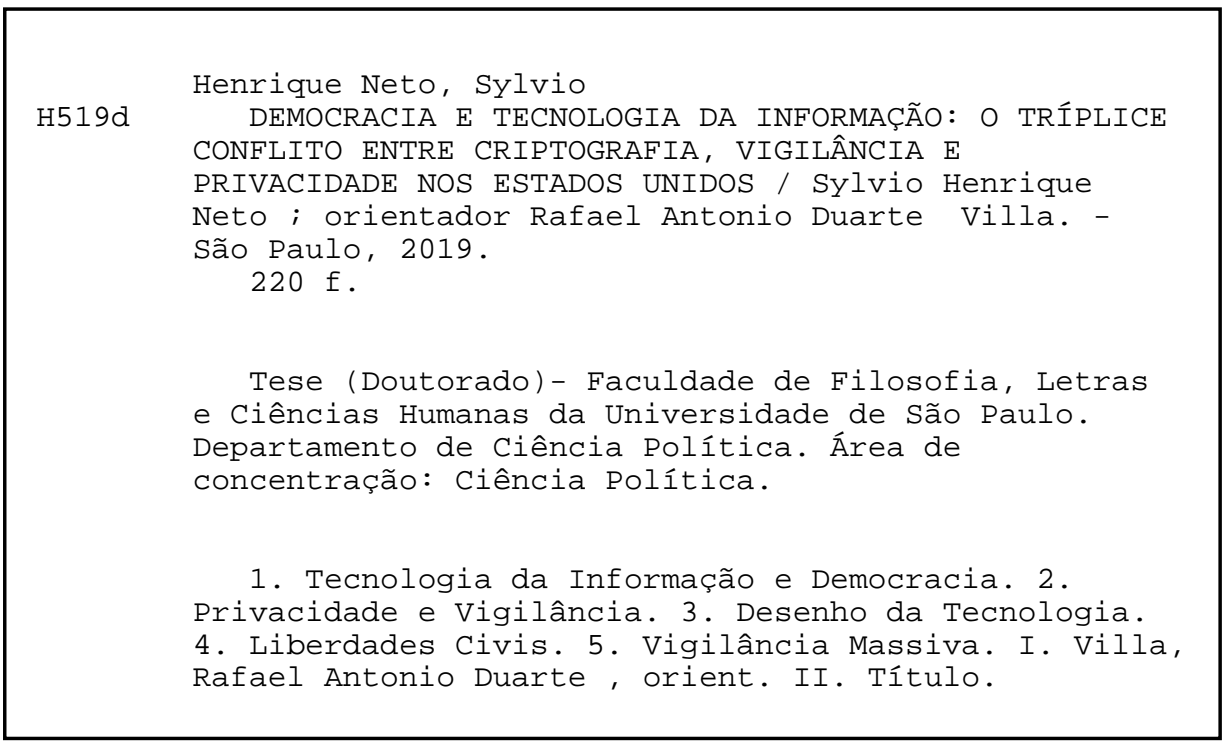


Errata 



\section{DEMOCRACIA E TECNOLOGIA DA INFORMAÇÃO: O TRÍPLICE CONFLITO ENTRE CRIPTOGRAFIA, VIGILÂNCIA E PRIVACIDADE NOS ESTADOS UNIDOS}

Tese de Doutorado apresentada para o Programa de Pós-Graduação em Ciência Política da Universidade de São Paulo.

Trabalho defendido em SÃO PAULO, em de de 2019 na Faculdade de Filosofia e Ciências Humanas da Univer-

sidade de São Paulo:

Rafael Antônio Duarte Villa

Orientador

Professor

Convidado 1

Professor

Convidado 2

Professor

Convidado 3

Professor

Convidado 4

SÃO PAULO

2019, v.1.1, versão corrigida. 

Este trabalho é dedicado ao Alison 



\section{Agradecimentos}

Diversos caminhos foram trilhados até o findar desse ciclo. Com trajetos cheio de encontros, encontrei, também, aqueles aos quais sou imensamente grato por terem compartilhado suas experiências e genuínas vontades comigo. Mais do que grato, concluo esse ciclo com meu singelo obrigado a todos que, pelos caminhos escolhidos, ajudaram a construir o brilho deste trabalho.

Compartilho meus agradecimentos ao Prof. Rafael Duarte Villa, meu orientador, que acreditou em minha pesquisa e a incentivou das mais diversas e instigantes formas - o meu muito obrigado pela oportunidade. Aos professores do Departamento de Ciência Política, aos quais tive a honra e o prazer de vivenciar grandes aprendizados, compartilho minha admiração e sincero agradecimento por todas oportunidades. Aos amigos do Departamento, Vasne, Rai e Márcia, a minha imensa gratidão pelo carinho e profissionalismo e por aconselharem, sempre, as melhores escolhas. Aos meus colegas de Pós-Graduação, pelas ricas interações e pelos anos de amizade. Poder fazer parte como um pequeno ponto na história do Departamento de Ciência Política da Universidade de São Paulo é uma conquista e motivo de grande orgulho pessoal e profissional.

Aos meus professores que, por longa jornada, compartilharam com generosidade todos os elementos necessários de transformação: os meus sinceros agradecimentos por enxergarem em mim o meu melhor. Àqueles que, nessa jornada, igualmente contribuíram com igual generosidade: agradeço ao Eder Abreu pelas oportunidades de reencontro e transformação profissional.

Agradeço, em especial, a CAPES, cujo fomento tornou possível a execução dessa pesquisa. Os meus agradecimentos, também, à Fundação Alexander von Humboldt, que nos recebeu em nome da Deutsch Gesellschaft e abriu as portas de grandes centros de excelência em pesquisa na Europa, como a Universidade de Paris Sorbonne IV, a Universidade de Copenhague e o Instituto Max Planck de Heidelberg, em uma intensa experiência internacional na Alemanha, Dinamarca e França sob o incentivo da Chanceler, Angela Merkel.

Aos meus amigos, em especial, Adriane - pelos primeiros dias de Graduação às grandes conquistas da Pós-Graduação.

E ao meu grande companheiro, Alison - ao qual dedico esta obra - por compartilhar, sempre estar presente e dar suporte nos piores e melhores momentos dessa trajetória.

O meu muito obrigado por fazerem parte dessa conquista! 

"À dolorosa luz das grandes lâmpadas eléctricas da fábrica Tenho febre e escrevo. Escrevo rangendo os dentes, fera para a beleza disto, Para a beleza disto totalmente desconhecida dos antigos. Ó rodas, ó engrenagens, $r-r-r-r-r-r-r$ eterno! Forte espasmo retido dos maquinismos em fúria! Em fúria fora e dentro de mim, Por todos os meus nervos dissecados fora, Por todas as papilas fora de tudo com que eu sinto! Tenho os lábios secos, ó grandes ruídos modernos, De vos ouvir demasiadamente de perto, E arde-me a cabeça de vos querer cantar com um excesso De expressão de todas as minhas sensações, Com um excesso contemporâneo de vós, ó máquinas! Em febre e olhando os motores como a uma Natureza tropical Grandes trópicos humanos de ferro e fogo e força Canto, e canto o presente, e também o passado e o futuro, Porque o presente é todo o passado e todo o futuro.

Excerto de "Ode Triunfal- Poesias de Álvaro de Campos. Fernando Pessoa. Lisboa: Ática, 1944, p.144. 



\section{Resumo}

A prática da vigilância massiva digital nos Estados Unidos colocou em evidencia antigas e conflitivas relações entre democracia e tecnologia, segurança nacional e liberdades civis, vigilância e privacidade. São observados alguns principais fenômenos, tais como a complexidade e dinâmicas internas da cibernética, tais como a àquelas que mobilizam a criptografia. A partir da averiguação sistemática do estudo de caso da vigilância massiva dos EUA, a pesquisa abordou três fenômenos como: (1) o primeiro fenômeno é caracterizado pela interseção (in)compatível entre democracia e "tecnologia da informação cibernética", com a apropriação política e politizada de recursos cibernéticos para fins (anti)democráticos; (2) o segundo fenômeno é caracterizado pelos embates entre "segurança nacional versus liberdades civis" e "vigilância massiva versus privacidade" que ganham um novo fôlego a partir dos movimentos de securitização pós-11/09; (3) por sua vez, o terceiro fenômeno catalisa as características anteriores - a partir da apropriação política do "cibernético" e do uso da "vigilância massiva " - a resgata os fatores que revelam tendências autoritárias em tecnologias de governo e no governo das tecnologias em democracias. A partir da análise dos três macros fenômenos, a hipótese defende que quando não há elementos democráticos suficientes para estabilizar os espaços cibernéticos e compatibilizá-los com o próprio processo democrático, habilitam-se dinâmicas e assimetrias de poder que tendem a assumir feições e se mobilizarem de forma incompatível e/ou antagônica aos pré-requisitos democráticos. Como consequência, torna-se possível a coexistência de processos e mecanismos cibernéticos, ações, instituições e políticas antidemocráticas produzidas e embebidas numa democracia. Para tanto, a pesquisa buscará categorizar e empreender as análises necessárias para se averiguar em que medida as politicas públicas cibernéticas, processos e instituições ferem ou corroboram o processo democrático nos Estados Unidos. Portanto, uma agenda de pesquisa se desdobra e busca, a partir da hipótese e dos insumos do estudo de caso, catalisar e diferenciar artefatos cibernéticos que sejam em escolha, desenho e uso compatíveis com os preceitos do processo democrático, tais como a criptografia e seu papel na sociedade enquanto instituição protetora das liberdades civis.

Palavras-chave: 1. Tecnologia da Informação e Democracia. 2. Privacidade e Vigilância. 3. Desenho da Tecnologia. 4. Liberdades Civis. 5. Vigilância Massiva. 



\section{Abstract}

The practice of mass digital surveillance in the United States has highlighted the old and conflicting relationships between democracy and technology, national security and civil liberties, surveillance and privacy. One of the main factors that has substantially modified these three phenomena is the complexity and the internal dynamics of cybernetics, such as those that mobilize cryptography in the Information Technology Age. Taking into consideration the systematic investigation of the case study of the massive surveillance of the USA, the research addressed three main phenomena:(1) the first phenomenon is characterized by the (in) compatible intersection between democracy and cybernetic information technology, with the political and politicized appropriation of cybernetic resources for (anti) democratic ends; (2) the second phenomenon is characterized by the clashes between "national security versus civil liberties" and "massive vigilance versus privacy" that gain new momentum from the post-11/09 securitization movements and the revelations about National Security Agency;(2) the second phenomenon is characterized by the clashes between "national security versus civil liberties" and "massive vigilance versus privacy" that gain new momentum after the post-11/09 securitization movements and the revelations about National Security Agency; (3) the third phenomenon, on the other hand, catalyzes the previous characteristics - from the political appropriation of the "cybernetic" and the use of "mass surveillance" - to bring to light the factors that reveal authoritarian tendencies in "technologies of government" and in "government of technologies" in democracies. From the analysis of the three macro phenomena, the hypothesis argues that when there are not enough democratic elements to stabilize cyber spaces and to reconcile them with the democratic process itself, the result is that dynamics and asymmetries of power are enabled, which are hidden by complexity and that act in a way incompatible and / or antagonistic to democratic prerequisites. As a consequence, "antidemocratic" coexistence of cybernetic processes and mechanisms, actions, institutions and policies, produced and embedded in a democracy, becomes possible. To investigate the hypothesis, the research sought to deepen and undertake the necessary analyzes with the main theoreticians of each research line in order to ascertain, in this context, the extent to which cyber public policies, processes, and institutions hurt or corroborate the democratic process in the United States. Therefore, a research agenda unfolds and seeks, from the hypothesis and the inputs of the case study, to catalyze and differentiate cybernetic artifacts that are in choice, design and use compatible with the precepts of the democratic process, such as cryptography and its role in society as a protective institution for civil liberties.

Keywords: 1. Information Technology and Democracy. 2. Privacy and Surveillance. 3. Technology Design. 4. Civil Liberties. 5. Massive Surveillance. 



\section{Résumé}

La pratique d'une surveillance accrue aux États-Unis a mis en lumière les relations anciennes et conflictuelles entre démocratie et technologie, sécurité nationale et libertés civiles, surveillance et respect de la vie privée. L'un des principaux facteurs modifiant ces trois phénomènes est la cohérence et la dynamique interne de la cybernétique, telles que celles qui mobilisent la cryptographie. Tenant compte de l'enquête systématique sur l'étude de cas de la surveillance de masse aux États-Unis, l'enquête a porté sur trois phénomènes principaux :(1) Le premier phénomène se caractérise par l'intersection "(in) compatible" de la démocratie entre cybernétique et technologies de l'information, avec l'appropriation politique et politisée de ressources "cybernétiques" à des fins (anti) démocratiques;(2) Le deuxième phénomène est caractérisé par des affrontements entre "sécurité nationale et libertés civiles" et "surveillance massive contre la vie privée" qui prennent un nouvel élan après les "mouvements de sécurisation" après le 11 septembre et les révélations sur l'Agence de Sécurité Nationale (NSA);(3) le troisième phénomène, en revanche, catalyse les caractéristiques antérieures, de l'appropriation politique de la "cybernétique" et du recours à la "surveillance de masse", pour mettre en évidence les facteurs révélant les tendances autoritaires à la "technologies gouvernementales" et "gouvernance des technologies" dans les démocraties. D'après l'analyse des trois phénomènes macro, l'hypothèse est que, lorsqu'il n'y a pas assez d'éléments démocratiques pour stabiliser le cyberespace et les réconcilier avec le processus démocratique lui-même, le résultat est que les dynamiques de pouvoir et les asymétries sont activées, cachées par la complexité et agissant de manière incompatible et / ou antagoniste par rapport aux conditions démocratiques. En conséquence, la coexistence "antidémocratique" de processus et mécanismes cybernétiques, actions, institutions et politiques, produits et intégrés dans une démocratie, est possible. Pour étudier cette hypothèse, la recherche visait à approfondir et à effectuer les analyses nécessaires avec les principaux théoriciens afin de déterminer, dans ce contexte, dans quelle mesure les politiques, processus et institutions publics cybernétiques nuisaient ou corroboraient le processus démocratique aux États-Unis. Par conséquent, un programme de recherche est élaboré et cherche, à partir des hypothèses et des éléments de l'étude de cas, à catalyser et différencier les artefacts cybernétiques trouvés dans le choix, la conception et l'utilisation compatibles avec les préceptes du processus démocratique, comme la cryptographie et son rôle dans la société comme une institution de protection des libertés civiles.

Mots-clés : 1. Technologie de l'information et démocratie. 2 Vie privée et surveillance. 3. Conception de la technologie. 4. Libertés civiles. 5. Surveillance massive. 



\section{Resumen}

La práctica de mas vigilancia en los Estados Unidos ha resaltado las relaciones antiguas y conflictivas entre la democracia y la tecnología, la seguridad nacional y las libertades civiles, la vigilancia y la privacidad. Uno de los principales factores que ha estado modificando estos tres fenómenos es la coherencia y la dinámica interna de los cybernetics tales como aquellos que movilizan la criptografía. Teniendo en cuenta la investigación sistemática del estudio de caso de la vigilancia masiva de los EE.UU., la investigación se dirigió a tres fenómenos principales: (1) El primer fenómeno se caracteriza por la intersección "(in) compatibles"de la democracia entre la cibernética y la tecnología de la información, con la apropiación política y politizada de recursos çibernéticos"para fines (anti) democráticos;(2) el segundo fenómeno se caracteriza por los choques entre "seguridad nacional versus libertades civilesz "vigilancia masiva contra privacidad"que cobran un nuevo impulso después de los "movimientos de la securitización"posteriores al 11/09 y de las revelaciones sobre la Agencia de Seguridad Nacional; (3) el tercer fenómeno, por otro lado, cataliza las características anteriores, desde la apropiación política de la çibernéticaz el uso de la "vigilancia masiva", para sacar a la luz los factores que revelan tendencias autoritarias en "tecnologías de gobiernoz en "gobierno de tecnologías. en democracias. A partir del análisis de los tres fenómenos macro, la hipótesis sostiene que cuando no hay suficientes elementos democráticos para estabilizar los ciberespacio y reconciliarlos con el proceso democrático en sí, el resultado es que se habilitan dinámicas y asimetrías de poder, que están ocultas por La complejidad y que actúan de forma incompatible y / o antagónica a los requisitos previos democráticos. Como consecuencia, la coexistencia . ${ }^{a}$ ntidemocrática"de procesos y mecanismos cibernéticos, acciones, instituciones y políticas, producidas e integradas en una democracia, se hace posible. Para investigar la hipótesis, la investigación se trató de profundizar y llevar a cabo los análisis necesarios con los principales teóricos de cada línea de investigación a fin de determinar, en este contexto, la medida en que las políticas públicas cibernéticos, los procesos y las instituciones herido o corroborar el proceso democrático en los Estados Unidos. Por lo tanto, un programa de investigación se desarrolla y busca, a partir de la hipótesis y las entradas del estudio de caso, catalizar y diferenciar artefactos cibernéticos que se encuentran en la elección, el diseño y el uso compatible con los preceptos del proceso democrático, como la criptografía y su papel en la sociedad como institución protectora de las libertades civiles.

Palabras clave: 1. Tecnología de la información y la democracia. 2. Privacidad y Vigilancia. 3.Diseño de la Tecnología. 4. Libertades civiles. 5. Vigilancia masiva. 



\section{Lista de ilustrações}

Figura 1 - Cronologia de eventos de impacto tecnológico no século XX . . . . . . 65

Figura 2 - Máquina Enigma . . . . . . . . . . . . 86

Figura 3 - Engrenagem Alfanumérica . . . . . . . . . . . . 86

Figura 4 - Alan Turing . . . . . . . . . . . . . . . . 87

Figura 5 - Bombe Decifradora . . . . . . . . . . . . 87

Figura 6 - Reichstagsbrandverordnung . . . . . . . . . . . . . 103

Figura 7 - Ermachtigungsgesetz $64 \ldots \ldots$. . . . . . . . . . 103

Figura 8 - Clipper Chip . . . . . . . . . . . . . . . . . 134

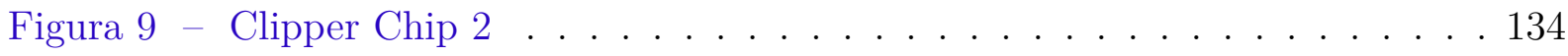

Figura 10 - Campanha Sink Clipper da RSA Security contra o chip Clipper, como parte do momento compreendido como Crypto Wars. . . . . . . . . . . 136

Figura 11 - A Coleta de dados Upstream e Downstream da NSA pela FISA 702 . 153

Figura 12 - Infraestrutura Global de Cabos de Fibra-Ótica . . . . . . . . . . . . 155

Figura 13 - Compilação das ações dos programas de coleta Upstream . . . . . . . . 157

Figura 14 - Apresentação do projeto XKEYSCORE da NSA - Parte 1 . . . . . . . 159

Figura 15 - Apresentação do projeto XKEYSCORE da NSA - Parte 2 . . . . . . . 160

Figura 16 - Apresentação do projeto XKEYSCORE da NSA - Parte 3 . . . . . . . 161

Figura 17 - Programa PRISM de Inteligência da NSA - parte 1 . . . . . . . . . . . 165

Figura 18 - Programa PRISM de Inteligência da NSA - parte 2 . . . . . . . . . . 166 



\section{Lista de tabelas}

Tabela 1 - Considerações de Robert Dahl acerca da Democracia . . . . . . . . . . 110

Tabela 2 - Conseq. da Democracia . . . . . . . . . . . . . . . 110

Tabela 3 - Democracia em Larga Escala . . . . . . . . . . . . . . . . 110

Tabela 4 - Tabela Consolidada da Capacidade de Atuação do XKEYSCORE para a coleta massiva de dados . . . . . . . . . . . . . . . . . 162

Tabela 5 - Tabela Consolidada de Formas de Classificação para Criptoanálise . . . 168

Tabela 6 - Classificação Criptográfica pela NSA . . . . . . . . . . . . . . 170

Tabela 7 - Recomendações do PCLOB sobre a Coleta Massiva de Registros de Telefone . . . . . . . . . . . . . . . . . . . 185

Tabela 8 - Recomendações do PCLOB sobre a Coleta Massiva de Registros de Telefone - Continuação da tabela 7 . . . . . . . . . . . . . 186

Tabela 9 - Recomendações do PCLOB Programa de Vigilância Operado de acordo com a Seção 702 da FISA - Parte 1 . . . . . . . . . . . . . . . . . . . 192

Tabela 10 - Recomendações do PCLOB Programa de Vigilância Operado de acordo com a Seção 702 da FISA - Parte 2 - Continuação da Tabela 9 . . . . . 193 



\section{Lista de abreviaturas e siglas}

\begin{tabular}{|c|c|}
\hline $\mathrm{ABNT}$ & Associação Brasileira de Normas Técnicas \\
\hline NSA & National Security Agency \\
\hline EUA & Estados Unidos da América \\
\hline SSL & Secure Sockets Layer \\
\hline SSH & Secure Shell \\
\hline TLS & Transport Layer Security \\
\hline $\mathrm{IC}$ & Intelligence Community \\
\hline VoIP & Voice over Internet Protocol \\
\hline VPN & Virtual Private Network \\
\hline PGP & Pretty Good Privacy \\
\hline HTTP & Hypertext Transfer Protocol \\
\hline HTTPS & Hyper Text Transfer Protocol Secure \\
\hline CIA & Central Intelligence Agency \\
\hline SIGINT & Signals intelligence \\
\hline COMINT & Communications Intelligence \\
\hline ELINT & Electronic Intelligence \\
\hline MASINT & Measurement and Signature Intelligence \\
\hline RADINT & Radar Intelligence \\
\hline FISA & Foreign Intelligence Surveillance Act of 1978 \\
\hline FAA & Foreign Intelligence Surveillance Act of 1978 Amendments Act of 2008 \\
\hline PRISM & $\begin{array}{l}\text { Planning Tool for Resource Integration, Synchronization, and Manage- } \\
\text { ment }\end{array}$ \\
\hline PCLOB & Privacy and Civil Liberties Oversight Board \\
\hline FBI & Federal Bureau of Investigation \\
\hline
\end{tabular}





\section{Lista de símbolos}

$\begin{array}{ll}\Gamma & \text { Letra grega Gama } \\ \Lambda & \text { Lambda } \\ \zeta & \text { Letra grega minúscula zeta } \\ \epsilon & \text { Pertence }\end{array}$





\section{Sumário}

INTRODUÇÃO $\ldots \ldots \ldots \ldots \ldots \ldots \ldots \ldots \ldots$

TECNOLOGIA E SUAS dinÂMICAS POLÍTICAS . . . . . . . . . 45 Tecnologia, Vigilância e Sociedade da Disciplina em Foucault . . . . 48 Tecnologia, Poder e a Sociedade do Controle em Deleuze . . . . . . 51

TECNOLOGIA DA INFORMAÇÃO, VIGILÂNCIA E PRIVACIDADE: A FUNÇÃO DEMOCRÁTICA DA CRIPTOGRAFIA . . . . . . . 81

3.1 Cibernética, Tecnologia da Informação e a Visão Sistêmica da Crip-

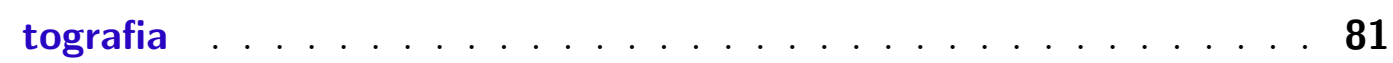

$3.2 \quad$ A visão sistêmica da criptografia . . . . . . . . . . . . . 84

PRIVACIDADE, VIGILÂNCIA E AS INSTITUIÇÕES DEMOCRÁ-

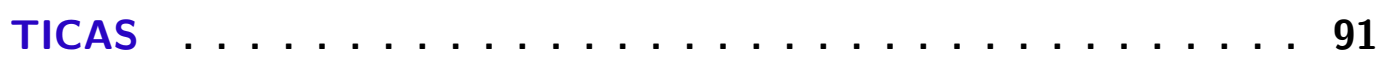

$4.1 \quad$ Um breve histórico sobre a privacidade . . . . . . . . 91

$4.2 \quad$ A Busca por Definições de Privacidade . . . . . . . . . . 96

$4.3 \quad$ A Privacidade em Seu Valor Relativo em Democracias . . . . . . . 99

4.4 Vigilância e a Tecnologia do Autoritarismo na Alemanha . . . . . . 102

$4.5 \quad \mathrm{O}$ espectro político da Vigilância e da Privacidade . . . . . . . 106

4.6 Os impactos da Vigilância e da Privacidade na Democracia . . . . 109

5 SEGURANÇA NACIONAL VERSUS LIBERDADES CIVIS: A PERSPECTIVA DA SECURITIZAÇÃO . . . . . . . . . . . . . 117 
CRYPTO WARS . . . . . . . . . . . . . . . . . . . . 131

$7.1 \quad$ O Monopólio Estatal da Criptografia . . . . . . . . . . . . . 131

$7.2 \quad$ Clipper Chip . . . . . . . . . . . . . . . . . . . . 133

7.3 Criptografia como liberdade de expressão: o caso do Pretty Good Privacy $(\mathrm{PGP}) \ldots \ldots \ldots \ldots$

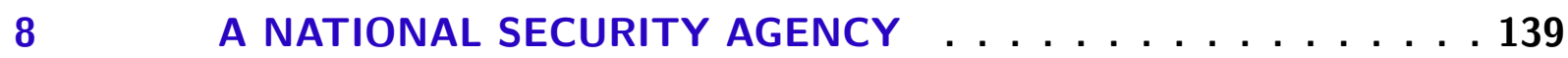

8.1 A National Security Agency e a Coleta Massiva de Dados . . . . . 139

9 A COLETA DE DADOS: TECNOLOGIAS E ARQUITETURAS LEGISLATIVAS DA VIGILÂNCIA . . . . . . . . . . . . . . . . 147

9.1 A arquitetura legislativa da Foreign Intelligence Surveillance Act . . 147

9.1.0.1 A Seção 702 da Foreign Intelligence Surveillance Act . . . . . . . . . . . . . 149

9.1.0.2 A Foreign Intelligence Surveillance Act e a coleta Upstream e Downstream de dados 151

$9.2 \quad$ A coleta de dados Upstream . . . . . . . . . . . . . 155

9.2.1 Os Programas OAKSTAR, STORMBREW, BLARNEY e FAIRVIEW . . . 155

9.2 .2 Os Programa XKeyscore . . . . . . . . . . . . . . . . . . . 159

$9.3 \quad$ A Coleta de Dados Downstream . . . . . . . . . . . . . . 164

$9.3 .1 \quad$ O Programa PRISM . . . . . . . . . . . . . . . . . . . 164

$9.4 \quad$ O Poder Criptográfico da NSA . . . . . . . . . . . . . . . 167

IV RESULTADOS E CONSIDERAÇÕES FINAIS 173

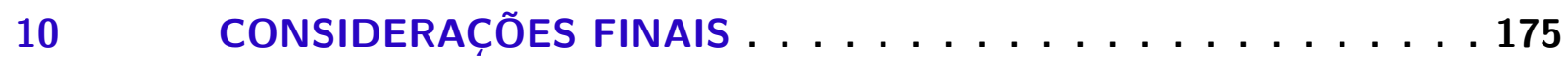

10.1 A Supervisão da Privacidade e Liberdades Civis: Resultados do

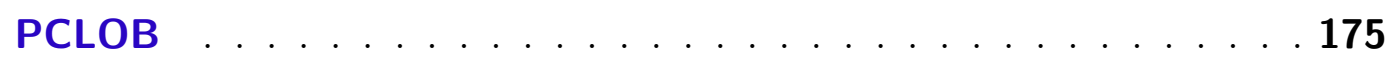

10.1.1 Relatórios dos Programas de Vigilância . . . . . . . . . . . . . . 177

10.2 Relatório sobre o Programa de Registros Telefônicos . . . . . . . 178

10.2.0.1 Resultados das Análises da Coleta Telefônica sob a Seção 215 . . . . . . . . 178

10.2.0.2 Parecer sobre a Coleta Telefônica sob a Seção 215 . . . . . . . . . . . . . . 183

10.3 Relatório sobre o Programa de Vigilância pela Seção 702 . . . . . 187

10.3.0.1 Resultados das Análises da Coleta Massiva sob a Seção 702 . . . . . . . . . . 188

10.3.0.2 Parecer sobre a Coleta Telefônica sob a Seção 702 . . . . . . . . . . . . . 189

$10.4 \quad$ A Teoria em Perspectiva . . . . . . . . . . . . . . . . . . . 194

10.5 A Pesquisa em Perspectiva . . . . . . . . . . . . . . . . . 197 


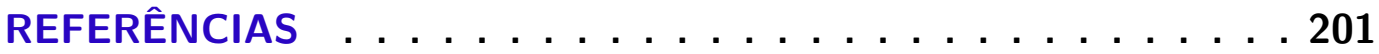

APÊNDICES

APÊNDICE A-METODOLOGIA. . . . . . . . . 213

Metodologia . . . . . . . . . . . . . . . . . 213

A.1 Material, Métodos e Forma de Análise dos Resultados. . . . . . . . 213

$\begin{array}{ll}\text { ANEXOS } & 217\end{array}$

ANEXO A - ACERVO DOCUMENTAL . . . . . . . . . 219

A.1 Anexo 1 - Discurso de Barack Obama, 17/01/2014: Remarks by the President on Review of Signals Intelligence . . . . . . . . . . . 219

A.2 Anexo 2 - Documento de Anúncio do Clipper Chip, 04/02/1994:

Statement of the Press Secretary . . . . . . . . . . . . 230 



\section{Parte I}

\section{Democracia e Tecnologia da Informação: $O$ \\ Tríplice Conflito Entre Criptografia, Vigilância e Privacidade nos Estados Unidos}





\section{Introdução}

"Big Brother Is Watching You". A frase pertencente à obra "1984", de George Orwel, criou frisson no mundo literário ao mostrar um futuro não muito distante no qual seus habitantes eram constantemente observados tecnologicamente, sem consentimento ou privacidade. Com sua ferramenta primária de poder, chamada de 'telescreen', o 'Big Brother', personagem do enigmático ditador, constantemente monitorava e espionava os cidadãos com tecnologias avançadas na tentativa de eliminar qualquer senso de privacidade ou individualidade - ameaças à segurança e a ordem coletiva. Ao menor sinal de subversão, executavam-se ações punitivas para o controle da população. A obra 1984 é especialmente importante não somente como recurso literário para ilustrar arbitrariedades e abusos de poder, como, também, para antecipar o fenômeno singular da conjunção da vigilância massiva, Estado de exceção e poder político da tecnologia.

Em um contexto altamente informatizado da segunda metade do século XXI, tal fenômeno perpassou o locus do autoritarismo tipificado na obra literária e passou a ser observado em governos liberais-democráticos a partir dos dois outros grandes fenômenos: a normatização da exceção, que tolera e naturaliza exceções à democracia frente a ameaças existenciais, e a manifestação do poder cibernético, enquanto apropriação política dos sistemas complexos cibernéticos - que compreendem todo o ecossistema da Tecnologia da Informação, tais como a própria Internet. Quase seis décadas se passaram desde a primeira publicação de "1984" e a contemporaneidade da obra de Orwell se mantém ao ecoar em nosso cotidiano digitalizado e tecnologicamente interdependente, o futuro obscuro da invasão de privacidade, vigilâncias massivas e arbitrariedades preconizadas em sua distopia.

Parte constituinte desse cotidiano digital, a ubiquidade da internet oferece uma importante plataforma de comunicação global que conecta e permeia todas as esferas da vida pública e privada. As informações, em grande parte criptografadas, trafegam por satélites de telecomunicação e cabos transatlânticos que se unificam numa infraestrutura digital global localizada e controlada majoritariamente pelos EUA. A intrincada rede de computadores não somente favorece a comunicação global como permite, devido à sua arquitetura e natureza cibernética, que qualquer indivíduo ou Estado com conhecimentos avançados possa gerar assimetrias de poder ao se utilizar, por exemplo, do domínio de inovações ou vulnerabilidades cibernéticas. O reconhecimento do poder político e militar dessas assimetrias digitais data de décadas antes à própria Internet, quando o interesse estatal se estendeu sobre o domínio cibernético da criptografia, tornando-a decisiva na definição dos rumos, ainda que em bastidores, da Primeira e Segunda Guerra Mundial (KAHN, 1997). Na liderança desse processo, a National Security Agency (NSA), criada 
pelo Presidente Truman em 1952, reafirmou ao longo de 60 anos o seu "compromisso" institucional de exercer a "Global Cryptologic Dominance through Responsive Presence and Network Advantage" (National Security Agency, 2010b). Nessa lógica, os objetivos da Global Cryptologic Dominance e Network Advantage combinavam as intenções de se construir a hegemonia estatal tanto no domínio cibernético, quanto no seu subdomínio da criptografia.

Embora tenha exercido papel preponderante nos bastidores das duas "grandes guerras", a articulação direta e interpretação da criptografia enquanto recurso de poder militar-cibernético é evidenciada com maior intensidade na década de 80, quando a exportação de tecnologia criptográfica, já amplamente difundida, passou a ser controlada por rígidas políticas públicas de cunho alfandegário-militar ${ }^{1}$, (KAHN, 1980). Em outras palavras, para os policymakers dos Estados Unidos, as políticas públicas relacionadas a Tecnologia da Informação representavam mais do que "esforços" militares; manifestavam o interesse hegemônico de expansão dos domínios da soberania estatal sobre as novas formas e assimetrias de poder político-cibernéticas - principalmente pelo controle de seus níveis de segurança, arquitetura, acesso, difusão e uso por parte da população civil e demais nações. Tais intenções se manifestaram claramente naquela que pode ser compreendida como a primeira política pública dedicada exclusivamente aos espaços cibernéticos: A Cyberspace Policy Review.

A militarização e securitização dos artefatos cibernéticos, intensificada pela massificação internacional da internet, contribuíram para aguçar a percepção de que a Tecnologia da Informação, outrora considerada "neutra", não era, contudo, desprovida de valores políticos e poderia, portanto, se dotada de intenções dúbias, representar riscos à segurança individual e nacional. Esse processo ainda contou com o agravante do atentado terrorista de 11 de setembro de 2001. Afinal, constataram-se, nos relatórios pós-11/09, que as células terroristas da Al Qaeda puderam permanecer ocultas com a utilização de mensagens criptografadas para orquestrar o atentado terrorista (THOMAS, 2002). Como resultado, os formuladores da Segurança Nacional e Política Cibernética estadunidense passaram a interferir na arquitetura da internet e seus aparatos criptográficos para adaptá-los ao combate às novas formas de difusão do terrorismo, tendo em vista que, os ataques poderiam ser conduzidos internamente ou externamente ao se explorar vulnerabilidades tecnológicas - sob o risco de se afetar desde sistemas de uma usina nuclear à satélites de comunicação. Como prevenir um novo ataque terrorista em solo americano se sua origem for digital? Como garantir que os novos cenários de vulnerabilidades cibernéticas não serviriam à atuação de grupos terroristas? Como assegurar a Segurança Nacional tendo em vista o eminente potencial de ameaças digitais?

1 Regulamentadas pelos decretos "International Traffic in Arms Regulations" (ITAR) e "Export Administration Regulations" (EAR) 
Por intermédio dos movimentos de "securitização", o Governo dos Estados Unidos pôde abrir janelas de oportunidades para que, em nome de sua segurança nacional, fossem adotados e legitimados processos extraordinários de prevenção ao terrorismo sob um novo paradigma na concepção da segurança nacional: a "guerra ao terror" em todos seus meios, físicos e virtuais. Pelo discurso preventivo, o Congresso dos Estados Unidos, consonante com o Executivo, posicionou a Internet, o controle criptográfico, as liberdades civis e, principalmente, a privacidade como objetos de intensos processos legislativos para normatizar a execução de ações que, outrora, seriam sumariamente rechaçadas devido às características que remontam ao "Estado de Exceção". Constituiu-se, nesse ínterim, uma complexa arquitetura legislativa, política e tecnológica que, ao passo que "fortalecia" a segurança nacional frente ao 'terrorismo' cibernético, dissipava os limiares entre o público e o privado, democracia e autoritarismo.

O potencial tecnológico da coleta de dados, aliado à adoção exponencial da Internet, habilitou um novo horizonte de possibilidades para o exercício da Segurança Nacional ao proporcionar o monitoramento e controle massivo de informações das mais variadas fontes, nacionalidades e propósitos. A espionagem, enquanto atividade milenar, foi "modernizada" e ressignificada em sua escala e amplitude ao tornar-se concomitantemente uma vigilância massiva e cibernética. O descompasso entre essa fusão se fez evidente em relação à legitimidade democrática. Conforme pontua Bertrand Russel, "modern techniques have made possible a new intensity of governmental control, and this possibility has been exploited very fully in totalitarian States"." (RUSSELL, 1995, p. 34). Dentre as ações normatizadas como exceção em prol do combate preventivo ao terrorismo, privilegiou-se a vigilância contínua dos novos espaços digitais, públicos e privados. Com o intuito de prevenir, "normatizou-se" ao Estado, por intermédio da PATRIOT Act, Terrorist Surveillance Act e Protect America Act, os processos cibernéticos de vigilância massiva de informações. Na institucionalização desse processo, o governo Bush lançou a National Strategy to Secure Cyberspace (THE WHITE HOUSE, 2003). Posteriormente, em 2009, Barack Obama aprofundou e ampliou a estratégia da segurança nacional cibernética anterior, tornando-a inerentemente vinculada com sua projeção internacional ao promulgar a Cyberspace Policy Review (THE WHITE HOUSE, 2009).

Nesse sentido, cabe indagar: em que medida a conjunção entre o domínio cibernético e a vigilância massiva resvala nas estruturas democráticas mais fundamentais, como a privacidade? Em um primeiro instante, a conjunção de uma complexa arquitetura próvigilância com a complexidade cibernético, ininteligível à população em geral, obscureceram as informações necessárias ao "accountability" das ações do Estado e a defesa de liberdades civis por parte da sociedade americana. Mais do que isso, obscureceram o próprio processo

2 "Técnicas modernas tornaram possível uma nova intensidade de controle governamental e essa possibilidade foi explorada muito plenamente nos Estados totalitários" (RUSSELL, 1995, p. 34), tradução nossa. 
democrático, colocando-o, portanto, em xeque. Desta forma, em um segundo momento, tornou-se premente conhecer até que ponto as estruturas do processo democrático não foram abaladas. Afinal, até que ponto a vigilância massiva digital, correlacionada com os desafios da complexidade cibernética, é compatível com as estruturas democráticas modernas? Como explicar a transformação da privacidade, outrora uma liberdade civil tão defendida nos Estados Unidos, em uma exceção Constitucional? Num país com fortes tradições de defesa das liberdades civis, como se tornou ordinária a violação das informações digitais e, consequentemente, "extraordinária" a sua proteção? A vigilância massiva cibernética pode ser considerada um indicador desse processo de transgressão de limiares democráticos ou um indicativo da necessidade de uma nova forma de democracia que se habilita enquanto "tecnocracia"?

\subsection{A Hipótese}

As respostas aos questionamentos expostos acima demandam a averiguação sistemática do estudo de caso da Política Cibernética dos EUA a partir da observação de três macrofenômenos sobrepostos e intrinsecamente interdependentes, a saber:

1. O primeiro fenômeno é caracterizado pela interseção (in)compatível entre democracia e "tecnologia da informação cibernética", com a apropriação política e politizada de recursos cibernéticos para fins (anti)democráticos; Por sua vez, toma como pressuposto básico que os artefatos cibernéticos possuem; em primeiro lugar, valor político por si próprios como, também, endógenos e exógenos; são capazes de expressar, articular e exercer poder; emanam e demandam uma organização de poder sui generis e tornaram-se, após a revolução da Tecnologia da Informação, estruturas indissociáveis da organização e das formas (anti)democráticas contemporâneas. Por estes pressupostos, não é possível, portanto, dissociar a relação da Tecnologia da Informação, enquanto cibernética, com as formas contemporâneas da democracia.

2. O segundo fenômeno é caracterizado pelos embates entre "segurança nacional versus liberdades civis" e "vigilância versus privacidade", que ganham um novo fôlego a partir dos movimentos de securitização pós-11/09 e após a revelação de acerca das ações da National Security Agency; Tais embates estariam dispostos em posições diferentes dos espectros políticos que levariam a questionamentos sobre em qual posição o pêndulo de (des) equilíbrio poderia figurar, tanto em regimes democráticos como em autoritários. Os conflitos entre as dicotomias acima mobilizaria, nesse ínterim, o próprio desenho da tecnologia, no caso, da criptografia. Por sua vez, o pêndulo também indicaria o modo como a criptografia deveria ser conduzida ao transitar entre os espectros políticos. Nesse sentido, a criptografia figuraria como o objeto de disputa entre as dicotomias e seria mobilizada igualmente como elemento 
conflitante e em discussão; o conflito, dessa forma, seria triplo: entre vigilância, criptografia e privacidade, enquanto expressões últimas das dicotomias.

3. Por sua vez, o terceiro fenômeno seria identificado como um catalizador dos fenômenos anteriores ao propor a análise - a partir da apropriação política da "tecnologia da informação cibernética" e do uso da "vigilância massiva eletrônica" - dos fatores que mobilizam e engendram feições autoritárias, de cunho racional e tectonológico, no abuso de poder por parte de forças totalitárias/totalizantes, que suspende de forma (não) deliberada o processo democrático na escolha, desenho e uso de tecnologias cibernéticas com impacto direto nas liberdades civis.

A pergunta de pesquisa realiza não é única, mas, sim, composta pelas seguintes inquietações: Em medida o desenho da tecnologia serviria à um propósito político predisposto entre a vigilância e a privacidade? Uma sociedade de base racional, tecno-científico serviria à fins autoritários ou totalizantes quando auferidas as consequências tecnológicas sobre as liberdades civis e instituições democráticas? Identificados tais consequências, seria possível compatibilizar as tecnologias cibernéticas com processos democráticos de governo da tecnologia e de tecnologias de governo? Se sim, seria possível encontrar, para tais fins, elementos/artefatos endógenos e exógenos às tecnologias cibernéticas que atuariam como transposição de instituições democráticas à espaço cibernético?

Nesse sentido, a hipótese defende que quando não há elementos democráticos suficientes para estabilizar os espaços cibernéticos e compatibilizá-los com o próprio processo democrático, habilitam-se formas, processos e assimetrias de poder que tendem a assumir feições e se mobilizarem de forma incompatível e/ou antagônica aos pré-requisitos do processo democrático. Como consequência, torna-se possível a coexistência de processos e mecanismos cibernéticos, ações, instituições e políticas antidemocráticas produzidas, embebidas e ocultas pela complexidade cibernética-tecnológica numa democracia.

\subsection{Os Objetivos}

A partir dos fenômenos que mobilizam a pergunta de pesquisa e culminam na hipótese, três objetivos de pesquisa são, então, desdobrados:

1. O primeiro é a consolidação de uma abordagem teórica capaz de fornecer referenciais para se distinguir a escolha, desenho e uso de tecnologias cibernéticas enquanto compatíveis com os preceitos e pré-requisitos do processo democrático;

2. O segundo objetivo consiste em fornecer insumos a partir dos estudos de caso para a identificação dessas escolhas, desenhos e uso de tecnologias cibernéticas para reafirmar ou caracterizá-las como nocivas ao processo democrático. A partir do 
estudo de caso proposto para a compreensão do segundo fenômeno, objetiva-se identificar, também, materiais empíricos para a averiguação da hipótese. Nesse sentido, a pesquisa indagará e buscará averiguar em que medida o primeiro embate entre segurança nacional e liberdades civis - e o segundo embate da vigilância massiva e privacidade- são frutos do processo de securitização após o atentado terrorista de 11/09 de $2001 \mathrm{ou}$, se se tratam, em um segundo plano, da apropriação política de recursos cibernéticos para fins (anti) democráticos que precedem tal período como, por exemplo, o controle do código e da criptografia;

3. O terceiro objetivo, por sua vez, será dedicado à consolidação das proposições teóricas com os resultados obtidos no segundo objetivo, ou seja, a partir dos insumos obtidos pelo segundo fenômeno e pelas lentes analíticas do primeiro, a pesquisa buscará categorizar e empreender as análises necessárias para se averiguar em que medida as politicas públicas cibernéticas, processos, instituições ferem ou corroboram o processo democrático nos Estados Unidos.

\subsection{A Pesquisa}

Para corroborar ou refutar a hipótese, a pesquisa buscou aprofundar as discussões teóricas pertinentes e aplicá-las ao estudo de caso das dinâmicas da NSA identificadas à partir das revelações de Edward Snowden em 2013. O recorte temporal da pesquisa, portanto, abarca os processos constituintes do objeto, considerados nessa pesquisa à partir do 11 de setembro de 2001 até os desdobramentos das revelações acerca da NSA no findar da Presidência de Barack Obama, em 20 de janeiro de 2017.

Para tanto, este trabalho divide-se em quatro grandes partes, compostas por capítulos e seções. A primeira grande parte trabalha justamente a introdução a pesquisa e transcorreu posteriormente à essa explicação. A segunda grande parte, denominada "Referenciais Teóricos", aborda os autores e abordagens teóricas empreendidas ou que contribuíram para o desenvolvimento da pesquisa. Nesse sentido, são abordadas na segunda grande parte, as seções acerca da "Tecnologia e Suas Dinâmicas Políticas", "Tecnologia Da Informação, Vigilância e Privacidade: A Função Democrática da Criptografia e Privacidade", "Vigilância E as Instituições Democráticas"e o ensejo da "Segurança Nacional Versus Liberdades Civis: A Perspectiva da Securitização".

Na terceira grande parte, denominada "A Política Cibernética Dos Estados Unidos"é dedicada ao estudo de caso e seu contexto histórico-político. São apresentadas nessa parte as seções "Das Liberdades Civis À Vigilância Massiva", "Crypto Wars", a "National Security Agency"e a "Coleta De Dados: Tecnologias e Arquiteturas Legislativas da Vigilância". Tais seções exploram o estudo de caso de acordo com a delimitação temporal, sem se restringir, contudo, à outros movimentos que compuseram ou enriqueceram o quadro analítico da 
pesquisa. Na quarta e última seção, os resultados obtidos e as considerações finais são então compartilhados, em consonância com os "Relatórios dos Programas de Vigilância", "A Teoria em Perspectiva"e, também, "A Pesquisa em Perspectiva".

A relevância deste trabalho consiste na possibilidade se fazer a releitura do debate clássico do processo para identificar estruturas cibernéticas que o sustente e reafirme. Para tanto, o estudo de caso da vigilância massiva digital nos EUA - ao resgatar os embates entre segurança nacional versus liberdades civis e vigilância massiva versus privacidade - será de profícua utilidade para se identificar como artefatos cibernéticos, como a criptografia, códigos e demais itens sofreram um intenso processo de securitização para fins incertos e preceitos questionáveis. A partir dos pressupostos do processo democrático, argumenta-se, também, que o desenho da tecnologia e seus princípios devam ser compatíveis com o ordenamento político à qual ela se insere: se democrático, a tecnologia deverá ser concebida igualmente como democrática em preceitos e processos.

O trabalho justifica-se, também, por tratar diretamente, primeiramente, das implicações teóricas e práticas desse conflito ora entre tecnologias cibernéticas e democracia, ora entre segurança nacional versus liberdades civis, bem como sua extensão à vigilância massiva versus privacidade em contextos cibernéticos. Pretende-se, desta forma, ao introduzir o fator inovador do potencial analítico resultante da conjunção entre Ciência Política e Tecnologia da Informação pela abordagem Cibernética, promover o debate acadêmico das novas relações de poder que se estabelecem em meios cibernéticos, tanto no microcosmo do indivíduo, quanto no macrocosmo da Ciência Política e Relações Internacionais. 

Parte II

\section{Referenciais teóricos}





\section{Tecnologia e suas Dinâmicas Políticas}

A abordagem teórica necessária para a compreensão dos fenômenos que dão origem à hipótese e delimitam o objeto de estudo se articulará em três recortes teóricos distintos: (Seção 3.1) O primeiro recorte abordará a relação política da tecnologia, expressa por Langdom Winner, em especial a tecnologia da informação, especificamente às vertentes cibernéticas de Norbert Wiener, com a compreensão de Dahl sobre o processo democrático; (Seção 3.2) Por sua vez, o segundo recorte teórico buscará elucidar, pelo viés da Securitização da Escola de Copenhague, a retomada do famigerado embate entre segurança nacional e liberdades civis, representados aqui pela vigilância massiva e a erosão da privacidade em um contexto cibernético-democrático; (Seção 3.3) O terceiro recorte sintetizará os anteriores na tentativa de explicar o terceiro fenômeno constituinte da hipótese: o "Estado de Exceção", baseado na apropriação política de recursos cibernéticos e nos movimentos de securitização nos Estados Unidos. Desta forma, buscaremos em um primeiro momento apresentar ponderações teóricas essenciais para a compreensão do objeto e, em um segundo momento, apresentar o estudo de caso, seus recortes e debates para que, em um terceiro momento, as ponderações iniciais sejam mobilizadas juntamente com o estudo de caso para elucidar a problemática aqui proposta.

\subsection{Tecnologia, Controle e Vigilância: Novas Formas de Poder}

A discussão de que a tecnologia não é neutra e, portanto, dota-se de essência política, remete-se inevitavelmente ao debate de que a Ciência compartilha de iguais propriedades. O quão política é a ciência e a tecnologia? O quão científica é a política e a tecnologia? A discussão filosófica decorrente destas questões está longe de ser um debate encerrado. Se a neutralidade da Ciência é um mito, tão mítico quanto a neutralidade da tecnologia, sua averiguação não encontrará uma resposta conclusiva nesse trabalho. Abrirá, contudo, os caminhos para a discussão crítica das categorias de análise aqui empreendidas: a tecnologia da informação, o poder que dela emana, a vigilância, a privacidade e todas suas respectivas interações na democracia. Para além da análise da intersecção dessas duas categorias, serão discutidos seus agentes, domínios e dinâmicas pela leitura de seus clássicos, fenômenos, métodos e circunstâncias.

Questões filosóficas acerca da tecnologia não são um fenômeno recente e datam, no mínimo, desde os primórdios da tradição grega. A busca da compreensão sobre a relação humana com a tecnologia não se restringiu obviamente ao período da filosofia clássica e encontrou seus lampejos também na Idade Média ${ }^{3}$. Embora possam ser encontrados breves

3 É consensual para alguns autores (FRANSSEN; LOKHORST; POEL, 2015) que textos de Platão, 
períodos de desenvolvimento nesse ínterim, a retomada dos esforços filosóficos que fizeram da tecnologia um objeto de estudo ganharam fôlego com as pulsões científico-industriais a partir do século XIX e XX.

Os dilemas éticos das descobertas do século XX, trouxeram, contudo questões críticas em relação aos riscos, suas probabilidades e impactos, das novas tecnologias. Se por um lado esses esforços filosóficos foram por vezes além de suas temporalidades, faz-se necessário contudo contextualizá-los em uma perspectiva histórica mais ampla. Do século XVIII ao XIX, as descobertas das ciências naturais introduziram vastos novos paradigmas tecnológicos, e não por menos, impulsionaram o desenvolvimento de novas ciências cujas feições tecnológicas tornavam-se mais abstratas, como a economia e sociologia. Marx capturou a essência dessas grandes transformações e transições no livro primeiro d' $O$ Capital ao observar a dinâmica tecnológica e sua apropriação pela crescente burguesia industrial:

\begin{abstract}
O princípio da grande indústria, a saber, o de dissolver cada processo de produção propriamente dito em seus elementos constitutivos, e, antes de tudo, fazê-lo sem nenhuma consideração para com a mão humana, criou a mais moderna ciência da tecnologia. As formas variegadas, aparentemente desconexas e ossificadas do processo social de produção se dissolveram, de acordo com o efeito útil almejado, nas aplicações conscientemente planificadas e sistematicamente particularizadas das ciências naturais. A tecnologia descobriu as poucas formas fundamentais do movimento, sob as quais transcorre necessariamente, apesar da diversidade dos instrumentos utilizados, toda ação produtiva do corpo humano, exatamente do mesmo modo como a mecânica não deixa que a maior complexidade da maquinaria a faça perder de vista a repetição constante das potências mecânicas simples. A indústria moderna jamais considera nem trata como definitiva a forma existente de um processo de produção. Sua base técnica é, por isso, revolucionária, ao passo que a de todos os modos de produção anteriores era essencialmente conservadora. Por meio da maquinaria, de processos químicos e outros métodos, ela revoluciona continuamente, com a base técnica da produção, as funções dos trabalhadores e as combinações sociais do processo de trabalho. Desse modo, ela revoluciona de modo igualmente constante a divisão do trabalho no interior da sociedade e não cessa de lançar massas de capital e massas de trabalhadores de um ramo de produção a outro. (MARX, 2013)
\end{abstract}

Para Marx, tecnologia era vista como elemento "motor", tanto em seu sentido literal, como figurado, das transformações pelas quais a sociedade industrial emergia. A produção, portanto, era também vinculada às dinâmicas tecnológicas e suas técnicas, que, impulsionada pela industria/burguesia, não cessava de revolucionar os meios produtivos pela própria revolução da tecnologia. A tríade de ciência, tecnológica e progresso estava para burguesia como um dogma para além de qualquer dúvida ou crítica. O "progresso", neutro, almejado, apropriado pelas perspectivas positivistas, virou um mantra para as

Heráclito, Democritus e Aristóteles são os primeiros a se dedicarem ao exercício filosófico sobre a Tecnologia. 
sociedades industriais como um fim em si mesmo ${ }^{4}$. A abrupta mudança de paradigma tecnológico foi e continua a ser uma das constantes das revoluções científico-industriais (KUHN, 1996). Marcuse $(1991,1964)$ complementa a visão de Marx (2013) sobre a tecnologia ao defender que os processos de dominação de uns sobre outros que vigoraram no decorrer histórico seriam alterados pela crescente tecnológica. Em sua visão, a dominação continuaria, contudo, uma alteração da relação de dependência também estaria em curso e transferiria a relação de dependência para a racionalidade das coisas, em sua obra, interpretada como a racionalidade tecnológica:

In the social reality, despite all change, the domination of man by man is still the historical continuum that links pre-technological and technological Reason. However, the society which projects and undertakes the technological transformation of nature alters the base of domination by gradually replacing personal dependence (of the slave on the master, the serf on the lord of the manor, the lord on the donor o $f$ the fief, etc.) with dependence on the "objective order of things" (on economic laws, the market etc.) ${ }^{6}$ (MARCUSE, 1991, 1964, p.146)

As vertiginosas mudanças da primeira Revolução Industrial apontadas por (MARX, 2013), acrescidas do aprofundamento em outras revoluções subsequentes, evidenciaram que não somente os meios de produção, seus instrumentos e suas formas de controle mudavam drasticamente, como também a própria relação entre sociedade e tecnologia tornava-se cada vez mais intrincada e interdependente: a tecnologia per se passara a ser um requisito existencial para a sociedade e, filosofar sobre suas possibilidades e domínios, uma prioridade ${ }^{7}$. As rápidas transformações dos dois séculos suscitaram inúmeros autores a repensarem as questões sociais afetadas pela tecnologia, com abordagens que buscavam interpretar as interações e impactos que a tecnologia trazia à sociedade. Não obstante, os temos Sociedade de Controle, Disciplina e Vigilância ganharam vinculações recorrentes às visões de mundo que moviam as discussões relacionadas à tecnologia, suas naturezas, efeitos, contextos, dentre tantos outros prismas de análise.

4 Para Kuhn, até mesmo a noção de progresso, ciência e tecnologia tornaram-se demasiadamente intricadas ao ponto que even today, to switch fields once more, part of our difficulty in seeing the profound differences between science and technology must relate to the fact that progress is an obvious attribute of both fields (KUHN, 1996, p.161) ${ }^{5}$.A crítica reside justamente na noção de progresso: afinal, se progresso é um valor subjetivo, o progresso ocorre para quem e para quais interesses?

6 "Na realidade social, apesar de toda mudança, a dominação do homem pelo homem ainda é o continuum histórico que liga a Razão pré-tecnológica à tecnológica. No entanto, a sociedade que projeta e realiza a transformação tecnológica da natureza altera a base da dominação, substituindo gradualmente a dependência pessoal (do escravo do mestre, do servo do senhor do solar, do senhor do doador do feudo, etc.). .) com dependência da "ordem objetiva das coisas" (sobre leis econômicas, o mercado etc.)" (MARCUSE, 1991, 1964, p.146), tradução nossa.

7 A primeira aparição do termo Filosofia da Tecnologia ocorreu, segundo Franssen, Lokhorst e Poel (2015), no livro Eine Philosophie der Technik de Kapp (1877). 


\subsection{Tecnologia, Vigilância e Sociedade da Disciplina em Foucault}

A temática da vigilância passa por Foucault em seu estudo sobre as dinâmicas de poder que são identificadas em estruturas prisionais. O autor é conhecido, principalmente, pela sua contribuição à disciplina acadêmica da Vigilância, pela qual analisou as mais variadas formas de poder que são exercidas por meio desta. Tais formas de poder são compreendidas por Foucault pelo prisma do poder sobre o corpo do indivíduo, ou do indivíduo em si que, pelo olhar constante da vigilância, seria dissociado de suas faculdades e autonomias, seria disciplinado e controlado. O domínio sobre os corpos humanos fora compreendido por Foucault (2013) numa análise filosófica do que pode se chamar de violações da soberania do corpo como forma de exercício do poder. Foucault (2013) retoma que em diversas sociedade ao longo do tempo o corpo foi vítima de condicionalismos, interdições ou obrigações de maneira imperativa seja pela cultura ou pela força, mas é diante das novas tecnologias que o autor enxerga formas de controle minuciosas das operações do corpo.

Em primeiro nível o autor trata da escala de controle, e verifica que os corpos estão sendo trabalhados sob uma coerção sutil no nível da mecânica, exercendo um poder infinitesimal sobre o corpo ativo; Em segundo nível, Foucault (2013) entende que essa coerção incide mais nas forças do que nos signos, uma vez que os objetos não são mais os elementos significantes, mas sim a eficácia dos movimentos e a sua organização interna; Em último nível, a modalidade de controle que se exerce sobre os corpos se trata de uma coerção ininterrupta que através de uma codificação exerce controle sobre o tempo, o espaço e os movimentos. O corpo controlado pelas novas tecnologias, de acordo com Foucault (2013), entra num "maquinismo" de poder que o explora, desarticula e recompõe. Essa "anatomia política" ou "mecânica do poder" se usa da disciplina para dissociar o poder dos corpos e assim exercer o domínio sobre o corpo dos outros, sobre o indivíduo.

Apresentada como uma estrutura de poder, a vigilância representaria as novas mecânicas de poder, repleta de técnicas e tecnologias voltadas à domesticação do indivíduo, sua massificação, racionalização econômica e comportamental. Invisível e ao mesmo tempo presente, a vigilância traz consigo as estruturas necessárias para disciplinar e colocar o indivíduo em sua intrínseca reprodução de poder: vigiar e punir. Nesse sentido, ultrapassaria seu sentido e indicaria uma vigilância cuja ação não é meramente punitiva, mas permanentemente presente, onisciente e disciplinar - ou, como pontua Foucault, um sistema integrado, sustentado, automático e anônimo de poder.

Graças a ela, o poder disciplinar torna-se um sistema «integrado», ligado do interior à economia e aos fins do dispositivo onde é exercido. Organiza-se também como um poder múltiplo, automático e anonimo; embora a vigilância se baseie em indivíduos, o seu funcionamento é o de uma rede de relações [...]; esta rede «sustenta» o todo e perpassa-o integralmente com efeitos de poder que se apoiam uns nos outros: vi- 
gilantes perpetuamente vigiados. O poder na vigilância hierarquizada das disciplinas não se possui como uma coisa, não se transfere como uma propriedade; funciona como um maquinismo. [...] Isto permite que o poder disciplinar seja absolutamente indiscreto, porque está sempre e em toda a parte alerta, não deixe em princípio nenhuma zona de sombra e controle incessantemente até os que estão encarregados de controlar; e absolutamente «discreto», porque funciona permanentemente e, em grande parte, em silêncio. (FOUCAULT, 2013)

Ao retratar a vigilância em suas dinâmicas de poder, Foucault (2013) analisa diversas estruturas e configurações espaciais de presídios até encontrar, no Panóptico de Bentham, a estrutura ideal para os controles em seu máximo potencial: "O Panóptico é uma máquina de dissociar o par ver-ser visto: no anel periférico, os indivíduos são totalmente vistos, sem nunca verem; na torre central, vê-se tudo, sem nunca se ser visto" (FOUCAULT, 2013). Seu efeito principal era incutir na corpo-indivíduo o estado e consciência de visibilidade permanente que, segundo Foucault (2013), "assegura o funcionamento automático do poder" (FOUCAULT, 2013). O efeito incutido é da vigilância onipresente, mantida indefinidamente - ou percebida como tal, independentemente de sua execução. A disciplina projetada pela vigilância, teria, portanto, no efeito coercitivo sobre a consciência, o seu maior trunfo.

Fazer de maneira a que a vigilância seja permanente nos seus efeitos, ainda que seja descontínua na sua ação; que a perfeição do poder tenda a tornar inútil a atualidade do seu exercício; que este aparelho arquitetônico seja uma máquina de criar e sustentar uma relação de poder independente de quem o exerce; em suma, que os reclusos estejam presos numa situação de poder de que eles próprios são os portadores. Para isso, é simultaneamente de mais e de menos que o prisioneiro seja incessantemente observado por um vigilante: de menos, porque o essencial é que saiba que está a ser vigiado; de mais, porque não precisa efetivamente de ser vigiado. (FOUCAULT, 2013)

O dispositivo panóptico, ou a estrutura de poder panóptica atingiria, desta forma, o aperfeiçoamento do exercício do poder - mais do isso, seria um amplificador para qualquer aparelho de poder pela racionalização econômica de material, pessoal e tempo. Esse aperfeiçoamento, para o autor, seria efeito direto das três variáveis material-pessoaltemporal; para cada uma das variáveis, Foucault explica que a estrutura panóptica (1) "pode reduzir o número dos que exercem o poder, ao mesmo tempo que multiplica o número daqueles sobre quem é exercido", ou seja, proporcionaria uma redução de esforços para ser mantido ao passo que amplificaria sua amplitude e escopo de atuação; a estrutura permitiria (2) "intervir incessantemente"e implementar a pressão constante"como modo de agir "antes que as faltas, os erros e os crimes sejam cometidos"e; (3) "Porque, nestas condições, a sua força consiste em nunca intervir, em exercer-se espontaneamente sem ruído, em constituir um mecanismo cujos efeitos se encadeiam uns nos noutros". Sua potência e eficácia seria assegurada pelo "caráter preventivo", "funcionamento contínuo"e 
sustentado por "mecanismos automáticos". Seria, portanto, uma forma de governo, controle, disciplina e poder - que, para Foucault, estaria disponível à qualquer instituição que o aplique.

A presença de uma estrutura panóptica em uma sociedade democrática acarretaria em prejuízos indeléveis, caso não fosse justificada e reforçada permanentemente. Para se utilizar do panóptico, outras forças precisariam ganhar legitimidade e propósito inequívoco, precisariam adotar o discurso de que, sem a utilização, haveria riscos, inclusive, existenciais. A segurança do indivíduo e da sociedade, nesse contexto, seria uma possível força de justificação - capaz de tornar os efeitos do panóptico e, por conseguinte, da maquinaria e da tecnologia da vigilância, imprescindíveis. Sua aceitação ganharia, então, força nas demandas da sociedade enquanto mecanismo de segurança, ainda que, em sua natureza, seja constituída enquanto estrutura de poder e controle sobre os indivíduos.

Em sua coletânea de seminários, compilada sob o nome de "Technologies of the self: A seminar with Michel Foucault", Foucault et al. (1988) elenca quatro tipos de tecnologia que poderiam dar suporte à questões pertinentes ao governo e controle dos indivíduos. A primeira delas seria a tecnologia de produção, que seria aplicada à natureza para "produzir, transformar ou manipular as coisas". Essa mesma concepção de tecnologia é aplicada por Marx ${ }^{8}$ como efeito da Revolução Industrial e diz respeito ao aspecto transformativo da tecnologia - no caso, aplicado à natureza e as coisas.

A segunda compreensão de tecnologia elaborada por Foucault está relacionada à tecnologia dos sistemas de signos, ou seja, dos sistemas de codificação - sejam eles ligados à linguagem ou a forma como as estruturas trocam suas dinâmicas. Em outras palavras, trata-se das tecnologias que permitem o uso de "signs, meanings, symbols, or signification" ${ }^{\prime \prime}$.As tecnologias que envolvem a comunicação, seja ela entre homens ou máquinas, estaria contemplada nessa categoria, por exemplo.

A terceira forma de tecnologia seria a tecnologia do poder (technologies of power), definida pelo autor como "[...] which determine the conduct of individuals and submit them

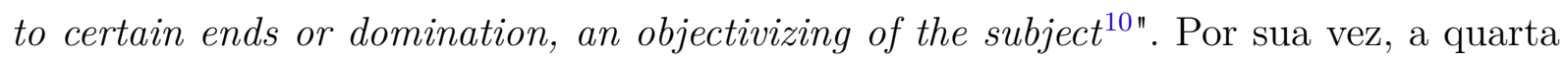
tecnologia seria a do Self, da construção do "eu"do indivíduo, aplicada à si mesmo para seus próprios meios e fins. Foucault identifica que "these four types of technologies hardly ever function separately, although each one of them is associated with a certain type of domination"11 (FOUCAULT et al., 1988, p. 18). Logo, o denominador comum para os

\footnotetext{
8 Foucalt complementa a compreensão do uso da tecnologia em Marx com a seguinte passagem "relation between manipulating things and domination in Karl Marx's Capitalwhere every technique of production requires modification of individual conduct-not only skills but also attitudes" (FOUCAULT et al., 1988, p. 18). Nesse sentido, seu uso não apenas transformaria a natureza, como tal transformação impactaria também na transformação do indivíduo.

9 "Signos, significados e símbolos, ou significações" (FOUCAULT et al., 1988, p. 18), tradução nossa.

10 " [...] que determinam a conduta dos indivíduos e os submetem a determinados fins ou dominação, objetivando o sujeito" (FOUCAULT et al., 1988, p. 18), tradução nossa.

11 "Esses quatro tipos de tecnologias quase nunca funcionam separadamente, embora cada um deles esteja
} 
quatro tipos de tecnologia seria, portanto, a dominação - seja ela da natureza, dos símbolos, dos indivíduos e dos indivíduos sobre si mesmos.

\subsection{Tecnologia, Poder e a Sociedade do Controle em Deleuze}

A obra "Vigiar e Punir" de Foucault (1995) e seu conceito de disciplina também influenciaram diretamente os pensamentos de Deleuze (1992) na elaboração do conceito de sociedade de controle em seu sucinto artigo "Postscript on the Societies of Control"12. A imagem do Pan-óptico (Panopticon), enquanto mecanismo de vigilância, faz-se novamente presente como uma tecnologia de controle adaptada à seu fim: vigiar para, quando necessário, punir. Para Deleuze, Foucault foi capaz de identificar como tais mecanismos inauguraram uma mudança na construção dos controles sociais que, em suas palavras, foram capazes de "initiate the organization of vast spaces of enclosure"13 (DELEUZE, 1992, p. 3). Com construções e modelos ideais datados há longa data, as tecnologias e seus fins perpassaram diversos momentos históricos, com as devidas modificações, sem, contudo, perderam suas características e finalidades enquanto controles. Todavia, as modificações tecnológicas exprimem mais do que a necessidade de manutenção de determinados tipos de controle - evidenciam, quando conjugadas à momentos de crise, a transição de um tipo de sociedade para outra (DELEUZE, 1992, p. 3). A transição da sociedade disciplinar para a sociedade de controle é parte da contribuição de Deleuze ao pensamento de Foucault.

As descobertas tecnológicas, posicionadas na concepção de Deleuze (1992), trariam consigo as demandas por controles que espelhassem a distribuição de poder pelas dinâmicas sociais em um determinado recorte histórico/temporal. Os períodos de transição tecnológica não foram forjados apenas por disrupturas paradigmáticas, mas, sim, dentre outras variáveis, pela demanda de controle almejada e aplicada pelas camadas dominantes da sociedade. Adicionalmente, a tecnologia e o "controle"desenhado em seu âmago incorporaram, com o avanço de sua racionalidade, novas formas de batalhas, nas quais, segundo Deleuze (1992), "forças libertadoras e escravizantes se confrontam mutuamente". Nessas premissas, Deleuze (1992) aplica, então, o termo "sociedade de controle"pela inerente relação que é derivada da tecnologia complexa, ubíqua e passível de compreensão apenas por suas próprias premissas/dinâmicas e lógicas internas:

"Control" is the name Burroughs proposes as a term for the new monster,
one that Foucault recognizes as our immediate future. Paul Virilio also is
continually analyzing the ultra-rapid forms of free-floating control that
replaced the old disciplines operating in the time frame of a closed system.
There is no need here to invoke the extraordinary pharmaceutical pro-
ductions, the molecular engineering, the genetic manipulations, although associado a um certo tipo de dominação" (FOUCAULT et al., 1988, p. 18), tradução nossa.

12 DELEUZE, G. Postscript on the Societies of Control. October, v. 59, p. 3-7, 1992. ISSN 01622870. Disponível em: <http://www.jstor.org/stable/778828>.

13 "Iniciam a organização de vastos espaços de confinamento" (DELEUZE, 1992, p. 3), Em nossa tradução. 
these are slated to enter into the new process. There is no need to ask which is the toughest or most tolerable regime, for it's within each of them that liberating and enslaving forces confront one another ${ }^{14}$. (DELEUZE, 1992, p. 4)

A manipulação genética, a engenharia molecular, a produção de medicamentos: faces públicas de tecnologias que, para Deleuze, estariam além da compreensão ordinária e iletrada. Poderiam, portanto, ser compreendidas por seus próprios regimes. Ponto pacífico que todas ensejariam formas de controle e dominação, formas expressas inerentemente por suas técnicas e racionalidades. A partir dessa compreensão, da leitura e compreensão de seus signos e estruturas racionalizadas, seria possível identificar as batalhas que nelas são travadas. Se as dinâmicas, por exemplo, da engenharia genética, seria movida por forças libertadoras ou escravizantes, na terminologia de Deleuze. Confrontar tais forças com as demais projeções dessas tecnologias, tais como impactos positivos ou negativos, traria, portanto, a régua do quão toleráveis eles poderiam ser.

Tais tecnologias seriam um prelúdio de um momento ainda mais complexo ao qual a sociedade adentraria, a sociedade de controle codificada, regulamentada por máquinas e seus códigos: "In the societies of control [...] what is important is no longer either a signature or a number, but a code: the code is a password, while on the other hand the disciplinary societies are regulated by watchwords ${ }^{115}$. Nessa sociedade envisionada e analisada por Deleuze (1992), os códigos passam a ser a instituição primária de controle, expressa na linguagem racionalizada dos códigos. Linguagem que delimitaria, por sua vez, a própria estrutura de controle, abordada por Deleuze (1992) como "The numerical language of control is made of codes that mark access to information, or reject it"16. Para Deleuze, quando inseridos nesse contexto, "We no longer find ourselves dealing with the mass/individual pair. Individuals have become "dividuals"and masses, samples, data, markets, or "banks"17

Deleuze (1992) adentra à ceara dos códigos e sua inserção e reprodução pelas máquinas: o controle passa a ser codificado, o poder ganha projeção pela linguagem de

14 "'Controle' é o nome que Burroughs propõe como um termo para o novo monstro, que Foucault reconhece como nosso futuro imediato. Paul Virilio também analisa continuamente as formas ultrarrápidas de controle flutuante que substituíram as antigas disciplinas que operam no período de tempo de um sistema fechado. Não há necessidade de invocar as extraordinárias produções farmacêuticas, a engenharia molecular, as manipulações genéticas, embora estas estejam programadas para entrar no novo processo. Não há necessidade de perguntar qual é o regime mais difícil ou mais tolerável, pois é dentro de cada um deles que as forças libertadoras e escravizantes se confrontam mutuamente".

15 "Nas sociedades de controle, por outro lado, o importante não é mais uma assinatura ou um número, mas um código: o código é uma senha, enquanto, por outro lado, as sociedades disciplinares são reguladas por palavras de ordem" (DELEUZE, 1992, p. 5), tradução nossa.

16 "A linguagem numérica de controle é feita de códigos que marcam o acesso à informação, ou a rejeitam. Já não nos encontramos lidando com o par massa/indivíduo. Indivíduos se tornaram "dividuais" e massas, amostras, dados, mercados ou "bancos"" (DELEUZE, 1992, p. 5), tradução nossa.

17 "Já não nos encontramos lidando com o par massa/indivíduo. Indivíduos se tornaram "dividuais" e massas, amostras, dados, mercados ou "bancos"" (DELEUZE, 1992, p. 5), tradução nossa. 
símbolos e codificações típicas das máquinas - representam sua inserção e ascensão como entidade, arena, espaço aberto de controle tecnológico. Na interação entre máquinas e sociedade, identifica Deleuze (1992) o fenômeno e a vinculação entre as forças que emanam da sociedade e tipo de tecnologia que são utilizadas que, para o autor, "Types of machines are easily matched with each type of society - not that machines are determining, but because they express those social forms capable of generating them and using them" (DELEUZE, 1992, p. 6). A principal diferença se encontra entre aquelas sociedades que Deleuze (1992) denomina de "sociedades soberanas"e as "sociedades de controle". Nas sociedades soberanas, a tecnologia é passível de uso simples, com propósito definido e sem uma ampla margem de utilização; nas sociedades de controle, a tecnologia demanda a alta complexidade, resulta em caráteres duais e finalidades ambíguas e impacta a compreensão de mundo com a extrema racionalidade e, paradoxal, obscuridade pela complexidade. Nas palavras de Deleuze (1992),

The old societies of sovereignty made use of simple machines-levers, pulleys, clocks; but the recent disciplinary societies equipped themselves with machines involving energy, with the passive danger of entropy and the active danger of sabotage; the societies of control operate with machines of a third type, computers, whose passive danger is jamming and whose active one is piracy and the introduction of viruses ${ }^{18}$. (DELEUZE, 1992, p. 6)

A sociedade de controle é marcada pela ascensão dos computadores como expoente máximo da racionalização das máquinas, da ultra linguagem matemático-binária, da complexidade da tecnologia-linguagem, da estrutura ofuscada de poder de chips de silício. Os perigos que tal sociedade traz é, por contraposição, a perda da própria soberania em seu sentido de perda do controle por parte do indivíduo e aumento do controle por parte dos guardiões da tecnologia das máquinas, dos computadores. A perda de agência sobre a tecnologia torna-se a característica do indivíduo que , embebido-objetificado nos controles dos computadores, tem sua soberania enquanto parte e todo da sociedade, desmantelada e alienada.

\subsection{Tecnologia e a Ascensão das Máquinas em Marcuse}

A conjunção de acadêmicos conhecida como Escola de Frankfurt (ou Frankfurter Schule) tornou-se uma das expoentes na difusão da crítica à tecnologia contemporânea e

18 "Tipos de máquinas são facilmente compatíveis com cada tipo de sociedade - não que as máquinas sejam determinantes, mas porque expressam essas formas sociais capazes de gerá-las e usá-las. As velhas sociedades de soberania usavam máquinas simples - alavancas, polias, relógios; mas as recentes sociedades disciplinares se equiparam com máquinas que envolvem energia, com o perigo passivo de entropia e o perigo ativo de sabotagem; as sociedades de controle operam com máquinas de um terceiro tipo, computadores, cujo perigo passivo é congestionamento e cujo ativo é a pirataria e a introdução de vírus" (DELEUZE, 1992, p. 6), tradução nossa. 
ao seu caráter ambíguo e, por vezes, nocivo. Marcuse (1998) incorporava em suas obras vastas argumentações e críticas ao uso, consequência e formas de poder que emanam da tecnologia: tanto liberalizante como de dominação. Como parte do "processo social"19, a tecnologia e o domínio da técnica era visto como agente-construtor e agente-construído pela sociedade - com a feição inerentemente política, impulsiona as relações de poder e o próprio poder enquanto instrumento de controle e dominação. Para (MARCUSE, 1998), a tecnologia é parte do indivíduo e, portanto, não caberia perguntar, sequer, o impacto sobre este. Não obstante, as características da "Era das Máquinas"trariam consigo sempre um componente de "controle"e "dominação"ou, como coloca o autor:

Technology, as a mode of production, as the totality of instruments, devices and contrivances which characterize the machine age is thus at the same time a mode of organizing and perpetuating (or changing) social relationships, a manifestation of prevalent thought and behavior patterns, an instrument for control and domination ${ }^{20}$. (MARCUSE, 1998, p.138)

Marcuse (1998) alertaria sobre os riscos que tecnologia traz ao afirmar que "The relationships among men are increasingly mediated by the machine process ${ }^{21}$ ". As relações humanas, mediadas pelas máquinas, traria consequências negativas sobre a própria natureza humana, ou, se balancearmos a perspectiva pessimista de Marcuse, tais relações seriam no mínimo alteradas e ressignificadas à medida que "everything cooperates to turn human instincts, desires and thoughts into channels that feed the apparatus ${ }^{122}$. A consequência desse processo é a completa absorção das faculdades e potencias humanas em relações mediadas pela "máquina"que retroalimentam o apparatus. Marcuse reforça essa concepção quando constata que a "máquina"acaba por se tornar um mecanismo vivo ao observar que "the machine that is adored is no longer dead matter but becomes something like a human being. And it gives back to man what it possesses: the life of the social apparatus to which it belongs"23 (MARCUSE, 1998, p.144). A onipresença da tecnologia, expressa pela

19 Para Marcuse (1998), a natureza social da tecnologia se revela na medida em que "technology is taken as a social process in which technics proper (that is, the technical apparatus of industry, transportation, communication) is but a partial factor. We do not ask for the influence or effect of technology on the human individuals. For they are themselves an integral part and factor of technology, not only as the men who invent or attend to machinery but also as the social groups which direct its application and utilization" (MARCUSE, 1998, p.138).

20 "A tecnologia, como modo de produção, como a totalidade de instrumentos, dispositivos e invenções que caracterizam a era da máquina é, ao mesmo tempo, um modo de organizar e perpetuar (ou mudar) as relações sociais, uma manifestação de padrões de pensamento e comportamento predominantes, um instrumento de controle e dominação" (MARCUSE, 1998, p.138), tradução nossa.

21 "As relações entre os homens são cada vez mais mediadas por processos da máquina" (MARCUSE, 1998, p.144), tradução nossa.

22 "tudo coopera para transformar os instintos, desejos e pensamentos humanos em canais que alimentam o aparelho" (MARCUSE, 1998, p.144), tradução nossa.

23 "a máquina que é adorada não é mais matéria morta, mas se torna algo como um ser humano. E devolve ao homem o que possui: a vida do aparato social ao qual pertence" (MARCUSE, 1998, p.144), tradução nossa. 
máquina, atinge, no caminhar dessa transformação, a sua ultra-racionalidade, algo que Marcuse (1998) analisa ao afirmar que "Human behavior is outfitted with the rationality of the machine process, and this rationality has a definite social content. The machine process operates according to the laws of mass production"24 (MARCUSE, 1998, p.144).

Ao incorporar gradativamente a maquina às relações humanas, a obediência requerida das máquinas volta-se contra seus criadores; Deleuze aponta esse fenômeno como um processo de adaptação ao próprio apparatus, cuja dinâmica seria ditada pelo controle das máquinas, já que, para o autor "In manipulating the machine, man learns that obedience to the directions is the only way to obtain desired results. Getting along is identical with adjustment to the apparatus. There is no room for autonomy" ${ }^{25}$. O processo é revolucionário e silencioso por si mesmo: revoluciona como sua condição sine qua non para a reprodução da sociedade construída sobre a ultra racionalidade.

Paulatinamente, essa revolução silenciosa substitui suas estruturas, instituições e relações sociais - o tecido fabril do humano - em tecnologia e seu primado das máquinas. Para Marcuse (1998), o fenômeno tem suas resultantes na constatação da premissa de que "business, technics, human needs and nature are welded together into one rational and expedient mechanism. He will fare best who follows its directions, subordinating his spontaneity to the anonymous wisdom which ordered everything for him" ${ }^{26}$ (MARCUSE, 1998, p.143). Caminhar conforme a ultra-racionalidade comanda, controle e subverte traz recompensas e se torna o padrão de atuação aceita. Nesse sentido, para Marcuse (1998), a crítica recaí sobre os resultados dessa revolução ${ }^{27}$ que não permitirá contestações ${ }^{28}$ :

The decisive point is that this attitude-which dissolves all actions into a sequence of semi-spontaneous reactions to prescribed mechanical norms - is not only perfectly rational but also perfectly reasonable. All

$\overline{24}$ "O comportamento humano é equipado com a racionalidade do processo da máquina, e essa racionalidade tem um conteúdo social definido. O processo da máquina opera de acordo com as leis da produção em massa" (MARCUSE, 1998, p.144), tradução nossa.

25 "Ao manipular a máquina, o homem aprende que a obediência às instruções é a única maneira de obter os resultados desejados. Ambientar no decorrer é idêntico ao ajuste do apparatus[ p.144]Marcuse.1941. Não há espaço para autonomia" (MARCUSE, 1998, p.144), tradução nossa

26 "Os negócios, as técnicas, as necessidades humanas e a natureza são unidas em um mecanismo racional e expedito. Ele se sairá melhor seguindo suas instruções, subordinando sua espontaneidade à sabedoria anônima que ordenou tudo para ele"(MARCUSE, 1998, p.143), tradução nossa.

27 O autor não utiliza a expressão "revolução"para denominar o fenômeno em questão.

28 Marcuse expressa a preocupação que à medida que a sociedade se transmuta para suas novas formas de controle, a racionalidade dará conta de explicar e convencer sobre os benefícios que a conjunção de tecnologia-racionalidade trarão. Tal preocupação é expressa por Marcuse na passagem: "The prevailing forms of social control are technological in a new sense. To be sure, the technical structure and efficacy of the productive and destructive apparatus has been a major instrumentality for subjecting the population to the established social division of labor throughout the modern period. Moreover, such integration has always been accompanied by more obvious forms of compulsion: loss of livelihood, the administration of justice, the police, the armed forces. It still is. But in the contemporary period, the technological controls appear to be the very embodiment of Reason for the benefit of all social groups and interests-to such an extent that all contradiction seems irrational and all counteraction impossible. (MARCUSE, 1991, 1964) 
protest is senseless, and the individual who would insist on his freedom of action would become a crank. There is no personal escape from the apparatus which has mechanized and standardized the world. It is a rational apparatus, combining utmost expediency with utmost convenience, saving time and energy, removing waste, adapting all means to the end, anticipating consequences, sustaining calculability and security ${ }^{29}$. (MARCUSE, 1998, p.143)

Revoltar-se contra o apparatus não seria legítimo, já que dele surge a própria razão e forças de racionalidade. Logo, sua defesa, na perspectiva de Marcuse, seria auto-evidente, famigeradamente aceita e incontestada. Não haveria escapatória contra sua dominação sobre o indivíduo, massificado. Marcuse aprofunda a visão crítica sobre a tecnologia ao considerar que o processo capitalista é uma força que, aliada à racionalidade, transforma a tecnologia em autoritarismo ${ }^{30}$. O apparatus, enquanto construção-sustentação sistêmica da tecnologia, ganharia momentum pelas forças capitalistas. O processo de convencimento seria explicado, segundo Marcuse, pela própria racionalização e otimização de custos e demais economias que se resvalariam nos indivíduos.

the apparatus imposes its economic and political requirements for defense and expansion on labor time and free time, on the material and intellectual culture. By virtue of the way it has organized its technological base, contemporary industrial society tends to be totalitarian. For " totalitarian" is not only a terroristic political coordination of society, but also a non-terroristic economic-technical coordination which operates through the manipulation of needs by vested interests. It thus precludes the emergence of an effective opposition against the whole. Not only a specific form of government or party rule makes for totalitarianism, but also a specific system of production and distribution which may well be compatible with a "pluralism" of parties, newspapers, "countervailing powers," etc ${ }^{31}$. (MARCUSE, 1991, 1964, p.5)

29 "O ponto decisivo é que essa atitude - que dissolve todas as ações em uma sequência de reações semi-espontâneas a normas mecânicas prescritas - não é apenas perfeitamente racional, mas também perfeitamente razoável. Todo protesto não tem sentido, e o indivíduo que insistiria em sua liberdade de ação se tornaria uma manivela. Não há escapatória pessoal do aparato que mecanizou e padronizou o mundo. É um aparato racional, combinando a máxima expediência com a máxima conveniência, economizando tempo e energia, eliminando o desperdício, adaptando todos os meios até o fim, antecipando as consequências, sustentando a capacidade de cálculo e a segurança" (MARCUSE, 1998, p.143), tradução nossa.

30 Marcuse faz menção à essa transformação ao abordar que "In advanced capitalism, technical rationality is embodied, inspite of its irrational use, in the productive apparatus. This applies not only to mechanized plants, tools, and exploitation of resources, but also to the mode of labor as adaptation to and handling of the machine process, as arranged by "scientific management." (MARCUSE, 1991, 1964)

31 "O apparatus impõe suas exigências econômicas e políticas de defesa e expansão do tempo de trabalho e tempo livre, da cultura material e intelectual. Em virtude da maneira como organizou sua base tecnológica, a sociedade industrial contemporânea tende a ser totalitária. Pois "totalitário" não é apenas uma coordenação política terrorista da sociedade, mas também uma coordenação técnico-econômica não-terrorista que opera através da manipulação de necessidades por interesses adquiridos. Impede, assim, o surgimento de uma oposição efetiva contra o todo. Não apenas uma forma específica de governo ou regra partidária contribui para o totalitarismo, mas também um sistema específico de produção e distribuição que pode ser compatível com um "pluralismo" de partidos, jornais, "poderes compensatórios", etc", (MARCUSE, 1991, 1964, p.5) tradução nossa. 
A crítica, por essa visão de Marcuse, reside na percepção de que os meios autoritários da racionalidade tecnológica do apparatus poderia facilmente ser compatibilizada com o "pluralismo"de partidos, a liberdade de expressão e outros mecanismos típicos de uma democracia. O adensamento tecnológico autoritário do apparatus mobilizaria, nesse sentido, os meios de produção e as instituições, faria parte destas, independentemente do regime político. A ultra racionalidade tecnológica, nesse sentido, comporia a sociedade de forma indissociável e independente da manifestação explícita de feições autoritárias - por vezes, travestidas de democráticas.

\subsection{A Transformação do Poder pela Tecnologia}

O poder político seria, em um contexto altamente racionalizado-tecnológico, igualmente transformado. Sua manifestação ocorreria através da própria tecnologia, de forma substanciada e processual. Substanciado quando manifestado intrinsecamente nas finalidades tecnológicas; processual, quando mediado pela tecnologia. Marcuse reconhece essa força quando descreve que "Today political power asserts itself through its power over the machine process and over the technical organization of the apparatus" ${ }^{\prime 2}$ (MARCUSE, 1991, 1964). Essa manifestação do poder pela tecnologia/apparatus estaria tão arraigado nas bases e instituições que mobilizam a sociedade que, mesmo pertencente à ela, o indivíduo já não mais teria relevância - as forças da tecnologia se sobreporiam a ele no processo de racionalização ${ }^{33}$. Quando finalizada e pacificada a revolução silenciosa das máquinas, a máquina seria em si a estrutura principal do exercício do poder e da política em uma sociedade. Marcuse $(1991,1964)$ compreende, nessa perspectiva, que a máquina, e sua força racionalizante, prevaleceria sobre o indivíduo:

The brute fact that the machine's physical (only physical?) power surpasses that of the individual, and of any particular group of individuals, makes the machine the most effective political instrument in any society whose basic organization is that of the machine process $^{34}$. (MARCUSE, 1991, 1964)

32 "Hoje, o poder político se impõe através de seu poder sobre o processo da máquina e sobre a organização técnica do aparato" (MARCUSE, 1991, 1964), tradução nossa.

33 Marcuse descreve a transformação do governo nesse contexto pela seguinte perspectiva: "The government of advanced and advancing industrial societies can maintain and secure itself only when it succeeds in mobilizing, organizing, and exploiting the technical, scientific, and mechanical productivity available to industrial civilization. And this productivity mobilizes society as a whole, above and beyond any particular individual or group interests" (MARCUSE, 1991, 1964). O que, por sua vez, poderia ser compreendido como uma tensão entre as forças tecnológicas do apparatus que ganham tração enquanto colocam em posições desfavoráveis a composição da individualidade.

34 "O fato bruto de que o poder físico (somente físico?) Da máquina supera o do indivíduo e de qualquer grupo particular de indivíduos, torna a máquina o instrumento político mais eficaz em qualquer sociedade cuja organização básica é a do processo da máquina" (MARCUSE, 1991, 1964), tradução nossa. 
À medida que a maquinização, enquanto adensamento das estruturas racionalizadas pela tecnologia, marcha silenciosamente, tendências autoritárias emergem ofuscadas pelas complexidades inerentes à tecnologia. Nesse processo, uma vez subjugado pelas forças "racionalizantes", o indivíduo, enquanto ente complicador do apparatus, seria um insumo de sua inevitável dominação. O pessimismo lançado por Marcuse não viria desacompanhado da possibilidade de reversão desse processo. Para Marcuse, essa reversão seria possível se considerarmos que "the political trend may be reversed; essentially the power of the machine is only the stored-up and projected power of man "35. O convite à contra-revolução é então lançado em sútil equiparação à lógica de Marx, quando Marcuse defende que "to the extent to which the work world is conceived of as a machine and mechanized accordingly, it becomes the potential basis of a new freedom for man ${ }^{\prime 36}$. O poder das máquinas, para Marcuse, nada mais seria do que a expressão do poder do Homem. A base racionalizante, nesse sentido, serviria apenas para legitimá-lo e torná-lo inconteste enquanto objetificação e ultra-racionalização de suas relações.

Enquanto legitimação, Habermas busca, na concepção da ciência, em consonância com Marcuse, a explicação para esse fenômeno: "a dominação eterniza-se e amplia-se não só mediante a tecnologia, mas como tecnologia" (HABERMAS, 2006). A proposição de ambos autores utiliza-se da constante racionalizante da Ciência como força propulsora, ratificante e legitimadora do poder e dominação que, por ventura, poderiam ser expressos pela tecnologia. Para Habermas, o método científico seria a força elementar da dominação tecnológica por encapsular a dominação da natureza e proporcionar meios mais eficientes da dominação de uns sobre outros:

\begin{abstract}
O método científico, que levava sempre a uma dominação cada vez mais eficaz da natureza, proporcionou depois também os conceitos puros e os instrumentos para uma dominação cada vez mais eficiente do homem sobre os homens, através da dominação da natureza... Hoje, a dominação eterniza-se e- amplia-se não só mediante a tecnologia, mas como tecnologia; e esta proporciona a grande legitimação ao poder político expansivo, que assume em si todas as esferas da cultura. Neste universo, a tecnologia proporciona igualmente a grande racionalização da falta de liberdade do homem e demonstra a impossibilidade «técnica» de ser autônomo, de determinar pessoalmente a sua vida. Com efeito, esta falta de liberdade não surge nem irracional nem como política, mas antes como sujeição ao aparelho técnico que amplia a comodidade da vida e intensifica a produtividade do trabalho. A racionalidade tecnológica protege assim antes a legalidade da dominação em vez de a eliminar e o horizonte instrumentalista da razão abre-se a uma sociedade totalitária de base racional». (HABERMAS, 2006)
\end{abstract}

Sujeitar-se e abdicar da liberdade e da autonomia seria o andar naturalizado das

35 " [...] a tendência política pode ser invertida; essencialmente, o poder da máquina é apenas o poder acumulado e projetado do homem. (MARCUSE, 1991, 1964), tradução nossa.

36 "[...]Na medida em que o mundo do trabalho é concebido como uma máquina e mecanicamente adequado, ele se torna a base potencial de uma nova liberdade para o homem" (MARCUSE, 1991, 1964), tradução nossa. 
coisas enquanto comodidade de vida; é o começo da pacificação do processo revolucionário que a tecnologia tem acelerado desde a revolução industrial. Seria o preço a se pagar pelas benesses da tecnologia. A alienação, nesse sentido, não seria apenas em relação às estruturas de classe, como preconiza Marx - seria, de igual modo, em relação à dominação tecnológica. A racionalidade cumpriria seu papel, na corporificação da ciência, de justificar e lançar sua legitimidade para a "construção de uma sociedade totalitária de base racional", justificada e, como critica Marcuse, democrática. Marcuse vislumbra, então, que a partir da consciência dessa servidão, a sociedade seria capaz de liberar-se e compreender os limites que a tecnologia necessitaria - uma nova forma de liberdade, nesse ínterim, emergiria:

The more rational, productive, technical, and total the repressive administration of society becomes, the more unimaginable the means and ways by which the administered individuals might break their servitude and seize their own liberation.[...] All liberation depends on the consciousness o f servitude, and the emergence of this consciousness is always hampered by the predominance of needs and satisfactions which, to a great extent, have become the individual's own ${ }^{37}$. (MARCUSE, 1991, 1964)

Por liberação, Marcuse defenderia mais estruturas democráticas? Defenderia a revolução vislumbrada por Marx, em sua perspectiva tecnológica? Caso a democracia seja capaz de lidar com o processo racionalizante-autoritário da tecnologia, preconizado por Marcuse, que tipo de democracia, então, seria? Se haveria a presença de forças não democráticas em marcha para o domínio de instituições democráticas, o quão conflitiva seria essa relação? De que forma e por quais meios a tecnologia se sobreporia ao regime e ao indivíduo em sociedades democráticas, como denuncia Marcuse? Nessa inquietação, é preciso, primariamente, questionar que tipo de relação entre democracia e tecnologia seria estabelecida ou seria possível.

\subsection{Tecnologia e Democracia: Uma Relação Conflitiva?}

Qual a relação entre democracia e tecnologia? A premissa de que há uma relação entre democracia e tecnologia, não é evidente ou, quando é observável, tende a não ser compreendida como politizada e/ou conflitiva. A despolitização e a falta de problematização acerca dessa relação é por si só um problema a ser averiguado. Afinal, até que ponto a despolitização tecnológica não é um ato político em si mesmo? Para além desse debate, faz-se necessário averiguar justamente pela premissa da inerente politização da tecnologia e seu potencial caráter conflitivo com a democracia.

37 "Quanto mais racional, produtiva, técnica e total for a administração repressiva da sociedade, mais inimagináveis serão os meios e modos pelos quais os indivíduos administrados poderiam quebrar sua servidão e tomar sua própria libertação. [...] Toda libertação depende da consciência da servidão, e o surgimento dessa consciência é sempre dificultado pela predominância de necessidades e satisfações que, em grande medida, se tornaram do próprio indivíduo" (MARCUSE, 1991, 1964), tradução nossa. 
Por um lado, a relação não é evidente por motivos tais como, a não-observância desta relação pelos círculos acadêmicos, pela complexidade que a tecnologia empreende, pela presunção de neutralidade (deliberada ou não) e, por sua vez, pela despolitização da tecnologia ao interpretá-la como mero aparato instrumental ${ }^{38}$, dentre outros. Por outro lado, a observação de que a relação tecnologia-democracia pode ser conflitiva, politizada e/ou incompatível fundamenta a linha mestra de nossa proposta. Afinal, é possível haver caraterísticas políticas na tecnologia? Se a resposta tender ao sim, é possível averiguar se o caráter político da tecnologia é compatível com a democracia? Nesse sentido, "what is the relationship between democracy and technology? And what should that relationship be?"39 (WINNER, 1992a, p.1).Para responder tais questões, é preciso contextualizar primeiramente a relação entre democracia e tecnologia, para depois se abarcar, propriamente dita, a Tecnologia da Informação a partir da consolidação do campo teórico/científico ${ }^{40}$, no período entre $1^{\mathrm{a}}$ e $2^{\mathrm{a}}$ Guerras Mundiais.

Cabem, também, três ressalvas enquanto pesquisa realizada nesse trabalho: (1) a primeira diz respeito ao recorte temporal - explicitado no começo deste trabalho - e indica que, embora seja relevante aprofundar a compreensão das dinâmicas que compõem os períodos predecessores, os fenômenos que serão analisados estão compreendidos majoritariamente a partir (e não somente dentro) da criação da NSA, com escolhas metodológicas que serão explicitadas no decorrer do trabalho.

A segunda (2) ressalva lida com o léxico das categorias que fundamentarão a análise: "tecnologia", "tecnologia da informação" e "cibernética". Há uma parte da literatura que utilizará o termo "tecnologia" no seu sentido amplo, sem especificar o termo "tecnologia da informação". Na abordagem aqui adotada, primeiro serão apresentas as análises da

38 Conforme explica Carpenter, o debate para de se compreender a natureza política da tecnologia pode ser subdivido em dois: um "instrumentalista" e outro "expressivista": "An ambiguity in our understanding of technology, the gap between instrumentalist and expressivist understandings, afflicts many contemporary efforts to evaluate the links between technology and the political order. Instrumentally, technology simply reflects human intentions; expressively, it constitutes them. Instrumentally, technology enables us to add new bits of furniture to our world; expressively, technology designs that world and gives form to our most basic priorities and necessities. Instrumentally, technology serves to meet independently generated preference and need schedules. Expressively, technology actually defines those needs, providing a basis for our self- understanding."(CARPENTER, 1992)

39 "Qual é a relação entre democracia e tecnologia? E o que deve ser essa relação?" (WINNER, 1992a, p.1), tradução nossa.

40 O surgimento do campo da Ciência da Computação tem em seu principalmente expoente Alan Turing e se desenvolve a partir da década de 30 com diversas contribuições de campos distintos. Conforme aponta Denning (1997, p.1), "The discipline of computer science was born in the early 1940s with the confluence of algorithm theory, mathematical logic, and the invention of the stored-program electronic computer. Examples are the works of Alan Turing and Kurt Godel in the 1930s about algorithms and their realizations as machines or rule-systems, the algorithms created by Ada Lovelace sixty years earlier, the analog computers built by Vannevar Bush in the 1920s, and the electronic computers built by Howard Aiken and Konrad Zuse in the 1930s. The writings of John von Neumann demonstrate considerable intellectual depth to the emerging discipline by the late 1940s. By the early 1960s, there was a sufficient body of knowledge to merit the first academic departments and degree programs. This discipline is also called computer science and engineering, computing, and informatics." (DENNING, 1997 , p.1) 
tecnologia na sua acepção genérica, para que, depois, seja possível especificar o subcampo da Tecnologia da Informação e, posteriormente, o campo multidisciplinar das abordagens cibernéticas para que, assim, faça-se a síntese enquanto "tecnologia da informação cibernética". É preciso ressaltar ainda que nem toda Tecnologia da Informação é cibernética e nem toda cibernética refere-se à Tecnologia da Informação. Especificamente em nossa proposta, o cibernético será necessariamente tecnológico e estará diretamente ligado à Tecnologia da Informação.

A terceira (3) ressalva aplica-se na relação quase mutualmente excludente entre as próprias Ciências Sociais com a Ciência da Tecnologia da Informação. Se a constatação da relação entre democracia e tecnologia sofre de seus lapsos teóricos na primeira, é possível observar que a literatura torna-se ainda mais escassa ou imprecisa quando se lida diretamente com a tecnologia da informação na Ciência Política ${ }^{41}$ - nesse sentido, também, não causa espanto que as abordagens cibernéticas padeçam de igual problema. Em relação ao lapso teórico, não há muito que ser feito, a não ser manter o otimismo de que ele se desenvolva no decorrer do tempo. Contudo, para mitigar parte da imprecisão, embora a Ciência Política/Sociologia e/ou Filosofia tenha como ponto de partida o seu arcabouço teórico próprio para a análise da Tecnologia da Informação em uma via de mão-única, o ponto de partida apresentado neste trabalho seguirá caminhos opostos ao propor a construção dialética entre as duas naturezas inerentes do campo científico da Tecnologia da Informação e da Ciência Política.

Ainda que desconhecida, a temática da relação da tecnologia com os preceitos democráticos, todavia, ganhou destaque devido à crescente interdependência de democracias contemporâneas em relação às tecnologias, sobretudo, as tecnologias da informação. Contudo, para analisar essa relação, é preciso, adotar como ponto de partida a discussão das caraterísticas políticas que compõem um "artefato", "aparato" ou "dispositivo" tecnológico: afinal, "in controversies about technology and society, there is no idea more provocative than the notion that technical things have political qualities" (WINNER, 1980). O desenvolver teórico dessa concepção contou inicialmente também com o aporte filosófico de Foucault ${ }^{42}$, Agamben, Deleuze e Guattari na definição das relações de poder que se ensejam como/num "aparatus" e ou "dispositiv" na sociedade2. Embora relevantes, coube a Langdon Winner problematizar novamente a discussão ao questioná-la em seu artigo "Do

$\overline{41}$ Apenas as ciências econômicas teriam observado com afinco a relevância dos processos tecnológicos enquanto objeto de estudo, conforme indica Sclove: "Technology is a taboo subject in philosophy and the social sciences. Yes, there is an occasional passing mention. Even a seminal book or two. But the vast mainstream of social science proceeds as though technologies simply do not exist, do not matter. The principal exception occurs within the discipline of economics, in which a modest scholarly industry now preaches the need to devise public policies that can accelerate the pace of technological innovation. The stated objective is to enhance national economic growth, productivity, and international competitiveness on the unexamined assumption that as long as an innovation sells profitably, it is an unalloyed social blessing" (SCLOVE, 1992, p.139) - Para o autor, a problematização ou politização necessária ao tema perderia relevância quando comparada, por exemplo, com os benefícios que a inovação traria.

42 (FOUCAULT, 1980; AGAMBEN, 1998; DELEUZE; GUATTARI, 1983; GUATTARI, 1984) 
Artifacts Have Politics?" para além das métricas instrumentais, seu caráter "neutro" ou "apolítico". Winner tipifica de forma elucidativa as posições e constatações de Marcuse e Habermas ao trazer a atenção para a necessidade de se identificar na tecnologia as formas que o poder assume:

\begin{abstract}
At issue is the claim that the machines, structures, and systems of modern material culture can be accurately judged not only for their contributions of efficiency and productivity, not merely for their positive and negative environmental side effects, but also for the ways in which they can embody specific forms of power and authority. Since ideas of this kind have a persistent and troubling presence in discussions about the meaning of technology, they deserve explicit attention ${ }^{43}$. (WINNER, 1980)
\end{abstract}

É consensual que as dinâmicas da Tecnologia e, de forma contemporânea, da Tecnologia da Informação, mobilizam e articulam de forma ubíqua as mais variadas esferas da sociedade; mobilizam satélites de comunicação, hospitais e implantes médicos, infraestruturas de energia, reatores nucleares, arsenais militares, sistemas eleitorais, dentre tantos outros sistemas, elementos e aparatos críticos. Tornou-se, portanto, inconteste o reconhecimento de que no limiar do Século XX para o XXI as sociedades amalgamaram-se à chips de silício e algoritmos complexos para a mobilização de suas dinâmicas, estruturas e infraestruturas.

Há dois problemas diretos decorrentes dessa amalgama: um reside na premissa de que a sociedade mobiliza a tecnologia, inserindo-a numa constante unilateral e hierarquizando-a como subserviente ao seu controle e determinismo. Sucede, porém, que por intermédio dessa premissa, incorre-se na alienação entre sociedade e tecnologia e vice-versa. Hierarquizar significa negar que a tecnologia exerce influência, interfere, cria e re-cria a sociedade ao mesmo tempo em que é criada. São elos e categorias que assumem uma relação não-hierárquica e passam a ser mutual-dialeticamente constituídas. O segundo problema é que, em decorrência da alienação tecnológica, a fusão com a tecnologia ultrapassou um ponto de "não-retorno"sem as devidas considerações político-sociais que dela decorreram. Um entusiasmado salto no escuro tecnológico pela sedutora componente avant-garde da tecno-ciência, monocrática, presunçosamente benéfica ao interesse coletivo e de "irrelevantes"consequências frente ao "progresso"que dela advém.

Desta forma, a observação de que a relação "tecnologia-democracia"possui um vasto potencial conflitivo, político e/ou incompatível traz a tônica de nossa proposta: o caráter político da tecnologia representa um risco à Democracia? Se a resposta tender ao sim,

\footnotetext{
43 "Em questão está a alegação de que as máquinas, estruturas e sistemas da cultura material moderna podem ser julgados com exatidão não apenas por suas contribuições de eficiência e produtividade, não apenas por seus efeitos colaterais ambientais positivos e negativos, mas também pelas maneiras pelas quais pode incorporar formas específicas de poder e autoridade. Como ideias desse tipo têm uma presença persistente e preocupante nas discussões sobre o significado da tecnologia, elas merecem atenção explícita" (WINNER, 1980), tradução nossa.
} 
é possível tornar o caráter político da tecnologia compatível com a democracia? Nesse sentido, "what is the relationship between democracy and technology? And what should that relationship be?" (WINNER, 1992b) ${ }^{44}$.

Uma das mais significativas mudanças dessa "moderna cultura material" pode ser compreendida pelas análises que se dedicam a explicá-la por meio da intensificação da inserção e uso de novas tecnologias no decorrer da Revolução Industrial. O ponto de partida dessas análises é de que essa inserção foi capaz de modificar substancialmente as formas de organização política - neste ponto, o que se argumenta é que nem sempre essas medicações serviram ao bem público ou tiveram suas promessas cumpridas.

Se a introdução e uso das tecnologias industriais pôde ser compreendida como uma das responsáveis pelas modificações nas formas de organizações políticas da sociedade e do Estado, para Wartofsky, contudo, faz-se necessário diferenciá-las das contemporâneas tecnológicas complexas, pois são substancialmente diferentes em escala, escopo e impactos. O autor defende que as tecnologias que compartilham dessa característica apresentam mais desafios para a sociedade e suas formas de organização, em especial, o Estado e suas esferas nacionais e internacionais: "it has become a central if not yet the dominant question in national and global politics, affecting the basic issues of power: political, economic, military and social power-thereby direct1y affecting the lives and future of people on a mass scale"45 (WARTOFSKY, 1992, p.16). Neste sentido, WARTOFSKY (1992, p.16), ao abordar a questão da influência política da tecnologia, refere-se especificamente às tecnologias de alta complexidade que colocam em questão inclusive a forma do exercício de poder.

Analisar politicamente os artefatos tecnológicos de alta complexidade tornou-se premente para se compreender essas novas feições de exercício de poder compostas pela conjunção de "poder", "conhecimento" e "autoridade" e, principalmente, sobre como escrutiná-las e colocá-las sobre controle. Em suas palavras, o autor corrobora que:

Control and direction of this technology has therefore become a matter of much greater complexity and scope than it has ever been in the past-one may say that it has become a qualitatively different question than it has been heretofore. These questions concerning power, knowledge and authority therefore became crucial political question, as well as a technological, or scientific or economic one. (WARTOFSKY, 1992, p.16) ${ }^{46}$.

44 "Qual a relação entre democracia e tecnologia? E como essa relação deve ser?"(WINNER, 1992b) Traduação nossa.

45 "Tornou-se uma questão central, se ainda não dominante, na política nacional e global, afetando as questões básicas do poder: poder político, econômico, militar e social, afetando diretamente a vida e o futuro das pessoas em grande escala" (WARTOFSKY, 1992, p.16), tradução nossa.

46 "O controle e a direção dessa tecnologia tornaram-se, portanto, uma questão de complexidade e abrangência muito maiores do que jamais foi no passado - pode-se dizer que se tornou uma questão qualitativamente diferente da que foi até agora. Essas questões relativas a poder, conhecimento e autoridade, portanto, tornaram-se questões políticas cruciais, assim como tecnológicas, científicas ou econômicas" (WARTOFSKY, 1992, p.16), tradução nossa. 
A compreensão da natureza, efeitos e exercício político da tecnologia é essencial para a se contextualizar o elo entre o poder que circunda e se insere na tecnologia com a projeção de valores políticos, tais como aqueles que diferenciam determinadas tecnologias como "opressoras" ou "libertadoras" - feições que se vinculam com caraterísticas típicas de regimes de governo: autoritários ou democráticos. Desta forma, o argumento de Winner toma como pressuposto que se os artefatos tecnológicos são inerentemente políticos e, como tais, eles impactam também a forma como o exercício político é constituído:

\begin{abstract}
None of the arguments and examples considered thus far address a stronger, more troubling claim often made in writings about technology and society - the belief that some technologies are by their very nature political in a specific way. According to this view, the adoption of a given technical system unavoidably brings with it conditions for human relationships that have a distinctive political cast-for example, centralized or decentralized, egalitarian or inegalitarian, repressive or liberating. This is ultimately what is at stake in assertions like those of Lewis Mumford that two traditions of technology, one authoritarian, the other democratic, exist side by side in Western history. (WINNER, 1980, p.128) ${ }^{47}$.
\end{abstract}

Há também dois fatores que precisam ser considerados para análise dessa correlação e interdependência entre feições políticas e a alta complexidade decorrente da "evolução tecnológica", a saber: a relação de subordinação e a capacidade de ocultar intenções e motivações dúbias. No primeiro fator, observa-se que as tecnologias em geral impõem desafios constantes, principalmente no tocante a capacidade de resposta em tempo hábil ou preventiva frente aos riscos que elas oferecem: "Society is always several steps behind; technologies are introduced into society and then its institutions, laws, and values must be altered and adjusted to accommodate them ${ }^{\prime 48}$ (FIELDER, 1992, p.107). A ponderação por parte da sociedade em tempo hábil ou preventiva seria capaz de esmiuçar os impactos de novas tecnologias de modo a controlá-las - capacidade esta que requer engajamento e conhecimento, pois, quando ausente, estabelece uma relação de subordinação da sociedade à própria tecnologia, ou, nas palavras de Fielder, "rather than serving consciously chosen, limited social ends, technology autonomously shapes and reshapes social life according to its needs"(FIELDER, 1992) ${ }^{49}$. Se há uma relação de subordinação, certamente existem

47 "Nenhum dos argumentos e exemplos considerados até agora tratam de uma afirmação mais forte e problemática, frequentemente feita em escritos sobre tecnologia e sociedade - a crença de que algumas tecnologias são, por natureza, políticas de uma maneira específica. De acordo com essa visão, a adoção de um determinado sistema técnico inevitavelmente traz condições para as relações humanas que têm um elenco político distinto - por exemplo, centralizado ou descentralizado, igualitário ou desigual, repressivo ou libertador. Em última análise, isso é o que está em jogo em afirmações como as de Lewis Mumford de que duas tradições da tecnologia, uma autoritária, a outra democrática, existem lado a lado na história ocidental" (WINNER, 1980, p.128), tradução nossa.

48 "A sociedade está sempre vários passos atrás; tecnologias são introduzidas na sociedade e, em seguida, suas instituições, leis e valores devem ser alterados e ajustados para acomodá-los" (FIELDER, 1992, p.107), tradução nossa.

49 "Em vez de servir a fins sociais limitados e conscientemente escolhidos, a tecnologia forma e modela autonomamente a vida social de acordo com suas necessidades" (FIELDER, 1992), tradução nossa 
outros fatores envolvidos, tais como a capacidade de ocultar intenções e motivações, as quais não se poderia facilmente mensurar se são benéficas, genuínas ou legítimas. A partir deste raciocínio, Winner argumenta que:

The ideas we use to think about technology often conceal more than they reveal. A crucial distinction in our traditional concept of technology, that of a tool and its use, helps to hide the political dimensions of technology. The distinction holds that tools are value-neutral, able to be used for a variety of purposes. It is only the purposes which have political significance, and the proper response is to discover and punish those who use technology for evil purposes. What is lost in this conception is the array of social and political conditions which must be established in order to make a place for technology $5^{50}$. (WINNER, 1992b, p.108).

A preocupação com essas duas dimensões das tecnologias complexas faz sentido somente quando elas estão embebidas em uma sociedade democrática - afinal, em feições autoritárias de governo, o uso arbitrário, subordinado e não transparente das tecnologias complexas torna-se mais do que uma ferramenta, torna-se parte do exercício de poder. Não por menos, as tecnologias de alta complexidade passaram a figurar não somente como elementos críticos das pautas de sociedades democráticas mas, também, como pré-requisitos para suas manutenções e equilíbrios. A evolução cronológica, esboçada na tabela 1 de uma ínfima fração da complexidade tecnológica traz a dimensão do quão vertiginosa ela passaria a ser.

Figura 1 - Cronologia de eventos de impacto tecnológico no século XX

1928 - Alexander Fleming descobre o primeiro antibiótico, a penicilina.

1933 - Leo Szilard inventa e patenteia o conceito de bomba nuclear.

1937 - Alan Turing apresenta o conceito dos computadores modenos.

1942 - Conceito da Bomba de Hidrogênio é apresentado por Edward Teller.

1948 - Norbert Wiener publica sua introdução à Cibernética.

1953 - O DNA em dupla-hélice é descoberto por Watson e Crick.

1957 - Satélites Sputnik 1 e 2 são lançados pela URSS.

1969 - Os primeiros servidores da ARPANET são conectados.

1989 - A World Wide Web (WWW) é inventada por Tim Berners-Lee.

1994 - A computação via DNA é provada enquanto conceito

1997 - Ovelha Dolly é clonada pelo Roslin Institute.

Fonte: Compilado de fontes diversas pelo autor

50 "As ideias que usamos para pensar sobre tecnologia geralmente ocultam mais do que revelam. Uma distinção crucial em nosso conceito tradicional de tecnologia, a de uma ferramenta e seu uso, ajuda a esconder as dimensões políticas da tecnologia. A distinção afirma que as ferramentas são neutras em termos de valor, podendo ser usadas para uma variedade de propósitos. São apenas os propósitos que têm significado político, e a resposta apropriada é descobrir e punir aqueles que usam a tecnologia para fins malignos. O que se perde nessa concepção é o conjunto de condições sociais e políticas que devem ser estabelecidas para se criar um lugar para a tecnologia" (WINNER, 1992b, p.108), tradução nossa. 
Para Winner, o debate entre tecnologia e "Ciência Política", ou politics, começa a demonstrar suas problemáticas quando incorpora as dinâmicas das tecnologias complexas na sociedade. As tecnologias complexas, tais como a Tecnologia da Informação, suas derivadas como a Internet e o tecnologias de outras áreas, como a engenharia genética, trariam pela alta complexidade uma nova categoria de riscos. Winner entende que "In areas of environmental policy, industrial planning, health care, the evaluation of hazards and 'risks', military affairs, many of the key disputes hinge upon the categories of analysis and evaluation employed as decisions evolve" ${ }^{11}$ (WINNER, 1992b, p.4). A problemática dessas tecnologias seria posta, justamente na capacidade de, pela alta complexidade, ocultar riscos inerentes ou premeditados em seus desenhos; uma tendência que Winner ressalta para "O que parece ser uma forma de análise filosófica e técnica eminentemente "racional"e politicamente "neutra"pode mascarar preconceitos profundamente hostis aos princípios democráticos" (WINNER, 1992b, p.4). Qual seria, portanto, a relação entre democracia e complexidade tecnológica?

\subsection{Democracia e o Prelúdio da Complexidade}

A busca por respostas aos efeitos das tecnologias complexas passa por caminhos não convencionais e pouco evidentes, mas compartilham de uma base comum: a cibernética. A título de regulamentar, governar e introduzir as mudanças e ganhos tecnológicos-científicos para a sociedade, o processo democrático frequentemente se vê diante da necessidade de colocar em pauta questões éticas sobre os "avanços" como, por exemplo, da genética ou "tecnologia da informação", dentre outros temas que trazem consigo a complexidade tecnológica-cientifica. Influenciado pelas abordagens de sistemas complexos e cibernéticas, Habermas cogita que há uma categoria de abstrações que figuram como vetores de mudança na sociedade que merecem especial atenção devido à capacidade de alterarem em profundidades ainda desconhecidas as dinâmicas não somente de entidades inorgânicas como, também, de sistemas orgânicos. Em seu livro "The theory of communicative action", Habermas aborda tal fenômeno sob a ótica de "Problems of excessive complexity" e indica que o mesmo pode ser mais bem compreendido pela lente dos sistemas complexos ou, no caso aqui delimitado, pelos sistemas cibernéticos:

There are certainly good reasons to fear military potentials for destruction, nuclear power plants, atomic waste, genetic engineering, the storage and central utilization of private data, and the like. These real anxieties are combined, however, with the terror of a new category of risks that are literally invisible and are comprehensible only from the perspective

\footnotetext{
51 "Em áreas de política ambiental, planejamento industrial, assistência médica, avaliação de ameaças e "riscos", assuntos militares, muitas das principais disputas dependem das categorias de análise e avaliação empregadas à medida que as decisões evoluem. O que parece ser uma forma de análise filosófica e técnica eminentemente "racional"e politicamente "neutra"pode mascarar preconceitos profundamente hostis aos princípios democráticos" (WINNER, 1992b, p.4), tradução nossa
} 
of the system. These risks invade the lifeworld and at the same time burst its dimensions. The anxieties function as catalysts for a feeling of being overwhelmed in view of the possible consequences of processes for which we are morally accountable-since we do set them in motion technically and politically - and yet for which we can no longer take moral responsibility - since their scale has put them beyond our control. Here resistance is directed against abstractions that are forced upon the lifeworld, although they go beyond the spatial, temporal, and social limits of complexity of even highly differentiated lifeworlds, centered as these are around the senses. ${ }^{52}$ (HABERMAS, 1984-1987, p. 394-395).

A resistência, segundo Habermas, volta-se contra as abstrações e avanço de limites da alta complexidade tecnológica da sociedade, contra esferas, por vezes, não democráticas - abstraídas de tecnologias de cunho totalitário-totalizante. Ainda assim, a coexistência de esferas não-democráticas em sociedades democráticas é um elemento muitas vezes tolerado e legalmente aceito. Fazem parte das burocracias estatais, entidades privadas e perpassam os mais diversos recortes e camadas de sociedades e seus regimes de governo. Para Dahl, a coexistência de tais esferas só seria um problema sanável com o imperativo de fossem equacionadas pela legitimidade que somente o método democrático poderia fornecer; nesse sentido, Dahl defende que

\begin{abstract}
One response to the existence of undemocratic institutions in a democratic country is to demand that they be democratized. Behind this demand lies the assumption that power can be legitimate - can be considered as acceptable authority - only if it issues from fully democratic processes. (DAHL, 1990, p. 3)
\end{abstract}

Estão presentes, nessa argumentação, três visões subjacentes. A primeira identifica que essas esferas não-democráticas são capazes per se de serem as responsáveis pela interferência ou subversão da natureza democrática de tais sociedades. A segunda visão identifica que a presença de esferas de poder não-democráticas impacta substancialmente a natureza democrática da sociedade. A terceira visão estabelece que não é possível a presença de esferas não-democráticas naquelas instituições e processos que são intrínsecos e fundamentais ao modus operandi das democracias. Para a primeira visão, Robert Dahl apresenta a linha argumentativa que:

52 "Certamente, há boas razões para se temer o potencial militar de destruição, usinas nucleares, resíduos atômicos, engenharia genética, armazenamento e utilização central de dados privados e coisas do gênero. Essas ansiedades reais são combinadas, no entanto, com o terror de uma nova categoria de riscos que são literalmente invisíveis e são compreensíveis apenas do ponto de vista do sistema. Esses riscos invadem o mundo da vida e ao mesmo tempo estouram suas dimensões. As ansiedades funcionam como catalisadores da sensação de estarem sobrecarregados em vista das possíveis consequências de processos pelos quais somos moralmente responsáveis- já que os colocamos em movimento técnica e politicamente - e ainda para os quais não podemos mais assumir a responsabilidade moral - já que sua escala os colocou além do nosso controle. Aqui, a resistência é dirigida contra abstrações que são forçadas sobre o mundo da vida, embora elas ultrapassem os limites espaciais, temporais e sociais da complexidade até mesmo dos mundos da vida altamente diferenciados, centrados em torno dos sentidos". (HABERMAS, 1984-1987, p. 394-395) Tradução nossa do excerto de Habermas (1984-1987, p. 394-395) 
To replace undemocratic ideas and practices with democratic institutions requires new ideas about authority and new practices. But even in countries where democratic institutions have been around for a long time not all forms of authority are necessarily democratic. Undemocratic forms of authority exist in democratic countries for at least two reasons. Even today what one ordinarily calls democracies are, as we all know, a very long way from fully democratized political systems. And in all democratic countries some kinds of organizations are explicitly and even legally governed by systems of nondemocratic authority: business firms, for example. ${ }^{53}$ (DAHL, 1990, p. 1)

Se há uma mobilização política por meio da tecnologia em sociedades democráticas, quais princípios democráticos são necessariamente afetados? Seria possível auferir os impactos que a tecnologia oferece aos preceitos democráticos de modo a desmistificá-la enquanto neutra ou racional? Se sim, como analisar a relação entre tecnologias altamente complexas com a democracia? A teoria democrática de Dahl revela, além da sintetização dos princípios do processo democrático, a capacidade de propor uma análise dos efeitos da complexidade tecnológica na democracia. Para relacioná-la em busca de respostas às questões acima, primeiramente serão apresentados os princípios do processo democrático, em um segundo momento os princípios da poliarquia e, logo em seguida, a correlação entre complexidades tecnológicas com os preceitos do processo democrático.

No livro "Democracy and its critics", Dahl defende que um dos vetores de transformação da democracia contemporânea consiste na crescente complexidade inerente ao Estado Nação, que por sua vez demanda processos democráticos em escalas massivas, interconectadas e complexas. O autor pondera que as transformações que as concepções de democracia sofreram desde as "Cidades Estado" até suas feições contemporâneas, definidas como "Poliarquias", são em grande parte compreensíveis pela necessidade de se alterar a escala devido ao crescimento populacional e a necessidade, após a Revolução Industrial, de se colocar em pauta a complexidade, seja ela tecnológica ou decorrente da organização social. Embora a discussão seja de suma relevância, nessa pesquisa, somente duas discussões serão exploradas a partir da obra de Dahl: a primeira discussão trata das ponderações acerca do processo democrático e as concepções de Poliarquia.

Dentre a primeira discussão, Dahl defende a priori que dos métodos de governo, o democrático é o que melhor consegue distribuir o poder decisório para que, com as devidas limitações, possa-se objetivar a construção do "bem comum". Ainda que bem conhecida, cabe especificar que a necessidade de um processo democrático, na acepção Dahl, pode ser

\footnotetext{
$\overline{53}$ "Substituir ideias e práticas antidemocráticas por instituições democráticas requer novas idéias sobre autoridade e novas práticas. Mas mesmo em países onde as instituições democráticas existem há muito tempo, nem todas as formas de autoridade são necessariamente democráticas. Formas antidemocráticas de autoridade existem em países democráticos por pelo menos duas razões. Até hoje, o que comumente chamamos de democracias, como todos sabemos, é muito distante dos sistemas políticos plenamente democratizados. E em todos os países democráticos, alguns tipos de organizações são explícita e até mesmo legalmente regidos por sistemas de autoridade não-democrática: firmas comerciais, por exemplo" (DAHL, 1990, p. 1), tradução nossa.
} 
compreendida na constatação de que "[... in order to live together in an association, the members of the association will need a process for making decisions about the association's principles, rules, laws, policies, conduct, and so on" ${ }^{54}$ (DAHL, 1991, p.81). Para que o processo democrático se estabeleça, Dahl elenca quatro critérios básicos: a participação efetiva (effective participation), equidade de voto em arenas decisórias (voting equality at the decisive stage), compreensão literata (enlightened understanding) e controle da agenda (control of the agenda).

De um modo geral, a "participação efetiva" pode ser compreendida como o mecanismo que garante que durante o processo decisório, cada indivíduo terá uma adequada e igual oportunidade de inserção de itens na agenda e expressão de suas preferências no resultado final. Por sua vez, a "equidade de voto" garante que cada expressão e voto sejam considerados com pesos iguais no processo decisório. A "compreensão literata" assegura que cada indivíduo tenha o domínio sobre os itens que compõem a agenda ou, em outros termos, "adequate and equal opportunities for discovering and validating [...] the choice on the matter to be decided that would best serve the citizen's interests. ${ }^{55}$ (DAHL, 1991, p.112). Por fim, o "controle da agenda" garante a capacidade de influenciar os itens que deverão passar pelo processo democrático.

Se a democracia contemporânea passou a demandar novas formas de distribuição de poder em decorrência da massificação de seus processos decisórios, Dahl pondera que as concepções clássicas não são suficientes para explicar esse fenômeno e, portanto, a democracia contemporânea seria equivalente a uma poliarquia. A ideia subjacente à concepção poliárquica de Dahl tem a noção básica de que as instituições que compõem o processo democrático evoluem, ou se diferenciam historicamente, para comportar a distribuição de poder frente aos novos fenômenos, como no caso, o aumento demográfico:

With the application of the democratic idea to the government of nationstates, the simple and direct policymaking systems of the assembly democracies were replaced by the more differentiated institutions of polyarchy. However, it was still possible to interpret polyarchy as a system in which policy decisions were made by the demos and its elected representatives and where, as before, certain limited administrative tasks were delegated to officials. The policymaking of early polyarchy - let me call it Polyarchy 1 - could thus be described as simple but indirect ${ }^{56}$ (DAHL, 1991, p.336).

54 "A fim de viverem juntos em uma associação, os membros da associação precisarão de um processo para a tomada de decisões sobre os princípios da associação, regras, leis, políticas, conduta, e assim por diante"(DAHL, 1991, p.81), tradução nossa.

55 "Oportunidades adequadas e iguais para descobrir e validar [...] a escolha sobre o assunto a ser decidido que melhor serviria os interesses do cidadão"(DAHL, 1991, p.112), tradução nossa.

56 "Com a aplicação da idéia democrática ao governo dos Estados-nação, os sistemas de formulação de políticas simples e diretos das democracias de assembléia foram substituídos pelas instituições mais diferenciadas da poliarquia. No entanto, ainda era possível interpretar a poliarquia como um sistema no qual as decisões políticas eram tomadas pelas demos e seus representantes eleitos e onde, como antes, certas tarefas administrativas limitadas eram delegadas aos funcionários. A formulação de políticas da poliarquia inicial - vamos chamá-la de Poliarquia 1 - poderia ser descrita como simples, mas indireta" (DAHL, 1991, p.336), tradução nossa. 
A poliarquia, nesse sentido, pode ser compreendida como uma resultante histórica advinda da democracia que mesmo ao adaptar-se, mantém perene o requisito do processo democrático. Para o autor, "although polyarchies are the most complete historical achievement of the democratic process on the large scale of the nation-state, what polyarchies have achieved is far from complete judged by the criteria of the democratic process". ${ }^{57}$ (DAHL, 1991, p.177). É interessante notar que a manutenção da poliarquia depende da preservação do método democrático que se adapta, compatibiliza e assimila as mudanças introduzidas por novos fenômenos. Em outras palavras, a despeito de qualquer inovação, a poliarquia se distingue pela estabilidade e manutenção do processo democrático conquistado historicamente: afinal, "polyarchies may be thought of as governments in which the institutions necessary to the democratic process exist above a certain threshold"58(DAHL, 1991, p.177). Face às adaptações, Dahl distingue em seu conceito de poliarquia três conceituações-temporalidades distintas, as da primeira, segunda e terceira poliarquia:

\begin{abstract}
Just as Polyarchy I resulted from the creation of new institutions necessary in order to adapt democracy to the nation-state, and Polyarchy II resulted from the addition of new institutions in order to adapt democracy to the growing need for the mobilization of specialized knowledge to the solution of public problems, so Polyarchy III would result from the need to narrow the growing gap that separates policy elites from the demos ${ }^{59}$ (DAHL, 1991, p.338).
\end{abstract}

Para o autor, a primeira poliarquia era caraterizada pela adaptação da democracia aos desafios do Estado-Nação. A segunda poliarquia, além de incorporar um corpo de direitos e liberdades básicas, caracterizou-se principalmente pela adaptação da primeira poliarquia às necessidades de se lidar, a partir de conhecimentos especializados, com a complexidade crescente dos processos decisórios e das políticas públicas. Nas palavras do autor, "the mobilization of specialized intelligence in the service of modem democratic government - let me call it Polyarchy II- was a heroic and generally speaking successful attempt to adapt democracy to the daunting complexity of public policies"60(DAHL, 1991, p.336).

57 "Embora as poliarquias sejam a realização histórica mais completa do processo democrático em grande escala do Estado-nação, o que as poliarquias alcançaram está longe de ser completo, julgado pelos critérios do processo democrático"(DAHL, 1991, p.177), tradução nossa.

58 "As poliarquias podem ser pensadas como governos em que as instituições necessárias ao processo democrático existem acima de um certo limite"(DAHL, 1991, p.177), tradução nossa.

59 "Assim como a Poliarquia I resultou da criação de novas instituições necessárias para adaptar a democracia ao estado-nação, e a Poliarquia II resultou da adição de novas instituições para adaptar a democracia à crescente necessidade de mobilização de conhecimento especializado para o Estado-nação. solução de problemas públicos, então a Polyarchy III resultaria da necessidade de diminuir a crescente lacuna que separa as elites políticas das demos" (DAHL, 1991, p.338), tradução nossa

60 "A mobilização da inteligência especializada a serviço do governo democrático moderno - vamos chamálo de Poliarquia II - foi uma tentativa heróica e geralmente bem-sucedida de adaptar a democracia à complexa complexidade das políticas públicas"(DAHL, 1991, p.336), tradução nossa. 
O aumento da complexidade do escopo da agenda, do processo, da participação e da decisão literata é apontado por Dahl como uma característica típica do segundo e terceiro tipo de poliarquia. Por sua vez, a terceira poliarquia consiste na predominância de uma substancial desigualdade de conhecimentos da classe política sobre o demos. A resposta de Dahl ao problema da complexidade inerente à "poliarquia três" passa pela facilitação do processo democrático com o aporte de mais tecnologias e, de igual modo, o aumento de consciência acerca do mesmo - ou seja, na própria adaptação do processo democrático à complexidade. Sua contribuição reside, também, na constatação de que a interseção entre tecnologias (em destaque as tecnologias da comunicação) e democracia pode não se dar de forma compatível ou harmônica:

The evolving technology is bound to be used somehow, for good or ill. It can be used to damage democratic values and the democratic process, or it can be used to promote them. Without a conscious and deliberate effort to use the new technology of telecommunications in behalf of democracy, it may well be used in ways harmful to democracy ${ }^{61}$ (DAHL, 1991, p.339).

Por usos nocivos à democracia, entende-se que a crescente interdependência entre poder político e tecnologia tem introduzido feições disformes, irreconhecíveis ou de complexa caracterização daquilo que deveria ser, por ventura, democrático, dedicado ao bem comum e de plena consideração aos Direitos Humanos, por exemplo. Dentre os problemas que decorrem dessa constatação, podemos elencar três que diretamente se inter-relacionam: (a) a falta de compreensão do demos para lidar com pautas complexas abordadas pelo processo democrático, (b) a formação de uma classe política capaz de subverter o processo democrático e transpô-lo ao "tecnocrático", e (c) a possibilidade de subversão do processo democrático para fins escusos. Em relação ao primeiro problema, é constatável que a complexidade de tais pautas demanda esforços e métodos de análise que podem não estar necessariamente presentes ou acessíveis ao papel que um "cidadão" ou "legislador" exerce em seu cotidiano, mas ao do expert ou de uma classe política diretamente vinculada às complexidades e, se caraterizada como tal, ao domínio e controle da tecnologia:

Other political theorists believe that the primary problem of technology and democracy concerns the citizen's ability to understand technological issues. They point out how difficult it is for ordinary citizens to become knowledgeable about public policy decisions involving technology. H. D. Forbes forcefully states this concern: "Consider some of the issues governments face today: recombinant DNA research, nuclear reactor safety, clean air, ozone depletion, government debt, and the cost of medical care. "What problems like these have in common is that they have enormously important consequences for a vast number of people, they seem to require

61 "A tecnologia em evolução está fadada a ser usada de alguma forma, para o bem ou para o mal. Pode ser usado para danificar os valores democráticos e o processo democrático, ou pode ser usado para promovê-los. Sem um esforço consciente e deliberado para usar a nova tecnologia de telecomunicações em nome da democracia, ela pode ser usada de maneiras prejudiciais à democracia" (DAHL, 1991, p.339), tradução nossa. 
government decisions of some kind, and in order to make wise decisions, decision-makers need specialized knowledge most citizens do not possess.".. The democratic process as we know it today - the institutions of liberal, representative democracy - seem incapable of achieving democratic control of the "crucially important and inordinately complex" issues of modem technological society" ${ }^{112}$ (WINNER, 1992b, p.109).

Nesse sentido, a complexidade não somente impõe desafios à manutenção do método democrático como, ao exigir o domínio técnico-científico da pauta e do processo, conduz a formação de uma classe política que exerce seu domínio pela tecnologia. Essa classe política presente na caracterização da poliarquia três além do domínio técnico-científico dos temas complexos pode deter também a capacidade de influenciar - seja pela construção da abstração que origina a complexidade - ou até mesmo, participar ou ser responsável pelo próprio processo de tomada de decisão.

\begin{abstract}
Another long-standing source of strain between modern technological development and the practice of democracy stems from the erosion of citizen participation in decision making when confronted with the evolving power of scientific and technical elites. In its c1assic form, this became the question of technocracy, the possibility explored by Thorstein Veblen and others that the complexities of an advanced technological society would inevitably bring it under the governance of a social class of well-trained experts. Thinkers who have described this as a problem rather than an opportunity have worried that modes of traditional understanding used by ordinary people would simply be overwhelmed by the rapidly proliferating varieties of scientific and technical knowledge needed to operate modern sociotechnical systems. What would become of a democracy whose citizens no longer understood the fundamentals upon which key decisions are based? ${ }^{63}$ (WINNER, 1992b, p.3).
\end{abstract}

62 "Outros teóricos políticos acreditam que o principal problema da tecnologia e da democracia diz respeito à capacidade do cidadão de entender as questões tecnológicas. Eles apontam como é difícil para os cidadãos comuns se tornarem informados sobre decisões de políticas públicas envolvendo tecnologia. A HD Forbes afirma enfaticamente essa preocupação: "Considerar algumas das questões que os governos enfrentam hoje: pesquisa de DNA recombinante, segurança de reatores nucleares, ar limpo, destruição do ozônio, dívida do governo e custo de assistência médica". que têm consequências enormemente importantes para um grande número de pessoas, elas parecem exigir decisões governamentais de algum tipo e, para tomar decisões sábias, os tomadores de decisão precisam de conhecimento especializado que a maioria dos cidadãos não possui. "... O processo democrático como a conhecemos hoje - as instituições da democracia liberal e representativa - parecem incapazes de alcançar o controle democrático das questões "crucialmente importantes e excessivamente complexas 'da moderna sociedade tecnológica'" (WINNER, 1992b, p.109), tradução nossa.

63 "Outra fonte de tensão de longa data entre o moderno desenvolvimento tecnológico e a prática da democracia advém da erosão da participação dos cidadãos na tomada de decisões, quando confrontados com o poder em evolução das elites científicas e técnicas. Em sua forma clássica, isso se tornou a questão da tecnocracia, a possibilidade explorada por Thorstein Veblen e outros de que as complexidades de uma sociedade tecnológica avançada inevitavelmente a colocariam sob o controle de uma classe social de especialistas bem treinados. Os pensadores que descreveram isso como um problema, e não como uma oportunidade, temem que os modos de compreensão tradicional usados pelas pessoas comuns sejam simplesmente subjugados pelas variedades rapidamente proliferantes de conhecimento científico e técnico necessários para operar sistemas sociotécnicos modernos. O que seria de uma democracia cujos cidadãos não mais entendessem os fundamentos sobre os quais se baseiam as principais decisões?" (WINNER, 1992b, p.3), tradução nossa. 
Em relação ao terceiro problema, de subversão dos fins e meios do processo democrático, a questão se apresentaria pela possibilidade de aparelhamento por vias tecnológicas do processo democrático. Nesta ótica, a contradição residiria na possibilidade de que propostas, soluções e mudanças, ao serem consideradas ou passarem despercebidas enquanto tecnologicamente "neutras" e portanto "inofensivas", crie-se a oportunidade de que àqueles que dominam a pauta de temas complexos possam se utilizar do método democrático para fins não democráticos. Nesse sentido, o efeito da prevalência tecnológica sobre valores, processos e instituições se mostra principalmente nocivo quando o fim tecnológico subverte os próprios valores que constituem o processo; ou seja, quando o desenho do artefato tecnológico impõe e demanda dinâmicas que não seriam aprovadas caso fossem efetivamente analisadas e votadas por deliberação e finalidade pública.

É possível observar que não somente a tecnologia embarca dinâmicas políticas de poder, agência e sistema, como também às co-criam em um processo contínuo e dialético. Desta forma, a compreensão do caráter inerentemente político da complexidade e da tecnologia nessa interseção não deixa espaço para dúvidas em relação à ausência de neutralidade, interesses a dinâmicas ocultas. Conforme aponta Winner, "[...] it is characteristic of societies based on large, complex technological systems, however, that moral reasons other than those of practical necessity appear increasingly obsolete, "idealistic", and irrelevant"64(WINNER, 1980, p.133). Por essa lógica, torna-se "aceitável", ainda que incompreendida, ações em prol de determinadas tecnologias que não são necessariamente democráticas, pois, segundo o autor, "[...] in many instances, to say that some technologies are inherently political is to say that certain widely accepted reasons of practical necessity [...] have tended to eclipse other sorts of moral and political reasoning"65(WINNER, 1980, p.133). Mesmo que seja evidenciada a supressão de valores e a subversão do processo democrático, a interdependência tecnológica atua como uma amalgama de situações conflitantes. O caráter interdependente torna-se evidente quando há a impossibilidade de se "regressar" (de modo a se "desfazer") a ponto de partida do conflito, principalmente após o aceite, uso e naturalização dessas tecnologias. Carpenter corrobora tal constatação ao situar que a interdependência, mesmo quando conflitiva e nociva, é a mesma que mantém a reprodução material da sociedade e, em suas palavras, define:

We are a mass democracy, a democracy of common possessions, a democracy made possible by the broadest possible distribution of consumer items and services of every description. This democracy, to an unprecedented degree, is embodied in technology. Our political impulses are expressed by means of technological acts and mass produced artifacts. Yet these same

64 "[...] é característico de sociedades baseadas em sistemas tecnológicos grandes e complexos, no entanto, que razões morais diferentes das de necessidade prática parecem cada vez mais obsoletas, "idealistas"e irrelevantes"(WINNER, 1980, p.133), Tradução nossa.

65 "[...] em muitos casos, dizer que algumas tecnologias são inerentemente políticas é dizer que certas razões amplamente aceitas de necessidade prática [...] tendem a eclipsar outros tipos de raciocínio moral e político"(WINNER, 1980, p.133), tradução nossa. 
egalitarian impulses, expressed in consumptive lifestyles, can render us unfree and politically impotent if we are unable to abandon them despite clear evidence that they are no longer appropriate ${ }^{66}$ (CARPENTER, 1992, p.163).

Em outras palavras, a interdependência da tecnologia e de sua complexidade, por vezes, adentra e amalgama-se de tal forma às estruturas mais básicas da sociedade e de suas instituições ao ponto de colocar em risco suas existências modernas caso regressem aos seus estados iniciais: recai-se, portanto, na metáfora da simbiose, cuja separação culminará em riscos existenciais para as partes. Compreender a escolha que se faz sobre determinados tipos de tecnologia traduz-se também na escolha que se faz por determinadas feições políticas. Para Winner, "[...] the idea we must now examine and evaluate is that certain kinds of technology do not allow such flexibility, and that to choose them is to choose a particular form of political life "67(WINNER, 1980, p.128). É cabível, portanto, o questionamento para averiguar se todo tipo de tecnologia apresenta essas características, pois não são necessariamente todas as tecnologias que apresentam essa característica. A compreensão de tal simbiose entre a complexidade, a tecnologia e a democracia requer por si só o escrutínio de suas causas e fundamentos. Afinal, seria possível estabelecer e escrutinar uma classe de "tecnologias complexas" por apresentarem maiores riscos?

\subsection{O Desenho da Tecnologia e o Processo Democrático}

Se por um lado a alta complexidade da tecnologia induz (premeditada ou de forma omissa) o processo democrático para limbos "desconhecidos", "imprevisíveis", "imprecisos" ou "fugazes" - por outro lado, quando constatada, ela passa ser objetivo de políticas públicas e legislações pouco capazes de compreender, regulamentar, mitigar os possíveis efeitos nocivos, ou compatibilizá-la com preceitos democráticos. Conforme corrobora Fielder, o resultado de tais processos, quando desprovidos de propósito, pode figurar como fora dos controles democráticos:

\footnotetext{
The large number and variety of technologies create interactions among these changes which cannot be anticipated and for which there are no existing politic mechanisms of control or regulation. The result is an expanding array of institutional adjustments, economic arrangements,
}

\footnotetext{
66 "Somos uma democracia de massa, uma democracia de posses comuns, uma democracia possibilitada pela distribuição mais ampla possível de bens de consumo e serviços de todos os tipos. Essa democracia, em um grau sem precedentes, é incorporada na tecnologia. Nossos impulsos políticos são expressos por meio de atos tecnológicos e artefatos produzidos em massa. No entanto, esses mesmos impulsos igualitários, expressos em estilos de vida consuntivos, podem nos tornar livres de liberdade e politicamente impotentes se não formos capazes de abandoná-los, apesar da clara evidência de que eles não são mais apropriados" (CARPENTER, 1992, p.163), Tradução nossa.

67 "[...] a ideia que devemos agora examinar e avaliar é que certos tipos de tecnologia não permitem tal flexibilidade, e que escolhê-los é escolher uma forma particular de vida política"(WINNER, 1980, p.128), Tradução nossa.
} 
and technical requirements without overall direction or control. It is technology determining social reality, outside the control of our democratic institutions. ${ }^{68}$ (FIELDER, 1992)

Nesse sentido, se as tecnologias complexas desafiam a lógica do processo democrático, como a democracia pode ser novamente reafirmada nesse contexto? A concepção de Dahl (1991) de que a "evolução e adaptação" democrática, expressa a partir das poliarquias que se modificam em prol da manutenção do processo democrático, fornece um relevante instrumental de análise e um possível caminho para responder tal questão. Se interpretarmos e aplicarmos o raciocínio proposto por Dahl (1991) em busca de uma resposta a pergunta acima, da mesma forma que a "extension of the democratic idea to the scale of the nationstate required a radical adaptation and innovation in political institutions - the creation of polyarchy" (DAHL, 1991), ao avaliarmos a crescente interseção entre democracia e domínios cibernéticos (enquanto domínios inerentemente complexos), tornar-se-á evidente que "so new institutions were now required in polyarchies to meet the demands of complexity in policy and policymaking"69 (DAHL, 1991). Embora não haja uma resposta evidente na literatura, os interesses tendem a convergir: "[...] their common ground is a desire to rethink the horizons of democratic politics in an age increasingly shaped by the power of technologically embodied institutions and practices"70 (WINNER, 1992a). Quais seriam, então, as prerrogativas para uma poliarquia cibernética?

Se a resposta buscar manter a prevalência do processo democrático, ela deverá por sua vez abordar seus requisitos mínimos ou cláusulas pétreas. Para tanto, a análise pode ser diferenciada entre o que, por um lado, demanda-se enquanto pré-requisitos mínimos ao processo democrático e, por outro lado, demanda-se enquanto pré-requisitos tecnológicos (cibernéticos) compatíveis para sua reafirmação enquanto tal. O pressuposto fundamental resultante dessa lógica é de que: não há margem para um processo democrático se estabelecer com tecnologias incompatíveis, ou seja, que o contradigam ou que atuem em sentido oposto aos seus requisitos mínimos, subjugando-os ou anulando-os; em consideração a esse pressuposto, essa impossibilidade será referenciada posteriormente como um "imperativo democrático-cibernético". Conforme elencado anteriormente, Dahl (1991) indica quatro prérequisitos ao processo democrático: participação efetiva (effective participation), equidade de voto em arenas decisórias (voting equality at the decisive stage), compreensão literata (enlightened understanding) e controle da agenda (control of the agenda). Para atender aos

68 "O grande número e variedade de tecnologias criam interações entre essas mudanças, que não podem ser antecipadas e para as quais não existem mecanismos políticos de controle ou regulação. O resultado é uma matriz em expansão de ajustes institucionais, arranjos econômicos e requisitos técnicos sem direção ou controle geral. É a tecnologia que determina a realidade social, fora do controle de nossas instituições democráticas"(FIELDER, 1992), tradução nossa.

69 "Assim, novas instituições eram necessárias nas poliarquias para atender às demandas de complexidade na formulação de políticas e políticas" (DAHL, 1991), tradução nossa.

70 "Seu terreno comum é o desejo de repensar os horizontes da política democrática em uma era cada vez mais moldada pelo poder das instituições e práticas tecnologicamente corporificadas" (WINNER, 1992a) , tradução nossa. 
requisitos mínimos do processo democrático, SCLOVE (1992) distingue duas categorias de análise: componentes "procedimentais" e "substanciais" ou, nos termos do autor:

Technological democratization would have both procedural and substantive components. Procedurally, there must be expanded opportunities for people from all walks of life to participate effectively in guiding the evolving technological order. Substantively, the resulting technologies ought to be compatible in their design with democracy's necessary conditions. ${ }^{71}$ (SCLOVE, 1992)

WARTOFSKY (1992)faz proposições semelhantes as de Dahl (1991) ao propor as duas condições básicas à "participação" e "controle" democrático da tecnologia: "(1) adequately democratic modes of sharing or participating or being represented in decisions; and (2) adequately informed understanding of scientific-technical questions" ${ }^{\text {"W2 }}$ (WARTOFSKY, 1992). Enquanto a primeira proposição aproxima-se do pré-requisito da participação efetiva (effective participation), a segunda proposição está diretamente vinculada, por sua vez, ao requisito da compreensão literata (enlightened understanding). Em complementação à essa segunda aproximação, SCLOVE (1992) pondera também que "an engaged citizenry must become critically involved with the choice, governance, and even design of technological artifacts and practices"73. (SCLOVE, 1992). O engajamento no desenho, escolha e governança das tecnologias traria, nessa lógica, a capacidade de auferir o grau de compatibilidade com valores e preceitos democráticos. Nesse sentido, (WINNER, 1992a) indaga se há um imperativo moral no engajamento no processo de produção dessas tecnologias. Segundo o autor,

Is it philosophically warranted to conclude that in an age of pervasive, world-shaping technological development, citizens have a right to be directly involved in technological choices that affect them? If one answers "yes" to that question, then means must be found to realize that right in practice $^{74}$ (WINNER, 1992a)

Por essa ótica, somente a partir da compreensão literata pode-se objetivar a efetiva participação no desenho, escolha e governança de tecnologias. SCLOVE (1992) aprofunda a discussão ao indicar que:

71 "A democratização tecnológica teria componentes processuais e substantivos. Processualmente, deve haver oportunidades ampliadas para pessoas de todas as esferas da vida participarem efetivamente na orientação da ordem tecnológica em evolução. Substancialmente, as tecnologias resultantes devem ser compatíveis em seu design com as condições necessárias da democracia" (SCLOVE, 1992), tradução nossa.

72 "Modos adequadamente democráticos de compartilhar ou participar ou ser representado nas decisões; e (2) compreensão adequadamente informada de questões técnico-científicas" (WARTOFSKY, 1992), tradução nossa.

73 "Uma cidadania engajada deve se envolver criticamente com a escolha, governança e até mesmo com o design de artefatos e práticas tecnológicas" (SCLOVE, 1992), tradução nossa

74 "É filosoficamente garantido concluir que, em uma época de desenvolvimento tecnológico difundido e modelador do mundo, os cidadãos têm o direito de estarem diretamente envolvidos nas escolhas tecnológicas que os afetam? Se alguém responder "sim" a essa pergunta, então deve-se encontrar meios para perceber isso na prática"(WINNER, 1992a), tradução nossa. 
If the essence of democracy is that citizens ought to be empowered to participate in determining the collective conditions of their existence, particularly as these bear upon the possibility of democracy itself, and if technologies are themselves social structures, it follows that it is morally imperative to democratize technological design and practice. ${ }^{75}$ (SCLOVE, 1992)

A preocupação de SCLOVE (1992) consiste em estabelecer um desenho democrático da tecnologia da informação, ou seja, que a tecnologia da informação seja concebida compatível como os princípios e preceitos democráticos. Contudo, o autor não apresenta quais seriam precisamente tais princípios ou preceitos de modo vistos pelas teorias da Ciência Política. Ainda que relevante como ponto de partida, a proposta de SCLOVE (1992) não se mostra suficiente justamente por não abarcar uma teoria do método democrático que seja cabível no contexto cibernético. O mérito, contudo, reside na constatação de princípios que são facilmente assimiláveis com teorias já conhecidas pelos cientistas políticos, como a própria abordagem da Poliarquia de (DAHL, 1991). Desta forma, a proposta de SCLOVE (1992) mostra-se perfeitamente compatível com a proposta de (DAHL, 1991) principalmente quando o autor aborda a necessidade de se habilitar os meios democráticos para a produção de artefatos e, principalmente, ao reafirmar que estes artefatos sejam compatíveis desde suas origens às suas finalidades com o método democrático.

A defesa de um desenho democrático da tecnologia esbarra nos próprios mecanismos para assegurá-lo. Se for necessário um "governo" deste desenho, qual forma ele deve adotar? A resposta padece do mesmo problema, pois a busca por uma poliarquia cibernética esbarra nos limites que a tecnologia cibernética oferece como, por exemplo, sua extrema permissividade e controle difuso. Afinal, seria possível implementar um processo democrático de controle do poder cibernético? Como estabelecer instituições, regulamentações ou processos que efetivamente reafirmem seu caráter democrático? Como garantir que não ocorram abusos de poder sobre as tecnologias cibernéticas? É possível estabelecer elementos e artefatos que efetivamente garantam a prevalência do processo democrático? Lessig (2006) em seu livro "Code" apresenta as mesmas preocupações ao argumentar as possibilidades de buscar feições de organizações de poder político no espaço cibernético. Segundo o autor:

But structure matters as well, though we have not even begun to understand how to limit, or regulate, arbitrary regulatory power. What "checks and balances" are possible in this space? How do we separate powers? How do we ensure that one regulator, or one government, doesn't become

75 "Se a essência da democracia é que os cidadãos devem ter o poder de participar na determinação das condições coletivas de sua existência, particularmente porque eles suportam a possibilidade da própria democracia, e se as tecnologias são elas mesmas estruturas sociais, segue-se que é moralmente imperativo democratizar o desenho e a prática tecnológica" (SCLOVE, 1992), tradução nossa. 
too powerful? How do we guarantee it is powerful enough? ${ }^{76}$ (LESSIG, 2006)

Os mecanismos que regulam, interferem e modificam as dinâmicas políticas em espaços cibernéticos são ainda pouco compreendidos. Ainda assim, é possível identificar a necessidade de que haja uma compatibilidade entre tais mecanismos e os preceitos que arquitetam o regime de governo - ou seja, se os mecanismos forem anti-democráticos, não serão compatíveis com o processo democrático. Mais do que isso, que se busque reafirmar essa necessidade mesmo que o poder político dessas tecnologias seja movimentado por agentes que, por vezes, são alienados dos preceitos democráticos. SCLOVE (1992) pontua essa questão ao expressar que:

\begin{abstract}
With respect to contemporary technological trends, its implications are also thoroughly radical. Assuming its validity, it is morally imperativenecessary to our own freedom and dignity-to take processes of technological development that are today guided primarily by market forces, distant bureaucracies, economic self-interest, or international rivalry, and instead subordinate them to democratic prerogatives ${ }^{77}$. (SCLOVE, 1992)
\end{abstract}

A partir dessa concepção, ainda que não tenha sido possível identificar na literatura mecanismos cibernéticos para se compatibilizar tecnologias com preceitos democráticos, há categorias que dão indícios para esse premente objetivo. Winner (1992a), todavia, contribui com uma abstração síntese de duas categorias que podem ser empreendidas nesse objetivo: I will [...] consider the concept of technological power-both as the power of technology and power over this technology, i.e., the power to effectively use and control it. ${ }^{78}$ (WINNER, 1992a). As duas categorias propostas por Winner (1992a) são particularmente úteis como ponto de partida devido à capacidade de racionalizar e enfatizar o poder sobre a tecnologia e o poder que emana dessa tecnologia. Essas categorias são, em princípio, dois vetores distintos: do exercício do poder sobre a tecnologia e o próprio poder da tecnologia. É preciso ressaltar que, ainda que tais categorias sejam aplicáveis inclusive para contextos não democráticos, a premissa da pesquisa é de buscar aplicar essas duas categorias em contextos exclusivamente democráticos. Contudo, caso tais categorias sejam abstraídas e descontextualizadas de propósitos democráticos, podem ser compreendidas

76 "Mas a estrutura também é importante, embora nem tenhamos começado a entender como limitar ou regular o poder regulatório arbitrário. Que "verificações e contrapesos" são possíveis neste espaço? Como separamos poderes? Como podemos garantir que um regulador, ou um governo, não se torne muito poderoso? Como garantimos que é poderoso o suficiente?" (LESSIG, 2006), tradução nossa

77 "Com relação às tendências tecnológicas contemporâneas, suas implicações também são completamente radicais. Assumindo sua validade, é moralmente imperativo - necessário à nossa própria liberdade e dignidade - tomar processos de desenvolvimento tecnológico que hoje são guiados principalmente pelas forças do mercado, burocracias distantes, interesses econômicos ou rivalidade internacional, e em vez disso os subordinam a democrática. prerrogativas" (SCLOVE, 1992), tradução nossa.

78 "Eu [...] considerarei o conceito de poder tecnológico - tanto como o poder da tecnologia e poder sobre esta tecnologia, ou seja, o poder de efetivamente usá-la e controlá-la" (WINNER, 1992a), tradução nossa 
não somente como nas categorias de poder, mas como uma sua extensão e organização. Desta forma, propõem-se aqui ainda duas novas categorias de análise para compor a matriz dessa democracia habilitada ciberneticamente, ou poliarquia cibernética: as "tecnologias de governo" e o "governo das tecnologias".

Salienta-se, todavia, que ainda que as categorias de Winner (1992a) sejam relevantes como ponto de partida, elas não se mostram capazes de fornecer uma caracterização precisa do fenômeno aqui estudado: os pré-requisitos para uma poliarquia cibernética, cujo processo democrático esteja presente tanto nas "tecnologias de governo" quanto no "governo das tecnologias" 79 . A caracterização do fenômeno, por considerar também as lógicas endógenas dos sistemas complexos da Tecnologia da Informação, precisa matizar sua análise em mais dois aspectos que diferenciam os meios para o exercício das categorias anteriores: aqueles que diferem o "cibernético" do "não-cibernético". A soma semântica das quatro categorias já fornece por si só um indício de suas relações e interdependências: as tecnologias de governo são àquelas que concebem a capacidade para um governo exercer seu domínio a partir do uso de tecnologias cibernéticas e, por sua vez, o governo das tecnologias consiste na capacidade de se determinar as dinâmicas internas de um sistema cibernético para que seja habilitada a capacidade de governá-las.

Cabe indagar em que medida o "governo das tecnologias" e as "tecnologias de governo" devem ser compatíveis com os meios "cibernéticos" e "não cibernéticos" de seus exercícios? A resposta implica uma relação lógica: se o governo utiliza-se do processo democrático, há o imperativo lógico da compatibilidade entre as tecnologias de governo democráticas e o governo democrático das tecnologias. Por sua vez, se o governo possuir feições antidemocráticas, haverá o imperativo de se utilizar tecnologias de governo e o governo das tecnologias com processos antidemocráticos. Dessa relação lógica entre as quatro categorias, observa-se portanto que há o imperativo de que sejam compatíveis em processo e substância. Desta forma, a proposta de uma poliarquia cibernética é concebida como a interseção harmônica entre as quatro categorias.

A partir do exposto, é possível pressupor que não é compatível a coexistência de antagonismos entre as "tecnologias de governo' e o "governo das tecnologias" no processo democrático. Em relação a esse pressuposto, o imperativo consiste em compatibilizar dois vetores político-dialéticos: àqueles que movimentam as "tecnologias do governo" e os que movimentam o "governo da tecnologia" com os meios "cibernéticos" e "não-cibernéticos"

79 Embora caiba uma vasta explicação acerca da temática, ressalta-se que o jogo de palavras que compõe relações semânticas, ontológicas e epistemológicas carregam relações de poder que por vezes interferem na compreensão de categorias de análise mais abstratas - o cuidado aqui será justamente de não reproduzir tais relações. Por vezes, controle é compreendido como governo, mas expressa mais do que a capacidade de governar e, ao menos na língua portuguesa, não traz consigo valores emancipatórios. Não que a palavra "governo" os expressem como emancipatórios, mas, ao menos, se aplicadas a contextos democráticos, atenuam o valor semântico da palavra "controle". Desta forma, "controle" será substituído por "governo" - para que se possa, assim, abstraí-lo para a aplicação de "governo democrático" sobre o "espaço cibernético". 
de exercê-los. A contribuição desta pesquisa consiste justamente em buscar compreender a relação dialética entre ambos os vetores e como, também, o imperativo - aqui expresso como democrático - de compatibilizá-los. 


\section{Tecnologia da Informação, Vigilância e Pri- vacidade: A Função Democrática da Crip- tografia}

\subsection{Cibernética, Tecnologia da Informação e a Visão Sistêmica da Criptografia}

A abordagem clássica, utilizada pela Tecnologia Informação e por aqueles que se aventuram a estudá-la, como por exemplo a famigerada dicotomia entre software e hardware, fornece categorias de análise simples e palatáveis ao interlocutor sem, contudo, dar contorno e visibilidade à fenômenos como a comunicação, controle, feedback e suas demais interdependências, artefatos e ações. A resultante simplificadora dessa análise clássica é evidenciada pela compreensão aparente de artefatos cibernéticos e suas relações não pelo seu potencial e interdependência, mas, sim, pela sua característica mais evidente. Nesse sentido, os que se utilizam dessa lógica passam, por sua vez, a avaliar o papel, por exemplo, quando se tratar de Tecnologia da Informação, de protocolos que compõem a internet, dos softwares per se, dos efeitos de vírus, da informação e seus metadados, dentre tantas outras categorias ou, quando se tratar da Biologia Celular, do DNA, seu sistema de enzimas, nucleotídeos e proteínas, sem se valerem também pelas dinâmicas endógenas e exógenas pouco aparentes ou ocultas pela complexidade cibernética, tais como, novamente, as relações de controle, feedback, comunicação e ação que permeiam ambos campos científicos. A abordagem clássica busca, portanto, empreender uma análise que elucida o artefato enquanto objeto e não enquanto dinâmica. Em, a análise que faz jus às dinâmicas que se ocultam sob a complexidade das coisas pode ser vislumbrada na compreensão cibernética. Denominaremos às primeiras de análises não-cibernéticas e, por conseguinte, as últimas de análises cibernéticas. O que caracteriza, portanto, a análise cibernética?

A cibernética constitui-se como um campo de estudos interdisciplinares que contemplam desde a biologia celular até a ciência da computação. Segundo a sua primeira definição, elaborada pelo matemático Norbert Wiener, "we have decided to call the entire field of control and communication theory, whether in the machine or in the animal, by the name Cybernetics, which we form from the Greek (...) or steersman" (WIENER, 1961). Neste contexto, a cibernética pode ser definida como a ciência que estuda sistemas complexos que criam em caráter endógeno, ou seja, composto de dinâmicas internas, a partir da virtualização e abstração da relação entre execução de linguagens, controles e 
feedbacks tanto em maquinas quanto em seres vivos (PASK, 1968; Vijver, Gertrudis van de, 1992; TURING; COPELAND, 2004; BERTALANFFY, 1973, C)1968; ASHBY, 1956; WIENER, 1961; WIENER, 1989, c1954; BEER, 1994; LUHMANN, 1995; MATURANA; VARELA, 1980) ${ }^{80}$. . Como exemplo biológico, cita-se a linguagem de nucleotídeos presente em codificações genéticas que, por sua vez, são capazes de sintetizar e virtualizar o ambiente necessário à sua replicação. De modo análogo, equiparam-se os "zeros e bits" que compõem a codificação binária necessária à sintetização dos ambientes tecnologicamente virtualizados da ciência da computação.

Como discussão semântica, é necessário também especificar que o se compreende por "espaço cibernético" e "ecossistema cibernético" . Por espaço cibernético entende-se toda virtualização capaz de se sustentar enquanto sistema hermético, fechado - e dotado de dinâmicas endógenas. A conjunção de diversos sistemas cibernéticos pode constituir também um ecossistema cibernético, desde que o caráter hermético inicial ceda espaço à troca mútua de dinâmicas, desta vez, externas. O exemplo prático disso é um computador que, quando desconectado da internet, pode ser concebido como um sistema cibernético com dinâmicas herméticas. Logo, se esse mesmo computador se conectar a diversos outros computadores e for capaz de estabelecer a troca de dinâmicas externas, a totalidade daquilo que se configura como rede pode ser compreendida como um ecossistema cibernético cujo exemplo mais evidente é a internet. A análise ganha outra dimensão quando um sistema cibernético virtualiza outro sistema cibernético, como por exemplo, nos termos da Tecnologia da Informação, quando um sistema operacional Linux é capaz de virtualizar e operacionalizar um sistema operacional Windows. A análise sistêmica da cibernética permite compartilhar sua base até mesmo para exemplos biológicos, quando uma célula é capaz de fornecer o ambiente necessário à outra célula em seu interior: o que efetivamente compõe a relação entre células que compartilham suas dinâmicas do DNA de seus próprios núcleos com o DNA presente em mitocôndrias ou cloroplastos - nessa lógica, a somatória dessas células constituem um ecossistema.

A crítica que se faz a algumas tentativas de análises realizadas acerca do aspecto político de sistemas cibernéticos tem recaído em dois problemas: por um lado, essas análises buscam explicar fenômenos com mera transposição de categorias da Tecnologia da Informação desprovidas de suas lógicas endógenas e sistêmicas e, por outro lado, por não possuírem um denominador comum, não são dotadas de resiliência ao ponto de suportarem o ritmo de incessante transformação dos processos de "destruição criativa" típicos da Tecnologia da Informação. O primeiro problema decorre do fato de que a escolha de categorias de análise transpostas da Tecnologia da Informação e desprovidas de suas

\footnotetext{
80 Há elementos que se ramificam em categorias para diferenciar os sistemas cibernéticos "vivos" dos "não-vivos" ou orgânicos e inorgânicos - tais categorias são igualmente compartilhadas pela Biologia e Neurociência. Em nosso estudo, abordaremos sucintamente somente as abstrações e dinâmicas dos sistemas cibernéticos inorgânicos
} 
lógicas sistêmicas não avançam na compreensão dos fatores da complexidade cibernética: a linguagem, o controle, o feedback e suas relações de poder endógenas. Explica-se: em suas análises, propõe-se raciocínios "instrumentais" e alheios às óticas endógenas que se limitam a explicar, por exemplo, como cabos, protocolos da internet, ou backbones se integram em camadas de "softwares" e "hardwares" para produzirem um efeito observável"

O segundo problema é relativo às próprias categorias instrumentais da Tecnologia da Informação, que nesse tipo de análise, não vislumbram como as lógicas de mercado deliberadamente as direcionam para o desuso e obsolescência programada, algo que Schumpeter (1976) denomina como parte do processo de "destruição criativa": em termos práticos, se o paradigma tecnológico avançar em poucos meses e os "cabos" ou determinados "protocolos" entrarem em desuso ${ }^{82}$, tais categorias de análise poderão ser concebidas somente enquanto artefatos natimortos. Nesse sentido, a preocupação dessas abordagens instrumentais não se traduz na busca pela compreensão daquilo que se oculta ou não pode ser facilmente observado quando se leva em consideração as lógicas sistêmicas, mas, sim pelos artefatos em si. A análise que se utiliza somente desse tipo de classificação instrumenta não abarca, portanto, as nuances das relações de poder endógenas, compreensíveis somente pelas óticas sistêmicas da abordagem cibernética. Cabe a ressalva, contudo, que a crítica recai pela utilização de boa parte dessas categorias como artefatos descontextualizados e separados de suas lógicas sistêmicas - ainda que sejam aconselháveis enquanto atalhos ou ilustrações em exemplos típicos do exercício didático do campo e, como tais, devidamente resguardadas.

Em sistemas cibernéticos, a comunicação, feedback, controle e ação devem ocorrer simultaneamente para que se dê origem ao fenômeno da virtualização. O que, em outras palavras, significa que controle, comunicação, feedback e ação tornam-se indistinguíveis do ponto de vista sistêmico: são fenômenos primários que ocorrem no mesmo fluxo matemático, contínuo, criando-se mutualmente e, por desenho, originando o espaço cibernético. Por essa lógica, todos os sistemas cibernéticos, sejam eles artificiais ou orgânicos, baseados em códigos binários ou em bases de ácidos nucleicos, compartilham das mesmas características: virtualização estará presente enquanto constante do espaço cibernético, resultante simbiótica dos seus elementos precursores, dotada de dinâmicas próprias (ou seja, virtuais) de impacto e concretude perceptível.

Como uma contrapartida à análise puramente instrumental, o argumento expresso em prol da abordagem cibernética - justificado e reiterado com a proposição de Habermas de que "a new category of risks that are literally invisible and are comprehensible only from the perspective of the system" (HABERMAS, 1984-1987) - figura como premissa básica para

\footnotetext{
81 Nye (2011) dedica um capítulo de seu livro "The Future of Power" para explicar as relações de poder cibernéticas a partir de categorias instrumentais.

82 Cita-se como exemplo as possíveis impossibilidades de se resgatar dados passados pela mudança paradigmática da computação quântica.
} 
a análise das relações de poder que só podem ser compreendidas se forem providas de suas lógicas endógenas enquanto sistemas cibernéticos. Trata-se, portanto, de dois paradigmas de análise das relações de "poder cibernéticas": o que leva em consideração os aspectos instrumentais e o que leva em consideração a ótica sistêmica endógena enquanto ótica cibernética. Nesse particular, o feito da cibernética reside justamente na movimentação das categorias analíticas que se mostram articuladas entorno de um denominador comum para a compreensão endógena das abstrações que se originam tanto em computadores, e seus códigos binários, quanto em células, e seus códigos nucleotídeos - blocos fundamentalmente complexos das dinâmicas cibernéticas.

\subsection{A visão sistêmica da criptografia}

A criptografia passa durante sua evolução histórica por radicais mudanças introduzidas pelas revoluções tecnológicas, especialmente após a revolução industrial e a segunda guerra mundial e a revolução da tecnologia da informação, ou revolução cibernética. Segundo Simmons, a história da criptografia é comumente compreendida em três grandes fases: (1) o período da criptografia manual; (2) o período da criptografia de máquinas e; (3) o período da criptografia na tecnologia da informação. O primeiro período remete aos primeiros registros na antiguidade clássica a vai até a primeira Guerra Mundial, cuja complexidade da criptografia poderia ser solucionada manualmente por aqueles que detinham o conhecimento para tal feito. O segundo período é delimitado à partir da mecanização dos processos de criptografia, iniciados marcadamente na segunda Guerra Mundial que chegam até à contemporaneidade, quando máquinas foram utilizadas para cifrarem as comunicações de militares. Por sua vez, o terceiro período inicia-se com a popularização da tecnologia da informação à partir da década de 80, que torna acessível à população o acesso às tecnologias criptográficas em larga escala e em grande volume nos mais diversos setores e processos da sociedade.

Datam-se os registros de que os espartanos foram os primeiros ${ }^{83}$ à desenvolverem mecanismos manuais de criptografia. Simmons relembra bem que "people have probably tried to conceal information in written form from the time that writing developed ${ }^{84}$ " (SIMMONS, 2016) e que alguns exemplos poderiam ser encontrados em protocryptographic systems de artefatos de povos da antiguidade clássica, tais como de Egípcios, Hebreus, Babilônicos

\footnotetext{
83 Segundo Simmons os espartanos foram os primeiros a utilizarem a criptografia em suas comunicações militares. Em suas palavras "the first recorded use of cryptography for correspondence was by the Spartans, who as early as 400 b c employed a cipher device called the scytale for secret communication between military commanders. The scytale consisted of a tapered baton, around which was spirally wrapped a strip of parchment or leather on which the message was then written. When unwrapped, the letters were scrambled in order and formed the cipher; however, when the strip was wrapped around another baton of identical proportions to the original, the plaintext reappeared". Id., 2016

84 Em tradução nossa, "as pessoas provavelmente tentaram esconder informações em forma escrita a partir do momento em que a escrita se desenvolveu."Id., 2016
} 
e Assírios com o objetivo de "deny information to the uninitiated and to enhance its significance when it was revealed ${ }^{85}$ " (SIMMONS, 2016).

Por volta do século IV A.C., segundo Simmons (2016), dois gregos produziram obras relevantes acerca da temática, dentre elas, Aeneas Tacticus dedica um capítulo de seu livro "On the Defense o f Fortifications"à um tratado de criptografia e Polybius cria um mecanismo capaz de codificar letras em pares simbólicos que ficou conhecido como o "Polybius checkerboard". Os Romanos fizeram igual uso de mecanismos similares, dentre eles Julius Caesar e Augustus Caesar, que emprediam a troca de letras sequenciais para cifrarem suas comunicações ${ }^{86}$. Os árabes foram, posteriormente, os responsáveis por aplicarem princípios matemáticos para analisarem e buscarem identificar os mecanismos e algoritmos de cada tipo de criptografia - análises, estas, que deram origem a criptoanálise ${ }^{87}$.

A criptografia avançou na Europa durante a Idade Média pelas mãos das Cidades Estados Italianas em conjunção com a estrutura Papal ${ }^{88}$. Tratados de criptografia foram feitos sob incentivo eclesiástico e algumas dessas obras padronizarão o algoritmo criptográfico das comunicações diplomáticas europeias da época. Desta forma, os europeus, em grande medida herdeiros dos conhecimentos adquiridos até então pelas demais civilizações pioneiras no campo, avançaram os estudos criptográficos e popularizaram a tecnologia como forma de comunicação estatal ao utilizá-la também nas comunicações diplomáticas. Ao cruzar o Atlântico, os conhecimentos criptográficos fizeram-se presentes nas comunicações

85 Em tradução nossa, "negar informações aos não iniciados e aumentar seu significado quando era revelado".Id., 2016

86 Simmons indica que o uso pelos Romanos tratava-se de mecanismos mais simples: "The Romans used monoalphabetic substitution with a simple cyclic displacement of the alphabet. Julius Caesar employed a shift of three positions so that plaintext A was encrypted as D, while Augustus Caesar used a shift of one position so that plaintext A was enciphered as B. " Id., 2016

87 A título de curiosidade, Simmons aponta que "The first people to understand clearly the principles of cryptography and to elucidate the beginnings of cryptanalysis were the Arabs. They devised and used both substitution and transposition ciphers and discovered the use of both letter frequency distributions and probable plaintext in cryptanalysis. As a result, by about 1412, al-Kalka-shandl could include a respectable, if elementary, treatment of several cryptographic systems in his encyclopaedia Subletlalshland give explicit instructions on how to cryptanalyze ciphertext using letter frequency counts complete with lengthy examples to illustrate the technique. "Id., 2016

88 A precisão e riqueza de detalhes desse momento histórico é elaborada por Simmons que em suas palavras, remonta que "The first European manual on cryptography (c. 1379) was a compilation of ciphers by Gabriele de Lavinde of Parma, who served Pope Clement VII. This manual, now in the Vatican archives, contains a set of keys for 24 correspondents and embraces symbols for letters, nulls, and several two-character code equivalents for words and names. The first brief code vocabularies, called nomenclators, were gradually expanded and became the mainstay well into the 20th century for diplomatic communications of nearly all European governments. In 1470 Leon Battista Alberti published Trattati in cifra ("Treatise on Ciphers"), in which he described the first cipher disk; he prescribed that the setting of the disk should be changed after enciphering three or four words, thus conceiving of the notion of polyalphabeticity. This same device was used almost five centuries later by the U.S. Army Signal Corps for tactical communications in World War I. (See figure.) Giambattista della Porta provided a modified form of a square encryption/decryption table and the earliest example of a digraphic cipher in De furtivis literarum notis (1563; "The Notorious Secret Literature"). The Traicte des ch iffres ("Treatise on Ciphers"), published in 1586 by Blaise de Vigenere, contains the square encryption/decryption table bearing his name and descriptions of the first plaintext and ciphertext autokey systems".Id., 2016 
diplomáticas e militares da Guerra Civil Americana, tanto na forma mais rudimentar dos codebooks quanto na forma mais complexa dos algoritmos.

Na segunda fase histórica da Criptografia, a mecanização foi capaz de articular e agregar eficiência, robustez e volume aos mecanismos até então desenvolvidos em tratados matemáticos. A demanda criada pela primeira Guerra Mundial impulsionou o desenvolvimento desses mecanismos que utilizavam motores de rotação, bobinas, engrenagens e demais artefatos mecânicos em verdadeiras máquinas de calcular e codificar textos e mensagens. Tais máquinas provaram-se eficientes, ainda que rudimentares ao olhas contemporâneo, para evitar que coordenadas e estratégias militares fossem descobertas por países inimigos. A evolução dessas tecnologias atingiu seu ápice na segunda Guerra Mundial, quando criptólogos alemães desenvolveram aquela que ficou conhecida como a mais famosa máquina de criptografia da história: a Enigma.

Figura 2 - Máquina Enigma

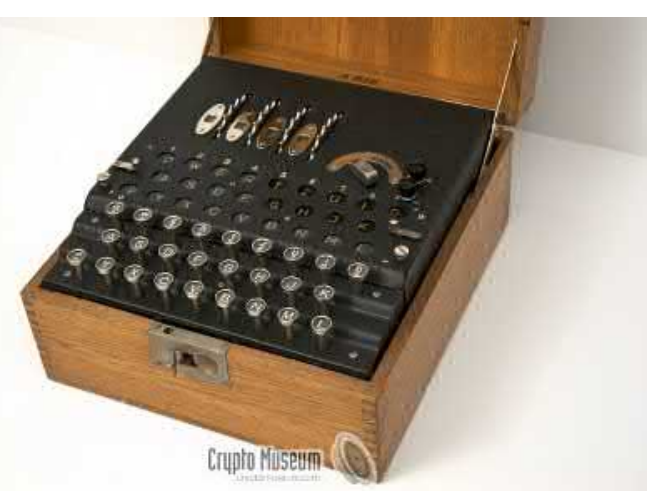

Legenda: Máquina de Criptografia Alemã utilizada na comunicação militar na segunda Guerra Mundial. Fonte: Crypto Museum (2018b)
Figura 3 - Engrenagem Alfanumérica

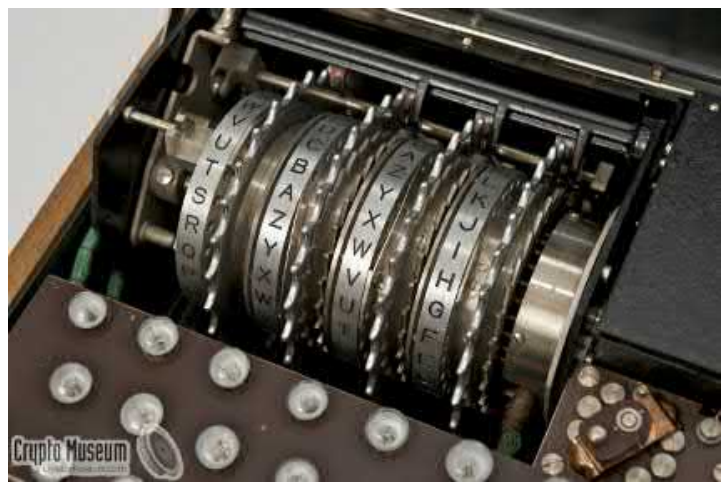

Legenda: Enfoque nos mecanismos e discos de rotação da Enigma que compunham a mensagem cifrada. Fonte: Crypto Museum (2018b)

Com o advento das criptomáquinas, ou máquinas de criptografar, da segunda Guerra Mundial, e sua crescente complexidade aliada à mecanismos elétricos, iniciou-se um novo momento para a criptografia que dava vantagem expressiva aos países detentores da tecnologia. A criptografia utilizada passou a contar com uma escala maior, elevado nível de confiabilidade em relação à erros, maior portabilidade e com a possibilidade de ser operacionalizada sem o requisito de conhecimento profundo nos $\mathrm{O}$ resultado da segunda Guerra Mundial por pouco não pendeu favoravelmente aos Alemães e aos demais países do Eixo (Japão e Itália). Como resultado dos esforços de Alan Turing e de sua equipe de matemáticos, os países Aliados foram capazes de decifrar a criptografia Alemã e mudar as estratégias de ataques de acordo com as movimentações nazistas. (BOYLE, 2014; DELALANDE, 2016; HENDERSON, 2011; HODGES, 1994; LAVINGTON, 2012; LEAVITT, 2006; OREGAN, 2013)

Para decifrar os códigos da criptomáquina alemã, o Governo Britânico reuniu em 
Bletchley Park as principais mentes matemáticas da época - dentre elas, Alan Turing ${ }^{89}$, que ficou como o principal responsável pela intrincada tarefa de desofuscar a comunicação inimiga. Para tal feito, Turing e sua equipe construíram a Bombe, máquina capaz de recalcular em termos probabilísticos o conteúdo original das comunicações alemãs interceptadas 90. É consensual entre a comunidade acadêmica que a entrada em cena de Alan Turing foi preponderante e ajudou a encurtar a guerra em dois anos - tamanha contribuição tornou-o ícone para a história da criptografia e da ciência da computação.

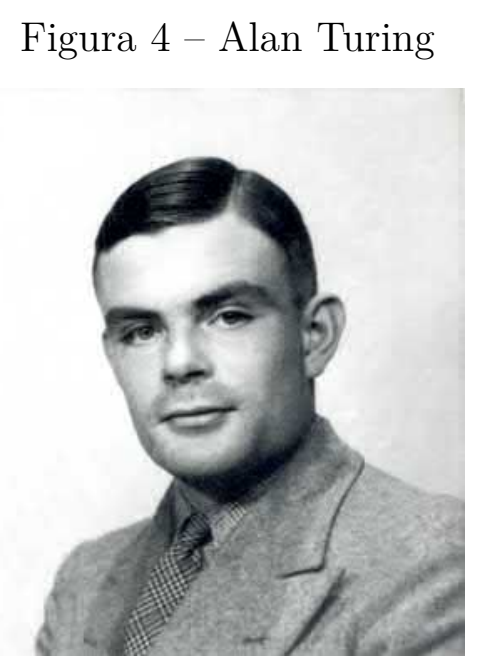

Legenda: Matemático e pai do computador moderno, Alan Mathison Turing. Fonte: National Security Agency (2019)
Figura 5 - Bombe Decifradora

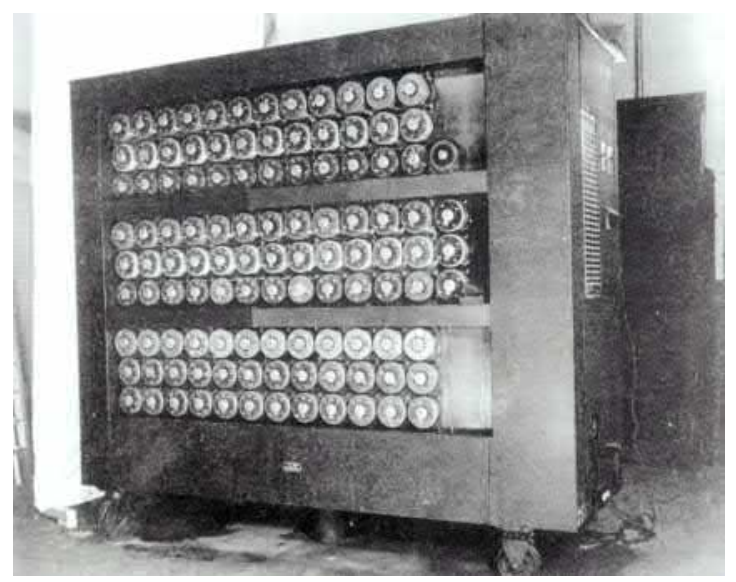

Legenda: Máquina criada por Alan Turing e equipe dedicada à decifrar o código Enigma. Fonte: O'Grady (06/02/2019)

O período da segunda Guerra Mundial é não somente emblemático como evento histórico como, também, para o surgimento da Computação contemporânea. O parêntese dedicado à Alan Turing faz-se novamente relevante principalmente por sua contribuição à criação de uma "universal computing machine", que em sua próprio artigo "On Computable Numbers, with an Application to the Entscheidungsproblem", ele apresenta a base dos computadores contemporâneos e seu então objetivo de "to invent a single machine which can be used to compute any computable sequence" (TURING, 1936, p. 241). Quando Turing cria a "universal computing machine", ele lança os principais conceitos para a criação dos computadores, com a lógica necessária para se aplicar os conceitos matemáticos

89 Em sua narrativa histórica, Henderson comenta que "On September 1, 1939, Germany launched an invasion of Poland. In accordance with their mutual defense treaties, Britain and France went to war against Germany two days later. The next day, Turing arrived at a place known as Bletchley Park a pleasant Victorian mansion" (HENDERSON, 2011, p. 47)

90 Henderson destaca o potencial da Bombe, que posteriormente foi exportada para os Estados Unidos conjuntamente com a expatriação temporária de Turing para a replicação em massa do equipamento. Segundo Henderson, a engenharia do equipamento era resultante de diversas técnicas desenvolvidas em Bletchley Park: "The result of all these techniques (and more) was to whittle millions of possible rotor settings down to a hundred thousand or so-a number that could be feasibly examined by a Bombe". (HENDERSON, 2011, p. 52). 
e transpô-los à máquinas físicas ${ }^{91}$ capazes de realizarem as mais diversas necessidades computacionais $^{92}$ - para clarificar, sem essa contribuição, não se teria o paradigma atual de computação e a revolução da Tecnologia da Informação.

A evolução da complexidade tecnológica proporcionada pela introdução dos computadores tornou-se exponencial no decorrer das décadas após o fim da segunda Guerra Mundial. Esse incremento tecnológico expandiu o uso e aplicação da criptografia para além da confidencialidade das informações e comunicação ao permitir que um grande volume de dados pudessem ser criptografados no menor tempo e custo possível. A partir da década de 80, com o início da popularização dos computadores pessoais, o poder computacional desse período passou a superar em diversas magnitudes o poder computacional dos grandes supercomputadores adquiridos para fins militares.

A terceira fase da história da criptografia começa no período no qual criptografia passou à ser acessível para a população. Esse terceiro período é compreendido como o "divisor de águas"por ampliar a utilização da criptografia nas mais diversas esferas da sociedade, cuja extensão é definida por Simmons (2016) como "the most radical change of all - the dramatic extension of cryptology to the information age: digital signatures, authentication, shared or distributed capabilities to exercise cryptologic functions" (SIMMONS, 2016). Compreender o uso e aplicação da criptografia na sociedade e em suas instituições faz-se premente quando direitos passam a depender de sua utilização.

Poucos fenômenos na História encontram correlações tão fortes quanto aquelas que se evidenciam na quase simbiótica aparição de criptografia e vigilância. Ainda que não sejam categorias antagônicas, tais como criptografar-descriptografar, vigiar-esconder, não se pode afirmar que suas aparições sejam binárias: o tripé de fenômenos que delas emana só pode ser compreendido quando os holofotes captam também as nuances da privacidade e, à partir destes, os indivíduos ${ }^{93}$. Nesse sentido, o tripé criptografia-privacidade-vigilância coloca em disputa o quanto de privacidade é permitida ao indivíduo. Coloca em disputa o quanto, por sua vez, a relação estado-tecnologia-cidadão encontra suas bases em equilíbrios democráticos e para qual lado a balança se inclina. No cerne da questão, encontra-se o conflito da tríade criptografia-privacidade-vigilância.

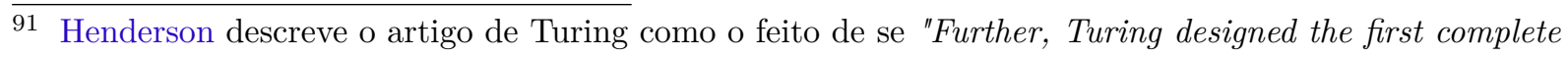
"machine language" - a set of low-level instructions for arithmetic and logical operations, carefully tailored for efficient movement of data between the machine's processing units and the working memory ".Id., 2011, p. 69

92 A contribuição do matemático avançou o campo da criptografia, da computação e da inteligência artificial, "Put more succinctly, Turing wanted to "build a brain" in order both to explore the ultimate capabilities of the machine and to better understand the essence of thinking and of intelligence. This topic, which would come to be known as artificial intelligence. " Id., 2011, p. 77

93 Não se questionará, neste trabalho, os limiares desse contexto frente à um histórico militar mas, sim, civil. Cabe excetuar, contudo, às nuances que um permanente Estado de Exceção, no sentido formulado por SCHMITT, traz ao texto como um todo. Ainda assim, cabe questionar quando e como o controle sobre as tecnologias de criptografia foram utilizadas para deixar civis vulneráveis. 
Ainda que famigerada a ausência de neutralidade nas ciências e suas derivações, é importante frisar que as escolhas realizadas ao discorrer sobre a criptografia muito diz sobre a compreensão de mundo do texto, seus posicionamentos e pontos de partida adotados. Não por acaso, muitos acadêmicos e demais interlocutores sequer mencionam o contexto nos quais a criptografia surge, é controlada e utilizada. O contexto aqui apresentado foca no conflito: no conflito entre governo e cidadãos, no controle da criptografia como arma ou como direito, no conflito entre vigilância e privacidade, no conflito entre segurança nacional e liberdades civis.

No limiar destes conflitos, encontra-se a necessidade de proteger, de ocultar, de delimitar o público e o privado, a necessidade de autonomia e privacidade, dentre tantos outros sentidos inerentes à própria origem da palavra criptografia. Com suas raízes no grego, criptografia surge como a junção de kryptos e graphein, que significam, respectivamente, "oculto" e "escrever". Segundo o dicionário Merriam-Webster, a palavra kryptos ainda remete ao verbo kryptein, que toma o sentido de "esconder". Como vetor forçosamente oposto ao sigilo, ao segredo, ao que se oculta, identifica-se a vigilância - aqui utilizada como um guarda-chuva conceitual que abrange mais significados; ora como espionagem, quando em pequena escala, ora vigilância massiva, quando empreendida em larga escala. Para todos os efeitos, compreende-se que haverá, independentemente da escala, um indivíduo que disputará os limiares do revelável/observável frente à uma entidade desproporcional, o Estado. 



\section{Privacidade, Vigilância e as Instituições De- mocráticas}

Privacidade dificilmente poderá ser compreendida ou conceituada por um único prisma teórico, cultural, histórico, antropológico, político, tecnológico, econômico, dentre outras feições. Enquanto miríade de composições, a vastidão das diversas concepções de privacidade perpassa inúmeros recortes e momentos históricos e podem ser, inclusive, resgatada nas igualmente amplas concepções de Polis e Oikos da antiguidade ateniense. A visão clássica acerca da privacidade pode ser encontrada, nesse recorte histórico, pela abordagem de Aristóteles da Polis Ateniense, enquanto dinâmicas da vida pública, e do Oikos, enquanto dinâmicas da vida doméstica e familiar. O público e o privado, o divulgável e o restrito, o segredo e o revelável, o transparente e o ofuscado; dicotomias que se aplicavam à ambas as dinâmicas ensejadas pela Polis e Oikos que são ainda reencontradas e passam por releituras nas concepções contemporâneas acerca do que vem a ser privacidade. Por se tratar de privacidade, dinâmica mutável e inconstante, cabe indagar: Seria possível definir precisamente o que é privacidade? De antemão, ainda que a ânsia acadêmica busque tal definição, delimitá-la categoricamente reduzirá seu valor enquanto "filha de seu tempo". Para atenuar essa ansiedade, serão apresentadas nessa seção as discussões pertinentes ao campo, ainda que longe da pretensão de se esgotar a temática que, por vezes, tem se mostrado inesgotável

\subsection{Um breve histórico sobre a privacidade}

O indivíduo enquanto propriedade de si mesmo é considerado pela literatura como um dos precursores filosóficos das definições contemporâneas de privacidade. Três séculos se passaram e a obra "Second treatise of government" de John Locke permanece relevante para compreendermos as delimitações que que são abstraídas da propriedade privada à privacidade. Para Locke e Macpherson (1980, p. 19), o homem é a propriedade de si mesmo que, em suas palavras, se traduz em "yet every man has a property in his own person: this no body has any right to but himself ${ }^{194}$. A propriedade privada surge, na filosofia política de Locke, a partir do indivíduo e dela se derivam, portanto, os demais direitos que à ele são naturais. Não obstante, o direito à si mesmo fundamenta a soberania do indivíduo sobre suas esferas de vida e passa a delimitar não somente a divisão entre indivíduos, como entre os demais entes sociais, tais como o Estado.

94 "Todavia, todo homem tem uma propriedade em sua própria pessoa: isso a que nenhum corpo tem direito senão ele próprio", tradução nossa da passagem Locke e Macpherson (1980, p. 19). 
Stuart Mill reforça essa concepção Lockeana acerca dos limites da intervenção de outros ou em outrem. Em sua obra "On liberty", o então filósofo e economista britânico compartilha da fundamentação de que o indivíduo é inviolável e que, portanto, suas ações não podem sofrer interferências sem justificativas rigorosamente fundamentadas na necessidade de proteção de outros em uma comunidade "civilizada". Em seus próprios termos, Stuart Mill argumenta que:

\begin{abstract}
"That principle is, that the sole end for which mankind are warranted, individually or collectively, in interfering with the liberty of action of any of their number, is self-protection. That the only purpose for which power can be rightfully exercised over any member of a civilized community, against his will, is to prevent harm to others. His own good, either physical or moral, is not a sufficient warrant ${ }^{195}$. (MILL et al., 2003, p. 80)
\end{abstract}

Não haveria de haver, na concepção de Stuart Mill, interferências contra o indivíduo e sua soberania, exceto em casos extraordinários, nos quais ações de proteção ao coletivo fossem demandadas. Se alguma interferência ocorrer em discordância desse princípio, o poder constituído perderia, portanto, sua legitimidade. A colocação de Mill, inclusive, não permite ações que digam ou estabeleçam o que deva ser benéfico ao próprio indivíduo, pois, compete à ele exclusivamente a liberdade de assim o decidir. A constituição da liberdade do indivíduo não suportaria interferências, excetuadas à premissa da segurança, em nenhuma esfera de sua vida e individualidade, seja ela enquanto propriedade de si mesmo, seja ela enquanto delimitação do que deve pertencer ao público ou ao privado. Da conjunção das concepções de Locke e Mill na construção da individualidade moderna, ou seja, daquilo que fundamentalmente pertence ou que tem característica inviolável ao indivíduo, abstraem-se algumas das bases fundantes da privacidade. Se na visão Aristotélica o Oikos e a Polis já eram dinâmicas que segregavam esferas de atuação e vivências do cidadão ateniense, Locke e Mill, acabam por sua vez, por aprofundar tal segregação.

James Madison, um dos founding fathers da Constituição Americana, reforça a base da propriedade privada e se utiliza da argumentação Lockeana da finalidade indivisível do governo em proteger o indivíduo e seus direitos ao passo que protege a propriedade privada. Para Madison, "Government is instituted to protect property of every sort; as well that which lies in the various rights of individuals, as that which the term particularly expresses. ${ }^{196}$ (MADISON; KETCHAM, 2006, p. 223). Madison argumenta, também, pela indissociabilidade da proteção do "indivíduo-propriedade privada", indivisibilidade esta que

95 "Esse princípio é que o único fim pelo qual a humanidade é garantida, individual ou coletivamente, ao interferir na liberdade de ação de qualquer um de seus números, é a autoproteção. Que o único propósito pelo qual o poder pode ser legitimamente exercido sobre qualquer membro de uma comunidade civilizada, contra sua vontade, é evitar danos a outros. Seu próprio bem, seja físico ou moral, não é uma garantia suficiente" Tradução nossa da passagem de Mill et al. (2003, p. 80)

96 "O governo é instituído para proteger propriedades de todo tipo; também o que está nos vários direitos dos indivíduos, como o que o termo expressa particularmente". Tradução nossa do excerto Madison e Ketcham (2006, p. 223) 
torna possível a própria realização da individualidade. Adicionalmente ao valor etimológico da palavra indivíduo, cuja a denotação de "não-divisível/indivisível"emerge, Madison agrega a propriedade privada, a propriedade de direitos e a autonomia de constituir e expressar opiniões. A vinculação da propriedade ao exercício da individualidade pode ser abstraída da afirmação de que "as a man is said to have a right to his property, he may be equally said to have a property in his rights ${ }^{197}$.(MADISON; KETCHAM, 2006, p. 223).

A inviolabilidade da propriedade, herança de Locke, faz-se presente em relação às liberdades individuais. Por essa herança lockeana, Madison argumenta no "Political Essay: Property"que violações arbitrárias estão distantes da concepção de um governo justo. Para Madison, compete ao governo proteger o cidadão de qualquer violação da propriedade e de direitos fundamentais. Proteger a propriedade sem, contudo, proteger os direitos dos indivíduos colocaria em questão a natureza do Governo, pois, segundo Madison:

Government is instituted to protect property of every sort; as well that which lies in the various rights of individuals, as that which the term particularly expresses. This being the end of government, that alone is a just government, which impartially secures to every man, whatever is his own. According to this standard of merit, the praise of affording a just security to property, should be sparingly bestowed on a government which, however scrupulously guarding the possessions of individuals, does not protect them in the enjoyment and communication of their opinions, in which they have an equal, and in the estimation of some, a more valuable property. ${ }^{98}$ (MADISON; KETCHAM, 2006, p. 223)

Madison faz sua contribuição à construção da concepção de privacidade ao ultrapassar o corolário da visão lockeana de propriedade e desenvolver a premissa de que a proteção aos direitos dos indivíduos pode assumir a feição de uma propriedade, comparativamente, de maior valor. A referência à privacidade como proteção à comunicação e liberdade de opiniões é ressaltada quando o autor exemplifica a partir da criticidade de um governo que "não os proteja no gozo e na comunicação de suas opiniões" 99 . A intersecção entre segurança à partir do Estado e proteção das liberdades individuais ganha delimitações lockeanas na argumentação de Madison quando os direitos individuais assumem, potencialmente, valorações maiores. Quando Madison traz a vinculação do conceito de propriedade à própria consciência, essa estrutura valorativa se consolida e revela que, para o autor:

97 "Como se diz que um homem tem direito a sua propriedade, ele pode ser igualmente dito ter uma propriedade em seus direitos". Tradução nossa do excerto de Madison e Ketcham (2006, p. 223).

98 "O governo é instituído para proteger propriedades de todo tipo; também o que está nos vários direitos dos indivíduos, como o que o termo expressa particularmente. Sendo este o fim do governo, somente este é um governo justo, que assegura imparcialmente a todo homem, seja qual for o seu. De acordo com esse padrão de mérito, o louvor de oferecer uma justa segurança à propriedade deve ser concedido com parcimônia a um governo que, embora guardando escrupulosamente as posses dos indivíduos, não os proteja no gozo e na comunicação de suas opiniões, nas quais eles tem um igual, e na estimativa de alguns, uma propriedade mais valiosa". Tradução nossa a partir da passagem de Madison e Ketcham (2006, p. 223)

99 Tradução nossa à partir da referência de (MADISON; KETCHAM, 2006, p. 223) 
Conscience is the most sacred of all property; other property depending in part on positive law, the exercise of that, being a natural and unalienable right. To guard a man's house as his castle, to pay public and enforce private debts with the most exact faith, can give no tide to invade a man's conscience which is more sacred than his castle, or to withhold from it that debt of protection, for which the public faith is pledged, by the very nature and original conditions of the social pact. ${ }^{100}$ (MADISON; KETCHAM, 2006, p. 223-224)

Consciência é a mais sagrada de todas as propriedades. Com essa afirmação, Madison além de reforçar os direitos individuais como superiores, apresenta outro ponto fundante da privacidade: a inviolabilidade da consciência. Fundamentada no tripé de indivíduo-propriedade-direitos, a consciência é então apresentada em maior grau, ou hierarquicamente elevada em relação às demais formas de propriedade. Violar a consciência em nome do bem público ou do pacto social não seria algo tolerável nesse contexto:

That is not a just government, nor is property secure under it, where the property which a man has in his personal safety and personal liberty, is violated by arbitrary seizures of one class of citizens for the service of the rest. [...] That is not a just government, nor is property secure under it, where arbitrary restrictions, exemptions, and monopolies deny to part of its citizens that free use of their faculties, and free choice of their occupations, which not only constitute their property in the general sense of the word; but are the means of acquiring property strictly so called ${ }^{101}$. (MADISON; KETCHAM, 2006, p.224)

Direitos individuais na obra de Madison ganham a tônica da posse da própria consciência e não conseguem se expandir sem a segurança de que esta seja inviolável: Para se exercer e estar em plenas faculdades, a liberdade e proteção à autonomia da consciência torna-se primordial. Gradativamente, do indivíduo à propriedade, da propriedade à consciência, os elos na Ciência Política que fornecem insumos para a compreensão da privacidade são identificados. Os fundamentos da privacidade encontram sua codificação posterior no campo do Direito, quando a sua primeira argumentação , "The Right to Privacy", toma forma no escrito de Samuel Warren e Louis Brandeis no final do século XIX.

Até o final do século XIX, não havia uma definição precisa ou a materialização no campo do Direito que tangenciasse a privacidade. O que seria o direito à privacidade

100 "A consciência é a mais sagrada de todas as propriedades; outra propriedade dependendo em parte do direito positivo, o exercício desse direito, sendo um direito natural e inalienável. Guardar a casa de um homem como seu castelo, pagar ao público e fazer cumprir as dívidas privadas com a mais exata fé, não pode dar a maré para invadir a consciência de um homem que é mais sagrada que seu castelo, ou reter dessa dívida de proteção. que a fé pública é prometida, pela própria natureza e condições originais do pacto social". Tradução nossa do excerto de Madison e Ketcham (2006, p. 223-224)

101 "Isso não é um governo justo, nem é uma propriedade segura sob ele, onde a propriedade que um homem tem em sua segurança pessoal e liberdade pessoal é violada por apreensões arbitrárias de uma classe de cidadãos para o serviço dos demais. [...] Isso não é um governo justo, nem é uma propriedade segura sob ele, onde restrições arbitrárias, isenções e monopólios negam a parte de seus cidadãos que o livre uso de suas faculdades e a livre escolha de suas ocupações, que não somente constituem sua propriedade no sentido geral da palavra; mas são os meios de adquirir propriedade estritamente assim chamados". Tradução nossa à partir do excerto de Madison e Ketcham (2006, p.224) 
e qual sua necessidade? A partir do princípio de privacidade vinculada à propriedade, Samuel Warren e Louis Brandeis identificam que "the individual shall have full protection in person and in property is a principle as old as the common law; but it has been found necessary from time to time to define anew the exact nature and extent of such protection $^{\prime 102}$ (WARREN; BRANDEIS, 1890, p. 193). Buscar um parâmetro no Direito para justificar as extensões normativas ao direito à privacidade perpassou, pela leitura dos autores, a mesma perspectiva contratualista de proteção ao indivíduo, à propriedade privada e as demais propriedades que do indivíduo advém.

Há um lugar comum no pensamento de Warren e Brandeis de que as mudanças sociais, políticas e econômicas seriam motivadores para o reconhecimento de novos direitos; contudo, o direito à privacidade surge gradualmente da projeção dos direitos da propriedade privada às extensões da vida moderna, segundo os autores. Nessa transformação, o "direito à vida", resinificado como "direito de aproveitar a vida", derivou o "direito de ser deixado à sós"ou "deixado em paz"103. Os motores das transformações sociais são identificados por Warren e Brandeis (1890) na tecnologia e nos processos de industrialização na modernidade $^{105}$. A modernidade impactaria o indivíduo de diversas formas e complexidades e paulatinamente dificultaria o desvinculamento do indivíduo da exposição pública e da constante invasão de privacidade:

The intensity and complexity of life, attendant upon advancing civilization, have rendered necessary some retreat from the world, and man, under the refining influence of culture, has become more sensitive to publicity, so that solitude and privacy have become more essential to the individual;

102 "A necessidade do indivíduo ter proteção integral em pessoa e na propriedade é um princípio tão antigo quanto o direito comum; mas, de vez em quando, foi considerado necessário definir de novo a natureza e a extensão exatas dessa proteção". Tradução nossa.

103 Os autores expõem essa transformação da seguinte forma: "Thus, in very early times, the law gave a remedy only for physical interference with life and property, for trespasses vi et armis. Then the " right to life " served only to protect the subject from battery in its various forms; liberty meant freedom from actual restraint; and the right to property secured to the individual his lands and his cattle. Later, there came a recognition of man's spiritual nature, of his feelings and his intellect. Gradually the scope of these legal rights broadened; and now the right to life has come to mean the right to enjoy life,- the right to be let alone; the right to liberty secures the exercise of extensive civil privileges ; and the term "property" has grown to comprise every form of possession-intangible, as well as tangible"104 (WARREN; BRANDEIS, 1890, p. 193).

105 Os autores citam o caso da introdução de novas câmeras fotográficas e bem como as práticas indiscriminadas de produção jornalística da época: "Recent inventions and business methods call attention to the next step which must be taken for the protection of the person, and for securing to the individual what Judge Cooley calls the right " to be let alone. "Instantaneous photographs and newspaper enterprise have invaded the sacred precincts of private and domestic life; and numerous mechanical devices threaten to make good the prediction that " what is whispered in the closet shall be proclaimed from the house-tops." For years there has been a feeling that the law must afford some remedy for the unauthorized circulation of portraits of private persons; and the evil of the invasion of privacy by the newspapers, long keenly felt, has been but recently discussed by an able writer. The alleged facts of a somewhat notorious case brought before an inferior tribunal in New York a few months ago, directly involved the consideration of the right of circulating portraits ; and the question whether our law will recognize and protect the right to privacy in this and in other respects must soon come before our courts for consideration". (WARREN; BRANDEIS, 1890, p. 195-196) 
but modern enterprise and invention have, through invasions upon his privacy, subjected him to mental pain and distress, far greater than could be inflicted by mere bodily injury. ${ }^{106}$ (WARREN; BRANDEIS, 1890, p. 196)

Distanciamento do mundo, em uma sociedade altamente tecnológica e complexa, reflete a construção de Warren e Brandeis da necessidade da privacidade: a privacidade como um alívio de um espaço reservado, distante das tecnologias e técnicas invasivas de observação. O papel potencialmente conflitivo da tecnologia começa, então, à aparecer pela primeira vez na própria gênese da necessidade de resguardar legalmente o indivíduo. $\mathrm{O}$ mérito do artigo de Warren e Brandeis, considerado um dos fundadores do campo Legal da privacidade, introduz uma das primeiras, senão a primeira, vinculação do uso da tecnologia como mecanismo de invasão da privacidade. Dois processos são identificados em atuação na percepção compartilhada por Warren e Brandeis: (1) a modernidade, por intermédio da tecnologia, inerentemente traria consigo menores níveis de privacidade e; (2) A privacidade, nesse contexto, atuaria como uma defesa do indivíduo contra a aflição moderna que as violações tecnológicas poderiam infligir. Privacidade, nesse sentido, surgiria como uma necessidade de liberdade, de autonomia, de espaço individual, de reclusão, desconexão de aparatos tecnológicos da sociedade e de suas dores.

\subsection{A Busca por Definições de Privacidade}

Não por coincidência, Privacidade como liberdade é justamente o leitmotif do nome do livro daquele que é considerado o expoente da privacidade contemporânea, Alan Westin. Em "Privacy and Freedom", Alan Westin desenvolve uma vasta e profunda análise de diversas facetas da privacidade e, principalmente, sua relação com a tecnologia. Na obra de Westin é frequente a aparição da tentativa de se equilibrar a necessidade de privacidade com a necessidade de vigilância em democracias liberais. Em sua obra, Westin busca desde as noções de privacidade observáveis em animais até a profusão de técnicas de invasão e violação da privacidade.Alan Westin divide a privacidade em quatro estados básicos da individualidade:(1) a solidão, (2) a intimidade,(3) o anonimato e a (4) reserva.

(1) Na solidão, o indivíduo estaria isolado da sociedade em seu mais alto nível de privacidade, ainda que o isolamento completo não necessariamente dependa da presença de outros indivíduos. Nesse estado, o indivíduo teria apenas na presença de sua própria consciência. Seu isolamento relativo dependeria da ausência de estímulos exteriores, ainda

\footnotetext{
106 "A intensidade e a complexidade da vida, inerentes à civilização avançada, tornaram necessária alguma reclusão do mundo, e o homem, sob a influência refinada da cultura, tornou-se mais sensível à publicidade, de modo que a solidão e a privacidade se tornaram mais essenciais para o indivíduo; mas a empreitada moderna e a invenção, através de invasões em sua privacidade, sujeitaram-no à dor e ao sofrimento mental, muito maiores do que poderiam ser infligidos por meras lesões corporais". Tradução nossa do excerto de Warren e Brandeis (1890, p. 196).
} 
que, caso possua uma visão religiosa de mundo, o indivíduo poderia evocar entidades religiosas dotadas de onisciência que constantemente o observariam. Logo, suas ações poderiam estar sob o julgo e a limitação da omnisciência imaginária;

(2) Pela Intimidade, Alan Westin descreve que o indivíduo seria autorizado por convenções e concessões sociais para criar espaços privativos, onde ele possa usufruir da privacidade em seus relacionamentos. Westin cita, como exemplo, a unidade familiar, os colegas de trabalho e os círculos de amizade que congregariam de níveis de privacidade dentro de um contexto social. Tais concessões poderiam ser cedidas pelo Estado (casamento, visitas em presídios, proteção ao lar, cultu religioso, cerimonial, dentre outros contextos), pela sociedade ou por demais organizações que gerem partes da construção da intimidade. A relação de intimidade, então, seria estabelecida como uma necessidade humana cuja imprescindibilidade está diretamente vinculada à privacidade.

(3) No Anonimato, a relação entre privacidade e indivíduo depende de sua intersecção com a esfera pública. Nesse cenário, o indivíduo busca pela privacidade quando teme ser identificado em sua projeção e ação pública; ação publico-política que não seria desempenhada plenamente sob a percepção coercitiva da vigilância por parte do grupo ou de seu aparato estatal. O indivíduo, por temer represálias ou por pressentir ser perseguido, utilizaria do anonimato para cumprir sua ação ou dar plena vazão à sua necessidade de atuação. Nesse cenário, o indivíduo equilibra o medo de agir com a necessidade de agir segundo seus próprios critérios para buscar a privacidade estabelecida pelo anonimato.

(4) A Reserva dependeria de concessões individuais ou coletivas acerca da privacidade de outrem, ou seja, da capacidade um indivíduo externo conseguir manter a esfera privada estipulada por outro indivíduo. Um exemplo seria a concessão que alguém faz por não revelar um segredo e manter a privacidade alheia: o que Westin denomina barreira psicológica da privacidade. Por essas concepções, a privacidade estaria sempre ligada enquanto fenômeno à espectros de interação social, que variam da busca pelo completo isolamento à concessão pública sobre a privacidade.

As concepções de privacidade definidas por Westin assumem quatro funções analíticas distintas, ainda que não exaustivas na complexidade humana e inseridas em contextos e fenômenos em uma sociedade democrática. Uma dessas funções é a (1) "Autonomia Pessoal" (personal autonomy) e o seu desenvolvimento. Três outras funções da privacidade se fazem presentes em democracias liberais, a saber; (2) O Alívio Emocional (emotional release), (3) a capacidade de autoavaliação (self-evaluation), (4) e Comunicações Protegidas e Limitadas (limited and protected communication).

Quando se trata de autonomia pessoal, Alan Westin baseia-se nos trabalhos de Simmel, dentre outros autores, para descrever a construção do "eu" (em inglês, Self) de modo a retratá-lo como um processo inerente à construção da individualidade humana, bem como suas zonas de atuação. Em sociedades democráticas, Westin analisa que há uma 
"necessidade de manter processos sociais que salvaguardem sua individualidade" - algo que cientistas políticos como Robert Dahl exploram em seus trabalhos como um dos pilares fundamentais da democracia. Segundo Westin, é identificável na literatura o vínculo do desenvolvimento e a manutenção do senso de individualidade à necessidade humana de autonomia que, por sua vez, traduz-se no "desejo de evitar ser manipulado ou dominado inteiramente pelos outros"

A descrição da construção do "Self" é objeto de pesquisa da psicologia e compartilhada por diversos outros campos, como a antropologia e ciências correlatas. Nas leituras de Westin sobre a concepção da privacidade na sociologia e antropologia, compartilha-se a concepção de que o "eu" é constituído de zonas de privacidade e segredos, que permeiam diversas camadas e profundidades. Essas zonas, ou círculos, guardam segredos e intimidades que, para além de constituírem o indivíduo, pode arruiná-lo quando expostas - são sua própria individualidade, muitas vezes não totalmente compreendida pelos processos conscientes do próprio indivíduo. Para Westin, nada seria mais grave do que a exposição desses círculos que compõem o "Self" e a individualidade:

The most serious threat to the individual's autonomy is the possibility that someone may penetrate the inner zone and learn his ultimate secrets, either by physical or psychological means. This deliberate penetration of the individual's protective shell, his psychological armor, would leave him naked to ridicule and shame and would put him under the control of those who knew his secrets. Autonomy is also threatened by those who penetrate the core self because they do not recognize the importance of ultimate privacy or think that the casual and uninvited help they may be rendering compensates for the violation. ${ }^{107}$ (WESTIN, 2018)

Deixar o indivíduo exposto, com o "Self"vulnerável perante um ou mais observadores seria uma das consequências da violação da privacidade. Por essa exposição ou pela barganha que resultaria nessa exposição, o indivíduo estaria passível de perder sua autonomia e, portanto, a capacidade de autodeterminar-se. A relação entre segredo e privacidade demonstraria, desta forma, um vínculo direto e posicionaria a privacidade como um conceito mais amplo do que a proteção de um segredo, mas, sim, a proteção de camadas e camadas que encobrem os segredos do "Self". A violação da privacidade e a consequente nudez do "Self"feririam diretamente a autonomia do indivíduo por rendê-lo e torná-lo vulnerável à forças escusas à sua própria vontade. Nesse sentido, invadir a

107 "A mais séria ameaça à autonomia do indivíduo é a possibilidade de alguém penetrar na zona interna e aprender seus segredos finais, seja por meios físicos ou meios psicológicos. Essa penetração deliberada do escudo protetor do indivíduo, sua armadura psicológica, o deixaria nu para ridicularizá-lo e envergonhálo e o colocaria sob o controle daqueles que conheciam seus segredos. A autonomia também é ameaçada por aqueles que penetram no eu nuclear porque não reconhecerem a importância da privacidade máxima ou acham que a ajuda casual e não solicitada que podem estar prestando compensaria a violação. A autonomia que a privacidade protege também é vital para o desenvolvimento da individualidade e da consciência da escolha individual na vida". Tradução nossa à partir do excerto de Westin (2018). 
privacidade de um indivíduo, na perspectiva de Westin, não justificaria bem maior em seu próprio proveito.

\subsection{A Privacidade em Seu Valor Relativo em Democracias}

De forma análoga a indissociabilidade da natureza política da tecnologia, é a privacidade como a democracia. Direta ou indiretamente, a privacidade torna-se um dos pilares da democracia liberal, cujas estruturas mínimas de sustentação e desenvolvimento encontram incessantes desafios nos (des) equilíbrios firmados em torno de um espectro de privacidade e vigilância. Compreender o espectro que circunda as decisões e concessões que uma determinada sociedade faz em um determinado período é elemento chave para que a relação entre privacidade e vigilância seja justificável. Assim como tais sociedades realizam escolhas sobre os níveis de liberdade acordados em seu estrato social, tais escolhas também são aplicadas as demais esferas, tais como as relacionadas à privacidade. Nesse espectro, entram outras cearas como a liberdade de expressão, a liberdade religiosa, dentre outras liberdades que encontram seus limites especificados nas cristalizações dos acordos socialmente justificados na lei. Afinal, se a liberdade não é absoluta, por que seria a privacidade?

O debate é outro clássico da Ciência Política que, de famigerado, poderia passar desapercebido das justificativas que contribuem e permeiam as visões relativísticas sobre privacidade. Locke, em seu "Second treatise of government"traz a discussão da não-absoluta liberdade quando contemplada pela sua inserção social. Para Locke, haveria duas liberdades, aquela absoluta - quanto vivenciada apenas pelas leis da natureza, sem a interferência dos Homens - e a liberdade em sociedade - quando é possível encontrar a liberdade em um conjunto normativo comumente acordado pela comunidade e outorgado por um poder legítimo. Quando vivenciada em sociedade, a liberdade encontraria seus limites na lei e tão somente para que pudesse ser vivenciada no coletivo. A passagem de Locke traz em riqueza de detalhes os limites da liberdade:

§. 22. THE natural liberty of man is to be free from any superior power on earth, and not to be under the will or legislative authority of man, but to have only the law of nature for his rule. The liberty of man, in society, is to be under no other legislative power, but that established, by consent, in the common-wealth; nor under the dominion of any will, or restraint of any law, but what that legislative shall enact, according to the trust put in it. ${ }^{108}$. (LOCKE; MACPHERSON, 1980, p. 17)

\footnotetext{
108 "A liberdade natural do homem é estar livre de qualquer poder superior na terra e não estar sob a vontade ou autoridade legislativa do homem, mas ter apenas a lei da natureza para seu governo. A liberdade do homem, na sociedade, não deve estar sob nenhum outro poder legislativo, mas aquele estabelecido, pelo consentimento, no bem-comum; nem sob o domínio de qualquer vontade, ou restrição de qualquer lei, mas o que aquele legislativo promulgar, de acordo com a confiança depositada nele". Tradução nossa a partir do excerto de Locke e Macpherson (1980, p. 17)
} 
Locke não é o único à abordar o tema, que aparece com frequência nas concepções contratualistas que, de certa forma, não se trata de um tema exclusivo da Ciência Política. Georg Simmel (1906), em seu estudo "The Sociology of Secrecy and of Secret Societies" traz uma consideração emblemática ao debate ao considerar que o segredo e, por conseguinte, a privacidade, gozam de posições mutáveis nos espectros democráticos de diferentes sociedades. Simmel (1906, p. 469) começa por considerar que mudanças contemporâneas, ao passo que trouxeram maior visibilidade para a esfera pública, agregaram maiores níveis de privacidade que, por sua vez, expressar-se-ia na capacidade do indivíduo se isolar da sociedade. Simmel (1906, p. 469) constata que nessa mudança, "the individual has gained possibility of more complete privacy ${ }^{109 " ~ " c o m o ~ c o n s e q u e ̂ n c i a ~ d e ~ c o n d i c ̧ o ̃ e s ~ d a ~ v i d a-m o d e r n a ~}$ que "has elaborated a technique for isolation of the affairs of individuals ${ }^{110 ", ~ c o n d i c ̧ a ̃ o ~ e s t a, ~}$ conforme ressalta o autor, que seria possível até então pela segregação geográfica-espacial. Eis que, então, Simmel sintetiza o fenômeno que surge do espectro de valores e definições da privacidade que, em nossa abordagem, podemos sistematizar em: (1) O relativismo de Simmel acerca do segredo-privacidade; (2) a consequência de uma estrutura de controle e; (3) o vetor sociológico dessa intersecção.

Em que medida o avanço da privacidade é vantajoso é questionável. A provocação de Simmel sobre a questão remete diretamente de sua constatação de que "balança"dependeria dos padrões sociais de valor/valoração. Adicionalmente, tal balança seria impactada diretamente pela necessidade de que, em democracias, haveria o desejo de uma publicidade frequente de ações, relacionamentos, eventos, dentre outras derivações da aplicação do "público"da Polis. Nesse quesito, Simmel pondera que o segredo é, portanto, um atributo dependente de seu contexto de padrões de valores socias:

To what extent this development is to be regarded as advantageous depends upon social standards of value. Democracies are bound to regard publicity as the condition desirable in itself. This follows from the fundamental idea that each should be informed about all the relationships and occurrences with which he is concerned, since this is a condition of his doing his part with reference to them, and every community of knowledge contains also the psychological stimulation to community of action. It is immaterial whether this conclusion is entirely binding ${ }^{111}$.(SIMMEL, 1906, p. 469)

A percepção contratualista permeia indiretamente a construção do argumento de

109 "O indivíduo ganhou possibilidade de uma privacidade mais completa", Tradução nossa do excerto de Simmel (1906, p. 469).

110 "Elaborou uma técnica para isolar os assuntos dos indivíduos". Tradução nossa do excerto de Simmel (1906, p. 469).

111 "Até que ponto esse desenvolvimento deve ser considerado como vantajoso depende dos padrões sociais de valor. As democracias são obrigadas a considerar a publicidade como a condição desejável em si mesma. Isso decorre da ideia fundamental de que cada um deve ser informado sobre todos os relacionamentos e ocorrências com os quais ele se preocupa, pois é uma condição de fazer sua parte com referência a eles, e toda comunidade de conhecimento contém também o estímulo psicológico à comunidade de ação. É irrelevante se esta conclusão é totalmente vinculativa". Nossa tradução à partir do excerto de Simmel (1906, p. 469). 
Simmel ao estipular que uma determinada sociedade aceita níveis diferentes de segredo e privacidade de acordo com suas justificativas e padrões sociais-normativos. Por essa tônica indiretamente contratualista, Simmel argumenta que uma estrutura de controle poderia ser construída caso ela sirva além dos interesses individuais e seja, de certa forma, vantajosa aos indivíduos em sua finalidade. A função-propósito dessa estrutura de controle, sua capacidade, finalidade e forma de atuação não é, todavia, elaborada por Simmel que, em sua passagem, stricto sensu, diz:

If an objective controlling structure has been built up, beyond the individual interests, but nevertheless to their advantage, such a structure may very well, by virtue of its formal independence, have a rightful claim to carry on a certain amount of secret functioning without prejudice to its public character, so far as real consideration of the interests of all is concerned. A logical connection, therefore, which would necessitate the judgment of superior worth in favor of the condition of publicity, does not exist ${ }^{112} \cdot($ SIMMEL, 1906, p. 469)

Pela passagem, Simmel não necessariamente faz referência à uma estrutura de vigilância, tal como um Panopticom, mas, sim, à uma estrutura pública de controle que goza de seus próprios segredos e, nesse contexto, não precisaria tornar pública suas ações sem prejudicar sua própria natureza - possivelmente exemplificado, em termos práticos, como "segredo-de-Estado". Abre-se, contudo, ensejo para abstrações de que a mesma analogia seja aplicada à uma estrutura que, excepcionalmente, atuaria em contraposição à valores essenciais ao segredo-privacidade e que, em seu caráter socialmente edificadojustificado, poderia lançar-se, pelo racional estabelecido por Simmel, à remover o caráter privativo de seus objeto-alvos. Simmel certamente não adentrou à essa ceara e compôs sua argumentação na observação dos movimentos sociológicos de diferenciação entre os caráteres públicos e privados:

On the other hand, the universal scheme of cultural differentiation puts in an appearance here: that which pertains to the public becomes more public, that which belongs to the individual becomes more private. Moreover, this historical development brings o-ut the deeper real significance: that which in its nature is public, which in its content concerns all, becomes also externally, in its sociological form, more and more public; while that which in its inmost nature refers to the self alone- that is, the centripetal affairs of the individual -must also, gain in sociological position a more and more private character, a more decisive possibility of remaining secret.(SIMMEL, 1906, p. 469)

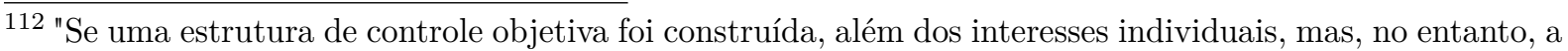
seu favor, tal estrutura pode muito bem, em virtude de sua independência formal, ter uma reivindicação legítima de exercer uma certa quantidade de funcionamento secreto, sem prejuízo de ao seu caráter público, no que se refere à consideração real dos interesses de todos. Uma conexão lógica, portanto, que exigiria o julgamento do valor superior em favor da condição de publicidade, não existiria". Nossa tradução à partir do excerto deSimmel (1906, p. 469).
} 
A diferenciação, nesse sentido, é de que cada vez mais as instituições de natureza pública tornar-se-ão cada vez mais públicas, enquanto as esferas de privacidade ficarão cada vez mais destinadas ao indivíduo e seus contextos - o que ensejaria para o indivíduo uma crescente tendência de fortalecimento da proteção de seus segredos. A provocação de Simmel acerca dessa movimentação e relativo posicionamento nos valores sociais abre, então, a discussão: o quanto de vigilância uma sociedade liberal democrática poderia acordar em torno de suas instituições democráticas? O quão justificável seria a permanência da privacidade frente à riscos eminentes? Quais instituições democráticas a vigilância impacta? Quais outras instituições democráticas a privacidade impacta?

\subsection{Vigilância e a Tecnologia do Autoritarismo na Alemanha}

"A única pessoa que ainda é um indivíduo privado na Alemanha é alguém que está dormindo". Hanna Arendt, despretensiosamente, relatava e analisava a completa ausência de privacidade imposta pelo regime Nazista no auge de seu autoritarismo. A escalada dessas ações remete à um episódio em particular; em 1933, Adolf Hitler demandou a aprovação do decreto "Reichstagsbrandverordnung" ${ }^{113}$, que suplantou diversas liberdades civis, dentre elas, a privacidade. O decreto foi outorgado após o incêndio do prédio do Reischstag - episódio utilizado para aplicar as medidas excepcionais ao povo Alemão durante o nazismo.

\footnotetext{
${ }^{113}$ Que ficou conhecido como Decreto do Incêndio do Reischstag ou, em seu nome original, "Verordnung des Reichspräsidenten zum Schutz von Volk und Staat", cuja nossa tradução seria "Decreto do Presidente do Reich para a Proteção do Povo e do Estado".
} 
Figura 6 - Reichstagsbrandverordnung

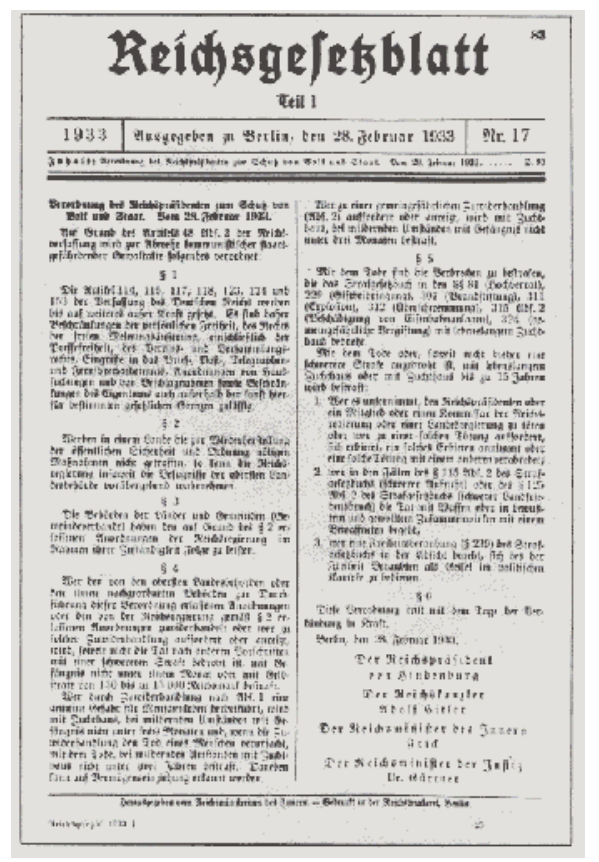

Figura 7 - Ermachtigungsgesetz 64

"Verordnung des Reichspräsidenten
zum Schutz von Volk und Staat vom 28.
Februar 1933.
Auf Grund des Artikels 48 Absatz 2 der
Reichsverfassung wird zur Abwehr kommu-
nistischer staatsgefährdender Gewaltakte
folgendes verordnet:
$\$ 1$
Die Artikel $114,115,117,118,123,124$ und
153 der Verfassung des Deutsches Reiches
werden bis auf weiteres ausser Kraft gesetzl.
Es sind daher Beschränkungen der persön-
lichen Freiheit, des Rechts der freien Mci-
nungsäusserung, einschliesslich der Presse-
freiheit, des Vereins- und Versammlungs-
rechts, Eingriffe in das Brief-, Post-, Tele-
graphen- und Fernsprechgeheimnis, Anord-
nungen von Haussuchungen und von
Beschlagnahmen, sowie Beschränkungen
des Eigentums auch ausserhalb der sonst
hierfür bestimmten gesetzlichen Grenzen
zulässig.«

Legenda:Excerto do "Reichstagsbrandverord- Legenda: Excerto "Reichstagsbrandverordnung"do repositório "NS-Archiv - Dokumente nung. Ermachtigungsgesetz 64". Fonte: DHM zum Nationalsozialismus". Fonte Reichstags- - Deutsches Historisches Museum. Artinger brandverordnung (2019)

O decreto pavimentou o Estado de Terror que se conflagrou após a derrocada das liberdades civis. Segundo a reportagem "Brand im Reichstag: Das Grundgesetz des Dritten Reichs"de MIX, do Jornal Berliner Zeitung, o decreto foi aplicado como uma base pseudo-legal para as ações emergenciais do Estado, que futuramente definiu o modus operandi do Estado de Exceção que se instaurava:

Os funcionários do Ministério do Interior providenciaram a base pseudolegal do terrorismo de estado. Na reunião de gabinete na manhã seguinte à noite do incêndio, o Ministro do Interior Frick apresentou o projeto para um "decreto do Presidente do Reich para a Proteção do Povo e do Estado". O estado de emergência, que se baseava nos poderes extraordinários do Presidente, havia sido repetidamente imposto pelos governos predecessores, mas o "Decreto do Incêndio do Reichstag"diferia de outras violações à constituição. "Para afastar os atos comunistas de atos de violência que ameaçam o Estado", os direitos constitucionais básicos foram "suspensos até novo aviso", as infrações penais existentes foram reforçadas e novas foram criadas $^{114}$.(MIX, 2013)

$\overline{114}$ Tradução nossa à partir do excerto da reportagem de Mix (2013), que no original em alemão, descreve: "Für die pseudolegale Grundlage des Staatsterrors sorgten die Beamten aus dem Innenministerium. In der Kabinettssitzung am Morgen nach der Brandnacht präsentierte Innenminister Frick den Entwurf für eine „Verordnung des Reichspräsidenten zum Schutz von Volk und Staat“. Den Ausnahmezustand, der sich auf die außerordentlichen Befugnisse des Reichspräsidenten stützte, hatten auch die Vorgängerregierungen mehrfach verhängt, doch unterschied sich die „Reichstagsbrandverordnung“ von anderen Eingriffen in die Verfassung. „Zur Abwehr kommunistischer staatsgefährdender Gewaltakte“ wurden die verfassungsmäßigen Grundrechte „,bis auf weiteres außer Kraft“ gesetzt, bestehende Straftatbestände 
O decreto, fac-símile da imagem 6, autorizou a suspensão das liberdades e direitos fundamentais. Em seu comunicado, representado pela imagem 7, estava posto que os artigos 114, 115, 117, 118, 123, 124 e 153 da Constituição do Reich Alemão estariam suspensos até segunda ordem e que se tratavam de restrições "à liberdade pessoal, direito à liberdade de expressão, inclusive liberdade de imprensa, associação e reunião, intervenções no sigilo postal, telegráfico e telefônico, busca domiciliar e apreensão e restrições à propriedade ${ }^{115}$ $116 "$ "ARTINGER, 2019). A "constituição"do Estado nazista foi então erguida com o decreto em questão. Sob a justificativa da Segurança Nacional, proteção do povo, "caça aos comunistas", as liberdades civis foram extintas na Alemanha no Terceiro Reich. A força da frase de Hannah Arendt carrega consigo o relato histórico das consequências das dissoluções das liberdades civis que se originaram após os atos da "Grundgesetz des Dritten Reichs" (Constituição do Terceiro Reich) em 1933.

O momento em questão ganha tração, segundo a análise de Hannah Arendt, a partir da dissolução das esferas públicas e privadas - e das liberdades civis que as dinamizavam. Dissolução, esta, tipificada por sua presença coincidente na natureza de regimes autoritários. Arendt faz menção direta à Hobbes, em O Leviatã, ao analisar de que se trata do único autor que caracteriza o Estado como não baseado exclusivamente nos interesses públicos do bem-comum à partir do Contrato Social, mas, sim, "on the individual interests themselves, so that 'the private interest is the same with the publique ${ }^{117}$ '". Arendt considera que a atenuação ou dissolução das diferenças do público e do privado seria, portanto, caraterística suficientemente coincidente com a natureza autoritária. Dissolução de limiares, esta, que impactaria diretamente a privacidade:

The coincidence of this identification with the totalitarian pretense of having abolished the contradictions between individual and public interests is significant enough [...]. However, one should not overlook the fact that Hobbes wanted most of all to protect private interests by pretending that, rightly understood, they were the interests of the body politic as well, while on the contrary totalitarian regimes proclaim the nonexistence of privacy 118. (ARENDT, 1973, p. 139)

verschärft und neue geschaffen".

115 Tradução nossa do original em Alemão. (ARTINGER, 2019)

${ }^{116} \mathrm{O}$ original em Alemão possui o seguinte teor: "Die Artikel 114, 115, 117, 118, 123, 124 und 153 der Verfassung des Deutschen Reichs werden bis auf weiteres außer Kraft gesetzt. Es sind daher Beschränkungen der persönlichen Freiheit, des Rechts der freien Meinungsäußerung, einschließlich der Pressefreiheit, des Vereins- und Versammlungsrechts, Eingriffe in das Brief-, Post-, Telegraphen- und Fernsprechgeheimnis, Anordnungen von Haussuchungen und von Beschlagnahmen sowie Beschränkungen des Eigentums auch außerhalb der sonst hierfür bestimmten gesetzlichen Grenzen zulässig".(ARTINGER, 2019).

117 "Sobre os interesses individuais, de modo que 'o interesse privado é o mesmo com o público". Tradução nossa de Arendt (1973, p. 139)

118 "A coincidência dessa identificação com o pretexto totalitário de ter abolido as contradições entre interesses individuais e públicos é suficientemente significativa [...]. No entanto, não se deve ignorar o fato de que Hobbes queria, acima de tudo, proteger interesses privados, fingindo que, com razão, entendiam que também eram interesses do corpo político, enquanto, ao contrário, regimes totalitários proclamam a inexistência de privacidade". Tradução nossa em relação à passagem de Arendt (1973, p. 139). 
A não-distinção entre o que é interesse público ou privado, para Arendt, impactaria na própria distinção daquilo que se considera esfera pública ou privada - logo, sem a separação, não haveria esfera privada, não haveria privacidade. A contribuição de Arendt para a compreensão da intersecção da privacidade com a natureza do regime vai muito além em a "The origins of totalitarianism". Em sua crítica à aliança que se formara em torno do Nazismo entre a elite e a grande massa alemã, Arendt apontou as contradições do apoio e fascínio que partes da população teria em se movimentar de forma atomizada, segmentada e alienada rumo à sua própria destruição.

The philistine's retirement into private life, his single-minded devotion to matters of family and career was the last, and already degenerated, product of the bourgeoisie's belief in the primacy of private interest. The philistine is the bourgeois isolated from his own class, the atomized individual who is produced by the breakdown of the bourgeois class itself. The mass man whom Himmler organized for the greatest mass crimes ever committed in history bore the features of the philistine rather than of the mob man, and was the bourgeois who in the midst of the ruins of his world worried about nothing so much as his private security, was ready to sacrifice every thing - belief, honor, dignity - on the slightest provocation. Nothing proved easier to destroy than the privacy and private morality of people who thought of nothing but safeguarding their private lives. After a few years of power and systematic co-ordination, the Nazis could rightly announce: "The only person who is still a private individual in Germany is somebody who is asleep. "119. (ARENDT, 1973, p. 338-339)

Vidas atomizadas, devotas de sua segurança individual, alienadas de sua classe; Hannah Arendt identifica na natureza da classe burguesa as dinâmicas que, pelo excesso de individualidade, de privacidade, acabam por arruiná-las. O grande paradoxo evidenciado por Arendt reside justamente na proteção individualista de vidas privadas que, por sua vez, desconectam o indivíduo de sua consciência e inserção. Nada seria mais sedutor do que a promessa de segurança de seus próprios círculos privados, individualidade e "valores- nem que para isso fosse preciso abdicar de crenças, honras e dignidades.

O indivíduo que Arendt identifica é o próprio burguês que, consigo, traz o fascínio da massa em prol de edificações político-autoritárias. Marcuse canaliza sua critica justamente na aceitação pacífica e alienante que uma estrutura social-tecnológica, um apparatus,

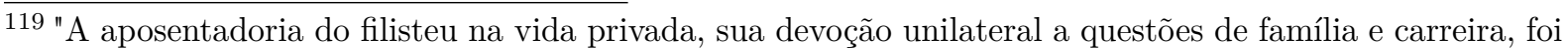
o último e já degenerado produto da crença da burguesia na primazia do interesse privado. O filisteu é o burguês isolado de sua própria classe, o indivíduo atomizado que é produzido pelo colapso da própria classe burguesa. O homem de massa que Himmler organizou para os maiores crimes em massa já cometidos na história tinha as características do filisteu e não do homem da máfia, e era o burguês que no meio das ruínas de seu mundo se preocupava com nada mais do que assegurar suas vidas privadas, estava pronta para sacrificar cada coisa - crença, honra, dignidade - à menor provocação. Nada se provou mais fácil de destruir do que a privacidade e a moralidade das pessoas que não pensavam em nada além de salvaguardar suas vidas privadas. Depois de alguns anos de poder e coordenação sistemática, os nazistas podiam anunciar com razão: "A única pessoa que ainda é um indivíduo privado na Alemanha é alguém que está dormindo"." Tradução nossa em relação à passagem de Arendt (1973, p. 338-339). 
poderia gerar, caso as necessidades básicas desse indivíduo fossem atendidas. Para o autor, essa ausência de criticidade dar-se-ía pela satisfação pessoal do indivíduo em detrimento do todo: "Independence of thought, autonomy, and the right to political opposition are being deprived of their basic critical function in a society which seems increasingly capable of satisfying the needs of the individuals"120 (MARCUSE, 1991, 1964, p.4).

Arendt toca, então, na maxima de que "Nada se provou mais fácil de destruir do que a privacidade e a moralidade das pessoas que não pensavam em nada além de salvaguardar suas vidas privadas ${ }^{121 "(A R E N D T, ~ 1973, ~ p . ~ 338-339) . ~ A ~ d e f e s a ~ d e ~ m i n o r i a s ~ v i l i p e n d i a d a s ~}$ por regimes autoritários não é uma preocupação, a quebra de instituições democráticas, idem. Desde que esteja garantida a satisfação individual daqueles que detêm as condições de mudança, pouco importa os meios pelos quais foram satisfeitos. A denúncia de Marcuse e Arendt recaem sobre essa indiferença, típica, segundo Marcuse, das sociedades de controle:

Such a society may justly demand acceptance of its principles and institutions, and reduce the opposition to the discussion and promotion of alternative policies within the status quo. In this respect, it seems to make little difference whether the increasing satisfaction of needs is accomplished by an authoritarian or a non-authoritarian system. (MARCUSE, 1991,1964, p.4)

Na Alemanha do Terceiro Reich, a aliança que docilmente se alienaria frente à barganha de liberdades civis por segurança seria temporária, frágil e com consequências historicamente cristalizadas. Até que ponto e do que a população em democracias contemporâneas estaria disposta a abdicar de direitos e liberdades civis em prol da salvaguarda de suas visões de mundo? Liberdade pessoal? Direito à liberdade de expressão? Liberdade de imprensa? Liberdade de associação e reunião? Intervenções no sigilo postal, telegráfico e telefônico? Liberdade de autodeterminação? Autonomia? Quais outras liberdades e instituições democráticas podem ser barganhadas em prol da segurança?

\subsection{O espectro político da Vigilância e da Privacidade}

A compreensão da privacidade como um valor democrático não é uma tarefa tão evidente e obvia que dispense sua explicação. De igual modo, justificar a necessidade controlada e legítima de vigilância em uma democracia não a tornaria menos democrática. O que auxiliaria, então, na ocorrência e incidência dos fenômenos da privacidade e vigilância em determinados espectros políticos? Westin (2018) parte do princípio que determinados regimes requerem ajustes diferentes nos pontos de equilíbrio entre privacidade e vigilância. O que é evidente para o autor, contudo, é que esse balanço encontra seus direcionadores no

\footnotetext{
120 "A independência do pensamento, a autonomia e o direito à oposição política estão sendo privados de sua função crítica básica em uma sociedade que parece cada vez mais capaz de satisfazer as necessidades dos indivíduos" (MARCUSE, 1991, 1964, p.4), tradução nossa.

121 Tradução nossa.
} 
regime político, já que "the political system in each society will be a fundamental force in shaping its balance of privacy, since certain patterns of privacy, disclosure, and surveillance are functional necessities for particular kinds of political regime"122(WESTIN, 2018).

Logo, de acordo com o regime político, ter-se-ia condições favoráveis para definir o ponto divisório entre privacidade e vigilância ou, em outras palavras, suas posições nos espectros políticos compreendidos entre autoritários e democráticos. Westin (2018) Discorre que uma das formas para se identificar as posições nos espectros políticos seria pela contraposição entre os espectros políticos ${ }^{123}$. Para Westin, haveria uma dicotomia entre Democracia e Autoritarismo que se projetaria, também, na subsequente dicotomia entre Privacidade e Vigilância. A abordagem do autor leva em consideração variantes internas dos regimes para identificar condições favoráveis à uma ou outra parte do espectro da dicotomia.

Por sua argumentação, são confrontadas os legados de regimes totalitários, que encontram exemplos tanto no Nationalsozialismus, de 1933 de 1945, como na posterior Deutsche Demokratische Republik (conhecida como DDR, Alemanha Oriental, East Germany ou Ostdeutschland - de 1949 à 1990), com seu aparato da Stasi. No tocante aos Estados Totalitários, Westin argumenta que "The modern totalitarian state relies on secrecy for the regime, but high surveillance and disclosure for all other groups" ${ }^{124}$. Essa demanda seria justificada pela busca constante de lealdade e necessidade de verificar possíveis desertores, pelo custo de ser temido à rationale de Maquiavel que, por tais razões, evidenciam que "autonomous units are denied privacy, traditional confidential relationships are destroyed, surveillance systems and informers are widely installed, and thorough dossiers are compiled on millions of citizens" ${ }^{125}$.

Westin (2018) identifica, por sua leitura da literatura que fomentou autoritarismos afora, que a ideia de privacidade é atacada como uma ameaça ao regime. Noções básicas de privacidade são, então, trocadas pela concepção do coletivo enquanto maxima e, portanto, sobressalente ao indivíduo. Segundo Westin (2018), "the literature of both fascism and communism traditionally attacks the idea of privacy as "immoral," "antisocial," and "part of the cult of individualism"126. A privacidade, em tais regimes, ganharia a denotação de

122 "O sistema político em cada sociedade será uma força fundamental na formação de seu equilíbrio de privacidade, uma vez que certos padrões de privacidade, divulgação e vigilância são necessidades funcionais para tipos particulares de regime político"(WESTIN, 2018), tradução nossa.

${ }^{123}$ Westin (2018) defende essa abordagem ao dizer que "This is shown most vividly by contrasting privacy in the democratic and the totalitarian state"(WESTIN, 2018).

124 "O Estado totalitário moderno depende do sigilo para o regime, mas de alta vigilância e divulgação para todos os outros grupos"(WESTIN, 2018), tradução nossa.

125 "Unidades autônomas têm privacidade negada, relações confidenciais tradicionais são destruídas, sistemas de vigilância e informantes são amplamente instalados e dossiês minuciosos são compilados em milhões de cidadãos"(WESTIN, 2018), tradução nossa.

126 "a literatura do fascismo e do comunismo tradicionalmente ataca a ideia de privacidade como "imoral", "antissocial" e "parte do culto do individualismo". Essa atitude é mais fortemente expressa na fase de consolidação de um novo regime totalitário"(WESTIN, 2018), tradução nossa. 
culto ao individualismo, com a equiparação ao desinteresse político, ausência de noção de coletivo e potencial discurso para conspiradores-desertores.

O sentimento coletivo não poderia ser outro senão o fomento do medo e da desconfiança, conforme aponta Westin (2018) ao afirmar que "these policies, by creating fear and distrust, tend to foster a sense of loneliness and isolation in the citizen"127. Tais movimentos acelerariam o processo de destruição das esferas privadas e induziriam, forçosamente, o indivíduo à uma vinculação leal e inconteste de seus ideais ao regime. Embebido por tais pressões, o indivíduo, segundo Westin (2018), "for relief, he turns to identification with the state and its programs so that he may find the satisfactions of affiliation and achievement"128. Não se poderia mais falar, por essa perspectiva, em indivíduo - sua concepção somente existiria como uma concessão pelo coletivo.

O ponto de equilíbrio entre vigilância e privacidade estaria portanto, em regimes totalitários, posicionado favoravelmente à vigilância. Em regimes democráticos, por sua vez, o ponto de equilíbrio se posicionaria de forma diametralmente oposta - sem, contudo, com as devidas ressalvas, abdicar da vigilância por completo. Nesse aspecto, é considerado por Westin que:

Just as a social balance favoring disclosure and surveillance over privacy is a functional necessity for totalitarian systems, so a balance that ensures strong citadels of individual and group privacy and limits both disclosure and surveillance is a prerequisite for liberal democratic societies ${ }^{129}$. (WESTIN, 2018).

A privacidade, conforme exposto nos capítulos anteriores, por vezes surge como uma abstração do arcabouço normativo de uma sociedade democrata. Ainda que em níveis diferentes, a democracia como um de seus pressupostos a autonomia do indivíduo enquanto capacidade inequívoca de fazer escolhas. Adicionalmente, regimes democráticos liberais preconizariam a privacidade como um limite da atuação do governo e de possíveis excessos, já que nenhum regime estaria imune à desequilíbrios nessa balança. Westin corrobora essa visão quando afirma que "the democratic society relies on publicity as a control over government, and on privacy as a shield for group and individual life ${ }^{1130}$. É possível identificar, portanto, que a vigilância pode se fazer presente, principalmente quando aplicada ao controle dos espaços públicos, funções de cobrança de impostos, monitoramento

\footnotetext{
127 "Essas políticas, ao criar medo e desconfiança, tendem a fomentar um sentimento de solidão e isolamento no cidadão" (WESTIN, 2018), tradução nossa.

128 "Para alívio, ele se volta para a identificação com o estado e seus programas para que ele possa encontrar as satisfações de afiliação e realização" (WESTIN, 2018), tradução nossa.

129 "Assim como um equilíbrio social que favorece a divulgação e a vigilância sobre a privacidade é uma necessidade funcional dos sistemas totalitários, um equilíbrio que assegure fortes cidadanias de privacidade individual e coletiva e limita tanto a divulgação quanto a vigilância é um pré-requisito para as sociedades democráticas liberais" (WESTIN, 2018), tradução nossa.

130 " A sociedade democrática depende da publicidade como controle sobre o governo e da privacidade como um escudo para a vida em grupo e individual" (WESTIN, 2018), tradução nossa.
} 
da saúde populacional, dentre outras funções que, por regulamentações e justificativas internas, podem atingir um ponto de equilíbrio comumente aceito. Westin (2018) nota que a privacidade enquanto fenômeno político-institucional é pouco notada, principalmente em relação ao impacto que ela desempenha na democracia: The reasons for protecting privacy tend to be familiar to citizens of liberal democracies; thus the specific functions that privacy performs in their political systems are often left unexpressed ${ }^{131}$. Portanto, o ponto de equilíbrio entre privacidade e vigilância estaria, em regimes democráticos, posicionado favoravelmente à privacidade.

\subsection{Os impactos da Vigilância e da Privacidade na Democracia}

Como avaliar os impactos, então, da vigilância e da privacidade, em instituições democráticas? O desafio é considerável, visto que, quando falamos de impacto nas instituições democráticas e liberdades civis, há uma vasta e inesgotável literatura que aborda a temática. De cunho universal ou limitadas às jurisdições e/ou dinâmicas histórico-sociais de seus países, Robert Dahl, com seu didatismo peculiar, construiu categorizações não exaustivas sobre as instituições e benefícios que comporiam um arcabouço minimalista para o funcionamento da democracia ${ }^{132}$. Ainda que o enfoque deste trabalho não seja avançar sobre tal discussão, a categorização de Dahl fornece insumos para a comparação com a obra de Alan Westin ${ }^{133}$ sobre o quão intrínseca a privacidade se faz nas instituições democráticas, adicionalmente à privacidade do indivíduo.

A democracia em larga escala, para Dahl e Shapiro (2015) em seu livro "On Democracy" - equiparada às democracias contemporâneas na concepção da poliarquia - teria diversas vantagens proporcionadas por suas instituições, como, por exemplo, o impedimento de governos de autocratas cruéis e corruptos, a garantia de direitos fundamentais que os sistemas não democráticos não são adeptos, o asseguramento de uma ampla gama de liberdade pessoal, a proteção de interesses fundamentais, a liberdade de autodeterminação, o desenvolvimento humano em seu plenipotencial, o exercício da responsabilidade moral

131 "As razões para proteger a privacidade tendem a ser familiares aos cidadãos das democracias liberais; Assim, as funções específicas que a privacidade desempenha em seus sistemas políticos são muitas vezes deixadas sem serem expressas" (WESTIN, 2018), tradução nossa.

${ }^{132}$ As instituições democráticas identificas por Dahl em regimes Democráticos estabelecem interconexões e interdependências tão relevantes quanto suas existências por si mesmas. A liberdade de expressão é um exemplo dessa interdependência, tal como colocado por Dahl: "Like the other rights essential to a democratic process, free expression has its own value because it is instrumental to moral autonomy, moral judgment, and a good life" (DAHL; SHAPIRO, 2015, p. 51). Nesse sentido, o impacto que tanto a vigilância, quanto a privacidade trazem às instituições não afeta apenas uma, mas todas, bem como o conjunto que as permeiam. Abordá-las diretamente e de forma categorizada é, portanto, conveniente apenas para fins analíticos e não exaustivos, pois o debate em si não apresentaria conclusões ou considerações imutáveis.

${ }^{133}$ Quando Westin começa a sintetizar sua argumentação acerca das intersecções da privacidade em uma democracia, uma linha analítica começa a ganhar forma e a se associar com as premissas minimalistas de Robert Dahl, fator que auxilia na comparação e avaliação sistemática das consequências da privacidade e da vigilância em Democracias. 
e um grau relativamente alto de igualdade política. Se sumarizadas as consequências da Democracia e suas instituições na perspectiva minimalista de Dahl, teríamos a seguinte composição da tabelas 2 e $3^{134}$ :

Tabela 1 - Considerações de Robert Dahl acerca da Democracia

Tabela 2 - Conseq. da Democracia Tabela 3 - Democracia em Larga Escala

1. Evita a tirania

1. Funcionários eleitos

2. Direitos essenciais

3. Liberdade geral

2. Eleições livres, justas e frequentes

4. Autodeterminação

3. Liberdade de expressão

5. Autonomia moral

4. Fontes alternativas de informação

6. Desenvolvimento Humano

5. Autonomia associativa

7. Protege interesses pessoais essenciais

6. Cidadania inclusiva

8. Igualdade política

9. Busca pela paz

10. Prosperidade

Fonte: Tabela sintetizada a partir das constatações de Robert Dahl em seu livro "On democracy"(DAHL; SHAPIRO, 2015)

Das instituições e resultantes desejáveis da Democracia, a autonomia que a privacidade protege é uma das mais vitais e necessárias. Westin aborda a questão da autonomia em seus diversos aspectos, tais como o psicológico, moral, a capacidade de autodeterminação e, principalmente, o de autodesenvolvimento sem interferências externas. Enquanto tentativa de conceituação, autonomia ganha um leque vasto de construções teóricas e interpretações, que compartilham um núcleo reconhecido como a capacidade de autodeterminar e fazer escolhas. Westin identifica que tais capacidades e os diversos aspectos da autonomia são inerentes ao processo democrático; de forma análoga à Dahl, Westin posiciona a autonomia como essencial ao desenvolvimento da individualidade, de visões e pensamentos diferentes e não-conformidade com padrões que trazem a diversidade e o conflito necessário à democracia. Em relação à essa relação da privacidade com a autonomia, Westin discorre que:

The autonomy that privacy protects is also vital to the development of individuality and consciousness of individual choice in life. [...] This development of individuality is particularly important in democratic societies, since qualities of independent thought, diversity of views, and nonconformity are considered desirable traits for individuals. Such independence requires time for sheltered experimentation and testing of ideas, for preparation and practice in thought and conduct, without fear

\footnotetext{
${ }^{134}$ Para mais informações sobre a dinâmica, descrição e relação de cada uma das instituições e resultantes da Democracia, segundo Dahl e Shapiro (2015), indica-se a consulta de seu livro "On Democracy"(DAHL; SHAPIRO, 2015).
} 
of ridicule or penalty, and for the opportunity to alter opinions before making them public ${ }^{135}$. (WESTIN, 2018)

Autonomia associativa é outro pilar democrático que a privacidade protege. A participação em grupos, em uma democracia, pode trazer ao público informações de caráter partidário, religioso, econômico, sexual, revolucionário, dentre tantos outros; pode significar o compartilhamento de ideais e ideias em uma esfera proteção depende a liberdade de expressão, a liberdade religiosa e a própria autonomia. Por vezes, a mera associação à determinados grupos, como por exemplo, coletivos anarquistas, ou movimentos considerados comunistas, partidos de oposição ou grupos de minorias religiosas podem resultar em perseguições políticas das mais variadas formas, seja por parte do Estado ou de próprios agentes da sociedade. A autonomia associativa e a liberdade associativa são indivisíveis e necessitam essencialmente da privacidade, quando evocada ${ }^{136}$, para a proteção de seus propósitos, membros, ideais e ações nas esferas democráticas:

Membership privacy represents a core secret for many civic organizations, especially those advocating controversial ideas. Forced public disclosure of members' names could lead to social sanctions against the members and, therefore, to wholesale defections that could destroy the organization. In democratic societies a legal right to privacy for membership lists and officers' names has been given to labor unions, religious and political bodies, and civil-rights organizations, especially when these groups were facing hostile community pressures. Such a right is often denied to organizations which are considered "illegitimate" in democratic theory, as with groups using violence (such as the Ku Klux Klan) or conspiratorial groups linked to foreign powers (such as Communist and Fascist parties) ${ }^{138}$. (WESTIN, 2018)

$\overline{135}$ A autonomia que a privacidade protege também é vital para o desenvolvimento da individualidade e da consciência da escolha individual na vida. [...] Esse desenvolvimento da individualidade é particularmente importante nas sociedades democráticas, uma vez que as qualidades do pensamento independente, a diversidade de opiniões e a não-conformidade são consideradas características desejáveis para os indivíduos. Tal independência requer tempo para experimentação protegida e teste de ideias, para preparação e prática em pensamento e conduta, sem medo de ridículo ou penalidade, e para a oportunidade de alterar opiniões antes de torná-las públicas.

136 Determinadas associações não necessariamente evocam a privacidade para proteger suas dinâmicas internas e se fazem abertas à sociedade como forma de interação. Ainda assim, não devem ser tomadas como régua para nivelar as ações das demais formas de organização que surgem na sociedade. Westin (2018) corrobora essa noção e frisa que "Just as with individuals, and subject to the same process of social limitation, organizations need the right to decide when and to what extent their acts and decisions should be made public ${ }^{\prime 137}$. (WESTIN, 2018)

138 "A privacidade dos membros representa um segredo central para muitas organizações cívicas, especialmente aquelas que defendem ideias controversas. A divulgação pública forçada dos nomes dos membros poderia levar a sanções sociais contra os membros e, portanto, a deserções no atacado que poderiam destruir a organização. Em sociedades democráticas, um direito legal à privacidade para listas de membros e nomes de oficiais foi dado a sindicatos trabalhistas, órgãos religiosos e políticos e organizações de direitos civis, especialmente quando esses grupos enfrentavam pressões comunitárias hostis. Tal direito é freqüentemente negado a organizações que são consideradas "ilegítimas" na teoria democrática, como em grupos que usam violência (como o Ku Klux Klan) ou grupos conspiratórios ligados a potências estrangeiras (como partidos comunistas e fascistas)" (WESTIN, 2018), tradução nossa. 
A privacidade que protege a autonomia e a liberdade associativa pode ser, então, aplicada à indivíduos e à organizações e, por esta última, pode ser considerada como privacidade organizacional ${ }^{139}$.Nesse sentido, a privacidade protege, pela autonomia associativa, instituições elementares à democracia por promoverem a liberdade de expressão, a diferenciação de ideias, a produção e resolução de conflitos, dentre tantos outros elementos. A interação social de tais grupos dita a própria dinâmica democrática, com a sobreposição, contestação e orquestração de ações na esfera pública. Proteger tais elementos é primordial para a manutenção de esfera pública e proteção da atuação autônoma de seus agentes; faz parte do próprio jogo democrático e dele não poderia ser subtraído. O Escândalo de Watergate, que ressoou os abusos cometidos contra o Partido Democrata dos Estados Unidos, é um exemplo clássico dos efeitos deletérios da não observância dos requisitos de privacidade associada à autonomia associativa. Como pontua Alan Westin, trata-se de uma atuação central na democracia:

Because of the central role played by groups in a democratic society - they provide opportunities for sociability, expression of independent ideas, resolution of community conflicts, criticism of government, and formation of a consensus on public policy - citizens are given wide freedom to join associations and participate in group affairs. To this end, privacy of membership and intra-group action are protected. Associations themselves are given substantial organizational privacy to achieve their objectives efficiently and responsibly ${ }^{140}$. (WESTIN, 2018).

Expressar-se com plena autonomia, seja em associação ou de forma individual, e sem receio de restrições, de acordo com os limites da lei, é outra instituição fundamental à democracia, consagrada pela "Liberdade de Expressão". Seu exercício é vital à democracia, com a sensibilidade emblemática de servir, inclusive, como instituição capaz de auferir o quão saudável a esfera pública se encontra. Sua incessante construção e defesa afeta para além de indivíduos propriamente ditos, outras instituições inteiras, como a imprensa e a ciência, primordiais à dinâmica democrática.

Sua instituição correlata, tratada por Dahl como "fontes alternativas de informação"é a resultante da busca e construção constante da esfera pública, de sua manifestação,

${ }^{139}$ Alan Westin traz o conceito da privacidade organizacional com a seguinte feição: "Organizational privacy is needed if groups are to play the role of independent and responsible agents that is assigned to them in democratic societies. Among these are the satisfaction of needs for affiliation in large-scale society; the expression of basic interests felt by sub-groups in the community; the operation of civic enterprises by private rather than government management; criticism of government policies; and measurement of public sentiment on issues and policies between elections" (WESTIN, 2018).

140 "Por causa do papel central desempenhado pelos grupos em uma sociedade democrática - eles fornecem oportunidades para sociabilidade, expressão de idéias independentes, resolução de conflitos comunitários, críticas ao governo e formação de um consenso sobre políticas públicas - os cidadãos recebem ampla liberdade para se associarem a associações. e participar de assuntos de grupo. Para este fim, a privacidade da associação e a ação intragrupo são protegidas. Associações recebem privacidade organizacional substancial para alcançar seus objetivos de forma eficiente e responsável" (WESTIN, 2018), tradução nossa. 
exercício, debate e confrontação. A privacidade, nessa esfera, atuaria de duas formas: protegeria o indíviduo em sua busca por informações - sem que ele tenha receio de, sob vigilância, acessar fontes de informações divergentes - e a sua fonte de informação. Enquanto fonte de informação, a instituição da "Imprensa"necessitaria da privacidade para proteger suas fontes de informação como elemento crucial ao desempenho autônomo, investigativo e independente do trabalho jornalístico, principalmente pela confiança de que a relação de confidencialidade de suas fontes não seria abalada ${ }^{141}$.

Se para uma imprensa livre, a privacidade é crucialmente necessária, ela pavimenta, também, todas faculdades investigativas e de produção intelectual. Por conseguinte, a liberdade de expressão também é compreendida como liberdade e autonomia da própria academia ${ }^{142}$, com tão ou mais criticidade para a ciência e a construção intelectual da sociedade. Garantir a privacidade para o trabalho intelectual, seja na academia ou na imprensa, é uma questão de se garantir diversas outras liberdades interdependentes da liberdade de expressão e ao direito de busca de informações distintas. Westin sumariza essa questão ao pontuar a necessidade de se garantir caminhos divergentes da opinião,

${ }^{141}$ No capítulo "The NSA Revelations as a Prism"do livro "Journalism and the NSA revelations", os(as) autores(as) Risto Kunelius, Heikki Heikkilä, Adrienne Russell e Elisabeth Eide comentam o impacto direto da proteção das fontes jornalísticas pós-Snowden. O caso é emblemático pela iniciativa de autoridades que incessantemente buscaram identificar as fontes de vazamento de informações. Em seu relato, constatam que "the category of national interest - and security as its core element - remains a powerful vehicle in controlling public discourse and disciplining (investigative) journalism. In the Snowden-NSA case, national interest sometimes translated as immediate legal pressure to break source protections and use diplomatic interventions to sanction and isolate individuals such as Snowden or Julian Assange. On a rhetorical level, this threat was also eminent when Rusbridger, editor of the Guardian, faced an official inquiry and was asked: 'Do you love this country?'"(KUNELIUS et al., 2017, p.17).

142 Jay Rosen (2013), repórter para o Jornal Britânico "The Guardian" publicou em seu artigo "The NSA's next move: silencing university professors?"a experiência que o professor Matthew Green da Universidade Johns Hopkins teve ao publicar um artigo sobre a NSA em seu blog. Rosen (2013) comenta inicialmente que "A professor in the computer science department at Johns Hopkins, a leading American university, had written a post on his blog, hosted on the university's servers, focused on his area of expertise, which is cryptography. The post was highly critical of the government, specifically the National Security Agency, whose reckless behavior in attacking online security astonished him". Após a publicação inicial, o Professor Matthew Green passou pela experiência de censura de seu artigo, quando compartilhou o seguinte relato: "The professor says he was told that someone at the Applied Physics Laboratory, a research institute with longstanding ties to the Department of Defense and the National Security Agency, determined that his blog post was hosting or linking to classified material, and sounded the alarm, which led to the takedown request from the dean. He says he thought Johns Hopkins University, his employer, had come down "on the wrong side of common sense and academic freedom", particularly since the only classified material he had linked to was from news reports in the Guardian, the New York Times and ProPublica.org - information available to the public". A Universidade publicou, após comoção pública, um comunicado institucional descrevendo o caso, conforme compartilhado a seguir: "The university received information this morning that Matthew Green's blog contained a link or links to classified material and also used the NSA logo. For that reason, we asked professor Green to remove the Johns Hopkins-hosted mirror site for his blog Upon further review, we note that the NSA logo has been removed and that he appears to link to material that has been published in the news media. Interim Dean Andrew Douglas has informed professor Green that the mirror site may be restored"(ROSEN, 2013). O caso foi também publicado em outra matéria pelo Jornal The Guardian com a retração "Johns Hopkins dean apologises for ordering NSA-related blog removed", em matéria conduzida por (GABBATT, 2013). 
por vezes, dominante: "Liberal democracy recognizes the special needs of scholars and scientists to be free of constant community and government examination so that paths to truth and discovery can be pursued even in directions that offend dominant opinion 143"(WESTIN, 2018).

Se por um lado a privacidade é essencial para a manutenção do fluxo livre, autônomo e independente da informação pela imprensa, comunidade acadêmica e pelo próprio indivíduo, por outro ela também garante que instituições ainda mais primordiais da democracia funcionem de forma legítima como, por exemplo, o direito ao voto e à total independência da escolha política. Dahl aborda a questão pelas instituições de "Eleições livres, justas e frequentes"e pela necessidade de uma democracia ser composta por "Funcionários eleitos". Tais instituições fornece insumo para analisar o quão essenciais elas são e o quão minimalista a abordagem de Dahl é: afinal, tratam-se de instituições imprescindíveis à composição da dinâmica democrática. O direito ao voto requer precisamente um forte componente de privacidade para que se mantenha livre de forças que prejudiquem processos eleitorais democráticos. Além disso, a privacidade protege o cidadão e o sigilo na urna de escrutínios por parte de empregadores, familiares, candidatos e do próprio governo acerca das escolhas realizadas. Westin (2018), nesse sentido, posiciona a privacidade e o direito ao voto como peças-chave ao processo democrático ao considerar que "Liberal democratic systems ensure maximum freedom for political choice by providing a secret ballot to protect the voting process and by forbidding governmental inquiries into a citizen's past voting record $^{144 "(W E S T I N, ~ 2018) . ~}$

Como contrapeso à demanda de absoluta transparência, Westin (2018) identifica que a privacidade tem sua presença, também, no segredo de Estado, ou nos próprios trâmites que classificam a informação para publicação e transparência no decorrer do tempo. Tal fenômeno é observado pelo autor no equilíbrio entre demanda por transparência versus segredo de Estado que em democracias liberais, há o convencionamento acerca do equilíbrio necessário entre "[...] government's organizational needs for preparatory and institutional privacy and the need of the press, interest groups, and other governmental agencies for the knowledge of government operations required to keep government conduct

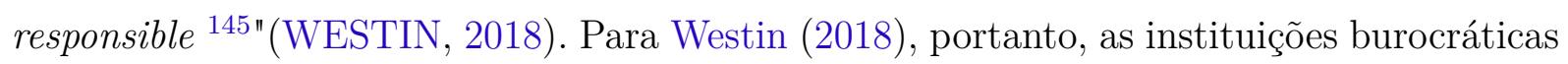
necessitam dessa proteção para o andamento de seus trabalhos internos. Se dotadas de

143 "A democracia liberal reconhece as necessidades especiais de estudiosos e cientistas de estarem livres de exames constantes da comunidade e do governo, de modo que os caminhos para a verdade e a descoberta possam ser perseguidos mesmo em direções que ofendam a opinião dominante"(WESTIN, 2018). Tradução nossa a partir da argumentação de Westin (2018).

144 "Os sistemas democráticos liberais garantem a máxima liberdade para a escolha política, fornecendo uma votação secreta para proteger o processo de votação e proibindo investigações governamentais em um histórico de votação passado do cidadão"(WESTIN, 2018). Tradução nossa.

145 " [...] as necessidades organizacionais do governo para a privacidade institucional e preparatória e a necessidade da imprensa, grupos de interesse e outras agências governamentais para o conhecimento das operações do governo necessárias para manter a conduta governamental responsável"(WESTIN, 2018). Tradução nossa. 
um arcabouço jurídico-normativo acerca do nível de privacidade, as burocracias estatais poderiam equilibrar as necessidades internas como a demanda por maiores níveis de transparência pública.

Nas categorias analíticas acerca das instituições elencadas de Dahl, a conjunção da privacidade também poderia contribuir no espectro democrático para se garantir "Direitos essenciais", a "Liberdade geral"e o imperativo de se "evitar a tirania". Westin (2018) traz a temática, comparativamente, quando introduz aquilo que denomina como "liberdades civis"e descreve o conceito a partir de "[...] its belief in limits on government and private power, freedom of expression and dissent, and institutionalized mechanisms for enforcing these rights, particularly the legal system and independent courts"146 (WESTIN, 2018). Evitar a Tirania, dentre um amplo escopo de possibilidades e definições, encontra, também, respaldo na privacidade por intermédio das instituições democráticas protegidas por tais limites.

Limites que impediriam, por exemplo, a busca e apreensão, a violência, o encarceramento, a violação da correspondência e do sigilo das comunicações, o confisco de bem como tantas outras possibilidades de suspensão temporária ou permanente de direitos que caracterizam, por sua vez, ou um Estado de Exceção, enquanto tirania temporária (conforme formulado por Schimidt), ou um governo despótico, enquanto tirania permanente. Uma rede de proteção de instituições democráticas, segundo Westin, poderia conter tais aspectos tirânicos. Pela concepção do autor, é preciso considerar que por intermédio de uma "network of constitutional, legal, and political restraints, democratic societies protect the individual's person and personality from improper police conduct such as physical brutality, compulsory self-incrimination, and unreasonable searches and seizures ${ }^{147 "(W E S T I N, ~}$ 2018).

\footnotetext{
146 "[...] sua crença em limites ao poder público e privado, liberdade de expressão e dissensão, e mecanismos institucionalizados para fazer valer esses direitos, particularmente o sistema legal e os tribunais independentes" (WESTIN, 2018), tradução nossa.

147 "Uma rede de restrições constitucionais, legais e políticas, sociedades democráticas protegem a pessoa e a personalidade do indivíduo de conduta policial imprópria, como brutalidade física, auto-incriminação compulsória e buscas e apreensões irracionais"(WESTIN, 2018). Tradução nossa.
} 



\section{Segurança Nacional versus Liberdades $\mathrm{Ci}$ - vis: A perspectiva da Securitização}

A proteção de direitos civis é uma variável recente na composição das sociedades modernas. Devido à sua importância, grande parte da literatura recente aborda a concepção de que os valores democráticos e uma sociedade justa só podem coexistir com uma estrutura básica equitativa de direitos e liberdades asseguradas, sobretudo, pelo processo democrático; Ainda que haja uma pluralidade de concepções destoantes em relação às estruturas básicas da democracia na literatura corrente, parte dessa literatura tende a reconhecer que "democracy has been variously conceived of as a distinctive set of political institutions and practices, a particular body of rights, a social and economic order, a system that ensures certain desirable results, or a unique process of making collective and binding decisions. 148 ” (DAHL, 1991, pp. 91). No desenrolar desse raciocínio, Dahl explica que:

It has long been recognized by both advocates and opponents of democracy that it is linked to freedom in a way different from that of any other kind of regime. Because certain rights, liberties, and opportunities are essential to the democratic process itself, as long as that process exists then these rights, freedoms, and opportunities must necessarily also exist. These include rights to free expression, political organization, opposition, fair and free elections, and so on. Consequently the minimal range of political freedom in a democratic system inherently comprises a fairly broad range of important rights. But these fundamental political rights are unlikely to exist in isolation. The political culture required to support the existence of a democratic order [...] tends to emphasize the value of personal rights, freedoms, and opportunities. Thus not only as an ideal but in actual practice, the democratic process is surrounded by a penumbra of personal freedom $^{149}$. (DAHL, 1991, p.88-89)

Essa correlação, apontada por Dahl (1991), entre regimes democráticos e a um espectro mínimo de diretos e liberdades expressa-se como uma constante na tradição

148 "A democracia tem sido concebida como um conjunto distinto de instituições e práticas políticas, um conjunto particular de direitos, uma ordem social e econômica, um sistema que garante certos resultados desejáveis ou um processo singular de tomada de decisões coletivas e vinculantes" (DAHL, 1991, pp. 91), tradução nossa.

149 "Há muito tempo é reconhecido por defensores e opositores da democracia que está ligado à liberdade de maneira diferente de qualquer outro tipo de regime. Como certos direitos, liberdades e oportunidades são essenciais para o próprio processo democrático, enquanto esse processo existir, esses direitos, liberdades e oportunidades também devem necessariamente existir. Estes incluem direitos à liberdade de expressão, organização política, oposição, eleições justas e livres e assim por diante. Consequentemente, o alcance mínimo da liberdade política em um sistema democrático inerentemente compreende uma gama bastante ampla de direitos importantes. Mas é improvável que esses direitos políticos fundamentais existam isoladamente. A cultura política necessária para apoiar a existência de uma ordem [...] democrática tende a enfatizar o valor dos direitos, liberdades e oportunidades pessoais. Assim, não apenas como um ideal, mas na prática atual, o processo democrático é cercado por uma penumbra de liberdade pessoal" (DAHL, 1991, p.88-89), tradução nossa. 
constitucionalista dos Estados Unidos. Dentre o espectro mínimo de direitos e liberdades, a privacidade figura-se com um ponto basilar da concepção democrática estadunidense que, em decorrência da luta pela privacidade enquanto liberdade civil nos Estados Unidos - impulsionada desde os debates "Federalistas" (Federalist Papers)- cristalizou-se em dois dispositivos fundamentais à Constituição estadunidense: o "First" e o "Four Amendment". Tais dispositivos, interpretados como partes integrantes do direto à "privacidade", garantem, respectivamente, a liberdade de expressão, manifestação e organização política e o direito "of the people to be secure in their persons, houses, papers, and effects, against unreasonable searches and seizures[... ${ }^{150 "}$. Se as liberdades civis, dentre elas a privacidade - aqui compreendida como a capacidade de se manter a confidencialidade de informações, comunicações e ações de naturezas diversas - são constituintes das bases democráticas dos Estados Unidos, por quais motivos, então, suas supressões têm sido gradativamente institucionalizadas no ordenamento jurídico estadunidense? Como explicar a transição das bases constitucionais da privacidade para um "estado de vigilância"? Em que medida a supressão da privacidade afeta o processo democrático estadunidense?

No tocante ao viés teórico da Securitização, de acordo com Buzan (1998), a percepção compartilhada pela Escola de Copenhague é de que, ao se deparar com uma ameaça existencial - que coloca em risco à existência do Estado - a resposta estatal tende a ser a busca por um nível elevado de segurança nacional, mesmo que o preço a ser pago seja ainda mais alto, como a suspensão "temporária" do ordenamento jurídico. Para a escola de Copenhague, a natureza da ameaça à segurança nacional justifica os termos extraordinários para se lidar com ela que, segundo Buzan, "In this context, security is about survival. It is when an issue is presented as posing an existential threat to a designated referent object (traditionally, but not necessarily, the state, incorporating government, territory, and society) ${ }^{151} "$ (BUZAN; WÆVER; WILDE, 1998). A chave para compreender esse fenômeno mais "excepcionalista"ou "extraordinário"pode ser encontrada no conceito de "Estado de Exceção"A contradição presente no estudo de caso da vigilância massiva e demais estruturas que compõem a "Política Cibernética Norte Americana" reside no fato de um "regime democrático" permitir-se coexistir com tais características, ou seja, uma democracia permitir-se à exceção, conforme indica Schmitt $(2005)^{152}$ como preponderante

150 "das pessoas para estar seguro em suas pessoas, casas, papéis e efeitos, contra buscas e apreensões injustificadas $[\ldots]^{\prime \prime}$, tradução nossa.

151 "Neste contexto, a segurança é sobre sobrevivência. É quando uma questão é apresentada como uma ameaça existencial a um objeto de referência designado (tradicionalmente, mas não necessariamente, o estado, incorporando governo, território e sociedade)" (BUZAN; WÆVER; WILDE, 1998), tradução nossa..

${ }^{152}$ Para problematizar essa questão,Schumpeter (1976) define a variável "tempo" em tais regimes. Para Schumpeter, somente quando não se determina um retorno à "normalidade", o Estado de Exceção se confunde com as demais formas autoritárias. Segundo o autor, "This may be generalized to read that the democratic method will be at a disadvantage in troubled times. In fact, democracies of all types recognize with practical unanimity that there are situations in which it is reasonable to abandon competitive and to adopt monopolistic leadership. In ancient Rome a non-elective office conferring such a monopoly of leadership in emergencies was provided for by the constitution. The incumbent was 
para discernir entre um regime democrático, de Carl Schmitt que, por sua vez, define que o poder "soberano" do Estado é a capacidade de se decretar à exceção do ordenamento legal em momentos de "ameaça existencial": The exception, which is not codified in the existing legal order, can at best be characterized as a case of extreme peril, a danger to the existence of the state, or the like. ${ }^{153}$ (SCHMITT, 2005, pp. 6-7). Neste sentido, as percepções de ameaças terroristas, que colocam em risco a integridade de uma nação, podem passar a compor a justificativa de ações de segurança que outrora não seriam aceitas, pois:

The invocation of security has been the key to legitimizing the use of force, but more generally it has opened the way for the state to mobilize, or to take special powers, to handle existential threats. Traditionally, by saying "security," a state representative declares an emergency condition, thus claiming a right to use whatever means are necessary to block a threatening development. ${ }^{154}$ (BUZAN; WEVER; WILDE, 1998).

Segundo os pesquisadores da Escola de Copenhague, a "Securitização" pode ser observada como um movimento que induz a política para além de seus limites e estabelece uma determinada pauta como hierarquicamente superior às regras existentes e, portanto, requerente de um tratamento excepcional. Segundo Buzan, de acordo com esse movimento, determinados assuntos podem passar de um espectro não politizado (não abordado pelo Estado e/ou não presentes nas esferas de desenvolvimento de políticas públicas), para espectros politizados (abordados pelo Estado e presentes nas esferas de desenvolvimento de políticas públicas) ou, até mesmo, espectros em que os assuntos são securitizados (ou seja, abordados pelo Estado como uma ameaça "existencial", requerente de ações emergenciais para além dos limites políticos constituídos).

Por quais meios, portanto, o estado conseguiria mobilizar seu público e legitimar a adoção de medidas e ações excepcionais que em outros momentos não seriam aceitas? O questionamento, levantado por Buzan, tem como resposta os "atos de discurso" aceitos pela intersubjetividade coletiva e estabelecidos ao redor de uma ameaça "existencial". Para

called magister populi or dictator. Similar provisions are known to practically all constitutions, our own included: the President of the United States acquires in certain conditions a power that makes him to all intents and purposes a dictator in the Roman sense, however great the differences are both in legal construction and in practical details. If the monopoly is effectively limited either to a definite time (as it originally was in Rome) or to the duration of a definite short-run emergency, the democratic principle of competitive leadership is merely suspended. If the monopoly, either in law or in fact, is not limited as to time-and if not limited as to time it will of course tend to become unlimited ato everything else-the democratic principle is abrogated and we have the case of dictatorship in the present-day sense" (SCHUMPETER, 1976)

153 "A exceção, que não está codificada na ordem jurídica existente, pode, na melhor das hipóteses, ser caracterizada como um caso de perigo extremo, um perigo para a existência do estado ou algo semelhante" (SCHMITT, 2005, pp. 6-7), tradução nossa.

154 "A invocação da segurança tem sido a chave para legitimar o uso da força, mas de maneira mais geral abriu o caminho para o Estado se mobilizar, ou tomar poderes especiais, para lidar com ameaças existenciais. Tradicionalmente, ao dizer "segurança", um representante do estado declara uma condição de emergência, reivindicando assim o direito de usar quaisquer meios necessários para bloquear um desenvolvimento ameaçador" (BUZAN; W ÆVER; WILDE, 1998), tradução nossa. 
o autor, os processos de securitização, são a combinação de mecanismos causais que se originam de "atos de discurso", mobilização e ação: If by means of an argument about the priority and urgency of an existential threat the securitizing actor has managed to break free of procedures or rules he or she would otherwise be bound by, we are witnessing a case of securitization. ${ }^{155}$ (BUZAN; WÆEVR; WILDE, 1998). A securitização pode ser considerada, desta forma, como um assunto/objeto dramatizado e apresentado como algo de extrema prioridade que, por sua vez, fornece subsídios para que o agente securitizador possa apoderar-se de direitos excepcionais em dissonância com os padrões já legitimados.

Contudo, é preciso notar que a securitização do assunto/objeto não implica necessariamente em seu sucesso para a adoção de medidas excepcionais. Para que a securitização seja plena, ela deve ser aceita por um público alvo ou audiência que legitime as ações a serem tomadas frente a uma ameaça - e, neste caso, a não aceitação do discurso poderá ser considerada apenas como um ato de securitização e não como a securitização plena. Buzan, Wæver e Wilde (1998) estipula três premissas para a securitização plena: ameaças existenciais, ações emergenciais e efeitos entre as relações das unidades que possibilitam a transgressão de regras. Nessa lógica, a securitização somente poderá ser considerada bem-sucedida se houver uma ameaça existencial que demande ações emergenciais e, por sua vez, que a transgressão de regras seja aceita para sustentá-las. Depreende-se, então, que o movimento de securitização, social e retoricamente construído com base na intersubjetividade coletiva sobre as ameaças, pode ser legitimado pela percepção e aceitação do indivíduo sobre o grau de risco atribuído às mesmas. Nesse sentido, o medo e o terror empreendido em discursos antiterrorismo são peças-chave para a compreensão da legitimação de ações preventivas que ultrapassem os limites previamente atribuídos ao estado.

Além da intersubjetividade coletiva de risco, a securitização depende de fatores facilitadores, como por exemplo, a própria linguagem e seu contexto histórico. Conforme pontua Buzan, "a successful speech act is a combination of language and society, of both intrinsic features of speech and the group that authorizes and recognizes that speech" ${ }^{\prime 156 " ~(B U Z A N ; ~}$ WÆVER; WILDE, 1998). Como consequência, a construção do discurso de securitização está atrelada substancialmente ao seu público/alvo, momento histórico e dinâmicas sociais. Condicionantes, estes, que tornam ainda mais relevante a observância da "gramática" da segurança: "Among the internal conditions of a speech act, the most important is to follow the security form, the grammar of security, and construct a plot that includes existential threat, point of no return, and a possible way out"157 (BUZAN; WÆVER; WILDE, 1998).

\footnotetext{
155 "Se, por meio de um argumento sobre a prioridade e a urgência de uma ameaça existencial, o agente de securitização conseguiu se libertar de procedimentos ou regras que ele ou ela estaria vinculado, estamos testemunhando um caso de securitização" (BUZAN; WÆVER; WILDE, 1998), tradução nossa.

156 "um ato de fala bem-sucedido é uma combinação de linguagem e sociedade, tanto das características intrínsecas da fala quanto do grupo que autoriza e reconhece que a fala" (BUZAN; WÆVER; WILDE, 1998), tradução nossa.

157 "Entre as condições internas de um ato de fala, o mais importante é seguir a forma de segurança, a gramática da segurança, e construir um enredo que inclui ameaça existencial, ponto de não retorno e
} 
Nesse sentido, o jogo de palavras pode implicar, para o processo de securitização, na construção de "speech acts" e retóricas com enfoque em ações distintas. Conforme aponta os estudos de Bendrath. "The basic question for security policy makers, since the debate over cyberthreats started, has always been: Are the most dangerous actors, terrorists, enemy states or just criminals? ${ }^{158}$ " (ERIKSSON; GIACOMELLO, 2007) . Em outros termos, os formuladores da segurança nacional digital indagam se precisarão lidar com "terrorismo", "guerra" ou somente "crimes" cibernéticos. A escolha de uma resposta para a indagação anterior pode resultar em ações contra o terrorismo digital, guerra digital ou somente contra um crime digital. Os discursos de securitização na segurança nacional tendem, portanto, a utilizar um referencial equivalente já pertencente à intersubjetividade coletiva para projetar as próximas percepções de risco como, por exemplo, terrorismo, guerra ou somente crimes comuns.

uma saída possível" (BUZAN; WÆVER; WILDE, 1998), tradução nossa

${ }^{158}$ A questão básica para os formuladores de política de segurança, desde o início do debate sobre as ameaças cibernéticas, sempre foi: os atores mais perigosos, os terroristas, os estados inimigos ou apenas os criminosos? (ERIKSSON; GIACOMELLO, 2007), tradução nossa. 



\section{Parte III}

A Política Cibernética dos Estados Unidos 



\section{Das Liberdades Civis à Vigilância Massiva}

Após o atentado de 11 de setembro de 2001, o medo de um novo ataque terrorista gerou uma onda de securitização, com a abertura de uma "janela de oportunidades" de reformas políticas e institucionais. Atribuiu-se às ameaças terroristas um risco existencial a toda a nação, sua população e infraestrutura. Essa percepção permitiu que fossem estabelecidas políticas de segurança nacional com poderes que excediam os já constituídos, haja vista a aprovação das leis USA PATRIOT ACT ${ }^{159}$, Terrorist Surveillance Act de 2006 e a Protect America Act em 2007. Os efeitos das ondas de securitização e de suas legislações fizeram-se sentir não somente na segurança física como, também, na digital. A explicação, de acordo com Bendrath et al. (2007) é que, "[..] though 9/11 was a brutally physical offline attack, images of cyberthreats were swept along with the general securitization of US policy and reform post-9/11" (ERIKSSON; GIACOMELLO, 2006).

The rapid proliferation and integration of telecommunications and com-
puter systems have connected infrastructures to one another in a com-
plex network of interdependence. This interlinkage has created a new
dimension of vulnerability, which, when combined with an emerging con-
stellation of threats, poses unprecedented national risk. (PRESIDENT'S
COMMISSION ON CRITICAL INFRASTRUCTURE PROTECTION,
1997)

Na concepção de Bendrath et al. (2007), as abordagens da 42 $2^{\text {a }}$ Presidência, ainda que tenham sido um resultado preliminar de um movimento de securitização, não representaram a securitização efetiva devido à ausência de medidas extraordinárias: "The Us government did talk the talk of securization, but they did not really walk the walk - not yet". (BENDRATH, ERIKSSON e GIACOMELLO, 2007). Sob a Presidência de George. W Bush, a pauta de políticas públicas e legislações consonantes com a intenção de Clinton em proteger à infraestrutura estadunidense foi impulsionada substancialmente. Desta vez, entretanto, seu objetivo principal não era somente a proteção de sua inata vulnerabilidade digital mas, também de possíveis atos de terrorismo. Na esfera legislativa, pela aprovação do PATRIOT ACT em 2001, foram introduzidos direitos de exceção, como uma legislação flexível para a invasão de privacidade e "Enhanced Surveillance Procedures" (TITLE II-USA PATRIOT Act - H.R. 3162). Em 2006 com a Terrorist Surveillance Act e em 2007, com Protect America Act foram concedidos direitos de interceptação de gravações de dados sem o consentimento judicial por parte do Estado. Na esfera das políticas públicas e integrada em seu esforço de combate ao terrorismo, George W. Bush lançou sua "National Strategy to Secure Cyberspace" (2003)- com uma visão para além da proteção da

$\overline{159}$ Acrônimo para "Uniting and Strengthering America by Providing Appropriate Tools Required to Intercept and Obstruct Terrorism Act of 2001" 
infraestrutura estadunidense: "While the attacks of September 11 were physical attacks, we are facing increasing threats from hostile adversaries in the realm of cyberspace as well". (NATIONAL STRATEGY TO SECURE CYBERSPACE, 2003).

Por intermédio das ondas de securitização, as medidas que ameaçavam as liberdades civis estadunidenses, inseridas pelo PATRIOT Act, Terrorist Surveillance Act e Protect America Act, se fortaleceram como requisito para a preservação da segurança nacional frente às ameaças terroristas. Conforme aponta Hughes: "As the mastermind of the attacks, Bin Laden's war on the west has been cited in post 9/11 rhetoric as justification for expanded surveillance powers in America, often at the expense of long recognized protections for civil liberties". (HUGHES, 2011). Bendrath pontua que Bush utilizou-se da agenda de securitização para facilitar a adoção de medidas extraordinárias para o espaço cibernético e, portanto, em contraste com a administração Clinton, "Now they meant serious business: they government both talked the talk, and walked the walk of securitization". (BENDRATH ET AL. 2007).

Enquanto fenômeno, a vigilância massiva difere-se substancialmente, em amplitude e impacto, da espionagem. A espionagem, figura milenar nas táticas militares, requer, além de investimentos altos, alvos específicos. Com custos inferiores, a vigilância massiva sequer determina alvos mas, sim, populações em sua amplitude - algo somente possível no atual momento histórico devido ao impacto da Tecnologia da Informação. Clarke denomina essa nova feição da vigilância massiva digital de "Mass Dataveillance" e define que, em um sentido amplo, "dataveillance is the systematic use of personal data systems in the investigation or monitoring of the actions or communications of one or more persons." (CLARKE, 1988, pp. 499). A inflexão histórica da mudança dos dois fenômenos ocorre justamente com a fusão dos propósitos políticos da vigilância com a capacidade de coleta, processamento e analise da Tecnologia da Informação. De acordo com Clarke,

\footnotetext{
Physical and even communications surveillance are labor-intensive activities, which have so far proved difficult to automate. Dataveillance is essentially computer based, with the "watch and report" responsibility delegated to a reliable, ever-wakeful servant. It is increasingly cost-effective for organizations to place people under surveillance via their records and transactions, and traditional methods are being relegated to the role of complementary techniques. Furthermore, because dataveillance is cheaper than traditional methods, there is a tendency for more organizations to monitor more people: Both personal and mass surveillance are becoming routinized
}

(CLARKE, 1988, pp. 499)

Inserida nessa conjuntura, a vigilância massiva, ao se viabilizar em sua feição digital, deixa de requerer volumosos investimentos mas, sim, a conjunção de alta tecnologia aliada ao ofuscamento de códigos e algoritmos que perpetram a "caixa preta" dos domínios cibernéticos. O que ambos os sistemas possuem em comum e qual o desdobramento 
político-sociológico do domínio cibernético? A metáfora da "caixa-preta" (PASQUALE, ) ou a ininteligibilidade da complexidade cibernética ao intelecto humano. Poucos possuem capacitação e acesso aos mecanismos de produção e controle dos domínios cibernéticos: Desta forma, conhecimento necessariamente constitui-se como uma ferramenta política do exercício do poder nos domínios cibernéticos. Apresenta-se o processador, subjugam-se os processos.

Na metáfora da "caixa-preta", a falta de transparência, "accountability" e governança dos domínios cibernéticos residem em silêncio conjuntamente com a exploração de vulnerabilidades, rotinas escusas, apropriação indébita de informações e formas de controle que permeiam a sociedade moderna de forma quase "inacessível", porém, impactante. Em termos práticos, apresentam-se como rotinas e algoritmos que, dentre outras funções, ora roubam silenciosamente informações privadas, ora permitem a invasão de controle de sistemas cibernéticos por completo. Nessa concepção, pode-se depreender que são, portanto, dois fenômenos que se sobrepõem: a vigilância massiva digital e o surgimento/domínio dos sistemas complexos cibernéticos. Para que se possa compreender o potencial do poder político e militar dessas assimetrias cibernéticas na defesa de liberdades civis é preciso, primeiro, fundir a Cibernética, a criptografia e seus impactos imediatos. A criptografia, última fronteira dos ambientes cibernéticos, é capaz de "esconder" em definitivo as informações do olhar e entendimento público ao indisponibilizá-las e ocultá-las em códigos cifrados e ininteligíveis. Enquanto que, por outro lado, torna tais informações acessíveis exclusivamente à inteligibilidade do ente privado àquele que detém as chaves criptográficas necessárias para se decifrar o conteúdo protegido. Seu domínio tecnológico por "codebreakers" ou "codemakers" (KAHIN; NESSON, 1997) concede o poder àquele que o detém, de se definir o que deverá permanecer nas esferas do privado ou tornar-se público.

De que forma o espaço cibernético tornou-se objeto e ferramenta do avanço do "Estado de Exceção" enquanto "Estado de Vigilância Permanente"? Em um ambiente virtualizado, como a Internet, o poder do domínio cibernético, apropriado por uma classe tecnocrática - "codebreakers/makers" - atuantes no Estado, transforma este em um ente capaz de defender as esferas privadas de sua soberania (ao cifrar e indisponibilizar suas informações ao estrangeiro), ou até mesmo fornecer o ambiente necessário para a proteção do "livre pensar", comunicar e agir sem coerções, interceptações ou julgo de qualquer natureza (ao conceber um ambiente cibernético seguro) (PETERSON, 1993; PETERSON, 1996; SUBRAMANIAN, 2008). De modo análogo, seu uso escuso (SWIRE, 2012) viabiliza o ataque a outros Estados e suas soberanias por intermédio de arsenais silenciosos e efetivos, da quebra de códigos criptografados e/ou exploração de vulnerabilidades. No nível do individuo, a quebra da privacidade digital, dantes protegida por códigos ininteligíveis, passa a constituir-se como tarefa fácil e corriqueira (Dataveillance) e resulta em um ambiente desfavorável ao desenvolvimento da personalidade, expondo-a a todas as sortes 
de discriminações, violações, coerções e julgamentos ex-ante de algoritmos e normas codificadas. Em ambos os níveis, o poder passa a ser exercido pelo código.

A aprovação das legislações de 'massive digital surveillance' não foi consensual e suas medidas de exceção levaram diversos setores da sociedade civil a se manifestarem contrariamente as suas táticas invasivas. Enquanto candidato a senador, Barack Obama demonstrou preocupação que o avanço das legislações de segurança cibernética colocasse em risco toda a estrutura legislativa de liberdades civis. Segundo Hughes (2011), "Barack Obama was still months away from being sworn in as the United States Senator from Illinois, but as a candidate, he was identifying the important balance that exists between intelligence gatherings and civil liberties". Posteriomente, enquanto senador, Obama (2004) indicou ainda que "often the issue of privacy vs. intelligence degenerated into an "either-or" type of debate framing the protection of American people against "cherished principles". A partir do paradigma da absoluta segurança nacional frente às ameaças digitais, a privacidade é invadida pela revelação de dados pessoais, monitoramento e quebra de sigilos outrora preservados. Como resultado de tais invasões, há a inibição do indivíduo frente à sua privacidade, impacto na capacidade de organização, manifestação política, autocensura, vergonha e dano a sua própria reputação. Portanto, o paradigma da segurança nacional, por intermédio das táticas de 'surveillance', impõe a coerção do indivíduo perante sua própria existência.

O discernimento entre a necessidade de proteção as liberdades civis e a necessidade de segurança nacional demonstrado por Obama, contudo, não se mostrou como impeditivo para sua a estratégia de domínio do espaço cibernético enquanto presidente. Barack Obama, em continuidade as estratégias de proteção da infraestrutura digital contra vulnerabilidades e terrorismo cibernético, estabeleceu a "Cyberspace Policy Review (2009)" como um novo pilar de sua Política Cibernética. O documento, estruturado em 5 capítulos, versa sobre a necessidade da Casa Branca se posicionar ativamente e liderar os movimentos de "segurança globais" no novo contexto digital internacional. Para tanto, a nova Política Cibernética estipulou estratégias que direcionam para: (a) uma liderança estabelecida pelo Executivo; (b) revalidação e atualização de leis e políticas públicas; (c) promoção e estímulo da percepção de risco sobre as ameaças digitais que recaem sobre a população; (d) estabelecimento e fortalecimento das parcerias público-privadas; e principalmente (e) o aprimoramento e extensão do compartilhamento e monitoramento de informações para todo o domínio cibernético.

Após a aprovação das leis já citadas, no governo Bush, e suas respectivas renovações no governo Obama, o Congresso ampliou os direitos e autorizou os orçamentos destinados à Agência de Segurança Nacional Estadunidense (NSA) para o monitoramento contínuo das informações que trafegam pela infraestrutura cibernética. Em matéria no jornal The Washington Post, averiguou-se que os Estados Unidos investiram U26.6 e U26,7 bilhões 
de dólares em 1997 e 1998 respectivamente. Na administração Obama de 2008 à 2012, o orçamento da U.S. Intelligence Community atingiu o patamar de 52 bilhões de dólares, investidos nas atividades de gerenciamento, coleta, processamento, exploração e análise de dados. Os valores e as informações sensíveis se mantiveram ocultos até então, censuradas ao público geral. O atentado de 11 de setembro completou 11 anos em 2012. Osama bin Laden foi capturado e executado pelas forças americanas no Paquistão em maio de 2011. Ainda assim, os movimentos de securitização continuaram a se institucionalizar e a movimentar as ações de proteção contra atos terroristas, tanto fisicamente, quanto digitalmente.

A NSA, como expoente do National Intelligence Program, lidera uma extensa comunidade de inteligência e 'surveillance', composta por um conglomerado de agências e organizações do Executivo que trabalham independentemente e colaborativamente na construção da burocracia e arquitetura político-normativa-cibernética que compõem a The U.S. Intelligence Community (IC). Nos capítulos e seções a seguir serão apresentados os momentos históricos que circundam a criação da NSA, as tenções e conflitos que debates sobre a criptografia trouxeram, bem como a forma de atuação da agência à partir das dinâmicas reveladas pós-Edward Snowden. Após o Estudo de Caso, a pesquisa prosseguira com as conclusões e resultados observados. 



\section{Crypto Wars}

\subsection{O Monopólio Estatal da Criptografia}

O avanço das tecnologias da informação durante a Guerra Fria foi marcadamente reconhecido por duas forças principais de cunho tecnológico; a corrida militar e espacial entre as grandes potências mundiais da época. Pela crescente tecnológica, os Estados Unidos destinam partes de seus recursos para construir um vasto aparato de inteligência e espionagem capaz de estudar os soviéticos e o avanço do comunismo no cenário internacional. A NSA, criada pelo então presidente Truman em 1952, ficaria à cargo, a priori, como expoente máximo da conjunção de tecnologia militar, criptografia e espionagem nos Estados Unidos. Nesse contexto, a espionagem passou a ser fortalecida como forma objetiva e direta de obtenção de informações privilegiadas - tornava-se uma vantagem competitiva no cenário geopolítico. Para essa passagem histórica, o então Presidente dos Estados Unidos, Barack Obama (2014), proferiu em seu discuso "Remarks by the President on Review of Signals Intelligence- disponível integralmente no Anexo 1 - a seguinte consideração:

In World War II, code-breakers gave us insights into Japanese war plans, and when Patton marched across Europe, intercepted communications helped save the lives of his troops. After the war, the rise of the Iron Curtain and nuclear weapons only increased the need for sustained intelligence gathering. And so, in the early days of the Cold War, President Truman created the National Security Agency, or NSA, to give us insights into the Soviet bloc, and provide our leaders with information they needed to confront aggression and avert catastrophe. ${ }^{160}$ (OBAMA, 2014).

O desenvolvimento tecnológico de espionagem como estratégia de ataque requeria o domínio da criptografia como fortalecimento da defesa nacional. Schwartzbeck (2014, p.21) aponta que os EUA, cientes do valor e da importância da criptografia, investiram estrategicamente nesta seara há mais tempo que os outros Estados. A hegemonia dos EUA nesta temática se manteve durante as duas primeiras guerras mundiais e somente se viu ameaçada com a exponencial exposição de dados e popularização do acesso à tecnologia fomentadas pela Era da Informação. O monopólio desse tipo de pesquisa e o direito estadunidense de controle da criptografia foi, desde então, paulatinamente colocado em pauta por setores da academia, do mercado e da sociedade organizada em prol da liberdade

160 "Na Segunda Guerra Mundial, os decifradores de código nos deram insights sobre os planos de guerra japoneses e, quando Patton marchou pela Europa, as comunicações interceptadas ajudaram a salvar as vidas de suas tropas. Depois da guerra, a ascensão da Cortina de Ferro e das armas nucleares só aumentou a necessidade de coleta de informações sustentadas. E assim, nos primeiros dias da Guerra Fria, o Presidente Truman criou a Agência de Segurança Nacional, ou NSA, para nos dar informações sobre o bloco soviético e fornecer aos nossos líderes as informações necessárias para enfrentar a agressão e evitar a catástrofe" (OBAMA, 2014), tradução nossa. 
de expressão e da democratização do acesso e da produção da criptografia. Para o autor, no seu artigo publicado internamente e classificado como "top secret"pela CIA, o governo dos EUA foi seriamente prejudicado pela discussão:

For decades, the US Government has monopolized encryption and decryption efforts, capabilities, and research. In recent years, however, the information revolution has begun to challenge this monopoly with some success. In rhe last year, several academic, commercial, and free speech advocates have seriously jeopardized the US Government's legal right to control encryption. ${ }^{161}$ (SCHWARTZBECK, 2014, p.21)

As estratégias de dominação do tema promovidas ao longo da história pelos governos dos EUA, conforme Scwartzbeck (2014) evidenciou, contemplavam mecanismos de dominação da discussão pública sobre criptografia. Assinado pelo presidente Truman em 1952, um memorando garantiu à Agência Nacional de Segurança (NSA) o domínio das funções criptológicas nacionais e, consequentemente, sua proteção e promoção, de forma que o debate acontecesse sob o controle e primazia da agência. Segundo Schwartzbeck (2014, p.23), esse esforço da NSA de controlar a agenda de debates públicos acerca da criptografia se deu por meio de organizações como o Conselho Consultivo Científico da Agência Nacional de Segurança (NSASAB), que englobava laboratórios de pesquisa corporativas e educacionais, com o intuito de atrair os pensadores, matemáticos e criptoanalistas mais brilhantes dos Estados Unidos - tanto nas ciências em geral, como, especificamente, aqueles que poderiam agregar ao campo científico da criptologia fomentado pela NSA. Com essa estratégica, a agência poderia, então, proceder com a classificação dos trabalhos destes cientistas e removê-los do acesso e disponibilidade públicos e, principalmente, dos olhos estrangeiros.

Um fato que Schwartzbeck (2014, p.23) se utiliza para exemplificar que o monopólio sobre a criptologia dos EUA começava a rui, foi o caso ocorrido com o Algoritmo criptográfico chamado "Lúcifer". Segundo o autor, na figura de seu presidente Thomas Watson Jr., a IBM investiu em grupos de pesquisa em criptologia para uso em um sistema de distribuição de dinheiro que a empresa vinha desenvolvendo. Com a ajuda de um engenheiro elétrico alemão com doutorado na Universidade da Pensilvânia, Carl Meyer, a IBM desenvolveu uma chave de 128 bits que, na época, foi considerada inquebrável até mesmo pela NSA - o que forçou a entidade à investir na readequação das suas capacidades de descriptografar. Desta forma, o governo buscava demonstrar que a criptografia "forte"ainda estava sob seus domínios e não disponível para uso do setor público.

\footnotetext{
161 "Por décadas, o governo dos EUA monopolizou os esforços, as capacidades e a pesquisa de criptografia e descriptografia. Nos últimos anos, no entanto, a revolução da informação começou a desafiar esse monopólio com algum sucesso. No ano passado, vários defensores acadêmicos, comerciais e de liberdade de expressão prejudicaram seriamente o direito legal do governo dos EUA de controlar a criptografia." (SCHWARTZBECK, 2014, p.21), tradução nossa.
} 
Por outro lado, segundo Schwartzbeck (2014, p.23), a NSA teve seu contrato com a IBM, para aquisição da tecnologia e da chave criptográfica, divulgado e muitos pesquisadores, cientes que seu trabalho poderia cair sob os domínios da NSA, insurgiramse em protestos. Os protestos envolveram grupos públicos de pesquisa criptográfica em resposta aos centros educacionais e corporativos que passavam, então, à cooperar com a agência.

Essa forma de atuação se deu até o final da década de 1980, com a crescente revolução da Tecnologia da Informação que tomou forma com a popularização das telecomunicações, computadores pessoais e o avanço dos processos de globalização - processo que refletiram na percepção pública sobre a necessidade de mudança das políticas criptográficas do governo, que passou a ter maior interesse em aplicá-las no combate ao narcotráfico, terrorismo, crimes transnacionais e questões econômicas de interesse do Estado.Adicionalmente, uma série de mudanças começaram a ocorrer, dentre elas, a percepção pela sociedade de que os computadores impactavam diretamente no exercício de seus direitos e liberdades fundamentais:

Computers are now viewed as contributing significantly to the expansion of personal freedoms such as free speech. Many see encryption as a critically important method of protecting personal privacy on computer networks. Many also use computer networks extensively for their private business and personal communications needs. ${ }^{162}$ (SCHWARTZBECK, 2014, p.23)

Para Schwartzbeck (2014, p.23), a criptografia precisaria se proliferar, sobretudo para fins não governamentais, porém, o governo dos Estados Unidos não poderia perder o controle e o acesso necessário para atender aos seus objetivos, dentre eles, questões de segurança nacional. Deste modo, as mudanças de paradigmas sociais, que concedeu ao mercado o domínio sobre a criptografia forte, provocaram reações de criptoanalistas públicos e governamentais (funcionários do governo) na direção de retomar o monopólio sobre a criptografia para o governo novamente. Segundo Schwartzbeck (2014, p.23), o governo Clinton tentou obter novamente o monopólio em sua primeira tentativa em abril de 1993 com o "Clipper Chip".

\subsection{Clipper Chip}

Segundo Schwartzbeck (2014), com a introdução do Clipper Chip pelo Governo Clinton, grupos de privacidade viram nesta ação do governo uma trama orwelliana (nas

\footnotetext{
162 "Os computadores agora são vistos como contribuindo significativamente para a expansão das liberdades pessoais, como a liberdade de expressão. Muitos veem a criptografia como um método criticamente importante de proteger a privacidade pessoal em redes de computadores. Muitos também usam extensivamente as redes de computadores para suas necessidades particulares de negócios e comunicações pessoais" (SCHWARTZBECK, 2014, p.23), tradução nossa.
} 
palavras do autor, "again, NSA was portrayed as 'Big Brother'".), e a AT\&T acabou por ser a única grande corporação de telecomunicações a se inscrever para o chip - e desistiu quando a direção descobriu ser um tremendo erro para a opinião pública. O Clipper Chip, contudo, chegou a ser fabricado e distribuído em algumas versões, conforme as imagens 8 e 9 revelam:

Figura 8 - Clipper Chip

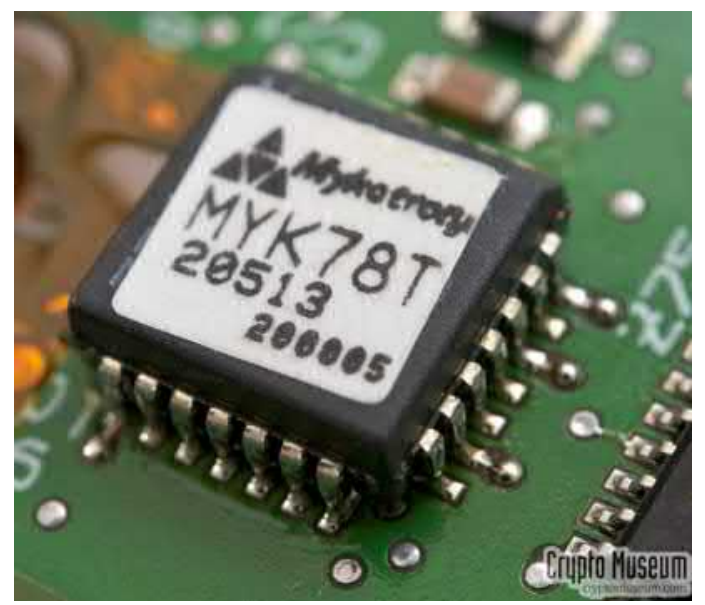

Fonte: Imagem compilada à partir do acervo do Crypto Museum (2018a)
Figura 9 - Clipper Chip 2

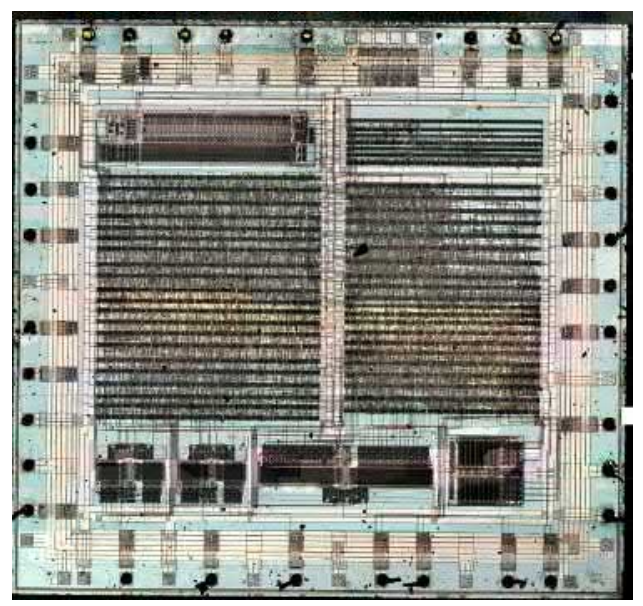

Fonte:Imagem compilada à partir do acervo do Crypto Museum (2018a)

Entretanto, segundo Dam e Lin (1996, p. VI), a Casa Branca teve pela iniciativa do Clipper Chip, "an honest attempt to address some of the issues underlying national cryptography policy, but one of its primary effects was to polarize rather than bring together the various stakeholders, both public and private" 163 , mas que de alguma forma contribuiu para aumentar a consciência pública sobre o assunto. Em seu anúncio oficial, disponível em inteiro teor no Anexo 2, a Casa Branca, pelo governo Clinton, anunciava os propósitos de proteção da segurança nacional pelo Clipper Chip.

The President today announced a new initiative that will bring the Federal Government together with industry in a voluntary program to improve the security and privacy of telephone communications while meeting the legitimate needs of law enforcement. Sophisticated encryption technology has been used for years to protect electronic funds transfer. It is now being used to protect electronic mail and computer files. While encryption technology can help Americans protect business secrets and the unauthorized release of personal information, it also can be used by terrorists, drug dealers, and other criminals. ${ }^{164}$ (The White House - Office of the Press Secretary, 1993).

163 "uma tentativa honesta de abordar algumas das questões subjacentes à política nacional de criptografia, mas um dos seus principais efeitos foi polarizar, em vez de reunir as várias partes interessadas, tanto públicas como privadas" (SCHWARTZBECK, 2014, p.23), tradução nossa.

164 "O Presidente anunciou hoje uma nova iniciativa que reunirá o Governo Federal com a indústria em um programa voluntário para melhorar a segurança ea privacidade das comunicações telefônicas, atendendo às legítimas necessidades de aplicação da lei. A sofisticada tecnologia de criptografia tem sido usada há 
Barlow (1994-04-01), por sua vez, compreende que o Clipper Chip foi uma das tentativas dos Estados Unidos de estabelecer o "controle imperial sobre o ciberespaço". Conforme apontado por Schwartzbeck (2014) anteriormente, os objetivos declarados dos Estados Unidos no controle da criptografia forte visavam evitar crimes e ataques terroristas Barlow (1994-04-01) argumenta que de fato o governo estadunidense não estava preocupado com o futuro da liberdade e da prosperidade americana pois, em primeira instância, o governo Clinton visava evitar um ataque terrorista ao World Trade Center:

However they reached it, Clinton and Gore have an astonishingly simple bottom line, to which even the future of American liberty and prosperity is secondary: They believe that it is their responsibility to eliminate, by whatever means, the possibility that some terrorist might get a nuke and use it on, say, the World Trade Center. They have been convinced that such plots are more likely to ripen to hideous fruition behind a shield of encryption.(BARLOW, 1994-04-01)

O artigo de Barrow, denominado "Jackboots on the Infobahn"havia sido escrito em 1994 na revista Wired. O atentado terrorista contra as torres gêmeas ocorreu em 11 de setembro de 2001, sete anos depois do artigo de Barrow. Ainda naquele momento, a lógica do governo Clinton, para Barlow (1994-04-01) não se sustentava, pois um "qualquer um inteligente o bastante para roubar um dispositivo nuclear é provavelmente esperto o suficiente para usar o PGP ou algum outro padrão de criptografia não comprometido" (BARLOW, 1994-04-01). Barlow (1994-04-01) destaca ainda que outros atentados que correram até então contra o World Trade Center foram efetivados sem utilização de qualquer tipo criptografia e sob a vigilância do próprio FBI.

O momento ficou compreendido como Cripto Wars, como forma de expressar os embates travados pelo Governo dos Estados Unidos pelo controle da criptografia - com direito à propagandas de setores empresariais, como a empresa de criptografia RSA e seu ataque ao monopólio estatal da criptografia, expressa pela imagem 7.2, que ficou conhecida como a campanha "Sink Clipper"da RSA Security.

anos para proteger a transferência eletrônica de fundos. Agora está sendo usado para proteger correio eletrônico e arquivos de computador. Embora a tecnologia de criptografia possa ajudar os americanos a proteger os segredos comerciais e a divulgação não autorizada de informações pessoais, ela também pode ser usada por terroristas, traficantes de drogas e outros criminosos" (The White House - Office of the Press Secretary, 1993), tradução nossa. 
Figura 10 - Campanha Sink Clipper da RSA Security contra o chip Clipper, como parte do momento compreendido como Crypto Wars.

On April 16, 1993, the New York Times broke the story of the Clipper Chip, an encryption technology developed by the National Security ilgensy that allows government to eavesdrop on

the communications of criminals, suspegts, and unfortumaryly, lawrabiding citizens allike.

On February 9, 1994, the U.S. Department of Commures and Vice President of the United States summarily announced that the Clipper Chip is the U.S. Government standard, and that the Govemment will do everything in its power to encourage its use in the private sector and the international community.

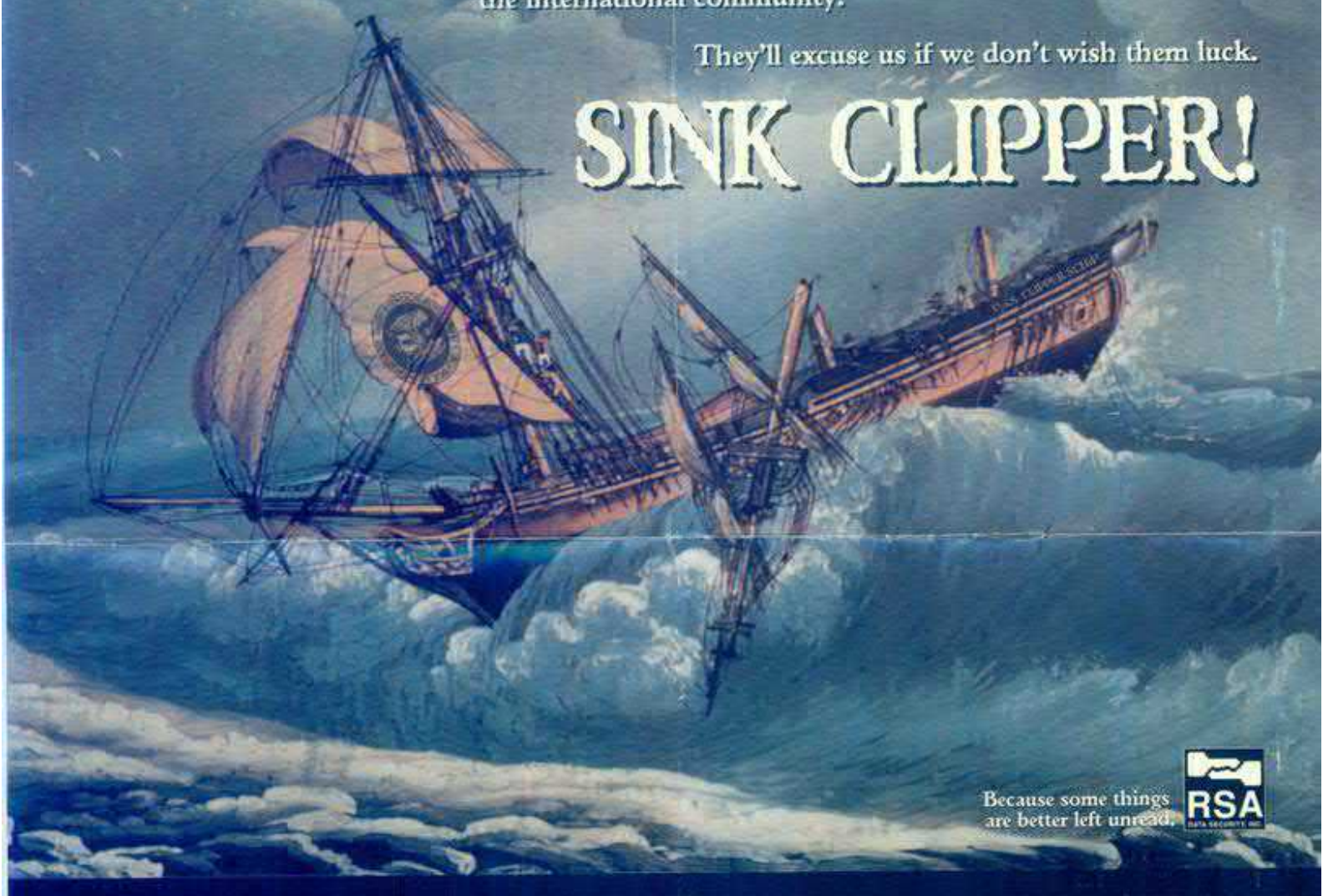

What you can do...

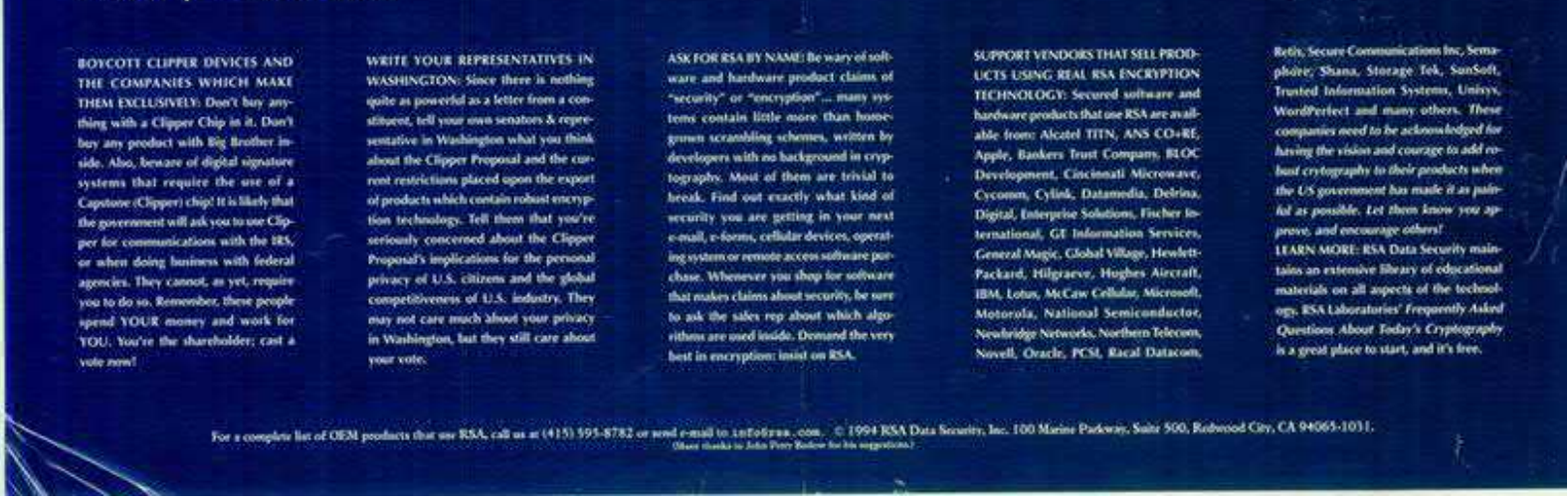

O encarte divulgado pela RSA traz a seguinte mensagem, traduzida livremente como: "Em 16 de abril de 1993, o New York Times divulgou a história do Clipper Chip, uma tecnologia de criptografia desenvolvida pela National Security Agency que permite que o governo escute as comunicações de criminosos, suspeitos e, infelizmente, cidadãos cumpridores da lei. Em 9 de fevereiro de 1994, o Departamento de Comércio dos EUA e o Vice-Presidente dos Estados Unidos anunciaram sumariamente que o Clipper Chip é o padrão do governo dos EUA e que o governo fará tudo o que estiver ao seu alcance para incentivar seu uso no setor privado e comunidade internacional. Eles que nos desculpem se não lhes desejarmos sorte. Afunde Clipper!- Fonte: Green (2019) 


\subsection{Criptografia como liberdade de expressão: o caso do Pretty Good Privacy (PGP)}

De acordo com os registros de Stay (1997, p. 581), o Pretty Good Privacy (PGP), foi lançado em 1991, e foi um marco no desenvolvimento da criptografia pública. Criado por Philip Zimmermann, o PGP surgiu como uma discordância de Zimmermann contra o deposito de chaves do governo, e baseado no algoritmo da RSA construiu seu próprio padrão público de criptografia de distribuição gratuita. O algoritmo criado por Ron Rivest, Adi Shamir e Len Adelman (RSA), segundo Stay (1997, p. 581) "combines the security of public-key cryptography with 'digital signatures', which allows the sender of a message to add an encrypted electronic 'signature' that is unforgeable"165 (STAY, 1997, p. 581).

Deste modo o PGP permitiu acesso a criptografia de nível militar ao público em geral, segundo (STAY, 1997, p. 581), até mesmo os computadores ultrasecretos da NSA não podiam decifrar as mensagens criptografadas pelo PGP. Com isso, uma ampla variedade de pessoas enxergou no PGP e seu código inquebrável uma ferramenta importantíssima para realização de seus trabalhos, não apenas para profissionais defensores dos direitos humanos, jornalistas e suas fontes como, também, segundo (STAY, 1997, p. 581), criminosos e seus de registros de transação de drogas.

Assim, o PGP se tornou rapidamente "o padrão mundial" de fato para criptografia de e-mail, segundo Stay (1997) - como incremento, programadores voluntários fizeram melhorias no programa original e o traduziram para que pudessem trabalhar com muitos sistemas de operacionais diferentes. Esse amplo destaque mundial de Zimmermann chamou atenção do governo dos EUA, que começou a interessar-se seriamente por figura de Phil Zimmermann:

At the airport, a Customs Special Agent diverted Zimmermann from the normal customs process and subjected him to an individualized luggage search and a lengthy interrogation regarding Zimmerman's possible illegal exportation of dangerous munitions. What was the dangerous "weapon" which interested the U.S. Government so much that it would individually interrogate a U.S. citizen? It was computer software ${ }^{166}$. (STAY, 1997, p. 581)

Garfinkel (1995) conta que Zimmermann se tornou uma espécie de criptólogo "fora da lei" enquanto que o PGP despertava paixões, transformando-o em ativista da Paz e

\footnotetext{
165 "combina a segurança da criptografia de chave pública com as "assinaturas digitais", que permite ao remetente de uma mensagem adicionar uma "assinatura"eletrônica criptografada que é inválida" (STAY, 1997, p. 581)

166 "No aeroporto, um agente especial da alfândega desviava Zimmermann do processo normal de alfândega e submetia-o a uma busca individualizada de malas e a um longo interrogatório sobre a possível exportação ilegal de munições perigosas por Zimmerman. Qual foi a "arma" perigosa que interessou tanto o governo dos EUA, que interrogaria individualmente um cidadão dos EUA? Era um software de computador" (STAY, 1997, p. 581), tradução nossa.
} 
porta-voz do movimento Cypherpunk. Assim, o PGP se tornou mais que um software de criptografia - ao atingir a luta pela criptografia e privacidade e a luta pelas patentes de software, ele virou um manifesto de uma comunidade de cientistas e ativistas pelos direitos e liberdades. Segundo Garfinkel (1995, p. 101), em 1992, um grupo do que ele chamou de cripto-rebeldes, organizou-se num coletivo que fora nomeado de "Cypherpunks" que, por sua vez, tinham por missão garantir liberdade de expressão, comunicações anônimas e outros benefícios da criptografia para todo o mundo:

In the fall of 1992, a group of crypto-rebels was forming. Calling themselves "Cypherpunks," the group organized itself loosely around the principle that the technologies of freedom strong cryptography, anonymous communications, and electronic signatures should be made available throughout the world. (GARFINKEL, 1995, p. 101)

Fundado por Tim May e Eric Hughes, o grupo Cypherpunk montou uma lista de discussão eletrônica em um site de FTP na Universidade da Califórnia, conforme narra Garfinkel (1995). Uma semana após o lançamento do PGP versão 2.0, ocorreu o primeiro encontro do grupo em Oakland, no qual foram distribuídos disquetes do programa, momento no qual o grupo aproveitou para analisar o material e encontrar problemas fundamentais, como o uso da patente da RSA sem licença, por exemplo. Para Garfinkel (1995) o PGP não era um verdadeiro movimento de guerrilha, dado que Phil Zimmermann não havia adotado a clandestinidade em suas ações e continuou a levar uma vida pública intensa, pois participava de conferências e falava sempre sobre a relevância que a criptografia possui nas dinâmicas livres de uma sociedade democrática. Por esse motivo, segundo Garfinkel (1995), Zimmermann se tornara um alvo fácil para o governo dos EUA, principalmente quando o PGP começou a aparecer no exterior. A perseguição sofrida por Zimmermann veio para demonstrar que as leis de controle de exportação de fato possuíam força e, mais do que isso, que o monopólio da criptografia deveria continuar nas mãos do Estado. 


\section{A National Security Agency}

\subsection{A National Security Agency e a Coleta Massiva de Dados}

É Setembro de 2002, um grande volume de trabalhadores agitam o cotidiano árido da cidade de Bluffdale. Com estranheza, a população local observa a chegada dos forasteiros que vieram escovar bits e bytes nas terras arenosas de Utah. A mensagem de boas-vindas do prédio principal não poderia ser mais convidativa para a população local e seus visitantes: Se você não tem nada à esconder, você não tem nada a temer ${ }^{167}$. A construção foi publicamente divulgada quando a reportagem "The NSA Is Building the Country's Biggest Spy Center (Watch What You Say)"de BAMFORD foi publicada revista Wired, em março de $2002^{168}$.

Utilizada pela NSA em diversos momentos, o mote do datacenter indicaria de antemão seu principal objetivo: como peça fundamental do programa de vigilância massiva, foi projetado para capturar, armazenar e analisar todas as informações da internet para quebrar suas proteções criptográficas hoje ou num futuro distante. O "repositório de dados maciço"de Utah acompanhou o crescimento exponencial do tráfego de dados pela internet e foi projetado para acompanhar sua expansão. A obra de mais de U\$ 2 bilhões de dólares e de magnitude 5 vezes maior do que o próprio capitólio americano, seria considerada como o maior datacenter (centro de dados) já construído, aquele que em sua ambição armazenaria informações em escalas jamais vistas até então, os yottabytes, o equivalente a 10 elevado à $24^{\mathrm{a}}$ potência de informações.

Após sua conclusão em 2013, o Centro de Dados de Utah, apelidado de Bumblehive, seria somado às capacidades da comunidade de Inteligência dos Estados com um aporte massivo de poder computacional e de armazenagem de dados. Sua atuação fornece suporte ao programa Prism ${ }^{169}$ para vigilância doméstica e internacional, criado e liderado pela própria NSA.

A coleta de dados pode abranger um escopo de vária de informações ordinárias e simples do cotidiano como informações precisamente sensíveis e críticas, tais como pesquisas na internet, sites visitados, e-mails enviados e recebidos, atividade de mídia social (Facebook, Twitter, etc), atividade de blogs, incluindo postagens lidas, escritos e comentados, vídeos assistidos e / ou enviados on-line, fotos visualizadas e / ou enviadas on-

\footnotetext{
${ }^{167}$ Em sua versão original, "If you have nothing to hide, you have nothing to fear" 168 (BAMFORD, 2012-03-15)

${ }^{169}$ Prism é o programa principal da agência para coleta massiva de informações e que alimenta boa parte da Comunidade de Inteligência dos EUA, considerado a fonte de informações principal de dados coletados de provedores de internet dos EUA.
} 
line, dados de localização GPS do telefone celular, aplicativos de celular baixados, registros de chamadas telefônicas - Veja nossa patente, mensagens de texto enviadas e recebidas, Vídeo chamadas do Skype, compras on-line e transações de leilão, transações com cartão de crédito / cartão de débito, informação financeira, documentos legais, documentos de viagem, registros de saúde, programas de TV a cabo assistidos e gravados, registros de pedágios, passagens eletrônicas de ônibus e metrô /Smartpasses, dados de reconhecimento facial de câmeras de vigilância, registros educacionais, registros de prisão, informação de licença de motorista e DNA.

Ainda que os dados não sejam de uso prático e imediato, a técnica utilizada não é apenas para identificar ações concretas; os dados coletados servirão para que num futuro próximo ou até mesmo distante, relações causais sejam traças e padrões e tendências de possíveis ameaças sejam identificados. As técnicas em questão não são diferentes das utilizadas pelo mercado corporativo e são reconhecidas como "data mining" e suas variantes; "data analytics", "data warehouse"... dentre tantas outras. Em questão, está a adoção cada vez mais complexa de se combinar dados e conectar pontos de modo que possam expressar valor em informações sobre potenciais ameaças.

Por que a agência coleta os dados irrestritamente? Os paralelos com a ficção científica tornam as próprias obras obsoletas quando comparadas com as capacidades desenvolvidas em torno das ciências de dados e sua utilização para fins estatais, no caso, de vigilância massiva de cidadãos. Obras de ficção, como Minority Report, lançado em 2002, trazem a tendência de se prever crimes com base em capacidades preditivas de comportamento, personalidade e estilo de vida. Afinal, não seria um valor para a sociedade caso seja possível poder prever um crime e mitigar suas causas antes que se concretizem? Não seria possível prever atentados terrorista, como os de 11 de setembro de 2001? É exatamente o que a NSA se perguntou para fundamentar seus programas de coletas massivas de dados.

Para identificar e determinar o que é um alvo é preciso apenas conectar os pontos com os dados coletados. Os algoritmos cuidam e julgam de classificar de acordo com os parâmetros configurados quais tipos de atividades podem ser consideradas suspeitas e qual a conjunção de atividades pode levar a classificar um indivíduo como um criminoso em potencial. As diversas técnicas de mineração de dados, somadas ao fácil acesso às fontes de inteligência, tornaram possível a adoção de táticas de profiling (construção de perfis) e análise preditiva. Assim como ocorreu com o fomento e nascimento da criptografia contemporânea, a NSA tem adotado e impulsionado tais metodologias na espionagem massiva.

O Arsenal da Vigilância Massiva: Como seus dados se transformam em dados da NSA Com o desenvolvimento da Tecnologia da Informação e suas dinâmicas correlatas, a crescente complexidade criptografia e a democratização da internet, tornou-se obsoleta o 
modus operandi da espionagem até então. O futuro da Comunidade de Inteligência dos Estados Unidos dependeria não somente da adaptação à esse novo cenário tecnológico e disruptivo, como deveria também ir além, explorar e liderar os avanços tecno-científicos até então. Ciente desse desafio, em dezembro de 2000, a NSA lançou internamente o documento "Transition 2001" como um manifesto que os novos cenários tecnológicos demandariam uma completa reformulação da atuação da agência, cuja transformação passaria pela constatação de que "To perform both its offensive and defensive missions, NSA must live on the network. (National Security Agency, 2000). O ponto de transformação marca a entrada na NSA na era da Tecnologia da Informação:

Now, communications are mostly digital, carry billions of bits of data, and contain voice, data and multimedia. They are dynamically routed, globally networked and pass over traditional communications means such as microwave or satellite less and less. Today, there are fiber optic and high-speed wire-line networks and most importantly, an emerging wireless environment that includes cellular phones, Personal Digital Assistants and computers. Encryption is commercially available, growing in sophistication, and packaged in off-the-shelf computer software. The volumes and routing of data make finding and processing nuggets of intelligence information more difficult. To perform both its offensive and defensive missions, NSA must "live on the network." (National Security Agency, 2000, p. 37)

Dois fatores distinguem-se e saltam aos olhos do leitor quando deparado como o documento em questão: (1) O primeiro passa pela constatação realizada pela NSA que expressa claramente a compreensão do desafio e necessidade de transformação da agência frente às mudanças tecnológicas e o (2) segundo deriva do reconhecimento, presente em todo o documento, do caráter político que a Tecnologia da Informação projetaria nessa nova era de atuação da agência. Em sua visão de mundo, como primeiro fator observado, a atuação da NSA deveria tirar proveito da vertiginosamente crescente presença da Tecnologia da Informação e da explosão de informações digitais que dela adveio; em grande medida, essa compreensão tornou-se um divisor de águas para atividades herdadas de um mundo analógico da Guerra-Fria para a intrincada rede que se formava: a internet.

Como segundo fator, há a plena associação do posicionamento da necessidade de se viver na rede como um direcionamento claramente político: tanto no sentido pragmático, institucional, de Política Externa e manutenção da Hegemonia, como em tantos outras leituras da Ciência Política. A presença da NSA garantiu importantes vitórias à Política Externa dos Estados Unidos, principalmente no período da Segunda Guerra Mundial e manter a relevância e participação da agência na Política Externa dos EUA nos novos cenários da tecnologia da informação constitui-se como objetivo primeiro e altamente crítico. Confiar no legado e apostar em sua capacidade de modernização tornaram-se, então, duas dinâmicas para guiar a NSA nesse novo caminho, corroborado por sua própria visão de que "NSA has been the premier information agency of the industrial age, and, 
through ongoing modernization and cutting edge research, will continue to be the premiere knowledge agency of the information age"(National Security Agency, 2000, p. 2).

Por sua vez, adicionalmente ao segundo fato, o capítulo intitulado "Major Policy Issues National Security Agency: Relevance of Existing Authorities In the Information Age" expressa claramente o inseparável caráter político da tecnologia como um todo necessário para a atuação dos Estados Unidos e, em especial, a tecnologia da informação enquanto forma e meio habilitador-mantenedor de sua projeção hegemônica internacional: "It also demands a policy recognition that NSA will be a legal but also a powerful and permanent presence on a global telecommunications infrastructure where protected American communications and targeted adversary communications will coexist"(National Security Agency, 2000, p. 31). Estar presente na Internet tornou-se mais do que premente para "garantir a segurança" dos cidadãos dos EUA e monitorar alvos de comunicação estrangeira, tornou-se crucial para a hegemonia norte americana, pois em seu núcleo, a transformação da NSA "firmly establishes SIGINT and Information Assurance as major contributors in ensuring information superiority of U.S. warfighters and policymakers." (National Security Agency, 2000, p. 2).

Marcadamente, não se tratava somente da capacidade de estar presente na nova rede, interceptar e explorar a comunicação alheia: era preciso controlar a própria tecnologia e, nesse sentido, desenvolver e empreender políticas públicas para liderar e controlar o desenvolvimento das capacidades de Segurança da Informação conjuntamente com a necessidade de se prover Inteligência. A Segurança da Informação com a capacidade de se gerar Inteligência é compreendida como forma indissociável da missão da NSA, visto que "Intelligence gives the nation an information advantage over its adversaries. Information systems security prevents others from gaining advantage over the nation. P2 O objetivo, novamente, passa pela necessidade politico-hegemônica de que "Together the two functions promote a single goal: information superiority for America and its allies" "(National Security Agency, 2000, p. 2).

Os recursos necessários para a transformação da NSA em uma agência atuante na Era da Tecnologia da Informação não seriam obtidos tão facilmente sem uma janela de oportunidades que colocassem sua relevância em eminência. Em 11 de setembro de 2011, os atentados terroristas colocaram em pânico os cidadãos norte-americanos e desencadearam uma série de ações que direcionariam o foco das atenções para a Guerra ao Terror e seu principal instrumento, a Inteligência. Como parte dos esforços mitigatórios, o Governo de George W. Bush autorizou em a Agência Nacional de Segurança a atuar ativamente na prevenção de futuros ataques à nação - para tanto, instituiu-se o "Programa de Vigilância do Presidente"(PSP), que permitia diversas ações extrajudiciais ou sem a necessidade de se obter uma autorização da Corte FISA, para a condução de atividades de vigilância massiva. 
Devido ao caráter de exceção do programa, ele deveria ser re-autorizado pelo governo à cada 45 dias. O Programa de Vigilância do Presidente incluía as seguintes instituições, além da NSA: Department of Justice, Department of Defense, Central Intelligence Agency e Office of the Director of National Intelligence. Em 10 de julho de 2009, foi publicado o primeiro relatório com uma revisão profunda da atuação do programa, em decorrência de emendas realizadas em 2008 à Foreign Intelligence Surveillance Act Amendments Act. Duas versões do relatório foram geradas, a aberta ao público, de aproximadamente 43 páginas, e a de cunho confidencial, com 746 páginas com censuras e segredos de Estado diversos.

O Programa de Vigilância do Presidente marcou o Estado de Vigilância massiva e irrestrita que se formou após o atentado terrorista de 11 de setembro. Com a sua instauração, todos os indivíduos do mundo, independentemente de nacionalidade, inclusive os cidadãos americanos, estavam sob o olhar e monitoramento constante da NSA. Sua estrutura foi composta pelos programas OAKSTAR, STORMBREW, Trailblazer, Turbulence, Genoa II, Total Information Awareness e o próprio "President's Surveillance Program".

Na Guerra ao Terror, a coleta massiva de dados em escalas internacionais dependia diretamente de tecnologias complexas desenvolvidas para lidar com escalas industriais de coleta, processamento e análise de dados dos meios de comunicação globais. Diversos programas, projetos, aplicações e iniciativas foram então arquitetadas de modo a interceptar todos os meios e pontas possíveis entre canais de comunicação e transmissão de dados. Dentre esses programas, destacam-se inicialmente o FAIRVIEW e STORMBREW, divulgados internamente por comunicados aos funcionários da agência. Os programas alinham-se na estratégia de aprofundar a atuação da NSA na internet e transformar seu meio de coleta de DNI (Digital Network Intelligence) e produção de Inteligência que, em sua terminologia, FAIRVIEW e STORMBREW estariam "producing SIGINT successes by "living on the global intelligent network".

Como o FAIRVIEW e STORMBREW se traduzem na prática atual da tecnologia da informação? A coleta passa a interceptar, por exemplo, os e-mails compartilhados entre indivíduos, classifica-los e filtrá-los de acordo com palavras-chave de dicionários e estruturas semânticas que indicam uma potencial conversa entre públicos alvos da agência. Essa abordagem é corroborada pelo próprio comunicado que explica que o volume de dados processados pelo FAIRVIEW, por exemplo, é extremamente volumoso e, no que tange a produção de e-mails, o programa em sua fase inicial conseguiu processar mais de um milhão de e-mails por dia para o sistema de seleção de palavras-chave da NSA. STOMRBREW e FAIRVIEW compõem, nesse interim, os dois primeiros grandes esforços para colocar em prática a estratégia de "viver na rede" da agência e de seu programa de transformação digital impulsionado pelos investimentos advindos da Política de Guerra ao Terror. 
[...] STORMBREW has a complementary large-scale DNI collection effort (covername PERFECTSTORM) that is just about ready for prime time. As the large-scale effort was being developed, STORMBREW deployed several QRC (Quick Reaction Capability) collection systems that have yielded critical intelligence supporting the Global War on Terrorism. STORMBREW engineers then worked with FAIRVIEW engineers to transfer this collection architecture to FAIRVIEW.[...]. In addition, STORMBREW and FAIRVIEW personnel worked side-by-side with CES personnel to add Voice over IP processing capabilities to both of these accesses to further exploit the targets' communications. (National Security Agency, 2003)

Nesse sentido, sua relevância reside justamente na exposição da forma altamente tecnológica, interconectada e orientada aos dados digitais necessárias para a estruturação de programas de vigilância massiva. Adicionalmente, mostra na prática a adoção de novas abordagens para lidar com tecnologias emergentes da época, como os protocolos de comunicação de voz pela internet, conhecidos como VoIP, utilizadas por programas de uso comum pela população, como o SKYPE. Em sua conjuntura, a comunicação interna da NSA não somente revelou a capacidade das primeiras etapas de desenvolvimento dos programas, como compartilhou informações de outras formas de atuação, tais como o foco também na coleta de metadados ${ }^{170}$, ou seja, os dados que descrevem o conteúdo nas suas mais variadas formas:

[...] In addition to email, FAIRVIEW and STORMBREW are also collecting metadata, or data about the network and the communications it carries. For September 2003 alone, FAIRVIEW captured several trillion metadata records - of which more than 400 billion were selected for downstream processing or storage. This metadata will be used to enable the surgical collection of much smaller amounts of target-rich data which should extend beyond FAIRVIEW and STORMBREW to many other DNI accesses across NSA. (National Security Agency, 2003)

A produção de metadados é conhecida por ser a mais abundante em sistemas de informação, seja na forma de LOGs, termo para designar registros de ações e eventos em computadores, seja na forma de outros atributos que permitam identificar facilmente padrões de uso. De posse desses metadados, é possível saber com precisão quem foi o autor, o local, a data, a forma, o meio, o tempo e permissão de criação de qualquer dado digital. Em sua quase totalidade, os sistemas de informação são construídos para gerarem e armazenarem em abundância a modalidade de metadados.

No caso da NSA, metadados são armazenados indefinidamente, lado à lado com os dados em si, tendo em vista que "This metadata is flowing to MAINWAY (contact chaining database) [...], and a major interface to the Knowledge System Prototype (kSP)"

\footnotetext{
${ }^{170}$ Metadados podem ser compreendidos como os dados sobre os dados, ou dados que descrevem atributos do conteúdo correlato, tais como a hora de acesso, dia de criação, tamanho de arquivo, permissões de acesso, geolocalização de criação, dentre tantos outros atributos.
} 
National Security Agency (2003). Mainway é considerado pela agência como um dos bancos de dados principais para esse tipo de informação e retroalimenta ambos os projetos STOMRBREW e FAIRVIEW. No caso destes programas, os metadados assumem o propósito de aumentar a acuracidade e precisão frente ao volume exponencial de dados: "both the STORMBREW and FAIRVIEW teams are working [...] to foster metadata exploitation, focus the access, improve the selectors and filters, and hunt for targets within the access"National Security Agency (2003). A alta interdependia e complementariedade entre os programas são consideradas a base fundamente da produção de inteligência em ambientes digitais. Para a NSA, esses atributos tornam possível a estrutura de vigilância massiva aplicada à internet e suas subredes de comunicação:

This collaborative process is the foundation for SIGINT success on the Net. [...] In a recent complementary modernization effort, the FAIRVIEW and STORMBREW programs quadrupled SIGINT production from these circuit-switched accesses, only a few months after implementation. As the FAIRVIEW and STORMBREW programs continue to expand their "live" presence on the global net, we are expecting even greater insight into the net itself, and the communications of our targets, resulting in similar SIGINT production gains from these packet-switched accesses. 171 (National Security Agency, 2003)

A presença na internet, pela NSA, além do acesso aos provedores de serviço, mostrase possível também pela inspeção profunda de pacotes de dados que trafegam pela rede. Nesse sentido, toda informação trocada, de forma encapsulada nos protocolos da internet, estaria igualmente disponível ao acesso da agência. Caso os pacotes não tenham um padrão criptográfico robusto ou capaz de retardar de forma suficiente a ação da agência, estariam, também, vulneráveis à vigilância massiva e indiscriminada que esse tipo de tecnologia promove.

171 "Este processo colaborativo é a base para o sucesso da SIGINT na Internet. [...] Em um recente esforço de modernização complementar, os programas FAIRVIEW e STORMBREW quadruplicaram a produção SIGINT desses acessos comutados por circuito, apenas alguns meses após a implementação. Como os programas FAIRVIEW e STORMBREW continuam expandindo sua presença "viva" na rede global, esperamos uma percepção ainda maior da própria rede e das comunicações de nossos alvos, resultando em ganhos semelhantes de produção SIGINT desses acessos comutados por pacotes" (National Security Agency, 2003), tradução nossa. 



\section{A Coleta de Dados: Tecnologias e Arquite- turas Legislativas da Vigilância}

\subsection{A arquitetura legislativa da Foreign Intelligence Surveillance Act}

Acrônimo para The Foreign Intelligence Surveillance,1978, que em Português é conhecida como Lei de Vigilância e Inteligência Estrangeira, foi aprovada pelo The Senate and House of Representatives of the United States of America, Pub.L. 95-511, 92 Stat. 1783, 50 USC ch. 36 (1978). A FISA permite que a NSA e outras agências do governo dos EUA solicitem o acesso à dados em casos excepcionais para conduzirem suas atividades de segurança. A história dos Estados Unidos fornece insumos suficientes para justificar a criação da FISA, Lei de Vigilância e Inteligência Estrangeira. Contudo, o fator motivador de sua criação encontra seu principal catalisador no escândalo de Watergate $^{172}$, quando o comitê do Partido Democrata dos EUA, localizado no complexo de Watergate, foi invadido em 1974 por 5 homens que implantaram tecnologias de vigilância e espionagem.

O escândalo se desdobrou por dois anos com a cobertura de diversas outras ações ilegais conduzidas sob o Governo de Richard Nixon e que culminaram na crise institucional e resultaram nos subsequentes pedidos de impeachment na posterior renúncia do trigésimo sétimo presidente dos EUA. Em uma das notas da Harvard Law Review, denominada "Shifting the Fisa Paradigm: Protecting Civil Liberties by Eliminating Ex Ante Judicial Approval", são narrados os desdobramentos do caso e os aspectos relevantes no tocante à vigilância aplicada em opositores políticos:

"the statute's [FISA] immediate catalyst was the work of the Senate Select
Committee to Study Government Operations with Respect to Intelligence
Activities. The Church Committee, as it was popularly known, was "con-
vened to investigate affairs surrounding the Watergate scandal and secret
executive surveillance of political enemies. "Its final report detailed a
startling history of constitutional violations stemming from electronic
surveillance conducted under the malleable rubric of "national security."
Surveillance had "seriously infringed . . Fourth Amendment Rights"
under "vague and elastic standards," leading to the government's accu-
mulation of "vast amounts of information - unrelated to any legitimate
government interest - about the personal and political lives of American
citizens, " and creating a powerful "chilling effect." " (Shifting the Fisa...,
2008, p. 2201)

A nota em questão revela que o relatório elaborado pelo Church Comittee, forúm

$\overline{172}$ Informações históricas, documentos, narrativas e pontos de vista podem ser encontrados nas obras de Kutler (2010), Olmsted (1996), Genovese e Morgan (2012), Friedman e Levantrosser (1992) 
criado para a investigação do caso Watergate, apontou uma correlação entre (1) "infrações"da Quarta Emenda da Constituição dos EUA, (2) com ações conduzidas sob padrões "vagos e elásticos"e; (3) que levaram o governo "grandes quantidades de informações - não relacionadas a qualquer interesse legítimo do governo - sobre a vida pessoal e política dos cidadãos americanos"Shifting the Fisa... (2008, p. 2201): o resultado dessa ação colocou em xeque o sistema político-normativo de proteção das liberdades civis de seus cidadãos. Tão em xeque que o Congresso decidiu por reformular a arquitetura de vigilância e incorporar um sistema de aprovações judiciais para a vigilância entre cidadãos e demais indivíduos localizados em solo dos EUA.

O sistema de salvaguardas criado pelo Congresso dos EUA para conter os abusos identificados pelo relatório do Caso Watergate apoiou-se na obtenção de mandados ex-ante para vigilância interna que passariam pelo escrutínio do arcabouço normativo da FISA e seus dois tribunais de análise, o FISC (Tribunal de Fiscalização de Inteligência Estrangeira) para fiscalização da obtenção de inteligência em âmbito doméstico e o FISCR (Corte de Fiscalização e Revisão de Inteligência Estrangeira), para âmbito externo ${ }^{173}$. Todavia, se a vigilância interna passou a ter salvaguardas para se coletar insumos de Inteligência doméstica, em contrapartida, tornou-se explicito que para os demais indivíduos não haveria qualquer garantia de não ser vigiado-espionado.

Com a FISA ${ }^{174}$, a estrutura de vigilância massiva ganhou velocidade com o mecanismo de autorização ex-ante do Presidente dos EUA, sem a necessidade de mandado judicial, que por intermédio de poderes atribuídos ao Procurador Geral, pode autorizar a vigilância eletrônica para adquirir informações de inteligência estrangeira - ainda que alguns critérios sejam atingidos, conforme determina a FISA The Senate and House of

\footnotetext{
$\overline{173}$ Segundo a nota da Harvard Law Review, essa arquitetura havia sido gerada precisamente para conter os abusos com a revisão de duas cortes dedicadas à vigilância "When Congress set out to curb the abuses detailed in the Church Committee Report, the system it created relied heavily on ex ante judicial approval through the issuance of warrants. FISA constituted two Article III courts to implement the Act: the Foreign Intelligence Surveillance Court (FISC), composed of seven federal district court judges, which would issue orders authorizing surveillance, and the Foreign Intelligence Surveillance Court of Review (FISCR), composed of three circuit court judges, which would hear appeals from denials". (Shifting the Fisa..., 2008, p. 2201)

${ }^{174}$ A parte específica dessa autorização pode ser encontrada na Seção 102 da FISA que versa que: "SEC. 102. 50 U.S.C. 1802 (a)(1) Notwithstanding any other law, the President, through the Attorney General, may authorize electronic surveillance without a court order under this title to acquire foreign intelligence information for periods of up to one year if the Attorney General certifies in writing under oath that - (A) the electronic surveillance is solely directed at - (i) the acquisition of the contents of communications transmitted by means of communications used exclusively between or among foreign powers, as defined in section 101(a) (1), (2), or (3); or (ii) the acquisition of technical intelligence, other than the spoken communications of individuals, from property or premises under the open and exclusive control of a foreign power, as defined in section 101(a) (1), (2), or (3); (B) there is no substantial likelihood that the surveillance will acquire the contents of any communications to which a United States person is a party; and $(C)$ the proposed minimization procedures with respect to such surveillance meet the definition of minimization procedures under section 101(h) [...]" (The Senate and House of Representatives of the United States of America, Pub.L. 95-511, 92 Stat. 1783, 50 USC ch. $36,1978)$.
} 
Representatives of the United States of America, Pub.L. 95-511, 92 Stat. 1783, 50 USC ch. 36 (1978), e a vigilância eletrônica seja exclusivamente dirigida à:

1. aquisição do conteúdo de comunicações transmitidas por meio de comunicações usadas exclusivamente entre ou entre potências estrangeiras ${ }^{175},[\ldots]$ ou;

2. a aquisição de inteligência técnica, que não as comunicações faladas de indivíduos, de propriedades ou instalações sob o controle aberto e exclusivo de uma potência estrangeira $[\ldots]$ ou;

3. não há probabilidade substancial de que a vigilância adquira o conteúdo de qualquer comunicação da qual uma pessoa dos Estados Unidos seja parte[...]

A determinação da FISA pode ser sintetizada pelas salvaguardas minimamente aplicadas aos cidadãos dos EUA e ausência de salvaguardas para cidadãos de outras nacionalidades. Para os Estadunidenses, seria preciso seguir o trâmite legal, com as devidas observâncias, para se proceder com a coleta e produção de inteligência. Essa obrigação desaceleraria e evitaria a produção de um mecanismo de coleta massiva de dados, ainda que fosse possível nos casos legalmente autorizados, a produção de inteligência para alvos internos. Contudo, para indivíduos de outras nacionalidades ou territorialidade que não a estadunidense, não haveria a obrigatoriedade - a vigilância destes estaria, portanto, autorizada até segunda ordem.

\subsubsection{A Seção 702 da Foreign Intelligence Surveillance Act}

A Agência Nacional de Segurança (NSA) e outras entidades da US Intelligence Community basearam suas ações de vigilância e produção de inteligência na relativamente recente Seção 702 da FISA (1978). A Seção 702, acrescida à FISA em 2008, trata de Procedimentos para tornar-alvo determinados indivíduos fora dos Estados Unidos que não sejam indivíduos dos Estados Unidos (Em inglês, "Procedures for targeting certain persons outside the United States other than United States persons") e especifica, dentre outros direcionamentos, que:

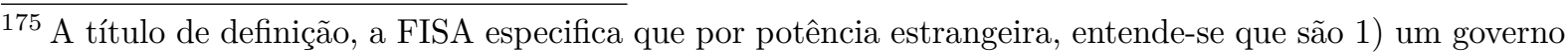
estrangeiro ou qualquer componente dele, reconhecido ou não pelos Estados Unidos; (2) uma facção de uma nação estrangeira ou nações, não substancialmente compostas de pessoas dos Estados Unidos; (3) uma entidade que seja abertamente reconhecida por um governo ou governos estrangeiros para ser dirigida e controlada por tal governo estrangeiro ou governos; (4) um grupo envolvido em terrorismo internacional ou atividades em preparação para o mesmo; (5) uma organização política baseada no exterior, não substancialmente composta de pessoas dos Estados Unidos; (6) uma entidade que é dirigida e controlada por um governo estrangeiro ou governos; ou (7) uma entidade não substancialmente composta por pessoas dos Estados Unidos que esteja envolvida na proliferação internacional de armas de destruição em massa. (The Senate and House of Representatives of the United States of America, Pub.L. 95-511, 92 Stat. 1783, 50 USC ch. 36, 1978)
} 
SEC. 702. 50 U.S.C. 1881 - PROCEDURES FOR TARGETING CERTAIN PERSONS OUTSIDE THE UNITED STATES OTHER THAN UNITED STATES PERSONS. (a) AUTHORIZATION - Notwithstanding any other provision of law, upon the issuance of an order in accordance with subsection (j)(3) or a determination under subsection (c)(2), the Attorney General and the Director of National Intelligence may authorize jointly, for a period of up to 1 year from the effective date of the authorization, the targeting of persons reasonably believed to be located outside the United States to acquire foreign intelligence information. (b) LIMITATIONS. - An acquisition authorized under subsection (a) - (1) may not intentionally target any person known at the time of acquisition to be located in the United States;[...]; and (6) shall be conducted in a manner consistent with the fourth amendment to the Constitution of the United States. ${ }^{176}$ (The Senate and House of Representatives of the United States of America, Pub.L. 95-511, 92 Stat. 1783, 50 USC ch. 36, 1978)

Especificamente desenhada para não interceptar a comunicação de cidadãos dos EUA, a prática conduzida pela NSA não necessariamente fazia distinção intencional ou acidental da coleta massiva de dados: em casos "acidentais", a vigilância é igualmente aplicada aos cidadãos do EUA, em detrimento das considerações e procedimentos proibitivos da FISA. A Eletronic Frontier Foundation ${ }^{177}$ aponta essa questão como um dos aspectos críticos e falhos da FISA, dentre outros, que permitem a vigilância massiva e irrestrita. De acordo com a ONG, "law gives the intelligence community space to target foreign intelligence in ways that inherently and intentionally sweep in Americans' communications. "(Eletronic Frontier Foundation, 2019b).

O espaço acidental ou incidental da coleta de dados de estadunidenses é considerada uma área cinzenta na Comunidade de Inteligência. Ainda que haja relatórios da própria NSA sobre as coletas, a Eletronic Frontier Foundation (2019a) argumenta que "apesar dos compromissos [...] de fornecer ao Congresso uma estimativa do número de pessoas dos EUA cujas comunicações são varridas "incidentalmente"sob a Seção 702, [...] (a NSA) disse

176 "SEC. 702.50 U.S.C. 1881a - PROCEDIMENTOS PARA A ALOCAÇÃO DE DETERMINADAS PESSOAS FORA DOS ESTADOS UNIDOS, QUE NÃO AS PESSOAS DOS ESTADOS UNIDOS. (a) AUTORIZAÇÃO - Não obstante qualquer outra provisão de lei, mediante a emissão de uma ordem de acordo com a subseção (j) (3) ou uma determinação sob a subseção (c) (2), o Procurador Geral eo Diretor da Inteligência Nacional podem autorizar conjuntamente, por um período de até um ano a partir da data efetiva da autorização, o direcionamento de pessoas que se acredita estar localizado fora dos Estados Unidos para adquirir informações de inteligência estrangeiras. (b) LIMITAÇÕES. - Uma aquisição autorizada de acordo com a subseção (a) - (1) não pode intencionalmente visar qualquer pessoa conhecida no momento da aquisição para estar localizada nos Estados Unidos; [...]; e (6) deve ser conduzido de maneira consistente com a quarta emenda à Constituição dos Estados Unidos" (The Senate and House of Representatives of the United States of America, Pub.L. 95-511, 92 Stat. 1783, 50 USC ch. 36, 1978), tradução nossa.

177 A Electronic Frontier Foundation, Fundada em 1990, é uma Organização Não-Governamental dos EUA considerada internacionalmente como a principal organização sem fins lucrativos que "defende as liberdades civis no mundo digital", principalmente em relação a privacidade, a liberdade de expressão e para que direitos e liberdades sejam aprimorados e protegidos de acordo com a democratização da tecnologia. 
que [...] não fornecerá essa estimativa" ${ }^{178}$. Adicionalmente, a Eletronic Frontier Foundation elenca dois outros cenários que permitem a coleta massiva de cidadãos estadunidenses:

1. comunicações dos americanos que se comunicam com pessoas específicas localizadas no exterior

2. comunicações de outros americanos que foram capturadas como parte da segmentação de estrangeiros por parte da NSA

Para a EFF, a Comunidade de Inteligência utiliza o tempo de coleta "incidental/acidental"como um eufemismo para "para minimizar o fato de que usa rotineiramente essa autoridade de vigilância de inteligência estrangeira ampla e invasora da privacidade para coletar as comunicações dos americanos que devem exigir um mandado (Eletronic Frontier Foundation, 2019a) ${ }^{179 " . ~ T e c n i c a m e n t e, ~ o ~ p r o g r a m a ~ d e ~ v i g i l a ̂ n c i a ~ m a s s i v a, ~ b e m ~}$ como o arsenal de ferramentas e softwares empreendidos enfrentariam desafios tecnologicamente complexos em relação à distinção entre as categorias dos alvos permitidos pela FISA. O que se argumenta, segundo a EFF, é que tal complexidade não seria um empecilho para NSA e que, portanto, não poderia ser utilizada como uma justificativa para a coleta de dados fora do escopo da FISA. Nada foi dito pela EFF, porém, das coletas massivas aplicadas na vastidão de cidadãos de outros países-alvo dos programas da Agência de Segurança Nacional.

\subsubsection{A Foreign Intelligence Surveillance Act e a coleta Upstream e Downstream de dados}

Com a adição da Seção 702, a interpretação da FISA passou a permitir, na concepção da NSA, que agência pudesse coletar e produzir inteligência de duas formas distintas:

"Upstream"e "Downstream". De acordo com a agência, tais coletas distinguem-se da seguinte forma:

Under Section 702, NSA collects internet communications in two ways: "downstream" (previously referred to as PRISM) and "upstream. " Under downstream collection, NSA acquires communications "to or from" a Section 702 selector (such as an email address). Under upstream collection, NSA acquires communications "to, from, or about" a Section 702 selector. An example of an "about" email communication is one that includes the targeted email address in the text or body of the email, even though the

$\overline{178}$ Tradução nossa para o excerto: "Despite past commitments to provide Congress with an estimate of the number of U.S. persons whose communications are swept up "incidentally" under Section 702, the Director of National Intelligence said his office will not be providing that estimate, leaving lawmakers in the dark about how exactly this law affects their constituents".(??)

179 Tradução nossa para a passagem da EFF: "The intelligence community calls this "incidental" collection to downplay the fact that it routinely uses this broad and privacy-invasive foreign intelligence surveillance authority to collect Americans' communications that should require a warrant"180. (Eletronic Frontier Foundation, 2019a) 
email is between two persons who are not themselves targets ${ }^{181}$. (National Security Agency, 2017)

A NSA utiliza a FISA para explicar legalmente os mecanismos que permitiriam a coleta massiva de dados de ambas as formas. A explicação institucional da NSA torna-se, contudo, elusiva ao expandir vastamente o escopo definido pela FISA e pouco acessível ao não detalhar os aspectos práticos das duas formas de coletas de dados "autorizadas"pela FISA. Na prática, a coleta Upstream se dá diretamente nos backbones ${ }^{182}$ de telecomunicações que passam pelos Estados Unidos. Por sua vez, a coleta Downstream ocorrerá diretamente de provedores de serviço e empresas cuja jurisdição encontra-se sob soberania dos EUA. Para a Eletronic Frontier Foundation, há o agravante de que esse tipo de coleta ultrapassa os limites da FISA e de suas restrições normativas.

Nas figuras $11^{183}$, geradas a partir do documento/apresentação chamado "PRISM/US984XN Overview"da NSA National Security Agency (2013b) explicam visualmente a atuação da agência em ambos os sentidos: Downstream e Upstream:

181 "Sob a Seção 702, a NSA coleta comunicações da Internet de duas maneiras: "downstream" (anteriormente referida como PRISM) e "upstream". Na coleta downstream, a NSA adquire comunicações "para ou de" um seletor da Seção 702 (como um endereço de e-mail). Na coleção upstream, a NSA adquire comunicações "para, de ou sobre" um seletor da Seção 702. Um exemplo de uma comunicação "por e-mail" é aquela que inclui o endereço de e-mail direcionado no texto ou no corpo do e-mail, mesmo que o e-mail seja entre duas pessoas que não são alvos" (National Security Agency, 2017), tradução nossa.

182 "Backbone"é o termo técnico para designar infraestruturas de telecomunicações globais que interligam países (e permite acessos entre geografias e localidades diferentes) e proveem a estrutura necessária para a internet, ligações telefônicas e demais tipos de transmissão de dados via satélites ou outros equipamentos.

${ }^{183}$ Bem como pelas 17 e 18 utilizadas no decorrer da pesquisa 
Figura 11 - A Coleta de dados Upstream e Downstream da NSA pela FISA 702

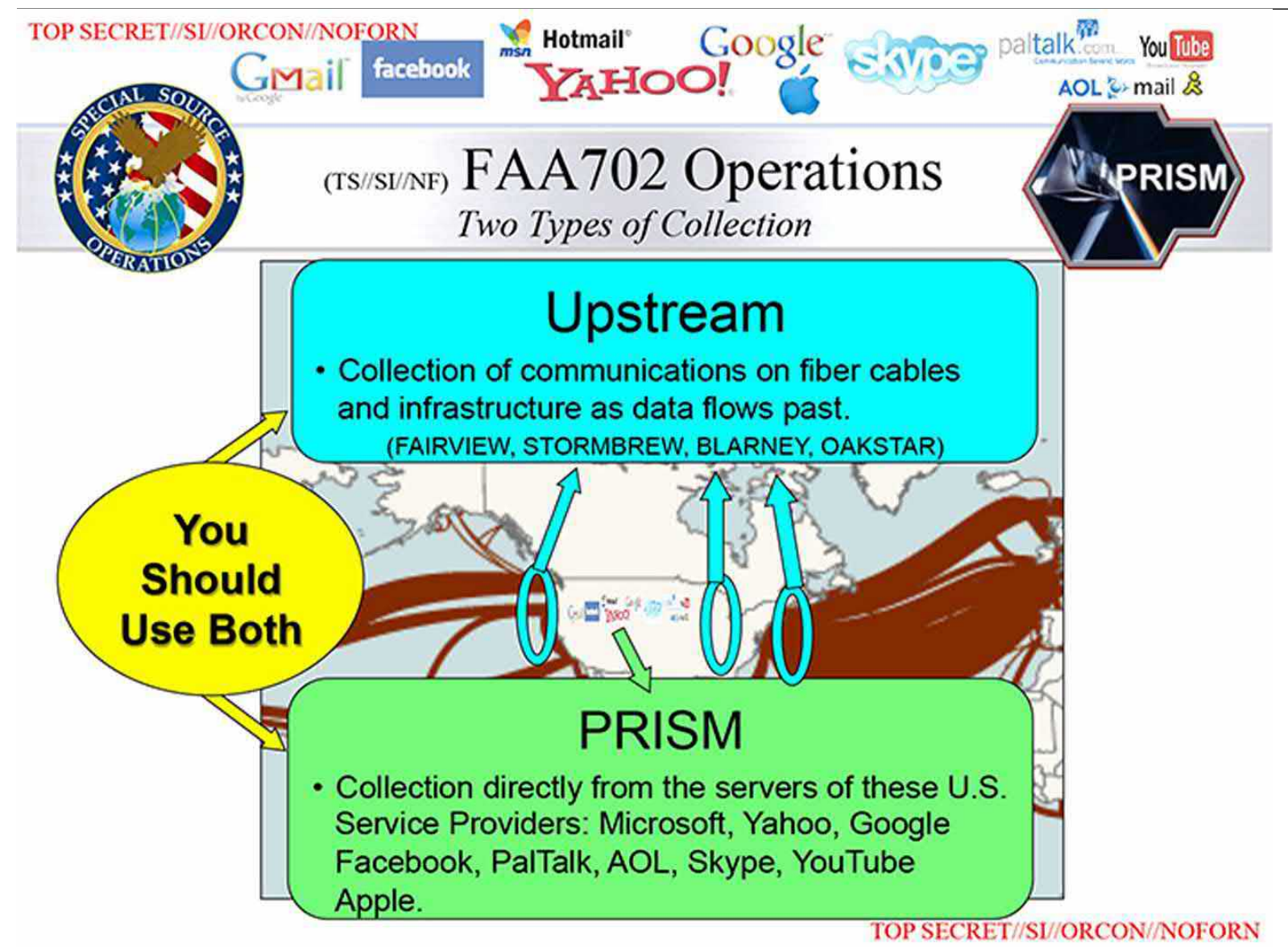

Fonte: Figura compilada à partir do documento da NSA. National Security Agency (2013b)

Pela referência "FAA702 Operations" é possível identificar que a imagem 11 faz menção à Seção 702 da FISA e às operações que dela derivam. A coleta Upstream é definida pela NSA como a "Collection of communications on fiber cables and infrastructure as data flows past", ou seja, a coleta de dados que passam ou utilizam em algum ponto a infraestrutura de telecomunicações globais dos Estados Unidos. Essa primeira abordagem de coleta massiva de dados fornece insumos para os programas FAIRVIEW, STORMBREW, $B L A R N E Y$ e OAKSTAR da agência. Por sua vez, a coleta Upstream é denominada como a coleta realizada pelo programa PRISM, ou seja, "collection directly from the servers of these U.S" cujo elenco mostra os principais provedores de serviços globais da internet, tais como "Microsoft, Yahoo, Google, Facebook, PalTalk, AOL, Skype, YouTube e Apple". A coleta de ambas as formas se somam (expressa pela frase You Should Use Both) na produção de inteligência da agência.

A Eletronic Frontier Foundation aponta que outras agências, como o FBI, teriam acesso às informações para a condução de atividades domésticas de investigação de crimes que em nada se relacionam com as atividades de inteligência estrangeira: 
Once those communications have been collected through downstream surveillance, they're put into databases that are routinely searched by the FBI when starting - or even before officially starting - investigations into domestic crimes that may ultimately have nothing to do with foreign intelligence issues. And the FBI doesn't need a warrant to do those searches. [...] the government is now allowed to conduct backdoor searches on communications collected as part of its "upstream" collection from the Internet backbone as well. ${ }^{184}$ (Eletronic Frontier Foundation, 2019a)

O endereço de destino das coletas massivas de dados são os diversos bancos de dados ${ }^{185}$ criados pela NSA para retroalimentar os programas de inteligência. Os dados são armazenados indefinidamente, com exceções que começaram a surgir em 2017, realizadas após a comoção pública e de congressistas que impactaram a avaliação da própria agência 186. Os bancos de dados haviam sido disponibilizados a outras entidades da Comunidade de Inteligência dos EUA como forma de auxiliar na resolução de crimes. O aspecto crítico residiria, portanto, na capacidade de outras agências terem acesso não somente à inteligência produzida a partir dos bancos de dados, como aos dados propriamente ditos, sem o devido trâmite, mandado e salvaguardas aplicadas à própria NSA e, nesse sentido, "thanks to a foreign intelligence surveillance authority, domestic law enforcement officials can, without a warrant, access Americans' communications that they would otherwise need a warrant to access ${ }^{\prime 188}$ (Eletronic Frontier Foundation, 2019a). A comunidade que defende as liberdades civis nos EUA denomina brecha de vigilância indiscriminada de "backdoor search loophole" na Seção 702 da FISA.

184 "Uma vez que essas comunicações tenham sido coletadas por meio de vigilância downstream, elas são colocadas em bancos de dados que são rotineiramente pesquisados pelo FBI quando começam ou até mesmo antes de começar oficialmente - investigações sobre crimes domésticos que podem não ter nada a ver com questões de inteligência estrangeira. E o FBI não precisa de um mandado para fazer essas buscas. [...] o governo agora tem permissão para realizar buscas backdoor em comunicações coletadas como parte de sua coleção "upstream" do backbone da Internet também" (Eletronic Frontier Foundation, 2019a), tradução nossa

${ }^{185}$ A agência utiliza diversos bancos de dados que vieram à conhecimento público após a divulgação não autorizada de seus documentos. A agência cita alguns desses bancos em seus documentos divulgados, e reafirma em referência à um de seus programas de coleta de dados a partir da Infraestrutura de servidores da Microsoft que "Data is stored multiple times (MARINA/MAINWAY, PINWALE, CLOUDs)" (National Security Agency, 2013a). As siglas em questão representam os bancos de dados para a armazenagem das coletas massivas de dados.

${ }^{186}$ O Charlie Savage, pelo New York Times, reportou que a agência decidiu parar a coleta de dados de telefonia de cidadãos americanos após avaliar a pertinência e legalidade do mesmo. Segundo o reporter, "The National Security Agency has quietly shut down a system that analyzes logs of Americans' domestic calls and texts, according to a senior Republican congressional aide, halting a program that has touched off disputes about privacy and the rule of law since the Sept. 11 attacks"187 (SAVAGE, 2019).

188 "Graças a uma autoridade de vigilância de inteligência estrangeira, os agentes da lei nacionais podem, sem um mandado, acessar as comunicações dos americanos de que, de outra forma, precisariam de um mandado de acesso" (Eletronic Frontier Foundation, 2019a), tradução nossa. 


\subsection{A coleta de dados Upstream}

\subsubsection{Os Programas OAKSTAR, STORMBREW, BLARNEY e FAIRVIEW}

Os programas OAKSTAR, STORMBREW, BLARNEY e FAIRVIEW fazem parte da coleta Upstream, que acessa os dados diretamente da infraestrutura de comunicações globais que, em algum momento, passam pelos EUA. A figura 12 fornece uma dimensão da interconectividade da infraestrutura global de telecomunicações e, em especial, a de cabos de fibra-ótica. Os programas identificados pelos documentos liberados por Eduard Snowden em 2013 e revelam detalhes da forma de atuação da agência em cooperação com provedores de internet e demais parceiros que detêm a propriedade da infraestrutura de telecomunicações. Os documentos liberados apontam que a NSA firma parcerias com corporações de telecomunicações para coletar diretamente os dados que trafegam por suas estruturas.

Figura 12 - Infraestrutura Global de Cabos de Fibra-Ótica

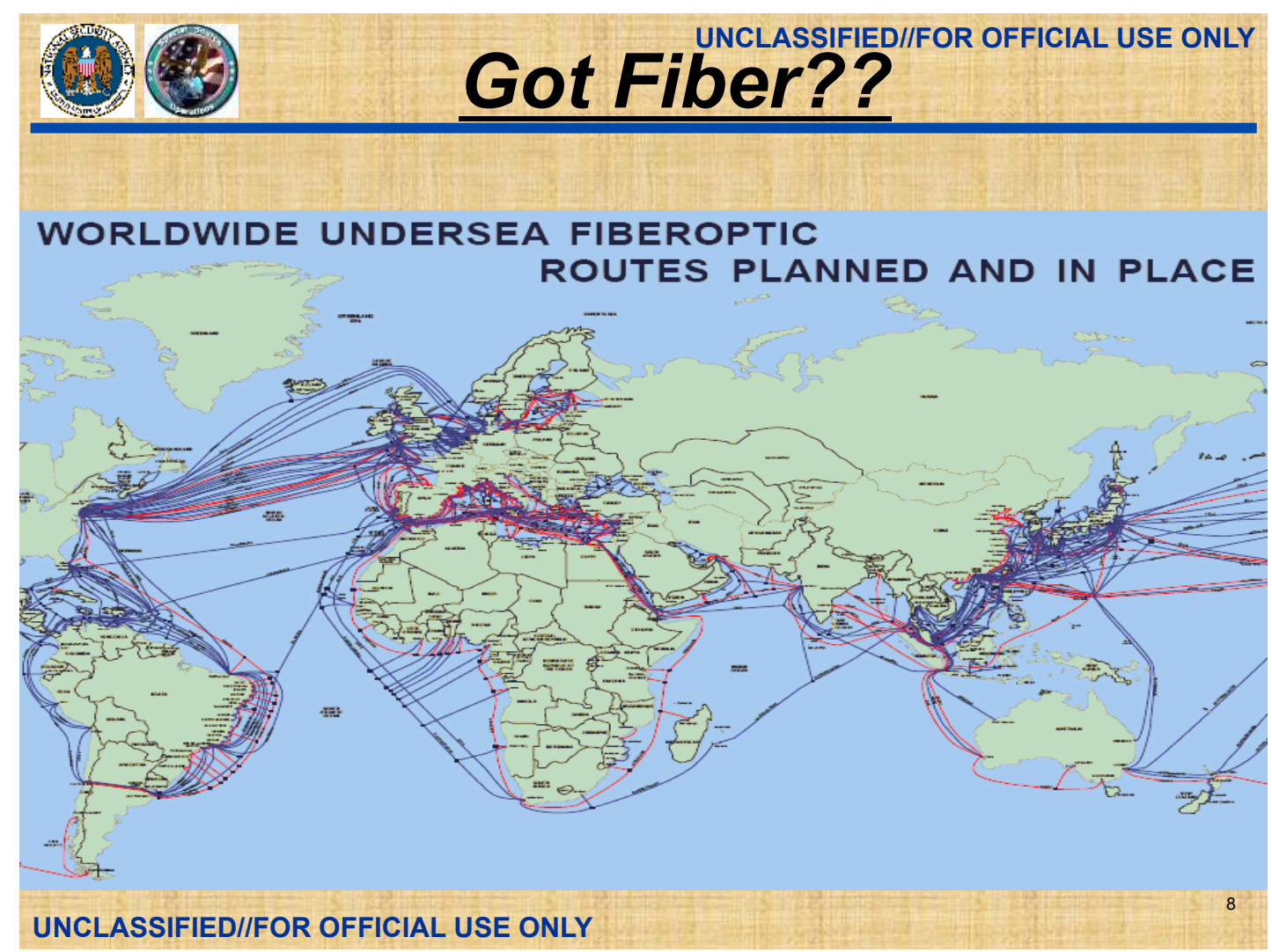

Fonte: Imagem compilada pelo autor à partir do documento "Special Source Operations. The Cryptologic Provider of Intelligence from Global High-Capacity Telecommunications Systems" da National Security Agency. (National Security Agency, 2013c) 
Os jornalistas Craig Timberg e Barton Gellman apontaram, pelo Jornal Washington Post no artigo "NSA paying U.S. companies for access to communications networks", que a agência "plugava"seus coletores para desviar o trafego de dados como parte do programa corporativo de parceiros: "New details of the corporate-partner project, which falls under the NSA's Special Source Operations, confirm that the agency taps into "high volume circuit and packet-switched networks," according to the spending blueprint for fiscal 2013". (TIMBERG; GELLMAN, 29/09/2013). Para obter acesso facilitado e cooperativo dos parceiros corporativos, segundo os jornalistas, a agência pagava pelo acesso aos dados aos provedores de internet - informações que apareceram nos orçamentos aprovados pelo Congresso dos EUA para a Comunidade de Inteligência.

A cooperação voluntária entre a agência e os provedores de telecomunicações remontam à décadas antes das revelações feitas por Snowden: "Voluntary cooperation from the 'backbone' providers of global communications dates to the 1970s under the cover name BLARNEY" (TIMBERG; GELLMAN, 29/09/2013). Um dos documentos que descrevem essa interação é sistematizado pela 13, que fornece informações sobre os países afetados, estruturas de aprovação, escopo da coleta e infraestrutura utilizada. A estratégia da agência reside na percepção de que é preciso "Leverage unique key corporate partnerships to gain access to high-capacity international fiber-optic cables, switches and/or routers throughout the world", ou seja, estabelecer o máximo de parcerias e cooperações (independentemente se forçadas por determinações das Cortes da FISA) - parcerias que já ocorreria intra-agências NSA, CIA, FBI e DOJ e provedores comerciais (Commercial Providers). 
Figura 13 - Compilação das ações dos programas de coleta Upstream

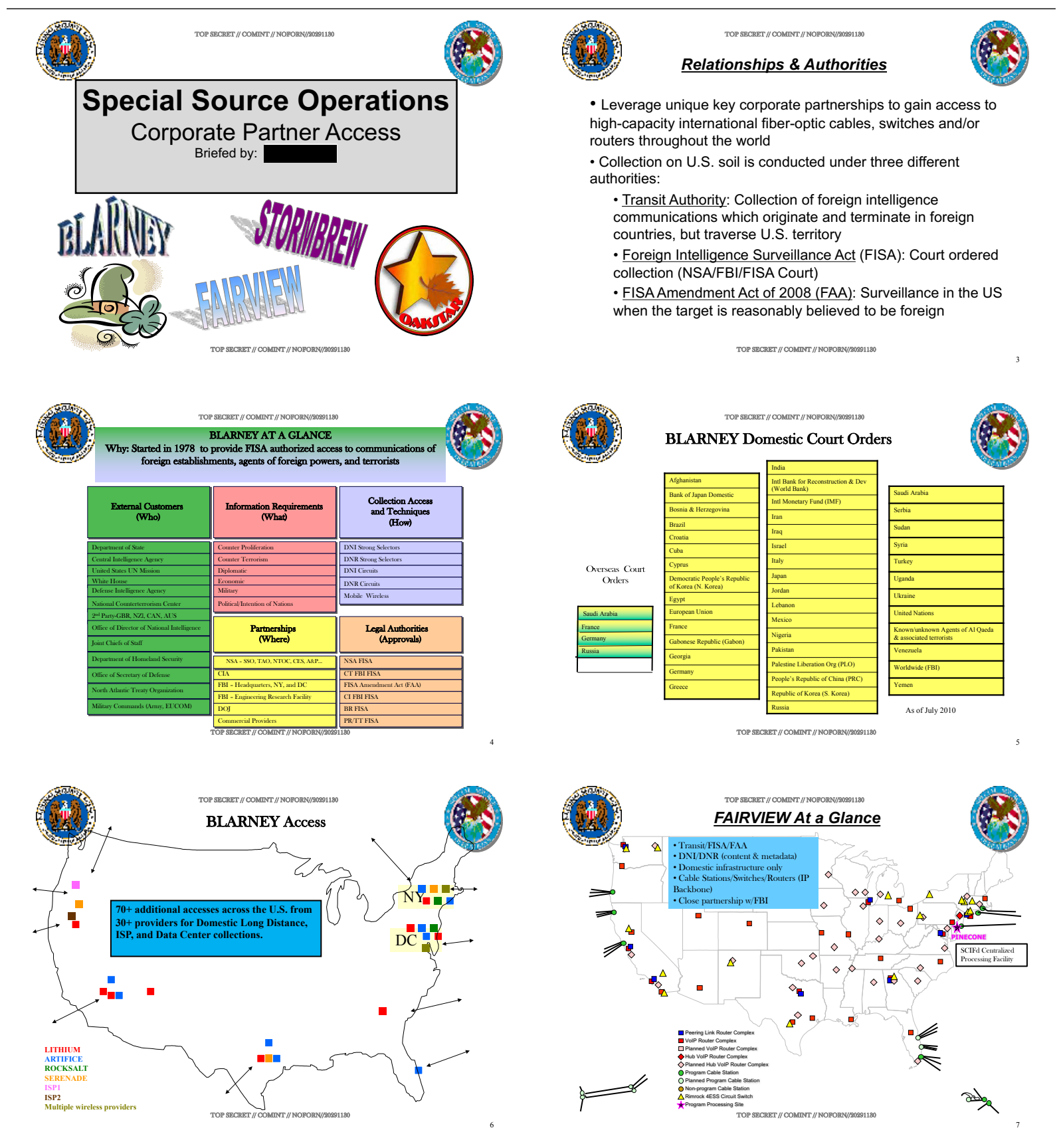

Fonte: Imagem compilada pelo autor à partir do documento "Special Source Operations: Corporate Partner Access" da National Security Agency. (National Security Agency, 2016)

Segundo os documentos, a estrutura Upstream começou após a aprovação da FISA, em 1978, para prover mecanismos de se gerar inteligência com acesso "autorizado às comunicações de estabelecimentos estrangeiros, agentes de potências estrangeiras e terroristas". Adicionalmente, a NSA aponta que há três diferentes autorizações para a coleta massiva de dados em solo estadunidense via cabos e backbones globais:

1. Autoridade por trânsito: Coleta de comunicações de inteligência estrangeiros que se 
originam e terminam em países estrangeiros, mas atravessar território EUA;

2. Lei de Vigilância e Inteligência Estrangeira (FISA): Tribunal mandados de coleta da FISA;

3. Lei de Emenda da FISA de 2008 (FISA Amendment Act of 2008- FAA): Vigilância nos EUA quando se acredita que a pessoa-alvo é estrangeira.

Por Autoridade em Trânsito (ou, em inglês, Transit Authority) compreende-se os aspectos de soberania dos EUA sobre seu próprio território e jurisdições. A NSA, nessa lógica, não precisaria de autorizações especiais de outros países, exceto em caso de cooperações internacionais. Os diversos acordos de cooperação não fazem parte do escopo da pesquisa e, portanto, serão abordadas em trabalhos futuros. Todavia, as alianças de cooperação foram retratados pela NSA no excerto "Party-GBR, NZ1, CAN, AUS,Office of Director of National Intelligence, Joint Chiefs of Stall, Department of Homeland Security, Office of Secretary of Defense, North Atlantic Treaty' Organization, Military Commands (Army, EUCOM)". Por essa passagem, são elencadas a cooperação internacional entre os países conhecidos como Five-Eyes - Grã-Bretanha, Nova Zelândia, Canada, Austrália e EUA. (National Security Agency, 2016).

Os dois demais itens são derivados da FISA, das cortes que se originaram dela e da emenda que introduziu a Seção 702 abordada anteriormente. Os mapas da imagem fornecem um referencial da conexão dos EUA com a infraestrutura global de telecomunicações com as indicações dos programas aplicados à cada ponta de entrada dos cabos de fibra-ótica. Além disso, indicam o volume dos provedores de serviço de internet (em inglês, Internet Service Provider) que cooperam com o programa de vigilância Upstream, com aproximadamente 70 pontos de acessos adicionais nos EUA , 30 provedores de longa distância nacional e um vasto catálogo de Data Centers em território nacional.

O escopo de atuação, segundo os documentos levantados, estaria focado em fornecer inteligência para o processo decisório e formulação de ações/políticas públicas ContraTerrorismo, bem como estratégias para atuação nas esferas Diplomáticas, Econômica, Militar, Política e na identificação do Interesse das Nações. Tais informações serviriam, desta forma, para os processos burocráticos e decisórios das demais instituições e missões, tais como o Department of State, Central Intelligence Agency, United States UN Mission, White House, Defense Intelligence Agency e o National Counterterrorism Center. A atuação e produção de inteligência possui, portanto, um interesse que transcende a justificativa da segurança nacional e passa, portanto, à produção de insumos decisórios que suportam a projeção dos próprios interesses nacionais no contexto internacional. 


\subsubsection{Os Programa XKeyscore}

Levado em consideração o volume exponencial de dados que trafegam pela infraestrutura global de telecomunicações, a agência teria um desafio em catalogá-los e indexá-los para se chegar no patamar de produzir inteligência. um dos programas destinados à solucionar esse problema é o XKeyscore, um software arquitetado para lidar com o excessivo volume de dados, filtrá-los, organizá-los e trazê-los de forma inteligível aos seus processos internos. O programa XKEYScore é um dos ápices da coleta upstream de dados, por realizar a busca confederada de todos os bancos de dados que foram alimentados pelos demais programas. A figura 14 traz a compilação de um treinamento oferecido internamente aos oficiais da agência e que fazia parte do escopo de documentos liberados por Edward Snowden em 2013:

Figura 14 - Apresentação do projeto XKEYSCORE da NSA - Parte 1
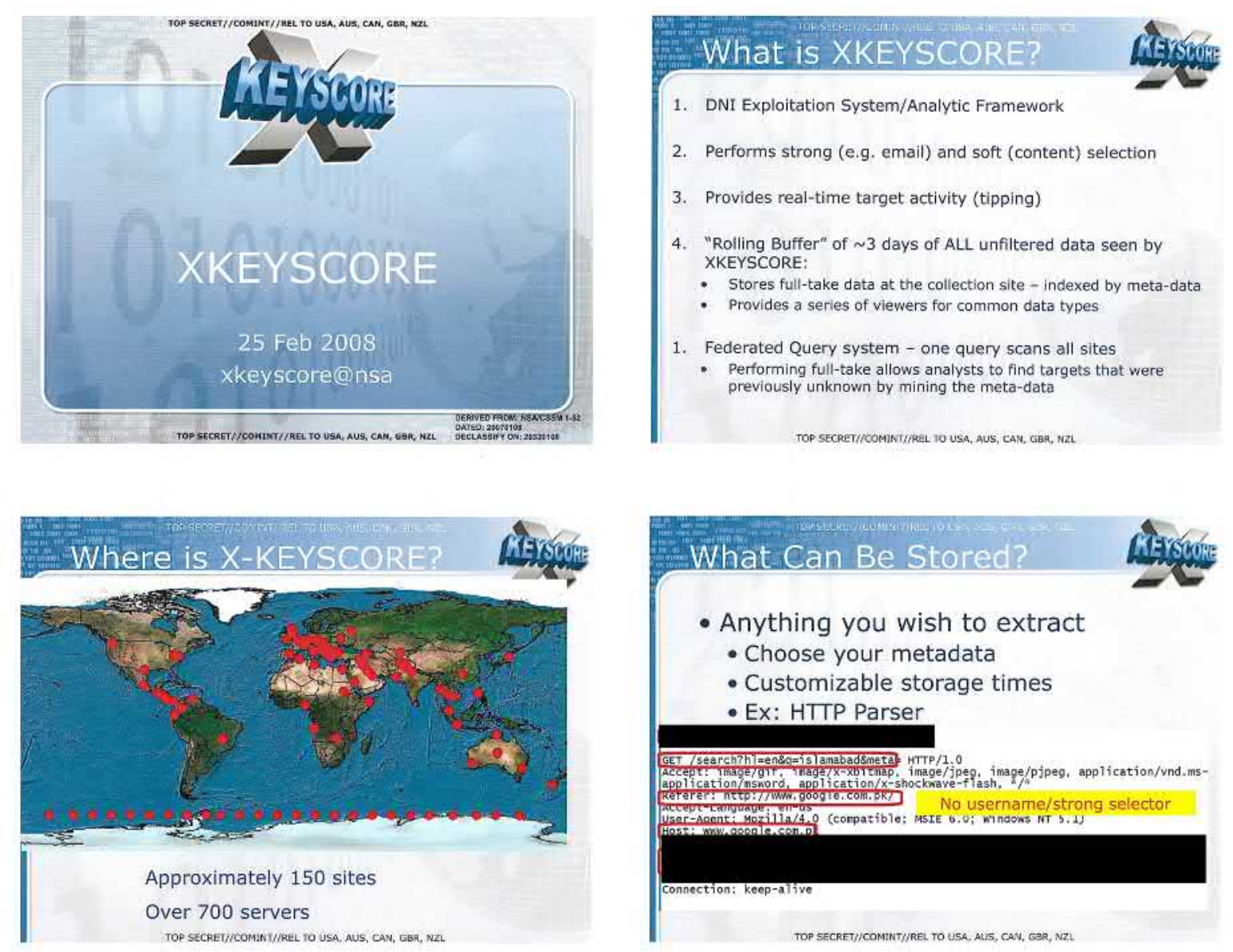

Fonte: Imagens reconstituídas e compiladas a partir do documento denominado XKEYSCORE elaborado pela National Security Agency (National Security Agency, 2008)

Pela compilação da figura 14, é possível identificar que o programa XKEYScore atua em mais de 150 localidades, incluindo o Brasil, e que sua base de servidores ultrapassava, 
em 2008, a marca de 700 equipamentos. O programa consegue consultar os dados coletados diariamente pelos seus programas predecessores; além disso, sua extensão tecnológica aprofunda-se ao nível de que o XKEYScore consegue visualizar, em tempo real, as ações, até mesmo de digitação, de um usuário-alvo de seu aparato ou, como descreve a NSA, "provides real-time target activity (tipping)" (National Security Agency, 2008). Adicionalmente, com o tempo de retenção indiscriminado, a estrutura que suporta o XKEYScore consegue voltar no tempo e "minerar"os dados em buscas de evidências forenses, padrões e anomalias ${ }^{189}$ que possivelmente passaram desapercebidas pelos oficiais de inteligência.

A engenharia por detrás do sistema não difere de um buscador de internet - ainda que seu escopo seja a aplicação tenha objetivos e meios de coleta diferentes. A figura 14 revela os objetivos do programa que, dentre suas capacidades, o programa executa o que a agência denomina "seleção forte"e outra suave que, respectivamente, podem ser interpretas como formas de seleção de metadados ou de conteúdo. A figura 15 demonstra como os seletores são aplicados como filtros nas comunicações globais e dos usuários da internet em geral. Segundo a NSA, os seletores de metadados possuem uma capacidade limitada de prover inteligência ${ }^{190}$ e, nesse sentido, os seletores de conteúdo acabam por trazer o maior potencial ao programa, segundo a figura 14 .

Figura 15 - Apresentação do projeto XKEYSCORE da NSA - Parte 2
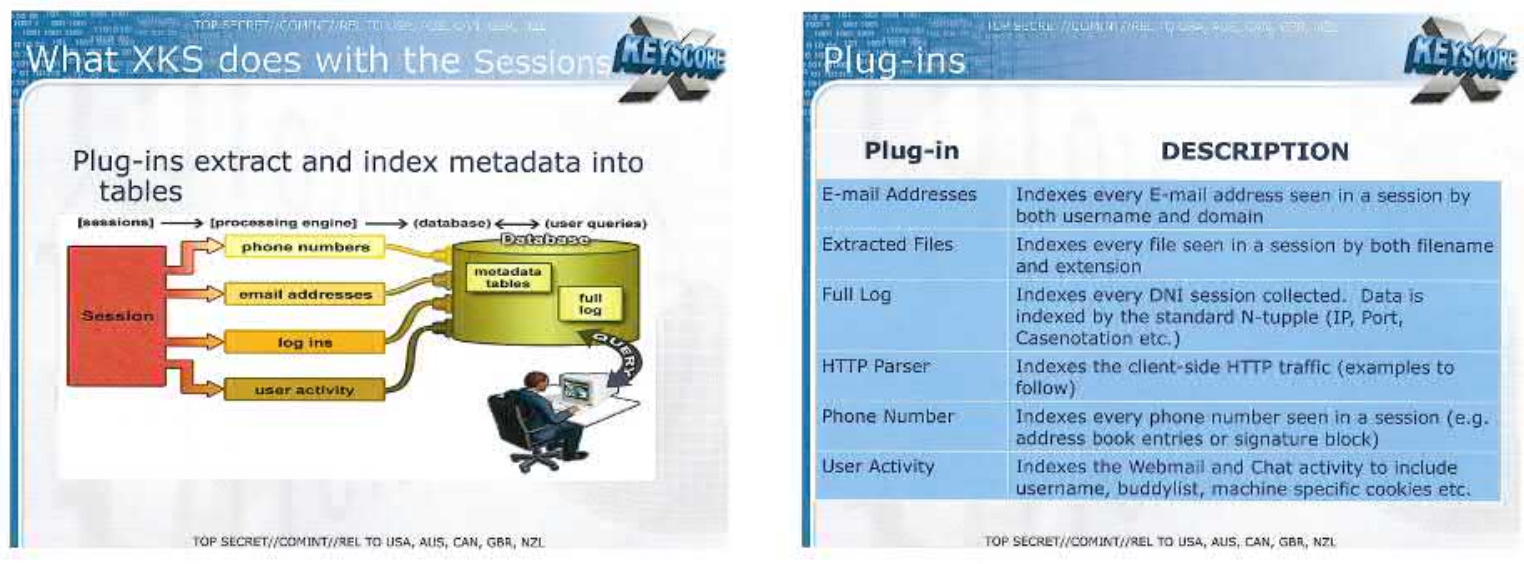

Fonte: Imagens reconstituídas e compiladas a partir do documento denominado XKEYSCORE elaborado pela National Security Agency (National Security Agency, 2008)

A dinâmica do XKEYSCORE perpassa pela coleta massiva de dados que trafegam pelos backbones, extração de informações por meio de plugins ${ }^{191}$ e aplicação de filtros à vastidão de dados coletados diariamente, tais como números de telefone, endereços de

\footnotetext{
${ }^{189}$ Segundo a agência, "We can use this traffic to detect anomalies which can lead us to intelligence by itself" (National Security Agency, 2008)

${ }^{190}$ Expresso pela passagem de que afirma que "Strong Selection itself give us only a very limited capability" (National Security Archive, 2000)

${ }^{191} \mathrm{O}$ mesmo que módulos que são utilizados sob demanda.
} 
e-mail, sessões de log-ins de usuários e demais atividades realizadas. De posse dessas informações, tabelas de bancos de dados armazenam os metadados dos usuários-alvo que, posteriormente, fornecem informações para a produção de inteligência ${ }^{192}$ por parte da interface de pesquisa do programa XKEYSCORE.

Figura 16 - Apresentação do projeto XKEYSCORE da NSA - Parte 3
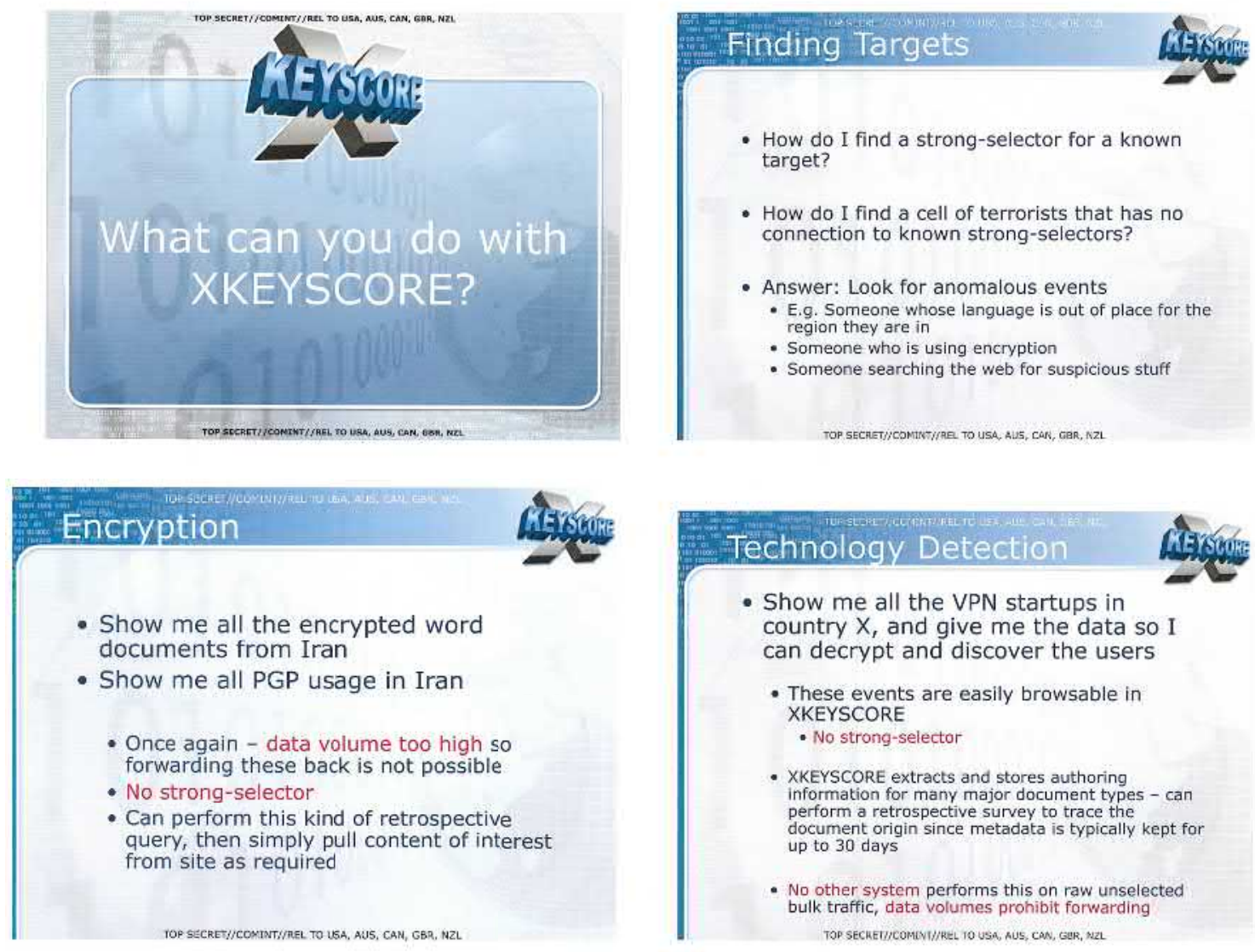

Fonte: Imagens reconstituídas e compiladas a partir do documento denominado XKEYSCORE elaborado pela National Security Agency (National Security Agency, 2008)

Tais capacidades fazem parte do sistema de Digital Network Intelligence ou DNI, acrônimo que se refere a "inteligência de comunicações de dados digitais interceptadas transmitidas entre, ou residentes em, computadores em rede"193. A complexidade do programa em relação aos potencial de invasão de privacidade torna-se explícita à medida que o potencial do XKEYScore é demonstrado. Afinal, o que é possível fazer na prática

$\overline{192}$ O programa armazena as informações indexadas por um curto período de tempo, ainda que elas permaneçam dormentes indefinidamente em outros bancos de dados: "XKEYSCORE extracts and stores authoring information for many major document types - can perform a retrospective survey to trace the document origin since metadata is typically kept for up to 30 days"(National Security Agency, 2008)

193 Tradução nossa para o excerto "the intelligence from intercepted digital data communications transmitted between, or resident on, networked computers." (National Security Archive, 2000) 
com o XKEYScore? A imagem 16 traz em detalhes a aplicabilidade prática do programa e é compilada em sua totalidade na tabela 4.

Tabela 4 - Tabela Consolidada da Capacidade de Atuação do XKEYSCORE para a coleta massiva de dados

\begin{tabular}{l|l}
\hline Domínio & Problema \\
\hline $\mathbf{1}$ - Encontrar alvos & Como encontrar um seletor \\
& forte para um alvo conhe- \\
& cido? Como encontrar uma \\
& célula de terroristas que não \\
& tem conexão com seletores \\
& fortes conhecidos? \\
\hline
\end{tabular}

2 - Criptografia
$\begin{aligned} & 3 \text { - Detecção de Tecnolo- } \\ & \text { gia }\end{aligned}$

Mostrar todos os documentos criptografados do Irã; Mostrar todo o uso de PGP no Irã

Capacidade do XKEYSCORE

Resposta: XKEYSCORE procura por eventos anômalos, por exemplo, alguém cuja linguagem está fora do lugar para a região em que está; Alguém que está usando criptografia; Alguém pesquisando na Web por material suspeito

XKEYSCORE pode realizar este tipo de consulta retrospectiva, basta especificar o conteúdo de interesse do local, conforme necessário

Mostrar todas as startups de VPN no país X e fornecer os dados para que se possa descriptografar e descobrir os usuários

Estes eventos são facilmente navegáveis em XKEYSCORE; O XKEYSCORE extrai e armazena informações de autoria para muitos tipos de documentos importantes - pode realizar uma pesquisa retrospectiva para rastrear a origem do documento, já que os metadados são normalmente mantidos por até 30 dias.

\section{4 - Acompanhamento de Linguagem}

5 - Google Maps
O indivíduo alvo fala alemão, mas está no Paquistão - como o XKEYSCORE pode encontrá-lo?

O indivíduo alvo usa o Google Maps para atingir locais - é possível utilizar essas informações para determinar o endereço de e-mail dele? E quanto às buscas na web - qualquer um se destaca e parece suspeito?
6 - Descoberta interessante de documentos

P: XKEYSCORE consegue mostrar todas as planilhas do Microsoft Excel contendo endereços MAC que saem do Iraque para que se possa realizar o mapeamento de rede

7 - TAO (Tailored Access Operations)
P: XKEYSCORE mostra todas as máquinas exploráveis no país $\mathrm{X}$
O plugin de atividade HTTP do XKEYSCORE extrai e armazena todas as tags de linguagem HTML que podem ser pesquisadas

XKEYSCORE extrai e banco de dados esses eventos, incluindo todas as pesquisas baseadas na web que podem ser consultadas retrospectivamente

Novo (plugin) extrator do XKEYSCORE permite que diferentes dicionários sejam executados nos corpos dos documentos / e-mails - esses dicionários mais complexos podem gerar e banco de dados a informação requerida

Resposta: As impressões digitais dos alvos das TAO (Tailored Access Operations) são carregadas no mecanismo application / fingerprintID do XKEYSCORE - Os dados são marcados e armazenados em banco de dados

Fonte: Tabela com informações compiladas a partir do documento denominado XKEYSCORE elaborado pela National Security Agency (National Security Agency, 2008). 
A partir da tabela 4, é possível depreender que as capacidades do programa XKEYSCORE abrangem desde a localização digital (endereço IP) e geográfica (coordenadas do Google Maps) dos indivíduos-alvo, o conteúdo de suas comunicações (e-mails), as ações realizadas na internet (buscas realizadas e sites visitados) e vulnerabilidades que podem ser exploradas diretamente para comprometer seus equipamentos (vulnerabilidades de Hardware e Software), dentre tantas outras possibilidades. A imprensa noticiou abundantemente a forma de atuação do programa da agência e alarmou para a possibilidade de se obter níveis de privacidade na internet:

[...] XKeyscore, which gives the US intelligence community (and probably most of the US's Western allies) full access to your email, IMs, browsing history, and social media activity. To view almost everything that you do online, an NSA analyst simply has to enter your email or IP address into XKeyscore. No formal authorization or warrant is required; the analyst just has to type in a "justification" and press Enter. To provide such functionality, the NSA collects, in its own words, "nearly everything a typical user does on the internet." Perhaps most importantly, though, it appears that HTTPS and SSL might not protect your communications from being snooped on by the NSA. (ANTHONY, 2013)

As magnitude acerca dessa forma, capacidade e granularidade de atuação da NSA na infraestrutura mundial da internet foram notificados pela imprensa internacional como uma das mais graves ameaças a privacidade em escala global e um indício que de a Internet não mais proveria níveis adequados de segurança. De certa forma, pode-se dizer que a NSA colocou em xeque a segurança utilizada por padrão na Internet, como as tecnologias HTTPS e SSL, que criptografam as trocas de informações na rede mundial. Caso as tecnologias de proteção de internet, tais como "HTTPS, PGP, and VPNs have been compromised" e a agência "really has its insidious tentacles hooked into fiber-optic cables [...] and foreign satellite links, there is almost no way of using the internet or any other communications network without the American [...] governments snooping on you (ANTHONY, 2013)". É preciso salientar a capacidade de se rastrear, identificar e localizar o uso de tecnologias de criptografia para que sejam tomadas duas ações: (1) localizar o fornecedor da tecnologia criptográfica e; (2) descriptografar os conteúdos a partir de então.

What is surprising is that the slides seem to suggest that VPNs and encrypted links may not be secure. "Show me all PGP usage in Iran" and "Show me all VPN startups in country $X$, and give me the data so I can decrypt and discover users" seem to be functions available to analysts using XKS. This isn't a direct admission they've broken ciphers such as AES-256 and 3DES, but it would seem that they've found some exploitable weaknesses. (ANTHONY, 2013)

Ainda que mais segura do que "texto puro"em sua capacidade de proteção na internet frente às capacidades da NSA, a criptografia dificultaria o trabalho da agência por tornar os dados inacessíveis aos programas da NSA - o que acaba por trazer parte do 
conteúdo coletado como anônimo ou requerer que a NSA busque o conteúdo diretamente nas principais empresas que prestam serviços aos clientes diretamente pela Internet, tais como Google, Microsoft e Apple e é, justamente neste momento, que a coleta Downstream e o Prism entram em ação.

\subsection{A Coleta de Dados Downstream}

\subsubsection{O Programa PRISM}

PRISM é um acrônimo para Planning Tool for Resource Integration, Synchronization, and Management ou, em Português, Ferramenta de Planejamento para Integração de Recursos, Sincronização e Gerenciamento. Com o PRISM, a NSA passou a ter acesso direito aos principais provedores de serviços digitais da internet, tais como Microsoft, Yahoo, Google, Facebook, Paltal, Youtube, Skype, Aol, Apple, dentre tantos. Diferentemente de outros programas cuja interceptação e captação de dados era realizada como interceptação intermediária dos canais de comunicação, backbones e cabos submarinos da infraestrutura da internet, o programa PRISM construiu uma produção de inteligência mais assertiva ao acessar diretamente os serviços cujos dados são, então, produzidos, armazenados e providos aos indivíduos diretamente por todo o mundo.

Nas figuras 17 e 18, geradas a partir do documento/apresentação chamado "PRISM/US984XN Overview"da NSA National Security Agency (2013b), pode-se observar a forma e a capacidade de atuação do programa com os maiores fornecedores de serviços online em escalas globais. 
Figura 17 - Programa PRISM de Inteligência da NSA - parte 1

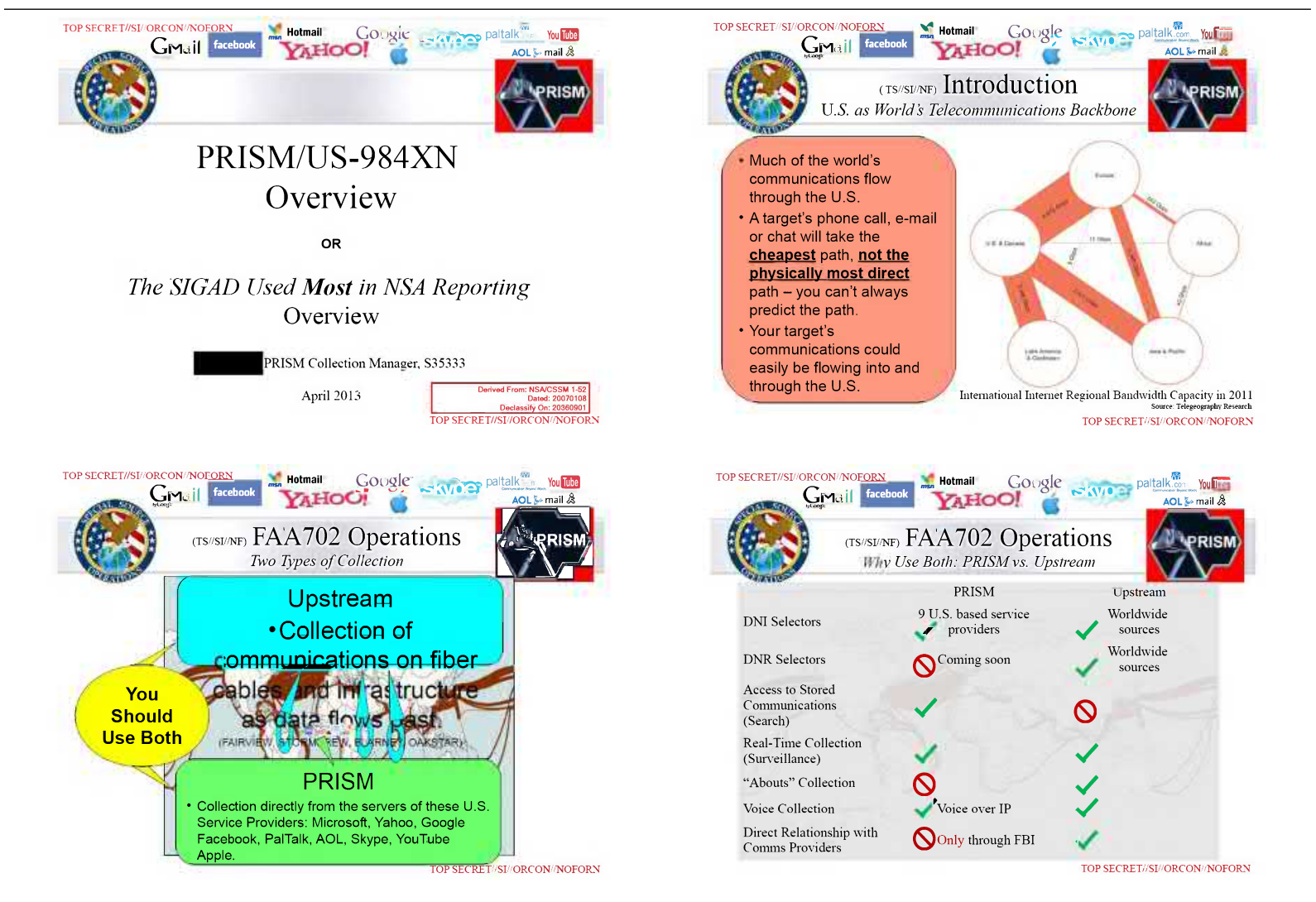

Fonte: Imagem compilada à partir da apresentação PRISM/US-984XN Overview da NSA (National Security Agency, 2013b)

Uma das possíveis interpretações, passível de ser identificada pela imagem 17, nos dá a dimensão de a NSA reconhece estrategicamente que grande parte das comunicações do mundo fluem pelos EUA e que é possível interceptar, portanto, uma ligação telefônica, e-mail ou bate-papo dos indivíduos que trafega pelo território dos EUA. A lógica das telecomunicações internacionais atende uma relação direta de custos, distância e soberanias, dentre outras variáveis. Por essa lógica, o país que detiver a melhor infraestrutura e prover os menores preços, acaba por concentrar e atuar como uma central: tal como os EUA. Nesse sentido, a NSA, por vezes, identifica que o "alvo"terá o caminho mais barato, não o caminho fisicamente mais direto, já que nem sempre é possível prever o caminho. Ainda assim, há uma tendência reconhecida até mesmo pela NSA de que as comunicações podem facilmente fluir para dentro e através dos EUA.

Conforme aponta Gleen Greenwald, no The Guardian, "Companies are legally obliged to comply with requests for users' communications under US law, but the Prism program allows the intelligence services direct access to the companies' servers". (GREENWALD; MACASKILL, 2013) Contudo, não é exatamente o que ocorre com o PRISM, pois não há solicitações ex-ante para acesso aos dados: são coletados diretamente sem salvaguardas legais, conforme explica Gleen Greenwald: 
When the FAA [Fisa Amendments Act in December 2012] was first enacted, defenders of the statute argued that a significant check on abuse would be the NSA's inability to obtain electronic communications without the consent of the telecom and internet companies that control the data. But the Prism program renders that consent unnecessary, as it allows the agency to directly and unilaterally seize the communications off the companies' servers. (GREENWALD; MACASKILL, 2013)

Os provedores de serviço citados ora não comentaram o caso ou demonstraram desconhecimento de que os dados de seus servidores estivessem disponíveis facilmente ao acesso da agência. O programa PRISM, até então, era desconhecido do público e em nenhum momento foi referendado pelos cidadãos dos EUA ou suas instituições democráticas. PRISM levantou questões de que a NSA teria, então, implantado backdoors nos provedores de serviço, uma prática recorrente da agência quando se trata do controle de tecnologias, como a criptografia e o caso do Clipper Chip, dentre outros.

Figura 18 - Programa PRISM de Inteligência da NSA - parte 2
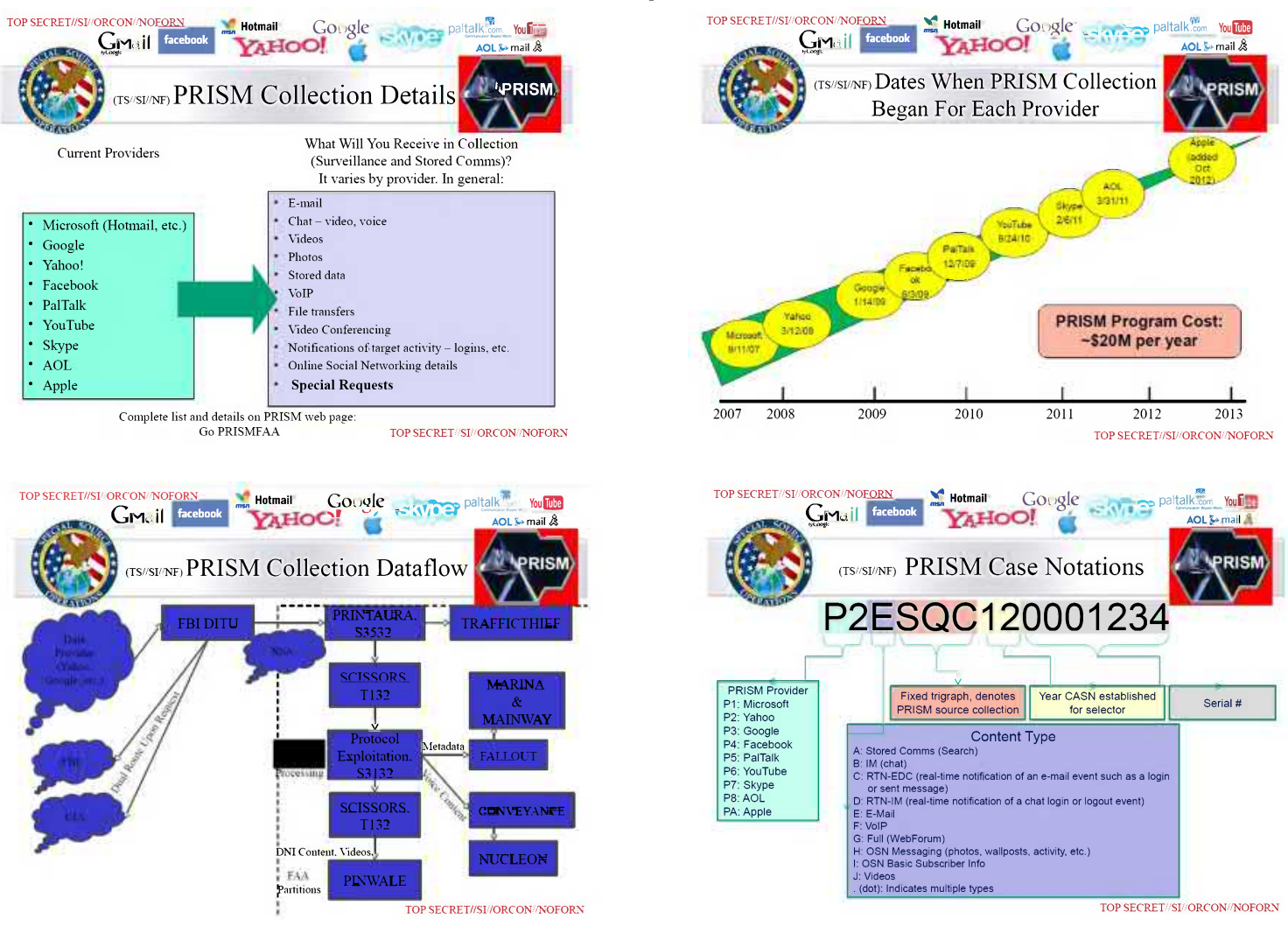

Fonte: Imagem compilada à partir da apresentação PRISM/US-984XN Overview da NSA (National Security Agency, 2013b) 


\subsection{O Poder Criptográfico da NSA}

As informações e documentos de acesso público versavam sobre a natureza da agência com a criptografia, o caráter estratégico e de advocacy da agência em torno de segurança nacional, bem como quais padrões criptográficos eram comumente utilizados na proteção da infraestrutura dos EUA. É preciso distinguir o que era informação disponibilizada publicamente das informações que efetivamente chegavam ao público. Para o cidadão dos EUA, tais considerações acerca da NSA não se materializavam ou se vinculavam no cotidiano do indivíduo. Ainda que tivessem a oportunidade de acessar os portais oficiais do governo, não se tratava de um tema de comoção nacional de forma que nada dizia exatamente como a agência atuava e como isso impactava o dia-a-dia do cidadão. Qual era esse impacto e até que ponto a NSA atuava doméstica e internacionalmente?

Não é segredo que a NSA trabalhou e trabalha deliberadamente para quebrar todo e qualquer código criptográfico que surja ou seja empregado em seu território ou demais países- afinal, quebrar códigos é a missão número um, divulgada publicamente pela agência. Nesse contexto, o segredo reside justamente nos métodos utilizados, nos alvos e na capacidade de realizá-los. De posse de informações divulgadas pelo whistleblower Eduard Snowden, diversos documentos trouxeram à tona essa capacidade de se dominar a criptografia e o desenho da tecnologia que a circunda e mantém. O espanto não foi somente dos cidadãos dos EUA, mas principalmente, pelos demais países - que em 2010 já tinham suas comunicações interceptadas em grandes volumes pela infraestrutura da NSA. Qual era o poder e domínio da agência sobre a criptografia utilizada pelo mundo todo?

A busca de respostas às questões acima depende de posicionamentos oficiais ou documentos que permitam compreender o escopo de atuação da agência em relação a criptografia. Seria um contrassenso esperar um posicionamento oficial da agência quando se trata da publicização de documentos cobertos por Segredo de Estado, balizados pela rationale da segurança nacional. Todavia, a partir da análise dos documentos "vazados"por Snowden, foram identificados os potenciais de atuação bem como a forma de classificação dessas capacidades criptográficas. Dois dos documentos foram considerados para compor o levantamento do de atuação da agência como a Criptografia. Denominados "Classification Guide Title/Number: (U//FOUO) Project Bullrun/2-16", publicado internamente à NSA em 16 de junho de 2010 com objetivo aplicar medidas de classificação de Segredo de Estado às capacidades criptográficas da NSA sob o nome de "Cryptanalysis and Exploitation Services" e o segundo documento, denominado CLASSIFICATION GUIDE FOR CRYPTANALYSIS, 2-12 explicitam uma fração da forma de atuação da agência com suas capacidades criptográficas e detalha aspectos do projeto BULLRUN, um complexo conjunto tecnologias e abordagens dedicadas à "quebrar"criptografias e atacar tecnologias.

Pela tabela 5, compilada à partir do "Classification Guide for Cryptanalysis" as capacidades criptoanalíticas da NSA são destacadas pormenorizadamente. A agência aplica, 
para cada uma de suas capacidades, níveis diferentes de "Segredo de Estado"e não se furta de demonstrar as ações que são classificadas, de facto, como ações que permitem, por intermédio de técnicas criptográficas, aplicar as capacidades de recuperar as criptovariáveis e explorar com êxito componentes e vulnerabilidades criptográficas não intencionais, mesmo que nem a vulnerabilidade e o dispositivo / sistema alvo seja identificado, bem como fazer modificações criptográficas em dispositivos ou sistemas de segurança de informações criptográficas comerciais ou nativos (indígenas) para torná-los exploráveis. Para tanto, a NSA trabalha com parceiros e tem a capacidade de obter detalhes criptográficos de sistemas comerciais de segurança de informações criptográficas através de relações industriais. A criticidade e classificação desse modus operandi foi reconstituído na tabela 5 à seguir, de acordo com as fontes internas da agência:

Tabela 5 - Tabela Consolidada de Formas de Classificação para Criptoanálise

\begin{tabular}{|c|c|}
\hline Descrição da Informação & Classificação \\
\hline $\begin{array}{l}1 \text { - O fato de que o NSA / CSS explora dispositivos e sistemas de segurança de } \\
\text { informações criptográficas. }\end{array}$ & $\begin{array}{l}\text { NÃO CLASSIFI- } \\
\text { CADO }\end{array}$ \\
\hline $\begin{array}{l}\text { trabalhar com parceiros do Second Party na exploração } \\
\text { de segurança de informações criptográficas. }\end{array}$ & {$[\mathrm{FID}]$} \\
\hline $\begin{array}{l}3 \text { - O fato de a NSA / CSS trabalhar com parceiros terceirizados não especi- } \\
\text { ficados na exploração de dispositivos e sistemas de segurança de informações } \\
\text { criptográficas. }\end{array}$ & SEGREDO \\
\hline $\begin{array}{l}4 \text { - O fato de a NSA / CSS explorar vulnerabilidades criptográficas não inten- } \\
\text { cionais em dispositivos e sistemas de segurança de informações comerciais ou } \\
\text { locais, desde que nem a vulnerabilidade nem o dispositivo / sistema alvo seja } \\
\text { identificado. }\end{array}$ & $\begin{array}{l}\text { NÃO CLASSIFI- } \\
\text { CADO }\end{array}$ \\
\hline $\begin{array}{l}\text { ato de a NSA / CSS fazer modificações criptográficas em dispositivos ou } \\
\text { as de segurança de informações criptográficas comerciais ou nativos para } \\
\text { os exploráveis. }\end{array}$ & $\begin{array}{l}\text { TOP SECRET // } \\
\text { COMINT no mí- } \\
\text { nimo }\end{array}$ \\
\hline $\begin{array}{l}6 \text { - O fato de que o NSA / CSS possui técnicas criptográficas para explorar com- } \\
\text { ponentes criptográficos de dispositivos ou sistemas de segurança de informações } \\
\text { comerciais ou locais. }\end{array}$ & $\begin{array}{l}\text { NÃO CLASSIFI- } \\
\text { CADO }\end{array}$ \\
\hline $\begin{array}{l}7 \text { - O fato de que a NSA / CSS tem a capacidade de recuperar as criptovariáveis } \\
\text { usadas para explorar dispositivos ou sistemas de segurança de informações } \\
\text { criptográficas comerciais ou autóctones. }\end{array}$ & CONFIDENCIAL \\
\hline $\begin{array}{l}8 \text { - O fato de o NSA / CSS explorar com êxito componentes criptográficos de } \\
\text { dispositivos ou sistemas de segurança de informações criptográficas comerciais } \\
\text { ou autóctones sem especificar o dispositivo ou sistema. }\end{array}$ & $\begin{array}{l}\text { NÃO CLASSIFI- } \\
\text { CADO }\end{array}$ \\
\hline $\begin{array}{l}9 \text { - O fato de o NSA / CSS explorar com êxito componentes criptográficos de } \\
\text { dispositivos ou sistemas de segurança de informações criptográficas comerciais } \\
\text { ou autóctones quando o dispositivo ou sistema é especificado. }\end{array}$ & $\begin{array}{l}\text { TOP SECRET // } \\
\text { COMINT no mí- } \\
\text { nimo }\end{array}$ \\
\hline $\begin{array}{l}10 \text { - O facto de a NSA / C } \\
\text { de segurança de informaç }\end{array}$ & $\begin{array}{l}\text { TOP SECRET no } \\
\text { mínimo }\end{array}$ \\
\hline
\end{tabular}

Fonte: Tabela com informações compiladas a partir do documento Classification Guide for Cryptanalysis National Security Agency (2005) da NSA

A quebra de padrões criptográficos, com o crescente adensamento da tecnologia 
envolvida, tornou-se uma atividade de agentes Estatais - tanto pela necessidade de recursos computacionais para a atividade como pela sofisticação estrutural e tecnológica necessária pra tal objetivo. Essa tendência de adensamento tecnológico na criptografia também identificada e patrocinada, por vezes, pela própria NSA e sua busca incessante pela hegemonia tecnológica/criptográfica. Um dos programas da agência dedicado à quebra da criptografia é o BULLRUN, executado com o propósito de efetivamente tornar seus objetivos em práticas concretas em relação à tecnologia. É à partir de programas como BULLRUN que a agência consegue descriptografar as comunicações domésticas e globais e potencialmente tornar qualquer canal de telecomunicação supostamente seguro, em inseguro aos olhos do Estado. BULLRUN, para a agência, é uma das principais ferramentas para revelar o conteúdo das comunicações protegidas pela criptografia. Em sua definição interna provida pelo documento "Classification Guide Title/number: Project BULLRUN", a agência descreve o programa da seguinte maneira:

Project BULLRUN deals with NSA's abilities to defeat the encryption used in specific network communication technologies. BULLRUN involves multiple sources, all of which are extremely sensitive. They include CNE 194 , interdiction, industry relationships, collaboration with other IC entities, and advanced mathematical techniques. Several ECIs ${ }^{195}$ apply to the specific sources, methods, and techniques involved. Because of the multiple sources involved in BULLRUN activities, "capabilities against a technology" does not necessarily equate to decryption. ${ }^{196}$ (National Security Agency, 2010a)

O projeto/programa BULLRUN, pela descrição provida pela Agência, unifica diversas iniciativas que auxiliam a NSA a atacar e descriptografar as tecnologias que protegem as comunicações indiscriminadamente. É necessário pontuar que, por vezes, a aquisição de inteligência não se dará pelas vias da quebra criptográfica, mas, sim, pela exploração de vulnerabilidades em outras frentes da tecnologia-alvo ou com parcerias que permitam acessar as variáveis necessárias para sua atuação. Nesse sentido, o Projeto BULLRUN também aporta diversas maneiras de conduzir "capabilities against a technology"de forma a habilitar a aquisição de inteligência.

\footnotetext{
${ }^{194}$ Acrônimo para Computer Network Exploitation, que se traduz em práticas de espionagem e reconhecimento de redes de computadores para aquisição de inteligência por intermédio da exploração de vulnerabilidades e brechas de segurança.

195 Acrônimo para Exceptionally Controlled Information que pode ser compreendido como classificações da informação que estãoa acima da categoria de "TOP SECRET". Schneier exemplifica a aplicação dessa categoria de informações para "It's for things that are so sensitive they're basically not written down, like the names of companies whose cryptography has been deliberately weakened by the NSA, or the names of agents who have infiltrated foreign IT companies". (SCHNEIER, 2014)

196 "O Projeto BULLRUN lida com as habilidades da NSA para derrotar a criptografia usada em tecnologias de comunicação de rede específicas. BULLRUN envolve múltiplas fontes, todas extremamente sensíveis. Eles incluem CNE, interdição, relações com a indústria, colaboração com outras entidades IC e técnicas matemáticas avançadas. Diversas ECIs aplicam-se às fontes, métodos e técnicas específicos envolvidos. Por causa das múltiplas fontes envolvidas nas atividades BULLRUN, "capacidades contra uma tecnologia" não necessariamente equivalem a descriptografia"(National Security Agency, 2010a), tradução nossa (as siglas foram referenciadas na citação original.).
} 
Tabela 6 - Classificação Criptográfica pela NSA

\begin{tabular}{|c|c|c|}
\hline Descrição da Informação & Classificação & Duração \\
\hline $\begin{array}{l}\text { B. 1. - O fato de os Serviços de Criptanálise e Exploração (CES) } \\
\text { trabalharem com: } \bullet \text { Centro de Soluções Comerciais da NSA / CSS } \\
(\text { NCSC) • Operações de Acesso sob Medida (TAO) • Parceiros } \\
\text { terceiros }\end{array}$ & $\begin{array}{l}\text { NÃO CLASSI- } \\
\text { FICADO }\end{array}$ & $\mathrm{N} / \mathrm{D}$ \\
\hline $\begin{array}{l}\text { B.2. - O fato de os Serviços de Criptanálise e Exploração (CES) } \\
\text { trabalharem com: } \bullet \text { Centro de Soluções Comerciais da NSA / CSS } \\
\text { (NCSC) para alavancar relacionamentos cooperativos e sensíveis } \\
\text { com parceiros específicos do setor } \bullet \text { Operações de acesso sob } \\
\text { medida (TAO) para alavancar computadores específicos ativida- } \\
\text { des de exploração de rede } \bullet \text { entidades específicas do governo dos } \\
\text { EUA / IC para aprimorar os recursos da NSA / CSS contra a } \\
\text { criptografia usada em tecnologias de comunicação de rede }\end{array}$ & TOP SECRET & 25 anos* \\
\hline $\begin{array}{l}\text { B.3. - Detalhes da colaboração do CES com: • Centro de Soluções } \\
\text { Comerciais da NSA / CSS (NCSC) para alavancar relaciona- } \\
\text { mentos cooperativos e sensíveis com parceiros da indústria } \bullet \\
\text { Operações de acesso sob medida (TAO) para alavancar ativida- } \\
\text { des de exploração de redes de computadores • Segundo Parceiros } \\
\text { do grupo } \bullet \text { entidades específicas do governo dos EUA / IC para } \\
\text { aprimorar os recursos da NSA / CSS contra a criptografia usada } \\
\text { em tecnologias de comunicação de rede }\end{array}$ & TOP SECRET & 25 anos* \\
\hline $\begin{array}{l}\text { Cl- O fato de que o Cryptanalysis and Exploitation Services } \\
\text { (CES) desenvolve capacidades criptoanalíticas para explorar as } \\
\text { vulnerabilidades inerentes à criptografia usada em tecnologias de } \\
\text { comunicação de rede não especificadas. }\end{array}$ & $\begin{array}{l}\text { NÃO CLAS- } \\
\text { SIFICADO } \\
/ / \quad \text { APENAS } \\
\text { PARA USO } \\
\text { OFICIAL }\end{array}$ & $\mathrm{N} / \mathrm{D}$ \\
\hline $\begin{array}{l}\text { C.2.- O fato da NSA / CSS visar tecnologias de comunicação de } \\
\text { rede encriptadas específicas }\end{array}$ & SEGREDO & 25 anos* \\
\hline $\begin{array}{l}\text { C.3. - O fato da NSA / CSS ter alguns recursos contra a cripto- } \\
\text { grafia em TLS / SSL, HTTPS, SSH, VPNs, VoIP, WEBMAIL e } \\
\text { outras tecnologias de comunicação de rede }\end{array}$ & TOP SECRET & 25 anos* \\
\hline $\begin{array}{l}\text { C.4. - O fato da NSA / CSS ter uma capacidade contra a cripto- } \\
\text { grafia usada em uma implementação específica de uma tecnologia } \\
\text { de comunicação de rede }\end{array}$ & TOP SECRET & 25 anos* \\
\hline $\begin{array}{l}\text { C.5. - Detalhes revelando fontes e métodos específicos que permi- } \\
\text { tem uma capacidade contra a criptografia usada em tecnologias } \\
\text { de comunicação de rede }\end{array}$ & TOP SECRET & 25 anos* \\
\hline $\begin{array}{l}\text { C.6. - O fato de que NSA / CSS desenvolve implantes para habi- } \\
\text { litar uma capacidade contra a criptografia usada em tecnologias } \\
\text { de comunicação de rede }\end{array}$ & TOP SECRET & 25 anos* \\
\hline $\begin{array}{l}\text { D.l. - Descriptografa (também conhecido como texto simples) } \\
\text { obtido das capacidades BULLRUN }\end{array}$ & TOP SECRET & 25 anos* \\
\hline D.2. Informação criptográfica obtida das capacidades BULLRUN & TOP SECRET & 25 anos* \\
\hline
\end{tabular}

Fonte: Compilado de fontes diversas pelo autor

De posse das informações orçamentárias da agência divulgadas no vazamento de dados de Edward Snowden, os jornalistas Perlroth, Shane e Larson (2013) do jornal The New York Times publicaram o artigo "Secret Documents Reveal N.S.A. Campaign Against Encryption"pelo qual descrevia outras capacidades da agência. Pelos documentos, 
Perlroth, Shane e Larson (2013) descobriram que os havia no orçamento descritivos que "outlines the ways in which the agency circumvents the encryption protection of everyday Internet communications"(PERLROTH; SHANE; LARSON, 2013) e em outra passagem, identificaram nos documentos alguns "excerpt from a 2013 budget proposal outlines some methods the agency uses to undermine encryption used by the public". Mais do que isso, o documento corroborara a classificação das capacidades da agência - algo que Perlroth, Shane e Larson (2013) descreveram como "The Sigint Enabling Project involves industry relationships, clandestine changes to commercial software to weaken encryption, and lobbying for encryption standards it can crack"(PERLROTH; SHANE; LARSON, 2013).

Em consonância com a análise documental realizada no decorrer desta pesquisa, os jornalistas identificaram descrições do poder criptoanalítico, desta vez, atreladas não à classificações de Segredo de Estado, mas, sim, à orçamentos para a continuidade e incremento de suas operações. Em um desses documentos, Perlroth, Shane e Larson (2013) identificam que "The agency defines capability as "the NSA/CSS ability to exploit a specific technology," according to a 2010 document outlining the Bullrun program ${ }^{197}$ "e relembram de episódios anteriores nos quais a Agência atuou ativamente na concepção e quebra de tecnologias, tal como " [...] In 2013, the agency planned to be able to decode traffic that was encoded by [...] encryption chips, either by working with the manufacturers of the chips to insert back doors or by exploiting a security flaw in the chips' design ${ }^{198 " . ~ O u ~ s e j a, ~ a ~}$ NSA agiria deliberadamente e com o aval Estatal no enfraquecimento das tecnologias que suportam as liberdades civis, como a criptografia suporta a privacidade; sem que, para isso, a criptografia fosse controla, mas, sim, um conjunto de tecnologias tivesse seu desenho enfraquecido com a introdução proposital de falhas que pudessem ser exploradas.

A vitalidade do projeto em 2013 era expressa pelo documento orçamentário, cuja análise dos jornalistas foi expressa na constatação de que "The N.S.A.'s Sigint Enabling Project is a 250 million-a-year program that works with Internet companies to weaken privacy by inserting back doors into encryption products ${ }^{199 " ~(P E R L R O T H ; ~ S H A N E ; ~}$ LARSON, 2013). A dinâmica de produção de backdoors pela NSA teria como objetivo a primazia sobre a tecnologia, o controle e ao acesso à aplicação ou aos dados per se. A compreensão também é compartilhada pelos jornalistas quando afirmar que "These back doors allow the agency, and in theory only the agency, to gain access to scrambled information that it would not be able to view otherwise $200 "$.

197 "A agência define capacidade como "a capacidade da NSA / CSS de explorar uma tecnologia específica", de acordo com um documento de 2010 delineando o programa Bullrun" (PERLROTH; SHANE; LARSON, 2013), tradução nossa.

198 "Em 2013, a agência planejou ser capaz de decodificar o tráfego codificado por chips [...] de criptografia, seja trabalhando com os fabricantes dos chips para inserir portas dos fundos ou explorando uma falha de segurança no design dos chips" (PERLROTH; SHANE; LARSON, 2013), tradução nossa.

199 "O Sigint Enabling Project do N.S.A. é um programa de 250 milhões de dólares anuais que trabalha com empresas de Internet para enfraquecer a privacidade, inserindo portas traseiras em produtos de criptografia" (PERLROTH; SHANE; LARSON, 2013), tradução nossa.

${ }^{200}$ Essas portas traseiras permitem que a agência e, em teoria, apenas a agência tenha acesso às informações 
O debate vai além e é visto pela literatura como problemático do ponto de vista da "Segurança da Informação"enquanto área, pois nada garantia que, por exemplo, outros agentes, hackers, terroristas e outros Estados não explorem as mesmas vulnerabilidades; nesse sentido, uma vulnerabilidade introduzida ou descoberta pela NSA, porém não compartilhada, representaria uma ameaça generalizada para todos os usuários da tecnologia vulnerável.Essa ambivalência da agência recai sobre seus próprios objetivos, ora o de fornecer os meios e mecanismos para a proteção às comunicações dos Estados Unidos, ora de enfraquecer todas as demais comunicações para suas ações de vigilância massiva e inteligência. Os jornalistas aponta a questão de que a NSA ensejaria essa ambivalência, quiçá, conflito entre seus objetivos:

Because the N.S.A. has long been considered the world's top authority on encryption, it has dual, sometimes competing, roles. One responsibility of the agency is to safeguard United States communications by promoting encryption standards, and the other is to break codes protecting foreign communications. Part of the Sigint Enabling Project's goal is to influence these standards - which are often used by American companies - and weaken them ${ }^{201}$. (PERLROTH; SHANE; LARSON, 2013).

Enfraquecer o desenho da tecnologia, tornando-a vulnerável, e explorar o desenho da tecnologia, para identificar vulnerabilidades: ambas ações seriam, portanto, rotineiras e objetivadas pelos programas da NSA em termos gerais; afinal, controle necessário passaria expressamente pelo controle da tecnologia que o promove. Quando a NSA exerce a primeira dinâmica citada, ela introduz deliberadamente para seus propósitos desenhos falhos ou com possibilidades de controle remoto, por vez, impossível ou dificultosamente complexos de desabilitar - a sociedade sequer teria ciência de tais mecanismos. Quando a NSA exerce a segunda dinâmica, ela descobriria então vulnerabilidades e falhas nos desenhos as quais, em sua política interna, dificilmente tornaria públicas ${ }^{202}$; já o objetivo de se explorar o controle da tecnologia seria o mesmo.

embaralhadas que não seriam capazes de visualizar de outra forma.

201 "Porque o N.S.A. Há muito tempo é considerada a maior autoridade do mundo em criptografia, tem papéis duplos, às vezes concorrentes. Uma responsabilidade da agência é proteger as comunicações dos Estados Unidos promovendo padrões de criptografia e a outra é quebrar os códigos que protegem as comunicações estrangeiras. Parte do objetivo do Sigint Enabling Project é influenciar esses padrões que são frequentemente usados por empresas americanas - e enfraquecê-los" (PERLROTH; SHANE; LARSON, 2013), tradução nossa.

${ }^{202}$ Em relação à essa segunda dinâmica, a agência estocaria vulnerabilidades desconhecidas lado à lado com as vulnerabilidades introduzidas à tecnologia; conhecidas como vulnerabilidades "Oday", elas estão presentes em praticamente todos os desenhos tecnológicos, sejam por falhas do desenho, das interfaces com que interage ou em relação às falhas do contexto. Ainda assim, seriam estocadas fora da visão da sociedade com o intuito de mantê-las irreparáveis e incorrigíveis, logo, exploráveis. (ZETTER, 2014) explora a questão ao aprofundar como armas cibernéticas foram capazes de parar centrífugas iranianas de enriquecimento de urânio por intermédio da exploração de quatro vulnerabilidades tecnológicas desconhecidas pela comunidade internacional, mas identificadas pelas ações e estudos de vulnerabilidade de agentes estatais: o caso do arma cibernéticaStuxnet, como ficou conhecido, representou um marco na atuação de agentes estatais na exploração de backdoors e vulnerabilidades "Oday" para fins militares 


\section{Parte IV}

\section{Resultados e Considerações Finais}





\section{Considerações Finais}

O processo de pesquisa passou por quatro países, Brasil, Alemanha, Dinamarca e França, nos quais interlocutores de grandes centros de excelência acadêmica contribuíram na crítica às argumentações da tese. Em relação ao levantamento bibliográfico, foram identificados, catalogados e fichados mais de 2500 livros e artigos que, por restrição de tempo, dentre outras variáveis, não puderam ser abarcados em sua totalidade neste trabalho - porém, certamente, farão parte da extensão do mesmo. No decorrer das dinâmicas de pesquisa e desenvolvimento deste trabalho, uma agenda de pesquisa se desdobrou e buscou, a partir das abordagens teóricas, dos insumos do estudo de caso, corroborar ou refutar a hipótese. Nesse sentido, os resultados aplicáveis a este trabalho, bem como as considerações finais, previstas nesse capítulo, serão compostas pela seções ligadas aos resultados do Privacy and Civil Liberties Oversight Board - PCLOB - bem como pela seção 10.4, denominada "A Teoria em Perspectiva"e pela seção 10.5 "A Pesquisa em Perspectiva". Nas seções apontadas, serão discutidos os resultados obtidos pela averiguação sistemática do objeto da pesquisa conjuntamente com as considerações finais do trabalho. ${ }^{203}$.

\subsection{A Supervisão da Privacidade e Liberdades Civis: Resultados do Privacy and Civil Liberties Oversight Board - PCLOB}

À luz dos documentos revelados por Edward Snowden, uma sucessão de eventos ocorreu tanto no debate doméstico dos Estados Unidos, acerca da relação entre vigilância, criptografia e privacidade, como pela mídia global, devido à espionagem massiva de cidadãos de outras nacionalidades e localizados em outros países. De posse dos documentos, jornais como o The Guardian (citados nesse trabalho), deram então curso à uma série de investigações e estudos sobre a profundidade das ações conduzidas pelos Estados Unidos e suas agências de inteligência lideradas pela NSA.

A sociedade civil organizada, a imprensa e o Congresso norte-americano colocaram em pauta e demandaram explicações sobre a extensão e profundidade das ações então executadas e, mais precisamente, "[...]central among the issues raised was the degree to which

$\overline{203}$ No decorrer do trabalho de pesquisa aqui realizado, até o seu dia de conclusão, notícias e novas fontes de informação foram então acrescentadas com rigor e ceticismo, inclusive, pela natureza de "Segredo de Estado"dos documentos que foram gradativamente transformados em passíveis de acessos públicos, documentos que até então não eram tidos como oficiais e fontes estritamente oficiais: dinâmica que, por sua vez, demandava e continua a demandar a atualização constante por parte da pesquisa para além de seu recorte temporal. Ainda que não sejam exaustivas do potencial da agenda que a pesquisa suscitou/suscitará. 
the programs included appropriate safeguards for privacy and civil liberties ${ }^{204 " ~(M E D I N E ~}$ et al., 2014b, p.1). Era fundamental, para o Congresso, frente às graves acusações que eram feitas contra as instituições dos EUA, que as ações e profundidade dos programas de vigilância fossem devidamente explicitadas à sociedade. Céticos da profundidade e penetração que a as ações da NSA possuíam, um grupo de senadores demandaram a revisão dos programas pelo Privacy and Civil Liberties Oversight Board (conhecido pela sigla "PCLOB").

\begin{abstract}
One week after the first news article appeared, a bipartisan group of thirteen U.S. Senators asked the recently reconstituted Privacy and Civil Liberties Oversight Board ("PCLOB") to investigate the two NSA programs and to provide an unclassified report "so that the public and the Congress can have a long overdue debate" about the privacy issues raised $^{205}$. (MEDINE et al., 2014b, p.1)
\end{abstract}

Criado em 2007 pela necessidade de se avaliar a extensão dos programas de inteligência e proteção contra o terrorismo iniciados à partir do atentado de 11/09 de 2001, o Conselho PCLOB foi reinstaurado com a finalidade de, desta vez, avaliar o mérito, as práticas e a legalidade das ações conduzidas pela NSA, bem como as consequências políticas e seus impactos nas liberdades civis. Em sua autodescrição institucional ${ }^{206}$, o Conselho se define como formado por uma composição bipartidária, com duas grandes funções complementares ligadas à prática e a legislação: (1) - "Analisar e rever as ações tomadas pelo poder executivo para proteger a Nação contra o terrorismo, assegurando que a necessidade de tais ações seja equilibrada com a necessidade de proteger a privacidade e as liberdades civis" (MEDINE et al., 2014b, p.2) - em outras palavras, seriam análises focadas na prática derivada das legislações de vigilância - e; (2) "Assegurar que as questões de liberdade sejam apropriadamente consideradas no desenvolvimento e implementação de leis, regulamentos e políticas relacionadas aos esforços para proteger a Nação contra o terrorismo" (MEDINE et al., 2014b, p.2) - compreendido como a análise do mérito legal de tais ações.

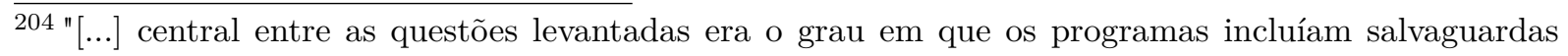
apropriadas para a privacidade e as liberdades civis" (MEDINE et al., 2014b, p.1), tradução nossa.

205 "Uma semana após o surgimento do primeiro artigo, um grupo bipartidário de treze senadores dos Estados Unidos solicitou ao recentemente reconstituído Comitê de Supervisão de Privacidade e Liberdades Civis ("PCLOB") que investigasse os dois programas da NSA e fornecesse um relatório não confidencial "para que o público eo público O Congresso pode ter um debate muito atrasado sobre as questões de privacidade levantadas" (MEDINE et al., 2014b, p.1), tradução nossa.

${ }^{206} \mathrm{~A}$ descrição pode ser encontrada na íntegra no seguinte excerto: "The PCLOB is an independent bipartisan agency within the executive branch established by the Implementing Recommendations of the 9/11 Commission Act of 200\%. The Board is comprised of four part-time members and a full-time chairman, all appointed by the President and confirmed by the Senate. The Board's authorizing statute gives it two primary responsibilities: 1) To analyze and review actions the executive branch takes to protect the Nation from terrorism, ensuring that the need for such actions is balanced with the need to protect privacy and civil liberties; and 2) To ensure that liberty concerns are appropriately considered in the development and implementation of laws, regulations, and policies related to efforts to protect the Nation against terrorism". (MEDINE et al., 2014b, p.2) 
O Conselho esteve "dormente"após o período de sua instauração. Sua reenergização ocorreu precisamente no período de divulgação de documentos por Edward Snowden, quando o então presidente Barack Obama demandou a elaboração de avaliações "independentes" 207 quando publicou a "Presidential Policy Directive/PPD-28"que continha a seguinte diretriz: "The Privacy and Civil Liberties Oversight Board is encouraged to provide me with a report that assesses the implementation of any matters contained within this directive that fall within its mandate ${ }^{208 "}$ (The White House - Office of the Press Secretary, 2014). Após a publicação da PPD-28 e em consonância com os dois objetivos do PCLOB e como resultado de seus esforços, foram publicados 4 (quatro) "Oversight Reports"principais, pelos quais o Conselho avaliou a Comunidade de Inteligência dos EUA e diversos outros relatórios anuais e semestrais das demais ações governamentais.

\subsubsection{Relatórios dos Programas de Vigilância}

O Conselho reuniu em seus relatórios, então, evidências tanto aquelas divulgadas inadvertidamente da NSA, como evidências providas diretamente pela própria NSA e demais agências da Comunidade de Inteligência ${ }^{209}$. Suas conclusões levaram em consideração aspectos validados com a agência e seus especialistas - fator que contribuiu para a análise e para as recomendações vislumbradas nos resultados dos relatórios. Os relatórios serão, então, abordados nesta seção como parte factual-institucional da pesquisa, com o peso corroborante de suas avaliações sobre o estudo de caso, nossos objetivos e, principalmente, com impacto na hipótese, conforme explicado nas seções finais deste capítulo.

$\overline{207}$ Que pese a ressalva metodológica de comprometimento da independência e autonomia institucional por considerarmos que os membros do PCLOB são compostos de 5 indicações pelo Presidente dos EUA, com a ratificação do Senado, fatores que não permitiriam uma avaliação multissetorial sobre o debate em questão e limitaria a independência de suas análises.

208 "O Conselho de Privacidade e de Liberdades Civis é encorajado a fornecer-me um relatório que avalie a implementação de quaisquer assuntos contidos nesta directiva que caiam dentro do seu mandato" (The White House - Office of the Press Secretary, 2014), tradução nossa.

${ }^{209}$ O Conselho PCLOB teve o cuidado de descrever sua forma de interação e metodologia na construção de seus relatórios, recomendações e conclusões. Como metodologia, PCLOB levou em consideração os seguintes aspectos: "In response to the congressional and presidential requests, the PCLOB undertook an in-depth study of the Section 215 and 702 programs as well as the operations of the FISA court. This study included classified briefings with officials from the Office of the Director for National Intelligence ("ODNI"), NSA, Department of Justice, Federal Bureau of Investigation ("FBI"), and Central Intelligence Agency ("CIA"). Board members also met with White House staff, a former presiding judge of the FISA court, academics, privacy and civil liberties advocates, technology and communications companies, and trade associations. The Board also received a demonstration of the Section 215 program's operation and capabilities at the NSA. The Board has been provided access to classified opinions by the FISC, various inspector general reports, and additional classified documents relating to the operation and effectiveness of the programs. At every step of the way, the Board has received the full cooperation of the intelligence agencies. Board staff have conducted a detailed analysis of applicable statutory authorities, the First and Fourth Amendments to the Constitution, and privacy and civil liberties policy issues". (MEDINE et al., 2014b, p.4). Maiores informações metodológicas podem ser consultadas diretamente no relatório em questão. 


\subsection{Relatório sobre o Programa de Registros Telefônicos Reali- zado sob a Seção 215 do USA PATRIOT Act e sobre as Ope- rações do Tribunal de Vigilância de Inteligência Estrangeira}

O primeiro relatório publicado pelo PCLOB, em 23 de Janeiro de 2014, tratava da questão da coleta massiva de metadados de telefones nos EUA sob a seção 215 do USA PATRIOT ACT e as operações autorizadas, nesse contexto, pelo Tribunal da FISA. O relatório propôs um total de 20 (vinte) recomendações para aumentar a proteção às liberdades civis e, em especial, a privacidade. A análise realizada pelo Conselho é relativamente extensa, com considerações pertinentes tanto à prática quando a legalidade de cada ação averiguada nos programas da Comunidade de Inteligência. Dentre as análises realizadas, o Conselho perpassou extensivamente pelas análises de antecedentes do programa: Descrição e Histórico do Programa da Seção 215; Análise Legal: Questões Estatutárias e Constitucionais; Implicações de política do Programa da Seção 215; Operação do Tribunal de Vigilância de Inteligência Estrangeira e, por fim; Problemas de transparência. Após a conclusão das análises e em consideração à dinâmica metodológica empregada, PCLOB desenvolveu diversas recomendações para serem implementadas amplamente pelas instituições dos EUA.

\subsubsection{Resultados das Análises do Programa de Registros Telefônicos Realizado sob a Seção} 215

Devido à extensiva análise do Conselho sobre o Programa de Registros Telefônicos Realizado sob a Seção 215 do USA PATRIOT Act e sobre as Operações do Tribunal de Vigilância de Inteligência Estrangeira, o enfoque será direcionado para os aspectos críticos identificados nos resultados divulgados, dentre eles: as implicações políticas da Seção 215 e os problemas de transparência do Programa. Mesmo com acesso exclusivo ${ }^{210}$ à informações classificadas como "segredo de Estado", o PCLOB não foi capaz de identificar provas materiais de que o programa de coleta massiva de metadados de telecomunicações fora benéfico sem propósito e que, portanto, causou mais dano às instituições democráticas e as liberdades civis.

O programa de coleta de metadados de telecomunicações tinha como objetivo figurar "as one tool to combat this threat - a tool that would help investigators piece together the networks of terrorist groups and the patterns of their communications with a speed and comprehensiveness not otherwise available ${ }^{211 " ~(M E D I N E ~ e t ~ a l ., ~ 2014 b, ~ p .11) . ~}$

\footnotetext{
${ }^{210}$ As informações foram diversas, principalmente pela passagem livro do PCLOB entre as agências de Inteligência e entre os três poderes -para essa análise em específico, o PCLOB ainda reforçou que os pareceres foram substanciados "based on the information provided to the Board, including classified briefings and documentation".

211 "Como uma ferramenta para combater essa ameaça - uma ferramenta que ajudaria os investigadores a
} 
Pela perspectiva do Conselho, essa missão não foi cumprida. Nesse sentido, o PCLOB constatou que não fora possível "[...]identified a single instance involving a threat to the United States in which the program made a concrete difference in the outcome of a counterterrorism investigation ${ }^{212 " ~(M E D I N E ~ e t ~ a l ., ~ 2014 b, ~ p .11) ~ e ~ q u e, ~ p o r t a n t o, ~ n a ̃ o ~}$ haveria nenhum ganho em termos de Segurança Nacional, pois o governo dos EUA não conseguiu demonstrar "[...] that the program materially enhances security to a degree that justifies its effects on privacy, free speech, and free association ${ }^{213 " ~(M E D I N E ~ e t ~ a l ., ~ 2014 b, ~}$ p.11). Para o Conselho, a conclusão sequer entrou no mérito se haveria a necessidade de se equacionar as necessidades dos EUA para a promoção da segurança nacional, pois o programa se mostrou inefetivo, ainda que lesivo.

O relatório aprofunda, em uma discussão análoga à aos capítulos teóricos deste trabalho, nas instituições democráticas afetadas pela vigilância massiva. Para o Conselho do PCLOB, haveria uma tensão entre a transparência e o segredo de Estado e que se essa tensão aparecia criticamente quando era abordada à coleta de inteligência. O relatório, por sua vez, acrescenta uma nova dicotomia não ainda necessariamente prevista pelo desenvolvimento deste trabalho: o equilíbrio entre as duas pontas do espectro entre transparência e segredo de Estado como um elemento essencial à sustentação das instituições democráticas:

In a representative democracy, the tension between openness and secrecy is inevitable and complex. The challenges are especially acute in the area of intelligence collection, where the powers exercised by the government implicate fundamental rights and our enemies are constantly trying to understand our capabilities in order to avoid detection. In this context, both openness and secrecy are vital to our survival, and we must strive to develop and implement intelligence programs in ways that serve both values $^{214}$. (MEDINE et al., 2014b, p.14-15)

A passagem marcadamente acrescenta outra camada analítica ao objeto e ao dilema da tese, que transita dentre os espectros-dicotomias tais como: Privacidade vs Vigilância, Segurança Nacional vs Liberdades Civis e, por esta última contribuição do PCLOB, Transparência e Segredo de Estado. As dicotomias, críticas pelos dilemas que suscitam em sociedades democráticas, foram então desdobradas pelo PCLOB em instituições que

reunir as redes de grupos terroristas e os padrões de suas comunicações com rapidez e abrangência que não estão disponíveis de outra forma" (MEDINE et al., 2014b, p.11), tradução nossa.

212 "[...] identificou um único caso envolvendo uma ameaça aos Estados Unidos em que o programa fez uma diferença concreta no resultado de uma investigação antiterrorista" (MEDINE et al., 2014b, p.11), tradução nossa.

213 "[...] que o programa aumenta materialmente a segurança a ponto de justificar seus efeitos sobre privacidade, liberdade de expressão e livre associação" (MEDINE et al., 2014b, p.11), tradução nossa.

214 "Em uma democracia representativa, a tensão entre abertura e sigilo é inevitável e complexa. Os desafios são especialmente agudos na área de coleta de inteligência, onde os poderes exercidos pelo governo implicam direitos fundamentais e nossos inimigos estão constantemente tentando entender nossas capacidades para evitar a detecção. Nesse contexto, tanto a abertura quanto o sigilo são vitais para nossa sobrevivência, e devemos nos esforçar para desenvolver e implementar programas de inteligência de maneiras que sirvam a ambos os valores" (MEDINE et al., 2014b, p.14-15), tradução nossa. 
remontam às instituições democráticas também apresentadas por Dahl e intrincadas à privacidade por Westin. As teorias, então trabalhadas pela pesquisa até este ponto, começam e encontrar seus alter-egos e desdobramentos em uma constante combinação entre teoria e praxis. A voz institucional do Conselho, ao abordar a questão da transparência e das liberdades civis nos EUA, conjuga também os impactos que se sucedem em regimes democráticos frente à vigilância massiva, no caso, observado pelo estudo de caso em questão. Nesse sentido, o alter-ego da teoria-praxis preconizadas são desdobrados pelo PCLOB primeiro em prol pela transparência e, segundo, em prol das liberdades civis.

A Transparência como base democrática, acompanhada pela participação de um eleitorado informado, com acesso público às informações, accountability são parte das instituições democráticas elencadas por Dahl e rememoradas pelo PCLOB nos relatórios de oversight. O relatório cita que "transparency is one of the foundations of democratic governance" (MEDINE et al., 2014b, p.14-15) e que, dependente dela, todo um sistema constitucional se desdobra e "relies upon the participation of an informed electorate [...] This in turn requires public access to information about the activities of the government[...] Transparency supports accountability. ${ }^{215}$ (MEDINE et al., 2014b, p.14-15)"Primordialmente à isso, a transparência evita a tirania e está diretamente vinculada enquanto preceito democrático quando se trata da proteção contra retrocessos em direitos e liberdades fundamentais, tal como aponta o relatório ao analisar que a transparência é "especially important with regard to activities of the government that affect the rights of individuals, where it is closely interlinked with redress for violations of rights ${ }^{216 " ~(M E D I N E ~ e t ~ a l ., ~}$ 2014b, p.14-15). Transparência, enquanto contraposição às arbitrariedades, violações e tiranias, é mais do que crítica, é essencial à uma democracia.

As implicações do programa conduzido sob bases legais da Seção 215 questionadas pelo Conselho não são poupadas no relatório. As liberdades civis são destacadas como aquelas que foram preteridas em vista das ações conduzidas, o que expressa a preocupação do Conselho ao afirmar que "The Board also has analyzed the Section 215 program's implications for privacy and civil liberties and has concluded that they are serious ${ }^{217 " ~(M E D I N E ~}$ et al., 2014b, p.12-13). As conjunção da coleta massiva de metadados telefônicos com outros programas da NSA forjariam um vasto banco de dados conectado e sem precedentes no curto histórico democrático. Para o Conselho, o programa traria consequências às liberdades civis para além das já previstas:

215 "conta com a participação de um eleitorado informado [...] Por sua vez, exige o acesso do público à informação sobre as atividades do governo [...] Transparência suporta a prestação de contas" (MEDINE et al., 2014b, p.14-15), tradução nossa.

216 "especialmente importante no que diz respeito às atividades do governo que afetam os direitos dos indivíduos, onde ele está intimamente interligado com a reparação por violações de direitos" (MEDINE et al., 2014b, p.14-15), tradução.

217 "A Diretoria também analisou as implicações do programa da Seção 215 para a privacidade e as liberdades civis e concluiu que elas são sérias" (MEDINE et al., 2014b, p.12-13), tradução nossa. 
Because telephone calling records can reveal intimate details about a person's life, particularly when aggregated with other information and subjected to sophisticated computer analysis, the government's collection of a person's entire telephone calling history has a significant and detrimental effect on individual privacy. The circumstances of a particular call can be highly suggestive of its content, such that the mere record of a call potentially offers a window into the caller's private affairs. Moreover, when the government collects all of a person's telephone records, storing them for five years in a government database that is subject to high-speed digital searching and analysis, the privacy implications go far beyond what can be revealed by the metadata of a single telephone call ${ }^{218}$. (MEDINE et al., 2014b, p.12-13)

A invasão de privacidade detalhada pela coleta de metadados certamente afetaria o indivíduo objetivamente e em suas esferas subjetivas; não seriam dados apenas de uma ligação, mas de um vasto histórico-temporal armazenado, "enriquecido"e "minerado"por sistemas de pesquisa do governo. A conclusão do PCLOB em relação à essa ceara seria inequívoca: "beyond such individual privacy intrusions, permitting the government to routinely collect the calling records of the entire nation fundamentally shifts the balance of power between the state and its citizens ${ }^{219 " ~(M E D I N E ~ e t ~ a l ., ~ 2014 b, ~ p .12-13) . ~ A ~ l i n h a ~}$ liberal entre cidadãos e Estado estaria em risco, com prejuízos indeléveis para a democracia: a vigilância de toda uma nação teria, portanto, seu custo expresso no desgaste para as liberdades fundamentais. O Conselho aprofunda, por conseguinte, algumas das possíveis consequências desse desequilíbrio:

With its powers of compulsion and criminal prosecution, the government poses unique threats to privacy when it collects data on its own citizens. Government collection of personal information on such a massive scale also courts the ever-present danger of "mission creep" 220 . An even more compelling danger is that personal information collected by the government will be misused to harass, blackmail, or intimidate, or to single out for scrutiny particular individuals or groups ${ }^{21}$. (MEDINE et al., 2014b, p.12-13)

218 "Como os registros de chamadas telefônicas podem revelar detalhes íntimos sobre a vida de uma pessoa, especialmente quando agregados a outras informações e submetidos a sofisticadas análises de computador, a coleção do histórico completo de chamadas telefônicas do governo tem um efeito significativo e prejudicial na privacidade individual. As circunstâncias de uma chamada específica podem ser altamente sugestivas de seu conteúdo, de modo que o simples registro de uma chamada possa oferecer uma janela para os assuntos particulares do chamador. Além disso, quando o governo coleta todos os registros telefônicos de uma pessoa, armazenando-os por cinco anos em um banco de dados do governo que está sujeito a pesquisas e análises digitais de alta velocidade, as implicações para a privacidade vão muito além do que pode ser revelado pelos metadados de uma única chamada telefônica" (MEDINE et al., 2014b, p.12-13), tradução nossa.

219 "além de tais intrusões de privacidade individuais, permitindo que o governo colete rotineiramente os registros de chamadas de toda a nação, fundamentalmente muda o equilíbrio de poder entre o estado e seus cidadãos" (MEDINE et al., 2014b, p.12-13), tradução nossa.

${ }^{220}$ Definido pelo dicionário de Cambridge como "the fact of doing a much larger job for a longer time than was originally expected, especially in a military operation", ou seja, desvio de função quando em uma execução prolongada de uma atividade , disponível em https://dictionary.cambridge.org/us/dictionary/english/mission-creep.

221 "Com seus poderes de incriminar e mover ações penais, o governo coloca ameaças únicas à privacidade quando coleta dados sobre seus próprios cidadãos. A coleta de informações pessoais em escala tão 
O Conselho denuncia a possibilidade de perseguição e criminalização ex-ante ou persecutória de cidadãos, cujo futuro distópico é amplamente trabalhado na literatura e artes audiovisuais. Perigo maior seria constituído na promoção de perseguições, chantagens e intimidações de indivíduos ou, até mesmo, de minorias. A probabilidade aumentaria com o tempo, já que eventualmente o programa poderia materializar as violações e riscos citados. As consequências, nesse cenário, prosseguiriam no efeito dominó sobre as instituições democráticas e resvalaria inevitavelmente na liberdade de expressão, associação, na liberdade de imprensa na própria constituição da autonomia elementar para a democracia - consonante com a contribuição de Alan Westin quando aborda os efeitos da vigilância nas instituições democráticas - conforme aponta o Conselho:

\begin{abstract}
Moreover, the bulk collection of telephone records can be expected to have a chilling effect on the free exercise of speech and association, because individuals and groups engaged in sensitive or controversial work have less reason to trust in the confidentiality of their relationships as revealed by their calling patterns. Inability to expect privacy vis-à-vis the government in one's telephone communications means that people engaged in wholly lawful activities - but who for various reasons justifiably do not wish the government to know about their communications - must either forgo such activities, reduce their frequency, or take costly measures to hide them from government surveillance. The telephone records program thus hinders the ability of advocacy organizations to communicate confidentially with members, donors, legislators, whistleblowers, members of the public, and others. For similar reasons, awareness that a record of all telephone calls is stored in a government database may have debilitating consequences for communication between journalists and sources ${ }^{222}$. (MEDINE et al., 2014b, p.12-13)
\end{abstract}

O Conselho faz a advertência que não foram encontradas evidências das ações descritas como efeitos do programa de vigilância massiva de telefonemas e, nesse sentido, fazem questão de mencionar que "to be clear, the Board has seen no evidence suggesting that anything of the sort is occurring at the NSA ${ }^{223 " ~(M E D I N E ~ e t ~ a l ., ~ 2014 b, ~ p .12-13) ~ e ~}$

grande pelo governo também corteja o perigo sempre presente de "desvio de missão". Um perigo ainda mais forte é que as informações pessoais coletadas pelo governo sejam usadas para perseguir, chantagear ou intimidar, ou para classificar e escolher para escrutínio indivíduos ou grupos específicos" (MEDINE et al., 2014b, p.12-13), tradução nossa.

222 "Além disso, a coleta em massa de registros telefônicos pode ter um efeito inibidor sobre o livre exercício da fala e da associação, porque indivíduos e grupos engajados em trabalhos sensíveis ou controversos têm menos motivos para confiar na confidencialidade de seus relacionamentos conforme revelado por seus contatos em padrões de chamada. A incapacidade de esperar por privacidade em relação ao governo nas comunicações telefônicas significa que as pessoas envolvidas em atividades totalmente legais - mas que por várias razões justificadamente não desejam que o governo saiba sobre suas comunicações devem renunciar à tais atividades, reduzir sua frequência ou tomar medidas caras para escondê-las da vigilância do governo. O programa de registros telefônicos, portanto, dificulta a capacidade das organizações de defesa e comunicação para se comunicarem confidencialmente com membros, doadores, legisladores, denunciantes, membros do público e outros. Por razões semelhantes, a consciência de que um registro de todas as chamadas telefônicas é armazenado em um banco de dados do governo pode ter consequências debilitantes para a comunicação entre jornalistas e fontes" (MEDINE et al., 2014b, p.12-13), tradução nossa.

223 "Para ser claro, o Conselho não viu nenhuma evidência sugerindo que algo do tipo está ocorrendo na NSA" (MEDINE et al., 2014b, p.12-13), tradução nossa. 
que, para os incidentes ocorridos, não havia indícios de ações mal-intencionadas, tal como posto pelo PCLOB ao afirmar que "the agency's incidents of non-compliance with the rules approved by the FISC have generally involved unintentional misuse ${ }^{224 " ~(M E D I N E ~ e t ~ a l ., ~}$ 2014b, p.12-13). Todavia, a tendência apontada pelo programa teria a probabilidade de eventualmente, no estender do tempo, materializar as violações evocadas. O ponto cético é até que ponto a situação não recairia no cenário distópico per se: "Yet, while the danger of abuse may seem remote, given historical abuse of personal information by the government during the twentieth century, the risk is more than merely theoretical ${ }^{225}$ " (MEDINE et al., 2014b, p.12-13). A materialidade vista na história do Século XX indicaria outras resultantes possíveis.

\subsubsection{Parecer sobre o Programa de Registros Telefônicos Realizado sob a Seção 215}

A recomendação geral, no tocante a execução desse programa em particular, é sumária: o programa de coleta massiva de metadados de comunicações via telefone deve ser encerrado. Pelo parecer, o PCLOB substancia com a indicação de que ainda que haja instrumentos normativos que possam conter parte dos efeitos da vigilância massiva sobre as comunicações telefônicas, não haveria controles e salvaguardas legais suficientes para garantir um robusto conjunto de proteções às liberdades civis. Sem resultados notórios de que a condução do programa preveniria uma ameaça existencial, não haveria motivos plausíveis para o detrimento das liberdades civis vis-à-vis o desequilíbrio entre estas. Nesse tocante, o parecer é inequívoco ao apontar que a agência, em sua visão, não teria condições para a condução de tamanha ação sem prejuízo à democracia:

To be sure, detailed rules currently in place limit the NSA's use of the telephone records it collects. These rules offer many valuable safeguards designed to curb the intrusiveness of the program. But in our view, they cannot fully ameliorate the implications for privacy, speech, and association that follow from the government's ongoing collection of virtually all telephone records of every American. Any governmental program that entails such costs requires a strong showing of efficacy. We do not believe the NSA's telephone records program conducted under Section 215 meets that standard ${ }^{26}$. (MEDINE et al., 2014b, 13)

224 "Os incidentes da agência de não conformidade com as regras aprovadas pelo FISC geralmente envolveram mau uso não intencional" (MEDINE et al., 2014b, p.12-13), tradução nossa.

225 "No entanto, enquanto o perigo de abuso pode parecer remoto, dado o abuso histórico de informações pessoais pelo governo durante o século XX, o risco é mais do que meramente teórico" (MEDINE et al., 2014b, p.12-13), tradução nossa.

226 "Com certeza, regras detalhadas atualmente em vigor limitam o uso da NSA dos registros telefônicos que ela coleta. Essas regras oferecem muitas salvaguardas valiosas destinadas a reduzir a intromissão do programa. Mas, em nossa opinião, eles não podem amenizar totalmente as implicações para a privacidade, a liberdade de expressão e associação que se seguem da coleção atual do governo de praticamente todos os registros telefônicos de todos os americanos. Qualquer programa governamental que implique esses custos requer uma forte demonstração de eficácia. Não acreditamos que o programa de registros telefônicos da NSA conduzido na Seção 215 atenda a esse padrão" (MEDINE et al., 2014b, 13), tradução nossa. 
O parecer sobre a condução e o modus operandi da coleta telefônica massiva realizada sob a Seção 215 do USA PATRIOT ACT é incisivo ao afirmar que não há base legal viável para sua execução e traz potenciais infrações constitucionais ao colocar em xeque as liberdades civis, sem demonstrar valor qualitativo ou ganhos substanciais. Salta aos olhos a consideração em relação ao impacto que a vigilância massiva e indiscriminada causaria enquanto questão inerentemente política. Parte do parecer, em seu inteiro teor, substância a análise:

The Section 215 bulk telephone records program lacks a viable legal foundation under Section 215, implicates constitutional concerns under the First and Fourth Amendments, raises serious threats to privacy and civil liberties as a policy matter, and has shown only limited value. As a result, the Board recommends that the government end the program 227. (MEDINE et al., 2014b, p.16)

Cientes do impacto e dos distúrbios que a vigilância massiva causaria no contexto estadunidense, o Conselho PCLOB, de igual modo ao recomendar o encerramento do programa, recomendou diversas outras ações e iniciativas reparadoras. Em certa medida, de acordo com o parecer oficial, tais ações teriam como propósito equacionar e balancear a necessidade de Segurança Nacional com as Liberdades Civis. Nesse sentido, 12 (doze) recomendações foram feitas às ações e demais variáveis analisadas da (A) Seção 215, das (B) Operações do Tribunal da FISA e no tocante à (C) Promoção Geral da Transparência ao governo. As recomendações foram, então, compiladas e sistematizadas nas tabelas 7 e 8 a seguir:

227 "O programa de registros telefônicos em grande parte da Seção 215 carece de uma base legal viável sob a Seção 215, implica em preocupações constitucionais sob a Primeira e Quarta Emendas, levanta sérias ameaças à privacidade e liberdades civis como uma questão política e tem mostrado apenas valor limitado. Como resultado, o Conselho recomenda que o governo termine o programa" (MEDINE et al., 2014b, p.16), tradução nossa. 
Tabela 7 - Recomendações do PCLOB sobre a Coleta Massiva de Registros de Telefone

Visão geral das recomendações do PCLOB

A. Seção 215 Programa

Recomendação 1

Recomendação 2

\section{B. Operações no Tribunal da FISA}

Recomendação 3

Recomendação 4

Recomendação 5

Fonte: Tabela compilada à partir das recomendações realizadas pelo "Report on the Telephone Records Program Conducted under Section 215 of the USA PATRIOT Act and on the Operations of the Foreign Intelligence Surveillance Court" elaborado pelo "The

Privacy and Civil Liberties Oversight Board" (MEDINE et al., 2014b)
O Congresso deve promulgar legislação que permita ao FISC ouvir opiniões independentes, além das opiniões do governo, sobre novos e significativos pedidos e em outros assuntos nos quais um juiz do FISC determine que a consideração das questões mereceria tais visões adicionais.

O Congresso deve promulgar legislação para expandir as oportunidades de revisão de apelação das decisões do FISC pelo FISCR e para revisão das decisões do FISCR pelo Supremo Tribunal dos Estados Unidos.

O FISC deve aproveitar ao máximo as autoridades existentes para obter assistência técnica e ampliar as oportunidades de contribuição legal de terceiros.
O governo deve encerrar seu programa de registros telefônicos em massa da Seção 215

O governo deve implementar imediatamente salvaguardas de privacidade adicionais ao operar o programa de coleta em massa da Seção 215. 
Tabela 8 - Recomendações do PCLOB sobre a Coleta Massiva de Registros de Telefone Continuação da tabela 7

\section{Visão geral das recomendações do PCLOB}

\section{Promoção da Transparência}

Recomendação 6

Na medida máxima consistente com a segurança nacional, o governo deve criar e liberar com redações mínimas versões desclassificadas de novas decisões, ordens e opiniões pelo FISC e FISCR em casos envolvendo novas interpretações da FISA ou outras questões significativas de direito, tecnologia ou conformidade.

Recomendação 7

Em relação a opiniões previamente escritas, o governo deve realizar uma revisão de desclassificação de decisões, ordens e opiniões pelo FISC e FISCR que ainda não foram divulgadas ao público e que envolvem novas interpretações da FISA ou outras questões de direito, tecnologia ou conformidade.

Recomendação 8

O Procurador Geral deve regular e publicamente informar sobre o funcionamento do programa de Advocacia Especial recomendado pelo Conselho. Isto deve incluir estatísticas sobre a frequência e a natureza da participação do Advogado Especial nos procedimentos do FISC e FISCR.

Recomendação 9

O governo deve trabalhar com provedores de serviços de Internet e outras empresas que recebam regularmente ordens de produção da FISA para desenvolver regras que permitam às empresas divulgar voluntariamente determinadas informações estatísticas. Além disso, o governo deve divulgar publicamente estatísticas mais detalhadas para fornecer uma visão mais completa das operações de vigilância do governo.

Recomendação 10

O Procurador Geral deve informar completamente o PCLOB sobre as atividades do governo sob a FISA e fornecer ao PCLOB cópias dos relatórios detalhados submetidos sob o FISA às comissões do Congresso especificadas. Isso deve incluir fornecer ao PCLOB cópias das decisões do FISC que devem ser produzidas nos termos da Seção 601 (a) (5) .24

Recomendação 11

A Junta insta o governo a começar a desenvolver princípios e critérios de transparência.

Recomendação 12

O escopo das autoridades de vigilância que afetam os americanos deve ser público.

Fonte: Tabela compilada à partir das recomendações realizadas pelo "Report on the Telephone Records Program Conducted under Section 215 of the USA PATRIOT Act and on the Operations of the Foreign Intelligence Surveillance Court" elaborado pelo "The Privacy and Civil Liberties Oversight Board" (MEDINE et al., 2014b)

As recomendações apresentadas atingem justamente a necessidade de democratização e participação de outros entes no processo do Tribunal FISA e a necessidade de se encerrar o programa de vigilância massiva de metadados de telecomunicações. Por sua vez, o Conselho PCLOB indica que ações de transparência devem ser empreendidas, tais como a desclassificação de sigilo de documentos na medida do possível - de modo que sejam acessíveis ao escrutínio democrático. Nesse quesito, relatórios e estatísticas devem ser providas com o intuito de se observar a atuação e ampliação de alvos por parte dos programas de vigilância. Dentre as recomendações apresentadas nas tabelas 7 e 8, duas devem ser ressaltadas: a necessidade de que o escopo das autoridades de vigilância que afetam os americanos deve ser público e que o governo deve implementar imediatamente 
salvaguardas adicionais de privacidade - conjuntamente, indicam que a flagrante desvantagem às liberdades civis e à transparência no tocante às ações de vigilância massiva afeta, portanto, princípios democráticos elementares.

The Board believes that the government must take the initiative and formulate longterm solutions that promote greater transparency for government surveillance policies more generally, in order to inform public debate on technology, national security, and civil liberties going beyond the current controversy. In this effort, all three branches have a role. ${ }^{228}$ (MEDINE et al., 2014b, p.15)

De posse das recomendações substanciadas, o relatório encerra seu parecer com a expectativa de que o programa seja encerrado e que novas medidas sejam tomadas para prevenir abusos por programas que adotem a vigilância massiva e que possam, em seus contextos, alterar o equilíbrio entre Segurança Nacional e Liberdades Civis. Adicionalmente, é de relevância a esta pesquisa ressaltar e corroborar a recomendação de que se faz premente "informar o debate público sobre tecnologia, segurança nacional e liberdades civis que vão além da atual controvérsia", temática preponderante do início ao fim deste trabalho.

\subsection{Relatório sobre o Programa de Vigilância Operado de acordo com a Seção 702 da Lei de Vigilância de Inteligência Estran- geira}

O segundo relatório publicado pelo PCLOB, em 02 de Julho de 2014, tratava da questão da coleta massiva de dados da infraestrutura de provedores e serviços nos EUA sob a seção 702 da FISA, Foreign Intelligence Surveillance Act, e as operações autorizadas, nesse contexto, pelo respectivo Tribunal. De igual modo ao relatório sobre a seção 215, o relatório propôs um total de 10 (dez) recomendações para aumentar a proteção às liberdades civis e, em especial, a privacidade.

A análise realizada pelo Conselho é igualmente extensa, com considerações sobre a extrema complexidade dos programas de vigilância e das problemáticas deles recorrentes sob a Seção 702 da FISA. Diferentemente da Seção 215 do USA PATRIOT ACT, as práticas da Seção 702 foi considerada legal pelo prisma de consonante com a legislação interna, ainda que haja preocupantes considerações acerca do impacto nas liberdades civis nos EUA e a promoção/proteção destas em outros países afetados. Em sua conclusão, o relatório ponderou as medidas que equacionaram excessos cometidos pelas práticas da

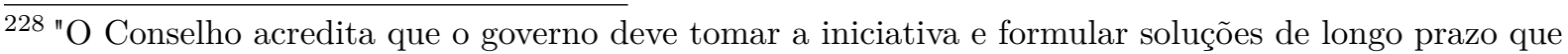
promovam maior transparência para as políticas de vigilância do governo em geral, à fim de informar o debate público sobre tecnologia, segurança nacional e liberdades civis que vão além da atual controvérsia. Nesse esforço, todos os três poderes têm um papel" (MEDINE et al., 2014b, p.15), tradução nossa. 
Seção 702, bem como práticas que contribuiriam para aumentar as salvaguardas e controles democráticos sobre as atividades de vigilância massiva nos EUA.

\subsubsection{Resultados das Análises do Programa de Coleta Massiva de Dados Realizado sob a Seção 702 da FISA}

A consideração geral pela avaliação do PCLOB é de que o programa opera fundamentalmente dentro de suas provisões legais e que "the information the program collects has been valuable and effective in protecting the nation's security and producing useful foreign intelligence $229 "$ (MEDINE et al., 2014a, p.2). A consideração do PCLOB, contudo, alerta para falhas e possíveis linhas críticas em suas ações e potenciais violações que possam, por ventura, surgir - o que direciona a constatação de que "The Board has found that certain aspects of the program's implementation raise privacy concerns" ${ }^{230}$ (MEDINE et al., 2014a, p.2). Essas preocupações, diferentemente das análises de consequências do relatório da Seção 215, faz menção especificamente à coleta incidental de comunicações de pessoas dos EUA e a capacidade de se pesquisar vastamente esse banco de dados sem restrições robustas. Pelo parecer, o PCLOB recomenda, nesse sentido, " a series of policy recommendations to strengthen privacy safeguards and to address these concerns" 231 (MEDINE et al., 2014a, p.2) sem entrar no mérito tecnológico de quebra de criptografia, exploração de vulnerabilidades ou outras estruturas tecnológicas de atuação.

De acordo com o relatório, a Seção 702 trouxe ganhos de velocidade a acuracidade à coleta de inteligência, ao passo que conseguiu, também, comprovar seu valor ao propósito de se combater o terrorismo. No tocante aos de velocidade e otimizações, o relatório constata que "Section 702 program has enabled the government to acquire a greater range of foreign intelligence than it otherwise would have been able to obtain - and to do so quickly and effectively ${ }^{232 " ~(M E D I N E ~ e t ~ a l ., ~ 2014 a, ~ p .9-10) . ~ A d i c i o n a l m e n t e, ~ n o ~ t o c a n t e ~}$ ao propósito e aderência à finalidade do programa, PCLOB argumenta que "[...]The program has proven valuable in the government's efforts to combat terrorism as well as in other areas of foreign intelligence ${ }^{233 " ~(M E D I N E ~ e t ~ a l ., ~ 2014 a, ~ p .9-10), ~ o ~ q u e, ~ e m ~ o u t r a s ~}$ palavras, serve como atestação e atendimento às necessidades de segurança e combate ao terrorismo pelo governo ${ }^{234}$. Por ambas constatações, o PCLOB apresenta sua análise de

\footnotetext{
$\overline{229}$ "as informações que o programa coleta têm sido valiosas e eficazes para proteger a segurança do país e produzir inteligência estrangeira útil" (MEDINE et al., 2014a, p.2), tradução nossa.

230 "A diretoria descobriu que certos aspectos da implementação do programa aumentam as preocupações com a privacidade" (MEDINE et al., 2014a, p.2), tradução nossa.

231 "Uma série de recomendações de políticas para fortalecer as salvaguardas de privacidade e abordar essas questões" (MEDINE et al., 2014a, p.2), tradução nossa.

232 "O programa da Seção 702 permitiu que o governo adquirisse uma gama maior de inteligência externa do que de outra forma poderia obter - e para fazê-lo de maneira rápida e eficaz" (MEDINE et al., 2014a, p.9-10), tradução nossa.

233 "[...] O programa provou ser valioso nos esforços do governo para combater o terrorismo, bem como em outras áreas de inteligência estrangeira" (MEDINE et al., 2014a, p.9-10), tradução nossa.

${ }^{234} \mathrm{O}$ valor dessas ações aos programas de Segurança Nacional é apresentado no relatório quando se adentra
} 
forma favorável ao programa, sem excetuar as condições críticas identificadas.

\subsubsection{Parecer sobre o Programa de Coleta Massiva de Dados Realizado sob a Seção 702 da FISA}

O Conselho do PCLOB identificou que, no geral, as atividades da Seção 702 são implementadas e planejadas de modo a se evitar fins ilegítimos ou abusos de acesso/uso por parte do programa - sem vestígios de desafios ou tentativas de burlar os controles do programa de coleta massiva de dados. Pela legalidade, o Conselho apresenta seu parecer favorável ao não indicar ilegalidades ou discrepâncias entre a prática e os preceitos descritos no legislação. Pela finalidade, o Conselho consubstancia seu parecer com a constatação de que, após averiguações sistemáticas e pela metodologia utilizada, mencionada anteriormente, foi possível identificar ganhos reais com o programa na prevenção de atividades terroristas. Distintamente da linguagem precisa do relatório sobre a Seção 215, a versão do relatório sobre a Seção 702 apresenta de maneira efusiva que as avaliações legais não são conclusivas, são permissivas (como expresso pela expressão "can permissibly be interpreted as allowing"). Já em relação ao montante de erros, o Conselho identificou que não foi possível identificar/ou que não configurava má-fé no programa. A consolidação dos resultados por parte do PCLOB traz, por conseguinte, a seguinte passagem:

The Board concludes that PRISM collection is clearly authorized by the statute and that, with respect to the "about" collection, which occurs in the upstream component of the program, the statute can permissibly be interpreted as allowing such collection as it is currently implemented. The Board also concludes that the core of the Section 702 program acquiring the communications of specifically targeted foreign persons who are located outside the United States, upon a belief that those persons are likely to communicate foreign intelligence, using specific communications identifiers, subject to FISA court-approved targeting rules and multiple layers of oversight - fits within the "totality of the circumstances" standard for reasonableness under the Fourth Amendment, as that standard has been defined by the courts to date ${ }^{236}$. (MEDINE et al., 2014a, p.9)

à seguinte passagem: "Monitoring terrorist networks under Section 702 has enabled the government to learn how they operate, and to understand their priorities, strategies, and tactics. In addition, the program has led the government to identify previously unknown individuals who are involved in international terrorism, and it has played a key role in discovering and disrupting specific terrorist plots aimed at the United States and other countries ${ }^{235}$ ", (MEDINE et al., 2014a, p.9-10)

236 "O Conselho conclui que a coleta do PRISM é claramente autorizada pelo estatuto e que, com relação à coleta "sobre", que ocorre no componente upstream do programa, o estatuto pode ser permissivelmente interpretado como permitindo tal coleta como está atualmente implementada. O Conselho também conclui que o núcleo do programa da Seção 702 - aquisição de comunicações de pessoas físicas especificamente alvos localizados fora dos Estados Unidos, sob a crença de que essas pessoas possam comunicar inteligência estrangeira, usando identificadores de comunicação específicos, sujeitos à regras de seleção aprovadas pelo tribunal à FISA e múltiplas camadas de supervisão - se enquadram no padrão de "totalidade das circunstâncias" por razoabilidade sob a Quarta Emenda, uma vez que esse padrão foi definido pelos tribunais até o momento" (MEDINE et al., 2014a, p.9), tradução nossa. 
As complicações não são, ainda assim, desconsideradas e constam como aspectos efetivamente críticos aos limiares constitucionais sobre o programa desenvolvido pela NSA a partir da Seção 702. Para corrigir a tensão desses limiares, o Conselho indica que um conjunto de ações são necessárias para "to push the program more comfortably into the sphere of reasonableness, ensuring that the program remains tied to its constitutionally legitimate core" ${ }^{237}$, (MEDINE et al., 2014a, p.9). Os limites não foram tão ricamente detalhados e expressados como no relatório de oversight da Seção 215 e as entrelinhas indicam o agravamento de aspectos potencialmente limítrofes, tais como:

Outside of this fundamental core, certain aspects of the Section 702 program push the program close to the line of constitutional reasonableness. Such aspects include the unknown and potentially large scope of the incidental collection of U.S. persons' communications, the use of "about" collection to acquire Internet communications that are neither to nor from the target of surveillance, and the use of queries to search for the communications of specific U.S. persons within the information that has been collected ${ }^{238}$. (MEDINE et al., 2014a, p.9)

Em palavras não-eufêmicas, o Conselho teve dificuldades de auferir o grau de legalidade do programa e, ainda assim, pôde fornecer um parecer favorável à execução e continuidade da vigilância massiva. Há diversos incidentes que, qualitativamente, o Conselho não teve a materialidade das intenções ou danos. Curiosamente, a tônica entre ambos os pareceres é distinta ao ponto de ser possível analisar o grau de precisão na linguagem de ambos relatórios, com destaque à precisão da linguagem do primeiro. Ao mesmo tempo que o relatório da Seção 702 afirma a legalidade e constitucionalidade das ações de vigilância, ele toma a licença de afirmar também que as ações são necessárias para "push the program close to the line of constitutional reasonableness ${ }^{239 " ~(M E D I N E ~ e t ~}$ al., 2014a, p.9).

A incoerência ou ausência de precisão na linguagem foi observada apenas no relatório em questão, que abriu margem para as áreas cinzentas apresentadas. Nesse sentido, o relatório continua a aprofundar, desta vez, ações destoantes das considerações iniciais, vislumbradas pelo excerto de que "[...] the applicable rules potentially allow a great deal of private information about U.S. persons to be acquired by the government"240 (MEDINE

237 "Empurrar o programa mais confortavelmente para a esfera da razoabilidade, assegurando que o programa permaneça vinculado ao seu núcleo legitimamente constitucionalmente" (MEDINE et al., 2014a, p.9), tradução nossa.

238 "Fora desse núcleo fundamental, certos aspectos do programa da Seção 702 aproximam o programa da linha de raciocínio constitucional. Tais aspectos incluem o desconhecido e potencialmente um grande escopo da coleta incidental de comunicações de pessoas dos EUA, o uso de "sobre" a coleta para adquirir comunicações pela Internet que não são nem para o alvo de vigilância e o uso de consultas para procurar as comunicações de pessoas específicas dos EUA dentro das informações que foram coletadas" (MEDINE et al., 2014a, p.9), tradução nossa.

239 "Empurre o programa para perto da linha de razoabilidade constitucional", (MEDINE et al., 2014a, p.9) tradução nossa

240 "[...] as regras aplicáveis permitem potencialmente que uma grande quantidade de informações privadas sobre pessoas dos EUA sejam adquiridas pelo governo" (MEDINE et al., 2014a, p.11), tradução nossa. 
et al., 2014a, p.11) e, portanto, "The Board [...] offers a series of policy recommendations to ensure that the program appropriately balances national security with privacy and civil liberties" $^{241}$ (MEDINE et al., 2014a, p.11).As recomendações foram consolidadas nas tabelas 9 e 10, apresentadas a seguir:

241 "O Conselho oferece [...] uma série de recomendações de políticas para garantir que o programa equilibre adequadamente a segurança nacional com a privacidade e as liberdades civis" (MEDINE et al., 2014a, p.11), tradução nossa. 
Tabela 9 - Recomendações do PCLOB Programa de Vigilância Operado de acordo com a Seção 702 da FISA - Parte 1

Visão geral das recomendações do PCLOB

\section{A. Segmentação}

Recomendação 1.0:

Os procedimentos de segmentação da NSA devem ser revisados para (a) especificar critérios para determinar o valor esperado de inteligência estrangeira de uma meta específica e (b) exigir uma explicação por escrito da base para essa determinação suficiente para demonstrar que a segmentação de cada $\mathrm{O}$ seletor provavelmente devolverá informações de inteligência estrangeiras relevantes para o assunto de uma das certificações aprovadas pelo tribunal da FISA.

\section{B. Consultas de pessoas nos EUA}

Recomendação 2:

Os procedimentos de minimização do FBI devem ser atualizados para refletir com mais clareza a prática real de conduzir consultas de pessoas nos EUA, incluindo a frequência com a qual os dados da Seção 702 podem ser pesquisados ao fazer consultas de rotina como parte das avaliações e investigações do FBI. Além disso, alguns limites adicionais devem ser colocados no uso do FBI e na disseminação dos dados da Seção 702 em conexão com assuntos criminais de inteligência estrangeiros.

Recomendação 3:

Os procedimentos de minimização da NSA e da CIA devem permitir que as agências consultem os dados coletados da seção 702 para fins de inteligência estrangeira usando identificadores de pessoas nos EUA somente se a consulta for baseada em uma declaração de fatos que mostre que é razoavelmente provável que retorne informações de inteligência estrangeiras definido na FISA.

\section{Papel do Tribunal da FISA}

Recomendação 4:

Para ajudar no julgo/consideração dos tribunais da FISA sobre os pedidos de certificação periódicos da Seção 702 do governo, o governo deve enviar uma lista aleatória de folhas de tarefas e uma amostra aleatória dos termos de consulta da pessoa da NSA e da CIA, com documentação de apoio.

Recomendação 5:

Como parte do processo de certificação periódica, o governo deve incorporar à sua apresentação ao tribunal da FISA as regras de operação do programa da Seção 702 que ainda não foram incluídas nas ordens de certificação do tribunal da FISA e que atualmente são contida em ordens e opiniões separadas, depoimentos, conformidade e outras cartas, transcrições de audiência e relatórios obrigatórios arquivados pelo governo.

\section{Coleção Upstream e "About"}

Recomendação 6:

Com base nos esforços atuais para filtrar as comunicações upstream para evitar a coleta de comunicações domésticas, a NSA e o DOJ, consultando os provedores de serviços de telecomunicações afetados e, conforme apropriado, com especialistas independentes, devem avaliar periodicamente se as técnicas de filtragem são aplicadas para garantir a utilização da melhor tecnologia compatível com as necessidades do programa para garantir a aquisição pelo governo de apenas comunicações autorizadas para a coleta e evitar a coleta inadvertida de comunicações domésticas.

Recomendação 7:

A NSA periodicamente deve rever os tipos de comunicações adquiridas através da "sobre" a coleta sob a Seção 702, e estudar até que ponto seria tecnicamente viável limitar, conforme apropriado, os tipos de coleta "sobre".

Fonte: Tabela compilada à partir das recomendações realizadas pelo "Report on the Surveillance Program Operated Pursuant to Section 702 of the Foreign Intelligence Surveillance Act" elaborado pelo "The Privacy and Civil Liberties Oversight Board" (MEDINE et al., 2014a). 
Tabela 10 - Recomendações do PCLOB Programa de Vigilância Operado de acordo com a Seção 702 da FISA - Parte 2 - Continuação da Tabela 9

\section{Visão geral das recomendações do PCLOB}

\section{E. Responsabilização e Transparência}

Recomendação 8:

Na máxima medida compatível com a segurança nacional, o governo deve criar e lançar, com redações mínimas, versões desclassificadas dos procedimentos de minimização da Seção 702 do FBI e da CIA, bem como os atuais procedimentos de minimização da NSA.

\section{F. Eficácia}

Recomendação 9:

O governo deve implementar cinco medidas para fornecer informações sobre até que ponto a NSA adquire e utiliza as comunicações envolvendo pessoas e pessoas dos EUA localizadas nos Estados Unidos sob o programa da Seção 702. Especificamente, a NSA deve implementar processos para contar anualmente o seguinte:

9.1 o número de comunicações telefônicas adquiridas em que um chamador está localizado nos Estados Unidos;

9.2 o número de comunicações da Internet adquiridas por meio de coleta upstream originadas ou encerradas nos Estados Unidos;

9.3 o número de comunicações de ou sobre pessoas dos EUA que a NSA identifica como tal no curso rotineiro de seu trabalho;

9.4 o número de consultas realizadas que empregam identificadores de pessoas nos EUA, especificamente distinguindo o número de tais consultas que incluem nomes, títulos ou outros identificadores potencialmente associados a indivíduos; $\mathrm{e}$

9.5 o número de casos em que a NSA divulga informações não públicas sobre pessoas dos EUA, especificamente distinguindo divulgações que incluem nomes, títulos ou outros identificadores potencialmente associados a indivíduos. Estes números devem ser reportados ao Congresso no relatório anual do Diretor da NSA e devem ser divulgados publicamente de forma consistente com a segurança nacional.

Recomendação 10:

O governo deve desenvolver uma metodologia abrangente para avaliar a eficácia e o valor relativo dos programas de contraterrorismo.

Fonte: Tabela compilada à partir das recomendações realizadas pelo "Report on the Surveillance Program Operated Pursuant to Section 702 of the Foreign Intelligence Surveillance Act" elaborado pelo "The Privacy and Civil Liberties Oversight Board" (MEDINE et al., 2014a).

Renegados em frente às práticas da vigilância internacional e sob as justificativas legais da Seção 702, os estrangeiros não possuiriam, pela legislação dos EUA, direitos acerca da proteção de sua privacidade. Contudo, o Conselho reconhece que tratados internacionais incorporam tais direitos no arcabouço normativo estadunidense e, como tal, deve levar em consideração a privacidade e seus direitos associados quando se tratar de um indivíduo estrangeiro quando argumenta que "Finally, the Board discusses the fact that privacy is a human right that has been recognized in the International Covenant on Civil and Political Rights ("ICCPR"), an international treaty ratified by the U.S. Senate"242 (MEDINE et 
al., 2014a, p.9). A passagem expressa preocupação de que a discriminação de tratamentos suscite debates sobre a legitimidade de tais ações, bem como "that the treatment of non-U.S. persons in U.S. surveillance programs raises important but difficult legal and policy questions" 243 (MEDINE et al., 2014a, p.9). Na finalização da questão, o Conselho então assimila que "Many of the generally applicable protections that already exist under U.S. surveillance laws apply to U.S. and non-U.S. persons alike"244 (MEDINE et al., 2014a, p.9) e, portanto, ações e medidas que equilibrem essa relação devem ser tomadas.

\subsection{A Teoria em Perspectiva}

Pela perspectiva de Foucault, conjugada à sua abordagem teórica, a vigilância massiva, evidenciada pelas ações da National Security Agency, continua a ser exercida como uma estrutura de dominação, invisível, integrado, sustentado, automático e anônimo de poder e, ao mesmo tempo, presente para disciplinar e colocar o indivíduo em sua intrínseca reprodução de poder. O objetivo, no caso em questão, ainda que tenha tido modificações desde sua criação, a agência continuaria à trabalhar em prol da hegemonia da superpotência, mesmo que, para isso, diversas instituições democráticas sejam colocadas em risco. Como modus operandi, pela perspectiva foucaultiana, a NSA atenderia exatamente às racionalizações econômico-técnicas de uma estrutura panóptica: (1) reduziria o número dos que exercem o poder ao passo que multiplicaria seus alvos (2) interviria incessantemente "antes que as faltas, os erros e os crimes sejam cometidos". A universalidade dessa estrutura panóptica, disponível pelo governo da tecnologia - leia-se, pelo controle da criptografia permitiria, também, as tecnologias de governo - leia-se, pelo exercício da vigilância massiva. O governo da tecnologia, nessa óptica, teria por objetivo a dominação e seus fins, no caso, sumariamente hegemônicos.

Governo da Tecnologia e Tecnologias de Governo comporiam, em uma perspectiva derivada de Deleuze, movimentos complementares de uma "sociedade de controle". Quando vista como governo da tecnologia, o controle exercido sobre o desenho tecnológico da criptografia abarcaria a disputa vislumbrada de Deleuze entre forças libertadoras e escravizantes; aplicadas ao período de desenvolvimento do Clipper Chip, esse controle influenciara o desenho da tecnologia em prol de tecnologias fracas, com vulnerabilidades especificamente desenhadas para a obtenção do domínio da finalidade tecnológica - em questão, a proteção das comunicações de mais estruturas da sociedade construídas à partir da criptografia. Controladas as variáveis e obtidos os controles dessa tecnologia, os Estados

no Pacto Internacional sobre Direitos Civis e Políticos ("ICCPR"), um tratado internacional ratificado pelo Senado dos EUA" (MEDINE et al., 2014a, p.9), tradução nossa.

243 "Que o tratamento de pessoas não americanas em programas de vigilância dos EUA levanta questões jurídicas e políticas importantes, mas difíceis" (MEDINE et al., 2014a, p.9), tradução nossa.

244 "Muitas das proteções geralmente aplicáveis que já existem sob as leis de vigilância dos EUA aplicam-se a pessoas dos EUA e de fora dos EUA" (MEDINE et al., 2014a, p.9), tradução nossa. 
Unidos passariam, então, ao exercício do poder pelas Tecnologias de Governo - o Clipper Chip seria, nesse prisma, uma tecnologia essencial ao exercício do poder por parte de entidades do Estado, com propósitos de, pela vigilância, diluir as proteções que indivíduos buscam - no caso, o Clipper Chip atuaria como uma armadilha, não para terroristas ou criminosos em geral, mas para o cidadão comum.

Os processos seriam inevitáveis, caso a sociedade não recupere sua soberania movidos pela ultra racionalidade tecno-científica preconizada por Marcuse, modificariam as dinâmicas elementares da sociedade de uma forma complexa de reverter. Seria expressa, ao retomar Marcuse, como "modo de organizar e perpetuar (ou mudar) as relações sociais, uma manifestação de padrões de pensamento e comportamento predominantes, um instrumento de controle e dominação" (MARCUSE, 1998, p.138). Recuperar a soberania, nesse sentido, significaria pela ótica do governo da tecnologia, torna-la democrática, acessível, transparente e legitimada para os fins da sociedade.

A sociedade de controle de Deleuze, nesse sentido, vislumbrada nas ações da NSA pelas construções de seus bancos de dados e mecanismos criptoanalíticos, adentraria ao novo período da "sociedade de controle" codificada e complexa, estruturada enquanto códigos e bancos de dados capazes de movimentar seus domínios e armazenar temporalmente as ações do passado para prerrogativas do futuro; seus alvos, dentre eles, cidadãos comuns, não teriam a possibilidade de escapatória ou redenção; a vigilância, aliada à memória indefinida do estado das ações íntimas e privadas de seus cidadãos, fariam desse sujeito um "corpo dócil", com autonomia debilitada e por toda sua existência, domesticado. Em contiguidade, perder-se-ia a agência sobre a tecnologia enquanto característica do indivíduo que, de igual forma, teria sua soberania, enquanto parte e todo da sociedade, desmantelada e alienada nos controles dos computadores. As sociedades, não somente nos EUA, nesse cenário de tecnologias complexas, não seriam mais soberanas; estariam cada vez mais codificadas como "sociedades de controle" - as ações da NSA, para o controle da tecnologia e como tecnologia de controle corroborariam essa maxima.

Os processos seriam inevitáveis, caso a sociedade não recupere sua soberania movidos pela ultra racionalidade tecno-científica preconizada por Marcuse, modificariam as dinâmicas elementares da sociedade de uma forma complexa de reverter. Seria expressa, ao retomar Marcuse, como "modo de organizar e perpetuar (ou mudar) as relações sociais, uma manifestação de padrões de pensamento e comportamento predominantes, um instrumento de controle e dominação" (MARCUSE, 1998, p.138). Recuperar a soberania, nesse sentido, significaria pela ótica do governo da tecnologia, torna-la democrática, acessível, transparente e legitimada para os fins da sociedade.

A partir das abordagens de Winner (1980), Winner (1992b), WARTOFSKY (1992), FIELDER (1992), SCLOVE (1992), aplicadas à forma como o desenho da criptografia é conduzida nos EUA pelo setor público, ela não poderia ser considerada como democrática 
em seus processos, nem em suas finalidades. Em ambos as análises, teriam suas dinâmicas de disponibilização controlada pelos setores estatais, balizados pelo arsenal de legislações aqui expostas. Em outra análise, o controle dessa tecnologia não teria a legitimação pública no processo de produção de seus desenhos e, dessa forma, tecnologias que potencialmente firam instituições democráticas poderiam passar pelo crivo tecnocrata do Estado. As debilidades desse processo de produção tecnológica encontrariam suas justificativas nas barreiras que a alta complexidade tecnológica imporia; seria igualmente complexo compreender os meandros da produção de um software de criptografia, bem já é a compreensão de suas aplicações pela sociedade - algo que o Winner descreveu como a "erosão da participação dos cidadãos na tomada de decisões, quando confrontados com o poder em evolução das elites científicas e técnicas".

Não obstante, o debate em questão, ainda que tenha contado com a mobilização da opinião pública, passou a ganhar tração quando as questões tecno-científicas foram traduzidas por entidades da sociedade civil organizada, tais como empresas e ONGs dentre elas, cita-se a RSA com as propagandas expostas nessa pesquisa contra o Clipper Chip e a EFF que, inserida em ecossistema de defesa de liberdades civis e promoção de tecnologias "democráticas", ganhou proeminência no debate contra a vigilância massiva conduzida pela NSA. Se a população não se "alfabetizada" na dinâmica das tecnologias complexas em volume e qualidade suficiente para participar do debate público acerca delas, certamente não haverá meios democráticos de se conduzir os processos de produção tecnológica - ficará à cargo de uma elite tecnocrata conduzir seus processos tecnocráticos para a promoção de sua tecnocracia.

Essas processos tecnocráticos recaíram no cidadão comum, pela perspectiva de Marcuse e Habermas, Habermas.19841987b tanto pela ultra-racionalização tecnológica como pela ultra-complexidade que dela advém - o indivíduo, sem soberania ou controle sobre a tecnologia que o circunda, sequer visualizaria ou teria consciência que preceitos e liberdades fundamentais lhe são subtraídas em um continuum totalizante. Em termos práticos, o indivíduo ao acessar seu celular, utilizar seu computador pessoal ou realizar uma transação em um terminal de autoatendimento, não poderia esperar que seus dados poderiam trafegar para bancos de dados controlados por uma elite tecnocrática. Em condição remota, ciente de tais fenômenos, não lhe restaria muitas ações senão à angustia da perda de autonomia e soberania sobre a tecnologia que o circunda - precisamente no ponto no qual se encontram aqueles que, por ventura, tomam ciência que todas as informações pessoais de seus e-mails, fotos íntimas, relações pessoais, posicionamentos políticos e dados de sua saúde, por exemplo, quando trafegar pela infraestrutura de telecomunicações e serviços dos Estados Unidos, terão altas chances de serem coletadas por agencias estatais. A ansiedade pior, segundo Habermas, é saber que os indivíduos foram parte e colocaram em movimento as dinâmicas tecno-políticas desse "Stand der Dinge". Que, por comodidade ou outras variáveis, foram inadvertidamente aceitas tecnologias 
que necessariamente não seguem a promessa de serem democráticas, ou estão sujeitas à domínios estatais (ou alvos de processos de "vulnerabilização"), tais como aquelas exercidas sob soberania dos Estados Unidos.

\subsection{A Pesquisa em Perspectiva}

A pesquisa, em determinado ponto, começa a encontrar seu desapego em relação à tentativa de fornecer compreensões e entendimentos que abordem cem por cento dos fenômenos, das dinâmicas do objeto e suas construções teóricas e práticas - seriam em recurso, tempo e possibilidades indeterminados. Desta forma, cientes dessa limitação, buscou-se elucidar conceitos chave ou pertinentes à hipótese e seus objetivos e a engendrar, a partir da conceitualização da evolução da democracia na forma de poliarquias, a correlação da evolução com a complexidade e a apresentação da nova feição cibernética, as feições democráticas e não democráticas da tecnologia em seu desenho e finalidade. Nesse contexto, identificou-se que há um fenômeno não previamente previsto pela pesquisa em sua concepção originária - obscurecido pelo limbo da complexidade - que se caracteriza pela permissividade de se combinar tecnologias de governo e governo de tecnologias cibernéticas que desconsideram os pré-requisitos e preceitos elementares ao processo democrático. No estudo de caso aqui proposto, defendeu-se que a Política Cibernética dos Estados Unidos adentra ao limbo da complexidade cibernética ao apresentar tanto feições de imperativos democráticos quanto antidemocráticos. Em outro momento, tais conceituações foram cruzadas com o embate entre vigilância massiva e as problematizações concernentes às liberdades civis e, principalmente, a privacidade - conceituações que fomentaram, por sua vez, a discussão sobre o quanto a tecnologia complexa, pela exemplo da criptografia, teria o potencial de prejudicar ou fortalecer instituições e processos democráticos considerados pela literatura como mínimos, tal como a privacidade e sua conjunção de instituições correlatas.

Nessa proposta, dentre os objetivos indiretos da pesquisa, aqueles que são originados pela necessidade ou pela curiosidade, buscou-se encontrar mecanismos e meios cibernéticos e não cibernéticos que habilitem aquilo que pode ser compreendido como pré-requisitos à poliarquia cibernética, ou uma democracia embebida pela alta complexidade tecnológica: por resposta, faz-se saber as instituições tecnológicas que, somente pela via sistêmica da tecnologia, podem suportar e introduzir elementos de equilíbrio democrático para a sustentabilidade das referidas democracias. Tal objetivo indireto surgiu como necessidade de diferenciação e pela categorização das tecnologias de governo e do governo das tecnologias que não figuram como compatíveis ao processo democrático. Esperou-se, assim, identificar tecnologias de governo e mecanismos de governo das tecnologias nas esferas cibernéticas e não cibernéticas no estudo de caso aqui proposto. Para tanto, como objetivo principal, foram abordados o estudo de caso da vigilância massiva eletrônica nos EUA, bem como os 
debates e as problemáticas que o cercam.

O estudo em questão abordou a NSA como exemplo único até então registrado na história de vigilância massiva em escala global, movimentada pelo tríplice embate configurado entre vigilância-criptografia-privacidade. O estudo de caso avançou a discussão ao passo que mostrou a intrincada relação entre a política, suas bases normativas e a aplicação com profundidade e compreensão tecnológica que as movem: não foram poupados termos técnicos, nem ocultadas as complexidades inerentes ao debate em questão. A NSA, nesse sentido, figura como um elemento máximo de conjunção das forças tecno-políticas aqui evidenciadas, tanto pelo exercício do governo da tecnologia, como pela máxima dominação das tecnologias de governo.

Cabe ressaltar que a pesquisa conduzida neste trabalho não teve por escopo avaliar a legalidade ou apontar as justificativas jurisprudenciais que sustentam as práticas de vigilância nos Estados Unidos. Quando iniciada, a pesquisa tinha como objeção metodológica o fornecimento de pareceres sobre os limites legais dessa atuação; não estaria no âmbito da Ciência Política. Todavia, em decorrência da hipótese apresentada, as avaliações legais conduzidas pelo PCLOB não somente sustentam, como corroboram institucionalmente a hipótese e a argumentação da pesquisa. Adicionalmente, indicam, por contraste, que somente as avaliações legais não são suficientes para captar o problema levantado pela hipótese. Ainda que em determinadas partes do relatório a legalidade de alguns dos programas é atestada em seu mérito, a hipótese deste trabalho se sustenta e continua a desafiar as considerações do relatório em decorrência do modus operandi identificado no estudo de caso com a NSA e seu modus operandi: afinal, a legalidade das ações de vigilância não necessárias e nem suficientes para justificar o controle da tecnologia exercido sobre "instituições tecnológicas"essenciais à democracia, como por exemplo, a criptografia.

O ponto em questão é que, ainda que haja uma vasta arquitetura normativa que dê suporte e moção as ações de vigilância, tanto doméstica, como internacional, tal arquitetura legislativa não se mostra suficiente para justificar o controle e as tendências de violações e exercício de poder exercido por intermédio da tecnologia: seu desenho, pelas vias materiais, estaria em contradição com as condições preconizadas legalmente. Além dessa materialidade representada no estudo de caso, há uma contradição básica em se exercer a vigilância massiva dentro da lei e por outro lado, corromper todos os padrões de criptografia. Os dois objetivos tornam-se conflitantes e tangem no cerne da questão: de que a criptografia garante a divisão entre o indivíduo e o Estado e que, muito além disso, garante a constituição do próprio espaço do indivíduo perante os ataques contemporâneos da vigilância.

Nesse sentido, a hipótese sustenta que quando não há elementos democráticos suficientes para estabilizar os espaços cibernéticos e compatibilizá-los com o próprio processo democrático, habilitam-se formas, processos e assimetrias de poder que tendem a assumir 
feições e se mobilizarem de forma incompatível e/ou antagônica aos pré-requisitos do processo democrático. O estudo de caso evidenciou que há um elemento que configura como uma instituição democrática equivalente no espaço cibernético, a criptografia. Contudo, esta instituição cibernética encontra-se ainda em franca disputa, com finalidades políticas e desenhos tecnológicos por vezes em trânsito nos espectros do autoritarismo ou da democracia. Em decorrência dessa disputa sobre seu desenho e finalidade, a criptografia torna-se frágil como salvaguarda democrática; afinal, outras instituições cibernéticas, tais quais a criptografia, seriam necessárias para estabilizar o espaço cibernético em prol de elementos não-autoritários. Como consequência, evidencia-se que se torna possível não somente a coexistência, como a ocultação de processos e mecanismos cibernéticos, ações, instituições e políticas antidemocráticas produzidas - cuja compreensão e debate esbarra nas dificuldades trazidas pela complexidade cibernética-tecnológica - mesmo que em uma democracia.

Enquanto governo da tecnologia, o impacto dessa ausência de instituições cibernéticas equivalentes às democráticas no espaço cibernético e numa democracia, em um primeiro momento, configurar-se-ia como uma das consequências, por sua vez, do vácuo de poder democrático, preenchido por tecnologias de cunho autoritário e totalizante. Tais tecnologias permitem, nesse sentido, que abusos de poder sejam cometidos - à revelia, inclusive, das próprias instituições democráticas não-cibernéticas - tais como as leis e a Constituição. Esse fenômeno fica evidenciado quando mesmo a NSA, suportada por um vasto arcabouço legal, extrapola suas jurisdições constitucionais - como abordado pelo Estudo de Caso aqui fomentado - utiliza tecnologias e processos de alta complexidade tecnológica que são, então, executados à revelia da Constituição ou Lei (conforme apontado pelos relatórios do PCLOB).

Enquanto tecnologia de governo, o impacto, em um segundo momento, ocorreria de forma direta nas instituições democráticas e nas liberdades civis; subverteria as liberdades e, principalmente, a privacidade, como técnica de governar que culminaria na vigilância como o método mais racionalmente econômico e produtivo de se exercer o poder. Nesse contexto, tecnologias de governo e o governo da tecnologia surgiriam ao mesmo tempo, de forma que se retroalimentam e sustentam, então, suas formas de poder pela tecnologia. $\mathrm{O}$ Tríplice Conflito Entre Criptografia, Vigilância e Privacidade nos Estados Unidos seria emblemático, desta forma, como prelúdio de novas tendências tecnológicas-racionalizantes com o potencial de se replicarem enquanto fenômeno em outras democracias; ensejariam a necessidade premente de se buscar formas de se compatibilizar e criar instituições que sejam em seu desenho e finalidade democráticas na Era, e pela perspectiva sistêmica, da Tecnologia da Informação. 



\section{Referências}

AGAMBEN, G. Homo sacer: Sovereign power and bare life / Giorgio Agamben ; translated by Daniel Heller-Roazen. Stanford, Calif.: Stanford University Press, 1998. (Meridian : crossing aesthetics). ISBN 0-8047-3217-5. Citado na página 61.

ANTHONY, S. XKeyscore: The NSA program that collects 'nearly everything' that you do on the internet - ExtremeTech. 2013. Disponível em: < https: //www.extremetech.com/extreme/162739-xkeyscore-the-nsa-program-that-collectsnearly-everything-that-you-do-on-the-internet $>$. Acesso em: 2018-05-05. Citado na página 163.

ARENDT, H. The origins of totalitarianism. New ed. New York: Harcourt Brace Jovanovich, 1973. HB244. (A Harvest book, HB244). ISBN 0156701537. Citado 3 vezes nas páginas 104, 105 e 106.

ARTINGER, K. Reichstagsbrandverordnung: Ermächtigungsgesetz 64. 2019. Disponível em: < https://www.dhm.de/archiv/ausstellungen/grundrechte/katalog/64-66.pdf>. Acesso em: 2019-03-02. Citado 2 vezes nas páginas 103 e 104.

ASHBY, W. R. An introduction to cybernetics. New York: J. Wiley, 1956. Citado na página 82.

BAMFORD, J. The NSA Is Building the Country's Biggest Spy Center: (Watch What You Say). Wired, 2012-03-15. Disponível em: <https://www.wired.com/2012/03/ffnsadatacenter/>. Acesso em: 2017-08-02. Citado na página 139.

BARLOW, j. P. Jackboots on the Infobahn. Wired, 1994-04-01. Disponível em: <https://www.wired.com/1994/04/privacy-barlow/>. Acesso em: 2019-03-04. Citado na página 135.

BEER, S. Designing freedom. Chichester, West Sussex, England and New York: Wiley, 1994. (The Stafford Beer classic library). ISBN 047195165X. Citado na página 82.

BERTALANFFY, L. v. General system theory: Foundations, development, applications. Rev. ed. New York: G. Braziller, 1973, (C)1968. ISBN 0807604526. Citado na página 82.

BOYLE, D. Alan Turing: Unlocking the enigma. Steyning, West Sussex: Real Press, 2014. ISBN 1500985376. Citado na página 86.

BUZAN, B.; WæEVER, O.; WILDE, J. de. Security: A new framework for analysis / Barry Buzan, Ole Waver, Jaap de Wilde. Boulder, Colo. and London: Lynne Rienner, 1998. ISBN 1555877842. Citado 4 vezes nas páginas 118, 119, 120 e 121.

CARPENTER, S. Instrumentalists and Expressivists: Ambiguous Links Between Technology and Democracy. In: WINNER, L. (Ed.). Democracy in a Technological Society. [S.l.: s.n.], 1992. p. 161-174. ISBN 978-90-481-4210-1. Citado 2 vezes nas páginas 60 e 74.

CLARKE, R. A. Information technology and dataveillance. Commun. ACM, v. 31, n. 5, p. 498-512, 1988. ISSN 0001-0782. Citado na página 126. 
Crypto Museum. Clipper Chip: Cryptographic Key Escrow. The Netherlands: [s.n.], 2018. Disponível em: <https://www.cryptomuseum.com/crypto/usa/clipper.htm>. Acesso em: 2019-03-04. Citado na página 134.

Crypto Museum. Enigma D: Commercial Enigma A26. The Netherlands: [s.n.], 2018. Disponível em: <https://www.cryptomuseum.com/crypto/enigma/d/index.htm>. Acesso em: 2019-03-04. Citado na página 86.

DAHL, R. A. After the revolution? Authority in a good society / Robert A. Dahl. Rev. ed. New Haven and London: Yale University Press, 1990. ISBN 0300049641. Citado 2 vezes nas páginas 67 e 68 .

DAHL, R. A. Democracy and its critics. [S.l.: s.n.], 1991. ISBN 9780300049381. Citado 7 vezes nas páginas 69, 70, 71, 75, 76, 77 e 117.

DAHL, R. A.; SHAPIRO, I. On democracy. Second edition / with a new preface and two new chapters by ian shapiro. New Haven: Yale University Press, 2015. ISBN 9780300194463. Citado 2 vezes nas páginas 109 e 110.

DAM, K. W.; LIN, H. Cryptography's role in securing the information society. Washington, DC: National Academy Press, 1996. ISBN 0309054753. Citado na página 134.

DELALANDE, A. The case of Alan Turing: The extraordinary and tragic story of the legendary codebreaker. Vancouver, British Columbia: Arsenal Pulp Press, 2016. ISBN 1551526514. Citado na página 86.

DELEUZE, G. Postscript on the Societies of Control. October, v. 59, p. 3-7, 1992. ISSN 01622870. Disponível em: <http://www.jstor.org/stable/778828>. Citado 3 vezes nas páginas 51, 52 e 53.

DELEUZE, G.; GUATTARI, F. Anti-Oedipus: Capitalism and schizophrenia. Minneapolis: University of Minnesota Press, 1983. ISBN 0816612250. Citado na página 61.

DENNING, P. J. Computer Science: The Discipline: Encyclopedia of Computer Science. [S.l.: s.n.], 1997. Citado na página 60.

Eletronic Frontier Foundation. Backdoor Search. 2019. Disponível em: <https: //www.eff.org/pt-br/pages/backdoor-search>. Acesso em: 2019-05-03. Citado 3 vezes nas páginas 150, 151 e 154 .

Eletronic Frontier Foundation. Decoding 702: What is Section 702? 2019. Disponível em: $<$ https://www.eff.org/pt-br/taxonomy/term/11442>. Acesso em: 2019-05-03. Citado na página 150.

ERIKSSON, J.; GIACOMELLO, G. The Information Revolution, Security, and International Relations: (IR) Relevant Theory? International Political Science Review / Revue internationale de science politique, v. 27, n. 3, p. 221-244, 2006. ISSN 01925121. Disponível em: <http://www.jstor.org/stable/20445053>. Citado na página 125.

ERIKSSON, J.; GIACOMELLO, G. (Ed.). International relations and security in the digital age. London and New York: Routledge, 2007. v. 52. (Routledge advances in international relations and global politics, v. 52). ISBN 0-203-96473-X. Citado na página 121. 
FIELDER, J. Autonomous Technology, Democracy, and the Nimbys. In: WINNER, L. (Ed.). Democracy in a Technological Society. [S.l.: s.n.], 1992. p. 95-122. ISBN 978-90-481-4210-1. Citado 3 vezes nas páginas 64, 75 e 195.

FOUCAULT, M. Power/knowledge: a selected interviews and other writings 1972-77. New York: Pantheon Books, 1980. ISBN 039473954X. Citado na página 61.

FOUCAULT, M. Discipline and punish: The birth of the prison. 2nd vintage books ed.. ed. New York: Vintage Books, 1995. ISBN 0679752552. Citado na página 51.

FOUCAULT, M. Vigiar e Punir. [S.l.]: Edições 70, 2013. (Biblioteca de Teoria Política). ISBN 9789724417660. Citado 2 vezes nas páginas 48 e 49.

FOUCAULT, M. et al. Technologies of the self: A seminar with Michel Foucault. Amherst: University of Massachusetts Press, 1988. ISBN 0-87023-592-3. Citado 2 vezes nas páginas 50 e 51.

FRANSSEN, M.; LOKHORST, G.-J.; POEL, I. van de. Philosophy of Technology. In: ZALTA, E. N. (Ed.). The Stanford Encyclopedia of Philosophy. [S.l.: s.n.], 2015. Citado 2 vezes nas páginas 45 e 47 .

FRIEDMAN, L.; LEVANTROSSER, W. F. Watergate and afterward: The legacy of Richard M. Nixon / edited by Leon Friedman and William F. Levantrosser ; prepared under the auspices of Hofstra University. Westport and London: Greenwood Press, 1992. no. 274. (Hofstra University's cultural and intercultural, 0195-802x, no. 274). ISBN 0313277818. Citado na página 147.

GABBATT, a. Johns Hopkins dean apologises for ordering NSA-related blog removed. The Guardian, 2013. Disponível em: < https://www.theguardian.com/world/2013/sep/10/johnshopkins-dean-apologises-for-blog $>$. Acesso em: 2018-02-09. Citado na página 113.

GARFINKEL, S. PGP: Pretty good privacy / Simson Garfinkel. Sebastopol, Calif.: O’Reilly \& Associates, 1995. ISBN 1565920988. Citado 2 vezes nas páginas 137 e 138.

GENOVESE, M. A.; MORGAN, I. W. Watergate remembered: The legacy for American politics / edited by Michael A. Genovese and Iwan W. Morgan. Basingstoke: Palgrave Macmillan, 2012. (The evolving American presidency series). ISBN 0230116507. Citado na página 147.

GREEN, M. 2019. Disponível em: < https://twitter.com/matthew_d_green/status/ 596674230214877184>. Acesso em: 2019-03-04. Citado na página 136.

GREENWALD, G.; MACASKILL, E. NSA Prism program taps in to user data of Apple, Google and others. 2013. Disponível em: < https://www.theguardian.com/world/2013/jun/ 06/us-tech-giants-nsa-data>. Acesso em: 2018-05-01. Citado 2 vezes nas páginas 165 e 166.

GUATTARI, F. Molecular revolution: Psychiatry and politics. Harmondsworth, Middlesex, England and New York, N.Y., U.S.A.: Penguin, 1984. (Peregrine books). ISBN 0140551603. Citado na página 61.

HABERMAS, J. The theory of communicative action. Boston: Beacon Press, 1984-1987. ISBN 0807014001. Citado 2 vezes nas páginas 67 e 83. 
HABERMAS, J. Técnica e Ciência como Ideologia. Lisboa: Edições 70, 2006. ISBN 9724413357. Citado na página 58.

HENDERSON, H. Alan Turing: Computing genius and wartime code breaker / Harry Henderson. Broomall, Pa.: Chelsea House and London : Eurospan [distributor], 2011. (Makers of modern science). ISBN 0816061750. Citado 3 vezes nas páginas 86, 87 e 88.

HODGES, A. Alan turing, enigma. Vienna: Springer Vienna, 1994. ISBN 9783709158326. Citado na página 86.

KAHIN, B.; NESSON, C. R. Borders in cyberspace: Information policy and the global information infrastructure. Cambridge, Mass. and London: MIT Press, 1997. ISBN 0262112205 . Citado na página 127.

KAHN, D. Cryptology goes public. Communications Magazine, IEEE, v. 18, n. 2, p. 19-28, 1980. ISSN 0163-6804. Citado na página 36.

KAHN, D. The codebreakers: The comprehensive history of secret communication from ancient times to the Internet. Rev. and updated ed. New York: Scribner's and Sons, 1997. ISBN 0684831309. Citado na página 35.

KAPP, E. Grundlinien einer Philosophie der Technik. [S.l.]: George Westermann, 1877. Citado na página 47.

KUHN, T. S. The structure of scientific revolutions (3rd edition). 3rd. ed. [S.l.]: University of Chicago Press, 1996. ISBN 0226458075. Citado na página 47.

KUNELIUS, R. et al. Journalism and the NSA revelations: Privacy, security and the press. London and New York, NY: I.B. Tauris \& Co. Ltd, 2017. ISBN 1784536768. Citado na página 113.

KUTLER, S. I. Watergate: A brief history with documents / edited by Stanley I. Kutler. 2nd ed.. ed. Chichester: Wiley-Blackwell, 2010. ISBN 1405188480. Citado na página 147.

LAVINGTON, S. H. Alan Turing and his contemporaries: Building the world's first computers / Simon Lavington (editor). Swindon: BCS, 2012. ISBN 9781780171074. Citado na página 86.

LEAVITT, D. The Man Who Knew Too Much. [Place of publication not identified]: W.W. Norton \& Company, 2006. (Great discoveries). ISBN 9780393346572. Citado na página 86.

LESSIG, L. Code: Version 2.0 ;. New York and London: Basic Books and Perseus Running distributor], 2006. ISBN 9780465039142. Citado 2 vezes nas páginas 77 e 78.

LOCKE, J.; MACPHERSON, C. B. Second treatise of government. 1. ed. Indianapolis Ind.: Hackett Pub. Co, 1980. ISBN 0915144867. Citado 2 vezes nas páginas 91 e 99.

LUHMANN, N. Social systems. Stanford, Calif.: Stanford University Press, 1995. (Writing science). ISBN 0804726256. Citado na página 82.

MADISON, J.; KETCHAM, R. L. Selected writings of James Madison. Indianapolis, Ind.: Hackett and Lancaster : Gazelle Drake Academic [distributor], 2006. (The American heritage series). ISBN 0872206963. Citado 3 vezes nas páginas 92, 93 e 94. 
MARCUSE, H. One-dimensional man: Studies in the ideology of advanced industrial society. London: Routledge, 1991, 1964. (Routledge classics). ISBN 9780415289764. Citado 7 vezes nas páginas 47, 55, 56, 57, 58, 59 e 106.

MARCUSE, H. Some social implications of modern technology. In: KELLNER, D. (Ed.). Collected papers of Herbert Marcuse. London: Routledge, 1998. v. 9. ISBN 0415137802. Citado 4 vezes nas páginas 54, 55, 56 e 195.

MARX, K. O Capital: Livro 1. [S.l.]: Boitempo, 2013. v. 1. Citado 2 vezes nas páginas 46 e 47.

MATURANA, H. R.; VARELA, F. J. Autopoiesis and cognition: The realization of the living. Dordrecht, Holland and Boston: D. Reidel Pub. Co., 1980. v. 42. (Boston studies in the philosophy of science, v. 42). ISBN 9027710163. Citado na página 82.

MEDINE, D. et al. Report on the Surveillance Program Operated Pursuant to Section 702 of the Foreign Intelligence Surveillance Act: The Privacy and Civil Liberties Oversight Board. United States: [s.n.], 2014. Disponível em: $<$ https://www.pclob.gov/library/702-Report-2.pdf $>$. Acesso em: 2019-05-19. Citado 7 vezes nas páginas 188, 189, 190, 191, 192, 193 e 194.

MEDINE, D. et al. Report on the Telephone Records Program Conducted under Section 215 of the USA PATRIOT Act and on the Operations of the Foreign Intelligence Surveillance Court: The Privacy and Civil Liberties Oversight Board. United States: [s.n.], 2014. Disponível em: <https://www.pclob.gov/library/215Report_on_the_Telephone_Records_Program.pdf $>$. Acesso em: 2017-04-25. Citado 12 vezes nas páginas 176, 177, 178, 179, 180, 181, 182, 183, 184, 185, 186 e 187.

MILL, J. S. et al. On liberty. New Haven and London: Yale University Press, 2003. (Rethinking the Western tradition). ISBN 0300096089. Citado na página 92.

MIX, A. Brand im Reichstag: Das Grundgesetz des Dritten Reichs. 2013. Disponível em: < https://www.berliner-zeitung.de/brand-im-reichstag-das-grundgesetz-des-drittenreichs-7107634>. Acesso em: 2017-05-15. Citado na página 103.

National Security Agency. Transition 2001. 2000. Disponível em: < https://www.eff.org/ document/nsa-transition-2001>. Acesso em: 2017-07-08. Citado 2 vezes nas páginas 141 e 142.

National Security Agency. FAIRVIEW and STORMBREW: 'Live' - On the Net. 2003. (SID Today). Disponível em: < https://search.edwardsnowden.com/ docs/FAIRVIEWandSTORMBREW\%E2\%80\%98Live\%E2\%80\%99\%E2\%80\% 93OntheNet2016-08-10_nsadocs_snowden_doc>. Acesso em: 17/08/2018. Citado 2 vezes nas páginas 144 e 145.

National Security Agency. CLASSIFICATION GUIDE FOR CRYPTANALYSIS, 2-12. 2005. Disponível em: <https://github.com/iamcryptoki/snowden-archive/blob/master/ documents/2013/20130905-theguardian__cryptanalysis_classification.pdf $>$. Acesso em: 18/03/2018. Citado na página 168.

National Security Agency. XKEYSCORE. 2008. Disponível em: <https:// github.com/iamcryptoki/snowden-archive/blob/master/documents/2013/20130731- 
theguardian__xkeyscore_training_slides.pdf>. Acesso em: 15/09/2018. Citado 4 vezes nas páginas 159, 160, 161 e 162.

National Security Agency. CLASSIFICATION GUIDE TITLE/NUMBER: U//FOUO) PROJECT BULLRUN/2-16. 2010. Disponível em: < https://github.com/iamcryptoki/ snowden-archive/blob/master/documents/2013/20130905-theguardian__bullrun.pdf $>$. Acesso em: 15/02/2018. Citado na página 169.

National Security Agency. NSA/CSS Strategy. 2010. Disponível em: < https: //fas.org/irp/nsa/strategy.pdf >. Acesso em: 2018-05-05. Citado na página 36.

National Security Agency. Address Books. 2013. Disponível em: <https:// github.com/iamcryptoki/snowden-archive/blob/master/documents/2013/20131126thewashingtonpost__microsoft_cloud_exploitation.pdf>. Acesso em: 25/03/2018. Citado na página 154.

National Security Agency. PRISM/US-984XN Overview: The SIGAD Used Most in NSA Reporting Overview. United States: [s.n.], 2013. Disponível em: $<$ https://github.com/iamcryptoki/snowden-archive/blob/master/documents/2013/ 20131022-lemonde__prism_april_2013.pdf>. Acesso em: 2018-12-08. Citado 5 vezes nas páginas 152, 153, 164, 165 e 166.

National Security Agency. Special Source Operations: The Cryptologic Provider of Intelligence from Global High-Capacity Telecommunications Systems. 2013. Disponível em: <https://github.com/iamcryptoki/snowden-archive/blob/master/documents/2013/ 20131104-thewashingtonpost__sso_overview.pdf>. Acesso em: 18/06/2018. Citado na página 155.

National Security Agency. Special Source Operations: Corporate Partner Access. 2016. Disponível em: <https://github.com/iamcryptoki/snowden-archive/blob/master/ documents/2016/20161116-theintercept__sso_corporate_overview.pdf $>$. Acesso em: 20/04/2018. Citado 2 vezes nas páginas 157 e 158.

National Security Agency. NSA Stops Certain Section 702 Upstream Activities: IMMEDIATE RELEASE. 2017. (Press Operations). Disponível em: < https: //www.nsa.gov/news-features/press-room/Article/1618699/nsa-stops-certain-section702-upstream-activities/>. Acesso em: 2018-05-01. Citado na página 152.

National Security Agency. Alan Turing: 2014 Hall of Honor Inductee: About Alan Turing, a cryptologist who's accomplishments shortened World War II and contributed heavily to the birth of the computer. 2019. Disponivel em: <https://www.nsa.gov/About-Us/CurrentLeadership/Article-View/Article/1621551/alan-turing/>. Acesso em: 2019-03-06. Citado na página 87.

National Security Archive. The National Security Agency Declassified. 2000. Disponível em: <https://nsarchive2.gwu.edu/NSAEBB/NSAEBB24/>. Acesso em: 2018-05-04. Citado 2 vezes nas páginas 160 e 161.

NYE, J. S. The future of power. 1st ed.. ed. New York: PublicAffairs, 2011. ISBN 978-1610390699. Citado na página 83. 
OBAMA, B. Remarks by the President on Review of Signals Intelligence. Department of Justice, Washington, D.C.: [s.n.], 2014. Disponível em: <https://obamawhitehouse.archives. gov/the-press-office/2014/01/17/remarks-president-review-signals-intelligence $>$. Acesso em: 17/02/2016. Citado na página 131.

O'GRADY, S. Most iconic figure of 20th century revealed: Alan Turing and his machines - fresh insights into the enigma. Kensington, London: [s.n.], 06/02/2019. Disponível em: < https://www.independent.co.uk/arts-entertainment/tv/reviews/icons-alan-turingbbc2-review-greatest-figure-twentieth-century-mandela-bowie-a8765021.html>. Acesso em: 2019-03-06. Citado na página 87.

OLMSTED, K. S. Challenging the secret government: The post-Watergate investigations of the CIA and FBI / Kathryn Olmsted. Chapel Hill and London: University of North Carolina Press, 1996. ISBN 0807845620. Citado na página 147.

OREGAN, G. Giants of Computing: A Compendium of Select, Pivotal Pioneers. [s.n.], 2013. ISBN 978-1-4471-5339-9. Disponível em: <http://sfxeu10.hosted.exlibrisgroup. com/sfxjon/?url_ver=Z39.88-2004\&ctx_ver=Z39.88-2004\&ctx_enc=info:ofi/enc: UTF-8\&rfr_id=info:sid/sfxit.com:opac_856\&url_ctx_fmt=info:ofi/fmt:kev:mtx:ctx\& sfx.ignore_date_threshold $=1 \&$ rft.object_id $=3710000000015731 \&$ svc_val_fmt $=$ info: ofi/fmt:kev:mtx:sch_svc\&>. Citado na página 86.

PASK, G. An approach to cybernetics. [London]: Hutchinson, 1968. (A Radius book). ISBN 0090868110. Citado na página 82.

PASQUALE, F. The black box society: The secret algorithms behind money and information. [S.l.: s.n.]. ISBN 0674368274. Citado na página 127.

PERLROTH, N.; SHANE, S.; LARSON, J. Secret Documents Reveal N.S.A. Campaign Against Encryption. The New York Times, 2013. Disponível em: < https: //archive.nytimes.com/www.nytimes.com/interactive/2013/09/05/us/documents-revealnsa-campaign-against-encryption.html?_r=0>. Acesso em: 2019-04-25. Citado 3 vezes nas páginas 170, 171 e 172.

PETERSON, I. Encrypting Controversy. Science News, v. 143, n. 25, p. 394-396, 1993. ISSN 00368423. Disponível em: < http://www.jstor.org/stable/3976908>. Citado na página 127.

PETERSON, I. Boosting Cryptography's Role in Security. Science News, v. 149, n. 23, p. 357, 1996. ISSN 00368423. Disponível em: <http://www.jstor.org/stable/3979743>. Citado na página 127.

Reichstagsbrandverordnung. 2019. Disponível em: < https://www.ns-archiv.de/system/ gesetze/1933/reichstagsbrand/faksimile/>. Acesso em: 2019-05-15. Citado na página 103.

ROSEN, J. The NSA's next move: silencing university professors? The Guardian, 2013. Disponível em: <https://www.theguardian.com/commentisfree/2013/sep/10/nsamatthew-green-takedown-blog-post-johns-hopkins $>$. Acesso em: 2018-02-07. Citado na página 113.

RUSSELL, B. Authority and the individual. London and New York: Routledge, 1995. ISBN 0-203-98879-5. Citado na página 37. 
SAVAGE, C. Disputed N.S.A. Phone Program Is Shut Down, Aide Says. The New York Times, 2019. Disponível em: <https://www.nytimes.com/2019/03/04/us/politics/nsaphone-records-program-shut-down.html>. Acesso em: 2019-05-04. Citado na página 154.

SCHMITT, C. Political theology: Four chapters on the concept of sovereignty. University of chicago press ed. Chicago: University of Chicago Press, 2005. ISBN 0226738892. Citado 3 vezes nas páginas 88, 118 e 119 .

SCHNEIER, B. NSA Classification ECI = Exceptionally Controlled Information Schneier on Security. 2014. Disponível em: <https://www.schneier.com/blog/archives/ 2014/10/nsa_classificat.html>. Acesso em: 2019-04-22. Citado na página 169.

SCHUMPETER, J. A. Capitalism, socialism, and democracy. London: Taylor \& Francis, Ltd, 1976. ISBN 0203202058. Disponível em: <http://www.myilibrary.com?id=10477>. Citado 3 vezes nas páginas 83, 118 e 119.

SCHWARTZBECK, M. The Evolution of US Government Restrictions on Using and Exporting Encryption Tech: Declassified Articles from Studies in Intelligence: The IC's Journal for the Intelligence Professional: CIA FOIA (foia.cia.gov). 2014. Disponível em: <https://www.cia.gov/library/readingroom/document/0006231614>. Acesso em: 2019-03-07. Citado 4 vezes nas páginas 131, 132, 133 e 134.

SCLOVE, R. E. The Nuts and Bolts of Democracy: Democratic Theory and Technological Design. In: WINNER, L. (Ed.). Democracy in a Technological Society. [S.l.: s.n.], 1992. p. 139-160. ISBN 978-90-481-4210-1. Citado 5 vezes nas páginas 61, 76, 77, 78 e 195.

Shifting the Fisa... Shifting the Fisa Paradigm: Protecting Civil Liberties by Eliminating Ex Ante Judicial Approval. Harvard Law Review, v. 121, n. 8, p. 2200-2221, 2008. ISSN 0017811X. Disponível em: <http://www.jstor.org/stable/40042737>. Citado 2 vezes nas páginas 147 e 148.

SIMMEL, G. The Sociology of Secrecy and of Secret Societies. American Journal of Sociology, v. 11, n. 4, p. 441-498, 1906. ISSN 00029602. Citado 2 vezes nas páginas 100 e 101.

SIMMONS, G. J. Cryptology. 2016. (Encyclopædia Britannica). Disponível em: $<$ https://www.britannica.com/topic/cryptology/Cryptanalysis>. Acesso em: 2017-12-10. Citado 3 vezes nas páginas 84, 85 e 88.

STAY, R. J. Cryptic Controversy: U.S. Government Restrictions on Cryptography Exports and the plight of Philip Zimmermann. Georgia State University Law Review, v. 13, n. 2, p. 580-604, 1997. Disponível em: <https://readingroom.law.gsu.edu/cgi/ viewcontent.cgi?article $=2264 \&$ context $=$ gsulr $>$. Citado na página 137 .

SUBRAMANIAN, R. Computer security, privacy, and politics: Current issues, challenges and solutions. Hershey PA: IRM Press, 2008. ISBN 978-1599048048. Citado na página 127.

SWIRE, P. From real-time intercepts to stored records: why encryption drives the government to seek access to the cloud. International Data Privacy Law, v. 2, n. 4, p. 200-206, 2012. Citado na página 127. 
The Senate and House of Representatives of the United States of America, Pub.L. 95-511, 92 Stat. 1783, 50 USC ch. 36. The Foreign intelligence surveillance act of 1978, H.R. 7308: FISA. Washington: [s.n.], 1978. Disponível em: <https://legcounsel.house.gov/ Comps/Foreign\%20Intelligence\%20Surveillance\%20Act\%20Of\%201978.pdf $>$. Acesso em: 20/01/2018. Citado 4 vezes nas páginas 147, 148, 149 e 150.

THE WHITE HOUSE. The National Strategy to Secure Cyberspace. Washington D.C.: [s.n.], 2003. Disponível em: <https://www.us-cert.gov/sites/default/files/publications/ cyberspace_strategy.pdf $>$. Acesso em: 2018-01-10. Citado na página 37.

THE WHITE HOUSE. Cyberspace Policy Review: Assuring a Trusted and Resilient Information and Communications Infrastructure. 2009. Disponível em: < https: //www.whitehouse.gov/assets/documents/Cyberspace_Policy_Review_final.pdf $>$. Acesso em: 2012-01-06. Citado na página 37.

The White House - Office of the Press Secretary. STATEMENT BY THE PRESS SECRETARY: Subject: 1993-04-16 Press Release on Clipper Chip Encryption Initiative: For Immediate Release April 16, 1993. 1993. Disponível em: $<$ https://clintonwhitehouse6.archives.gov/1993/04/1993-04-16-press-release-on-clipperchip-encryption-initiative.html>. Acesso em: 2019-04-03. Citado 2 vezes nas páginas 134 e 135.

The White House - Office of the Press Secretary. Presidential Policy Directive 28: Signals Intelligence Activities. 2014. Disponível em: < https://www.pclob.gov/library/PPD28Signals_Intelligence_Activities.pdf $>$. Acesso em: 2019-05-24. Citado na página 177.

THOMAS, D. Hacker culture. Minneapolis: University of Minnesota Press, 2002. ISBN 9780816633456. Citado na página 36.

TIMBERG, C.; GELLMAN, B. NSA paying U.S. companies for access to communications networks. The Washington Post, 29/09/2013. Disponível em:

$<$ https://www.washingtonpost.com/world/national-security/nsa-paying-us-companiesfor-access-to-communications-networks/2013/08/29/5641a4b6-10c2-11e3-bdf6e4fc677d94a1_story.html?noredirect $=$ on\&utm_term $=. b 5 f 8 f 37 f e 420>$. Acesso em: 2018-04-20. Citado na página 156.

TURING, A. On Computable Numbers, with an Application to the Entscheidungsproblem. Proceedings of the London Mathematical Society, v. 42, n. 1, p. 230-265, 1936. Citado na página 87.

TURING, A. M.; COPELAND, B. J. The essential Turing: Seminal writings in computing, logic, philosophy, artificial intelligence, and artificial life, plus the secrets of Enigma. Oxford and New York: Clarendon Press and Oxford University Press, 2004. ISBN 0-19-825079-7. Citado na página 82.

Vijver, Gertrudis van de (Ed.). New perspectives on cybernetics: Self-organization, autonomy, and connectionism / edited by Gertrudis van de Vijver. Dordrecht and London: Kluwer Academic Publishers, 1992. v. 220. (Synthese library : studies in epistemology, logic, methodology and philosophy of science, v. 220). ISBN 978-0792315193. Citado na página 82.

WARREN, S. D.; BRANDEIS, L. D. The Right to Privacy. Harvard Law Review, v. 4, n. 5, p. 193, 1890. ISSN 0017811X. Citado 2 vezes nas páginas 95 e 96. 
WARTOFSKY, M. W. Technology, Power, and Truth: Political and Epistemological Reflections on the Fourth Revolution. In: WINNER, L. (Ed.). Democracy in a Technological Society. [S.l.: s.n.], 1992. p. 15-34. ISBN 978-90-481-4210-1. Citado 3 vezes nas páginas 63, 76 e 195.

WESTIN, A. F. Privacy and freedom. New York, NY: Ig Publishing, 2018. ISBN 9781632460738. Citado 10 vezes nas páginas 97, 98, 106, 107, 108, 109, 111, 112, 114 e 115 .

WIENER, N. Cybernetics; or, Control and Communication in the animal and the machine. 2d ed.. ed. New York: M.I.T. Press, 1961. ISBN 026273009X. Citado 2 vezes nas páginas 81 e 82 .

WIENER, N. The human use of human beings: Cybernetics and society. London: Free Association, 1989, c1954. ISBN 1853430757. Citado na página 82.

WINNER, L. Do Artifacts Have Politics? Daedalus, v. 109, n. 1, p. 121-136, 1980. ISSN 0011-5266. Citado 6 vezes nas páginas 61, 62, 64, 73, 74 e 195.

WINNER, L. Autonomous technology: Technics-out-of-control as a theme in political thought. 11. print. ed. Cambridge, Mass. [u.a.]: M.I.T. Press, 1992. ISBN 9780262730495. Citado 5 vezes nas páginas 60, 75, 76, 78 e 79 .

WINNER, L. (Ed.). Democracy in a Technological Society. [S.l.: s.n.], 1992. ISBN 978-90-481-4210-1. Citado 5 vezes nas páginas 63, 65, 66, 72 e 195.

ZETTER, K. Countdown to Zero Day: Stuxnet and the launch of the world's first digital weapon. First edition. New York: Crown Publishers, 2014. ISBN 077043617X. Citado na página 172. 
Apêndices 



\section{APÊNDICE A - Metodologia}

\section{A.1 Material, Métodos e Forma de Análise dos Resultados.}

Em relação aos aspectos metodológicos, o estudo de caso em si é emblemático e bastante popular pela sua divulgação midiática - fatores que não auxiliam no trabalho do pesquisador devido aos excessivos ruídos de informação. O cuidado metodológico, em especial com a análise do estudo de caso, é expresso pela escolha e preponderância de fontes de informação primárias aliadas ao auxílio posterior de fontes secundárias. Em relação à revisão bibliográfica, o que se observa é que no decorrer da pesquisa foi-se capaz de angariar insumos para propor mudanças drásticas em relação à proposta inicial. Cita-se, por exemplo, os principais autores aqui utilizados que, ainda que não dialoguem entre si, são capazes de prover categorias iniciais de análise. De igual modo, houve uma constante troca com os pares do Departamento de Ciência Política que contribuíram significativamente para se depurar o método e distinguir os conflitos das mais variadas formas presentes em versões anteriores do projeto.

Os métodos que foram utilizados correspondem àqueles referentes ao estudo de caso de "N" pequeno, empregado tipicamente em análises e inferências qualitativas de causalidades. A extensa análise das causalidades que desencadeiam o processo securitização e seu impacto nos procedimentos democráticos, exposto acima, demanda não somente uma abordagem qualitativa, como também uma expressiva contribuição métodos multivariados para a análise de outras fontes de informações, dados e perspectivas metodológicas. Uma alternativa para equacionar essa necessidade pode ser encontrada na "triangulação" de métodos. É preciso destacar que, segundo Keohane e Verba, o trabalho científico baseiase primordialmente na capacidade de se realizar inferências fundamentadas e lógicas, indiferentemente de uma abordagem qualitativa ou quantitativa. Para tanto, os autores resgatam na "triangulação" a capacidade de não se ater a uma corrente específica para que se possa, assim, buscar o maior número de dados e informações, bem como os melhores métodos para interpretá-los.

[...] a major theme [...] is that there is a single unified logic of inference. Hence it is possible effectively to combine different methods. However, the issue of triangulation that Tarrow so effectively raises is not the use of different logics or methods, as he argues, but the triangulation of diverse data sources trained on the same problem. Triangulation involves data collected at different places, sources, times, levels of analysis, or perspectives, data that might be quantitative, or might involve intensive interviews or thick historical description. The best method should be chosen for each data source. But more data are better. Triangulation, then, refers to the practice of increasing the amount of information 
brought to bear on a theory or hypothesis [...].(King, Keohane, Verba, 2010)

A triangulação metodológica apresentada por KING, KEOHANE, VERBA permitirá, por exemplo, em aspectos práticos, que cada fonte de dados tenha um tratamento único, capaz de extrair o máximo de informações-inferências para a pesquisa. Por exemplo, Buzan (1998) estipula que a forma de se analisar os processos de securitização se dá por intermédio dos "atos de discurso" e processos políticos aceitos pela intersubjetividade coletiva e estabelecidos ao redor de uma ameaça "existencial". Para o autor, os processos de securitização são a combinação de atos de discurso, mobilização e ação:

The way to study securitization is to study discourse and political constellations; If by means of an argument about the priority and urgency of an existential threat the securitizing actor has managed to break free of procedures or rules he or she would otherwise be bound by, we are witnessing a case of securitization. (BUZAN,1998)

Enquanto estudo de caso típico e de posse de fontes de dados multivariados, as inferências causais de abordagens multivariadas da "triangulação" tornar-se-ão possíveis se a teoria da Securitização for empreendida conjuntamente com a estratégia de "patternmatching investigation". Essa compatibilidade decorre do fato de que a teoria apresenta detalhadamente os caminhos causais específicos que movem a ação de "securitização" de um Estado frente às ameaças existenciais. De acordo com Gerring, "the typical case is well explained by an existing model, the puzzle of interest to the researcher lies within that case". Ainda segundo o autor, o estudo de caso típico permite uma multivariada exploração dos mecanismos causais:

\footnotetext{
If the existing theory suggests a specific causal pathway, then the researcher may perform a pattern-matching investigation, in which the evidence at hand (in the case) is judged according to whether it validates the stipulated causal mechanisms or not. Otherwise, the researcher may try to show that the causal mechanisms are different than those that had been previously stipulated. Or he or she may argue that there are no plausible causal mechanisms connecting this independent variable with this particular outcome. (GERRING, 2004)
}

Ocorre que a pesquisa em questão suscita um considerável volume de informações e narrativas históricas que, por sua vez, não podem ser consideradas como parte totalizante das possíveis inferências e relações causais. Afinal, segundo a perspectiva de King, Keohane e Verba, é preciso distinguir um trabalho histórico-descritivo, cuja natureza será caracterizada como "describing historical detail and occasionally also conducting very limited descriptive inference" (KING, KEOHANE, VERBA, 2010). Por essa visão, ainda que a descrição histórica seja uma importante ferramenta analítica, principalmente para os estudos de caso típicos, ela não pode ser equiparada com a inferência científica de uma pesquisa, pela qual 
o cientista social "must make descriptive or causal inferences, thus seeking explanation and generalization" (KING, KEOHANE, VERBA, 2010).

Para tanto, as relações causais podem ser identificadas em um arcabouço coerente de inferências, sem desconsiderarem o sentido e a disposição histórica no período analisado, ao se explorar a técnica conhecida como "Process Tracing". O Process Tracing equciona essa questão pois, segundo os autores, "what is being traced is not a series of empirical events or narratives, but instead the underlying theorized causal mechanism itself [...]". (BEACH, PEDERSEN, 2013). A técnica pode ser aplicada em estudos de caso confirmatórios para verificar se a causalidade hipotética entre as variáveis encontra - se presente. Portanto, para o estudo de caso de "N=1" apresentado nesta pesquisa, a estratégia de "pattern-matching" enquanto estudo de caso típico pode ser combinada metodologicamente com a técnica do "Process Tracing" - combinação esta que torna possível manter a inferência das relações causais a partir das variáveis identificadas mesmo em face ao seu inerente volume e valor de informações históricas.

A análise dos dados, nesse sentido, indicou a necessidade de se pelo menos contextualizar e analisar historicamente outros períodos históricos para a compreensão do estudo de caso, caracterizados como: A relação da Primeira e Segunda Guerra Mundial com a criptografia; o embate que ficou conhecido como Cryptowars devido as propostas de se implementar e enfraquecer a tecnologia criptográfica disponível ao público. Em algum momento tais períodos foram abordados nessa pesquisa sem, contudo, o devido aprofundamento, análise e contextualização com a riqueza de detalhes que somente estudos dedicados poderiam prover. O que se observou, contudo, é que esses períodos fornecem uma vasta compreensão do objeto de pesquisa e do próprio estudo de caso principal e, desta forma, figuraram como subseções nos capítulos da tese. 

Anexos 



\section{ANEXO A - Acervo Documental}

\section{A.1 Anexo 1 - Discurso de Barack Obama, 17/01/2014: Remarks by the President on Review of Signals Intelligence}

Inteiro teor da transcrição do discurso proferido pelo então Presidente dos Estados Unidos, Barack Obama, em 17/01/2014.

The White House Office of the Press Secretary For Immediate Release January 17, 2014 Remarks by the President on Review of Signals Intelligence Department of Justice Washington, D.C.

\section{1:15 A.M. EST}

THE PRESIDENT: At the dawn of our Republic, a small, secret surveillance committee borne out of the "The Sons of Liberty" was established in Boston. And the group's members included Paul Revere. At night, they would patrol the streets, reporting back any signs that the British were preparing raids against America's early Patriots.

Throughout American history, intelligence has helped secure our country and our freedoms. In the Civil War, Union balloon reconnaissance tracked the size of Confederate armies by counting the number of campfires. In World War II, code-breakers gave us insights into Japanese war plans, and when Patton marched across Europe, intercepted communications helped save the lives of his troops. After the war, the rise of the Iron Curtain and nuclear weapons only increased the need for sustained intelligence gathering. And so, in the early days of the Cold War, President Truman created the National Security Agency, or NSA, to give us insights into the Soviet bloc, and provide our leaders with information they needed to confront aggression and avert catastrophe.

Throughout this evolution, we benefited from both our Constitution and our traditions of limited government. U.S. intelligence agencies were anchored in a system of checks and balances - with oversight from elected leaders, and protections for ordinary citizens. Meanwhile, totalitarian states like East Germany offered a cautionary tale of what could happen when vast, unchecked surveillance turned citizens into informers, and persecuted people for what they said in the privacy of their own homes.

In fact, even the United States proved not to be immune to the abuse of surveillance. And in the 1960s, government spied on civil rights leaders and critics of the Vietnam War. And partly in response to these revelations, additional laws were established in the 1970s to ensure that our intelligence capabilities could not be misused against our citizens. In the long, twilight struggle against Communism, we had been reminded that the very liberties 
that we sought to preserve could not be sacrificed at the altar of national security.

If the fall of the Soviet Union left America without a competing superpower, emerging threats from terrorist groups, and the proliferation of weapons of mass destruction placed new and in some ways more complicated demands on our intelligence agencies. Globalization and the Internet made these threats more acute, as technology erased borders and empowered individuals to project great violence, as well as great good. Moreover, these new threats raised new legal and new policy questions. For while few doubted the legitimacy of spying on hostile states, our framework of laws was not fully adapted to prevent terrorist attacks by individuals acting on their own, or acting in small, ideologically driven groups on behalf of a foreign power.

The horror of September 11th brought all these issues to the fore. Across the political spectrum, Americans recognized that we had to adapt to a world in which a bomb could be built in a basement, and our electric grid could be shut down by operators an ocean away. We were shaken by the signs we had missed leading up to the attacks how the hijackers had made phone calls to known extremists and traveled to suspicious places. So we demanded that our intelligence community improve its capabilities, and that law enforcement change practices to focus more on preventing attacks before they happen than prosecuting terrorists after an attack.

It is hard to overstate the transformation America's intelligence community had to go through after $9 / 11$. Our agencies suddenly needed to do far more than the traditional mission of monitoring hostile powers and gathering information for policymakers. Instead, they were now asked to identify and target plotters in some of the most remote parts of the world, and to anticipate the actions of networks that, by their very nature, cannot be easily penetrated with spies or informants.

And it is a testimony to the hard work and dedication of the men and women of our intelligence community that over the past decade we've made enormous strides in fulfilling this mission. Today, new capabilities allow intelligence agencies to track who a terrorist is in contact with, and follow the trail of his travel or his funding. New laws allow information to be collected and shared more quickly and effectively between federal agencies, and state and local law enforcement. Relationships with foreign intelligence services have expanded, and our capacity to repel cyber-attacks have been strengthened. And taken together, these efforts have prevented multiple attacks and saved innocent lives - not just here in the United States, but around the globe.

And yet, in our rush to respond to a very real and novel set of threats, the risk of government overreach - the possibility that we lose some of our core liberties in pursuit of security - also became more pronounced. We saw, in the immediate aftermath of $9 / 11$, our government engaged in enhanced interrogation techniques that contradicted our values. As a Senator, I was critical of several practices, such as warrantless wiretaps. And all too 
often new authorities were instituted without adequate public debate.

Through a combination of action by the courts, increased congressional oversight, and adjustments by the previous administration, some of the worst excesses that emerged after $9 / 11$ were curbed by the time I took office. But a variety of factors have continued to complicate America's efforts to both defend our nation and uphold our civil liberties.

First, the same technological advances that allow U.S. intelligence agencies to pinpoint an al Qaeda cell in Yemen or an email between two terrorists in the Sahel also mean that many routine communications around the world are within our reach. And at a time when more and more of our lives are digital, that prospect is disquieting for all of us.

Second, the combination of increased digital information and powerful supercomputers offers intelligence agencies the possibility of sifting through massive amounts of bulk data to identify patterns or pursue leads that may thwart impending threats. It's a powerful tool. But the government collection and storage of such bulk data also creates a potential for abuse.

Third, the legal safeguards that restrict surveillance against U.S. persons without a warrant do not apply to foreign persons overseas. This is not unique to America; few, if any, spy agencies around the world constrain their activities beyond their own borders. And the whole point of intelligence is to obtain information that is not publicly available. But America's capabilities are unique, and the power of new technologies means that there are fewer and fewer technical constraints on what we can do. That places a special obligation on us to ask tough questions about what we should do.

And finally, intelligence agencies cannot function without secrecy, which makes their work less subject to public debate. Yet there is an inevitable bias not only within the intelligence community, but among all of us who are responsible for national security, to collect more information about the world, not less. So in the absence of institutional requirements for regular debate - and oversight that is public, as well as private or classified - the danger of government overreach becomes more acute. And this is particularly true when surveillance technology and our reliance on digital information is evolving much faster than our laws.

For all these reasons, I maintained a healthy skepticism toward our surveillance programs after I became President. I ordered that our programs be reviewed by my national security team and our lawyers, and in some cases I ordered changes in how we did business. We increased oversight and auditing, including new structures aimed at compliance. Improved rules were proposed by the government and approved by the Foreign Intelligence Surveillance Court. And we sought to keep Congress continually updated on these activities.

What I did not do is stop these programs wholesale - not only because I felt that 
they made us more secure, but also because nothing in that initial review, and nothing that I have learned since, indicated that our intelligence community has sought to violate the law or is cavalier about the civil liberties of their fellow citizens.

To the contrary, in an extraordinarily difficult job - one in which actions are second-guessed, success is unreported, and failure can be catastrophic - the men and women of the intelligence community, including the NSA, consistently follow protocols designed to protect the privacy of ordinary people. They're not abusing authorities in order to listen to your private phone calls or read your emails. When mistakes are made which is inevitable in any large and complicated human enterprise - they correct those mistakes. Laboring in obscurity, often unable to discuss their work even with family and friends, the men and women at the NSA know that if another 9/11 or massive cyber-attack occurs, they will be asked, by Congress and the media, why they failed to connect the dots. What sustains those who work at NSA and our other intelligence agencies through all these pressures is the knowledge that their professionalism and dedication play a central role in the defense of our nation.

Now, to say that our intelligence community follows the law, and is staffed by patriots, is not to suggest that I or others in my administration felt complacent about the potential impact of these programs. Those of us who hold office in America have a responsibility to our Constitution, and while I was confident in the integrity of those who lead our intelligence community, it was clear to me in observing our intelligence operations on a regular basis that changes in our technological capabilities were raising new questions about the privacy safeguards currently in place.

Moreover, after an extended review of our use of drones in the fight against terrorist networks, I believed a fresh examination of our surveillance programs was a necessary next step in our effort to get off the open-ended war footing that we've maintained since 9/11. And for these reasons, I indicated in a speech at the National Defense University last May that we needed a more robust public discussion about the balance between security and liberty. Of course, what I did not know at the time is that within weeks of my speech, an avalanche of unauthorized disclosures would spark controversies at home and abroad that have continued to this day.

And given the fact of an open investigation, I'm not going to dwell on Mr. Snowden's actions or his motivations; I will say that our nation's defense depends in part on the fidelity of those entrusted with our nation's secrets. If any individual who objects to government policy can take it into their own hands to publicly disclose classified information, then we will not be able to keep our people safe, or conduct foreign policy. Moreover, the sensational way in which these disclosures have come out has often shed more heat than light, while revealing methods to our adversaries that could impact our operations in ways that we may not fully understand for years to come. 
Regardless of how we got here, though, the task before us now is greater than simply repairing the damage done to our operations or preventing more disclosures from taking place in the future. Instead, we have to make some important decisions about how to protect ourselves and sustain our leadership in the world, while upholding the civil liberties and privacy protections that our ideals and our Constitution require. We need to do so not only because it is right, but because the challenges posed by threats like terrorism and proliferation and cyber-attacks are not going away any time soon. They are going to continue to be a major problem. And for our intelligence community to be effective over the long haul, we must maintain the trust of the American people, and people around the world.

This effort will not be completed overnight, and given the pace of technological change, we shouldn't expect this to be the last time America has this debate. But I want the American people to know that the work has begun. Over the last six months, I created an outside Review Group on Intelligence and Communications Technologies to make recommendations for reform. I consulted with the Privacy and Civil Liberties Oversight Board, created by Congress. I've listened to foreign partners, privacy advocates, and industry leaders. My administration has spent countless hours considering how to approach intelligence in this era of diffuse threats and technological revolution. So before outlining specific changes that I've ordered, let me make a few broad observations that have emerged from this process.

First, everyone who has looked at these problems, including skeptics of existing programs, recognizes that we have real enemies and threats, and that intelligence serves a vital role in confronting them. We cannot prevent terrorist attacks or cyber threats without some capability to penetrate digital communications - whether it's to unravel a terrorist plot; to intercept malware that targets a stock exchange; to make sure air traffic control systems are not compromised; or to ensure that hackers do not empty your bank accounts. We are expected to protect the American people; that requires us to have capabilities in this field.

Moreover, we cannot unilaterally disarm our intelligence agencies. There is a reason why BlackBerrys and iPhones are not allowed in the White House Situation Room. We know that the intelligence services of other countries - including some who feign surprise over the Snowden disclosures - are constantly probing our government and private sector networks, and accelerating programs to listen to our conversations, and intercept our emails, and compromise our systems. We know that.

Meanwhile, a number of countries, including some who have loudly criticized the NSA, privately acknowledge that America has special responsibilities as the world's only superpower; that our intelligence capabilities are critical to meeting these responsibilities, and that they themselves have relied on the information we obtain to protect their own 
people.

Second, just as ardent civil libertarians recognize the need for robust intelligence capabilities, those with responsibilities for our national security readily acknowledge the potential for abuse as intelligence capabilities advance and more and more private information is digitized. After all, the folks at NSA and other intelligence agencies are our neighbors. They're our friends and family. They've got electronic bank and medical records like everybody else. They have kids on Facebook and Instagram, and they know, more than most of us, the vulnerabilities to privacy that exist in a world where transactions are recorded, and emails and text and messages are stored, and even our movements can increasingly be tracked through the GPS on our phones.

Third, there was a recognition by all who participated in these reviews that the challenges to our privacy do not come from government alone. Corporations of all shapes and sizes track what you buy, store and analyze our data, and use it for commercial purposes; that's how those targeted ads pop up on your computer and your smartphone periodically. But all of us understand that the standards for government surveillance must be higher. Given the unique power of the state, it is not enough for leaders to say: Trust us, we won't abuse the data we collect. For history has too many examples when that trust has been breached. Our system of government is built on the premise that our liberty cannot depend on the good intentions of those in power; it depends on the law to constrain those in power.

I make these observations to underscore that the basic values of most Americans when it comes to questions of surveillance and privacy converge a lot more than the crude characterizations that have emerged over the last several months. Those who are troubled by our existing programs are not interested in repeating the tragedy of $9 / 11$, and those who defend these programs are not dismissive of civil liberties.

The challenge is getting the details right, and that is not simple. In fact, during the course of our review, I have often reminded myself I would not be where I am today were it not for the courage of dissidents like Dr. King, who were spied upon by their own government. And as President, a President who looks at intelligence every morning, I also can't help but be reminded that America must be vigilant in the face of threats.

Fortunately, by focusing on facts and specifics rather than speculation and hypotheticals, this review process has given me - and hopefully the American people - some clear direction for change. And today, I can announce a series of concrete and substantial reforms that my administration intends to adopt administratively or will seek to codify with Congress.

First, I have approved a new presidential directive for our signals intelligence activities both at home and abroad. This guidance will strengthen executive branch 
oversight of our intelligence activities. It will ensure that we take into account our security requirements, but also our alliances; our trade and investment relationships, including the concerns of American companies; and our commitment to privacy and basic liberties. And we will review decisions about intelligence priorities and sensitive targets on an annual basis so that our actions are regularly scrutinized by my senior national security team.

Second, we will reform programs and procedures in place to provide greater transparency to our surveillance activities, and fortify the safeguards that protect the privacy of U.S. persons. Since we began this review, including information being released today, we have declassified over 40 opinions and orders of the Foreign Intelligence Surveillance Court, which provides judicial review of some of our most sensitive intelligence activities including the Section 702 program targeting foreign individuals overseas, and the Section 215 telephone metadata program.

And going forward, I'm directing the Director of National Intelligence, in consultation with the Attorney General, to annually review for the purposes of declassification any future opinions of the court with broad privacy implications, and to report to me and to Congress on these efforts. To ensure that the court hears a broader range of privacy perspectives, I am also calling on Congress to authorize the establishment of a panel of advocates from outside government to provide an independent voice in significant cases before the Foreign Intelligence Surveillance Court.

Third, we will provide additional protections for activities conducted under Section 702 , which allows the government to intercept the communications of foreign targets overseas who have information that's important for our national security. Specifically, I am asking the Attorney General and DNI to institute reforms that place additional restrictions on government's ability to retain, search, and use in criminal cases communications between Americans and foreign citizens incidentally collected under Section 702.

Fourth, in investigating threats, the FBI also relies on what's called national security letters, which can require companies to provide specific and limited information to the government without disclosing the orders to the subject of the investigation. These are cases in which it's important that the subject of the investigation, such as a possible terrorist or spy, isn't tipped off. But we can and should be more transparent in how government uses this authority.

I have therefore directed the Attorney General to amend how we use national security letters so that this secrecy will not be indefinite, so that it will terminate within a fixed time unless the government demonstrates a real need for further secrecy. We will also enable communications providers to make public more information than ever before about the orders that they have received to provide data to the government. 
few months - the bulk collection of telephone records under Section 215. Let me repeat what I said when this story first broke: This program does not involve the content of phone calls, or the names of people making calls. Instead, it provides a record of phone numbers and the times and lengths of calls - metadata that can be queried if and when we have a reasonable suspicion that a particular number is linked to a terrorist organization.

Why is this necessary? The program grew out of a desire to address a gap identified after 9/11. One of the 9/11 hijackers - Khalid al-Mihdhar - made a phone call from San Diego to a known al Qaeda safe-house in Yemen. NSA saw that call, but it could not see that the call was coming from an individual already in the United States. The telephone metadata program under Section 215 was designed to map the communications of terrorists so we can see who they may be in contact with as quickly as possible. And this capability could also prove valuable in a crisis. For example, if a bomb goes off in one of our cities and law enforcement is racing to determine whether a network is poised to conduct additional attacks, time is of the essence. Being able to quickly review phone connections to assess whether a network exists is critical to that effort.

In sum, the program does not involve the NSA examining the phone records of ordinary Americans. Rather, it consolidates these records into a database that the government can query if it has a specific lead - a consolidation of phone records that the companies already retained for business purposes. The review group turned up no indication that this database has been intentionally abused. And I believe it is important that the capability that this program is designed to meet is preserved.

Having said that, I believe critics are right to point out that without proper safeguards, this type of program could be used to yield more information about our private lives, and open the door to more intrusive bulk collection programs in the future. They're also right to point out that although the telephone bulk collection program was subject to oversight by the Foreign Intelligence Surveillance Court and has been reauthorized repeatedly by Congress, it has never been subject to vigorous public debate.

For all these reasons, I believe we need a new approach. I am therefore ordering a transition that will end the Section 215 bulk metadata program as it currently exists, and establish a mechanism that preserves the capabilities we need without the government holding this bulk metadata.

This will not be simple. The review group recommended that our current approach be replaced by one in which the providers or a third party retain the bulk records, with government accessing information as needed. Both of these options pose difficult problems. Relying solely on the records of multiple providers, for example, could require companies to alter their procedures in ways that raise new privacy concerns. On the other hand, any third party maintaining a single, consolidated database would be carrying out what is essentially a government function but with more expense, more legal ambiguity, potentially 
less accountability - all of which would have a doubtful impact on increasing public confidence that their privacy is being protected.

During the review process, some suggested that we may also be able to preserve the capabilities we need through a combination of existing authorities, better information sharing, and recent technological advances. But more work needs to be done to determine exactly how this system might work.

Because of the challenges involved, I've ordered that the transition away from the existing program will proceed in two steps. Effective immediately, we will only pursue phone calls that are two steps removed from a number associated with a terrorist organization instead of the current three. And I have directed the Attorney General to work with the Foreign Intelligence Surveillance Court so that during this transition period, the database can be queried only after a judicial finding or in the case of a true emergency.

Next, step two, I have instructed the intelligence community and the Attorney General to use this transition period to develop options for a new approach that can match the capabilities and fill the gaps that the Section 215 program was designed to address without the government holding this metadata itself. They will report back to me with options for alternative approaches before the program comes up for reauthorization on March 28th. And during this period, I will consult with the relevant committees in Congress to seek their views, and then seek congressional authorization for the new program as needed.

Now, the reforms I'm proposing today should give the American people greater confidence that their rights are being protected, even as our intelligence and law enforcement agencies maintain the tools they need to keep us safe. And I recognize that there are additional issues that require further debate. For example, some who participated in our review, as well as some members of Congress, would like to see more sweeping reforms to the use of national security letters so that we have to go to a judge each time before issuing these requests. Here, I have concerns that we should not set a standard for terrorism investigations that is higher than those involved in investigating an ordinary crime. But I agree that greater oversight on the use of these letters may be appropriate, and I'm prepared to work with Congress on this issue.

There are also those who would like to see different changes to the FISA Court than the ones I've proposed. On all these issues, I am open to working with Congress to ensure that we build a broad consensus for how to move forward, and I'm confident that we can shape an approach that meets our security needs while upholding the civil liberties of every American.

Let me now turn to the separate set of concerns that have been raised overseas, and focus on America's approach to intelligence collection abroad. As I've indicated, the 
United States has unique responsibilities when it comes to intelligence collection. Our capabilities help protect not only our nation, but our friends and our allies, as well. But our efforts will only be effective if ordinary citizens in other countries have confidence that the United States respects their privacy, too. And the leaders of our close friends and allies deserve to know that if I want to know what they think about an issue, I'll pick up the phone and call them, rather than turning to surveillance. In other words, just as we balance security and privacy at home, our global leadership demands that we balance our security requirements against our need to maintain the trust and cooperation among people and leaders around the world.

For that reason, the new presidential directive that I've issued today will clearly prescribe what we do, and do not do, when it comes to our overseas surveillance. To begin with, the directive makes clear that the United States only uses signals intelligence for legitimate national security purposes, and not for the purpose of indiscriminately reviewing the emails or phone calls of ordinary folks. I've also made it clear that the United States does not collect intelligence to suppress criticism or dissent, nor do we collect intelligence to disadvantage people on the basis of their ethnicity, or race, or gender, or sexual orientation, or religious beliefs. We do not collect intelligence to provide a competitive advantage to U.S. companies or U.S. commercial sectors.

And in terms of our bulk collection of signals intelligence, U.S. intelligence agencies will only use such data to meet specific security requirements: counterintelligence, counterterrorism, counter-proliferation, cybersecurity, force protection for our troops and our allies, and combating transnational crime, including sanctions evasion.

In this directive, I have taken the unprecedented step of extending certain protections that we have for the American people to people overseas. I've directed the DNI, in consultation with the Attorney General, to develop these safeguards, which will limit the duration that we can hold personal information, while also restricting the use of this information.

The bottom line is that people around the world, regardless of their nationality, should know that the United States is not spying on ordinary people who don't threaten our national security, and that we take their privacy concerns into account in our policies and procedures. This applies to foreign leaders as well. Given the understandable attention that this issue has received, I have made clear to the intelligence community that unless there is a compelling national security purpose, we will not monitor the communications of heads of state and government of our close friends and allies. And I've instructed my national security team, as well as the intelligence community, to work with foreign counterparts to deepen our coordination and cooperation in ways that rebuild trust going forward.

Now let me be clear: Our intelligence agencies will continue to gather information 
about the intentions of governments - as opposed to ordinary citizens - around the world, in the same way that the intelligence services of every other nation does. We will not apologize simply because our services may be more effective. But heads of state and government with whom we work closely, and on whose cooperation we depend, should feel confident that we are treating them as real partners. And the changes I've ordered do just that.

Finally, to make sure that we follow through on all these reforms, I am making some important changes to how our government is organized. The State Department will designate a senior officer to coordinate our diplomacy on issues related to technology and signals intelligence. We will appoint a senior official at the White House to implement the new privacy safeguards that I have announced today. I will devote the resources to centralize and improve the process we use to handle foreign requests for legal assistance, keeping our high standards for privacy while helping foreign partners fight crime and terrorism.

I have also asked my counselor, John Podesta, to lead a comprehensive review of big data and privacy. And this group will consist of government officials who, along with the President's Council of Advisors on Science and Technology, will reach out to privacy experts, technologists and business leaders, and look how the challenges inherent in big data are being confronted by both the public and private sectors; whether we can forge international norms on how to manage this data; and how we can continue to promote the free flow of information in ways that are consistent with both privacy and security.

For ultimately, what's at stake in this debate goes far beyond a few months of headlines, or passing tensions in our foreign policy. When you cut through the noise, what's really at stake is how we remain true to who we are in a world that is remaking itself at dizzying speed. Whether it's the ability of individuals to communicate ideas; to access information that would have once filled every great library in every country in the world; or to forge bonds with people on other sides of the globe, technology is remaking what is possible for individuals, and for institutions, and for the international order. So while the reforms that I have announced will point us in a new direction, I am mindful that more work will be needed in the future.

One thing I'm certain of: This debate will make us stronger. And I also know that in this time of change, the United States of America will have to lead. It may seem sometimes that America is being held to a different standard. And I'll admit the readiness of some to assume the worst motives by our government can be frustrating. No one expects China to have an open debate about their surveillance programs, or Russia to take privacy concerns of citizens in other places into account. But let's remember: We are held to a different standard precisely because we have been at the forefront of defending personal privacy and human dignity. 


\section{A.2 Anexo 2 - Documento de Anúncio do Clipper Chip, 04/02/1994: Statement of the Press Secretary}

Inteiro teor da transcrição do discurso proferido pelo então Presidente dos Estados Unidos, Barack Obama, em 17/01/2014.

As the nation that developed the Internet, the world expects us to ensure that the digital revolution works as a tool for individual empowerment, not government control. Having faced down the dangers of totalitarianism and fascism and communism, the world expects us to stand up for the principle that every person has the right to think and write and form relationships freely - because individual freedom is the wellspring of human progress.

Those values make us who we are. And because of the strength of our own democracy, we should not shy away from high expectations. For more than two centuries, our Constitution has weathered every type of change because we have been willing to defend it, and because we have been willing to question the actions that have been taken in its defense. Today is no different. I believe we can meet high expectations. Together, let us chart a way forward that secures the life of our nation while preserving the liberties that make our nation worth fighting for.

Thank you. God bless you. May God bless the United States of America. (Applause.)

\section{1:57 A.M. EST THE WHITE HOUSE OFFICE OF THE PRESS SECRETARY} EMBARGOED UNTIL 3 PM (EST) FRIDAY, February 4, 1994

\section{STATEMENT OF THE PRESS SECRETARY}

Last April, the Administration announced a comprehensive interagency review of encryption technology, to be overseen by the National Security Council. Today, the Administration is taking a number of steps to implement the recommendations resulting from that review.

Advanced encryption technology offers individuals and businesses an inexpensive and easy way to encode data and telephone conversations. Unfortunately, the same encryption technology that can help Americans protect business secrets and personal privacy can also be used by terrorists, drug dealers, and other criminals.

In the past, Federal policies on encryption have reflected primarily the needs of law enforcement and national security. The Clinton Administration has sought to balance these needs with the needs of businesses and individuals for security and privacy. That is why, today the National Institute of Standards ant Technology (NIST) is committing to ensure a royalty-free, public-domain Digital Signature Standard. Over many years, NIST has 
been developing digital signature technology that would provide a way to verify the author and sender of an electronic message. Such technology will be critical for a wide range of business applications for the National Information Infrastructure. A digital signature standard will enable individuals to transact business electronically rather than having to exchange signed paper contracts. The Administration has determined that such technology should not be subject to private royalty payments, and it will be taking steps to ensure that royalties are not required for use of a digital signature. Had digital signatures been in widespread use, the recent security problems with the Intemet would have been avoided.

Last April, the Administration released the Key Escrow chip (also known as the "Clipper Chip") that would provide Americans with secure telecommunications without compromising the ability of law enforcement agencies to carry out legally authorized wiretaps. Today, the Department of Commerce and the Department of Justice are taking steps to enable the use of such technology both in the U.S. and overseas. At the same time, the Administration is announcing its intent to work with industry to develop other key escrow products that might better meet the needs of individuals and industry, particularly the American computer and telecommunications industry. Specific steps being announced today include:

- Approval by the Commerce Secretary of the Escrowed Encryption Standard (EES) as a voluntary Federal Informahon Processing Standard, which will enable govemment gencies to purchase the Key Escrow chip for use with telephones nd modems. The department's National Institute of Standards and Technology (NIST) will publish the standard.

- Publication by the Department of Justice of procedurs for the release of escrowed keys and the announcement of NIST and the Automated Services Division of the Treasury Department as the escrow agents that will store the keys needed for decryption of communications using the Key Escrow chip. Nothing in these procedures will diminish tne existing legal and procedural requirements that protect Americans from unauthorized wiretaps.

- New procedures to allow export of products containing the Key Escrow chip to most countries.

In addition, the Department of State will streamline export licensing procedures for encryption products that can be exported under current export regulations in order to help American companies sell their products overseas. In the past, it could take weeks for a company to obtain an export license for encryption products, and each shipment might require a separate license. The new procedures announced today will substantially reduce administrative delays and paperwork for encryption exports.

To implement the Administration's encryption policy, an interagency Working 
Group on Encryption and Telecommunications has been established. It will be chaired by the White House Office of Science and Technology Policy and the National Security Council and will include representatives of the Departments of Commerce, Justice, State, and Treasury as well as the FBI, the National Security Agency, the Office of Management and Budget, and the National Economic Council. This group will work with industry and public-interest groups to develop new encryption technologies and to review and refine Administration policies regarding encryption, as needed.

The Administration is expanding its efforts to work with industry to improve on the Key Escrow chip, to develop key-escrow software, and to examine alternatives to the Key Escrow chip. NIST will lead these efforts and will request additional staff and resources for this purpose.

We understand that many in industry would like to see all encryption products exportable. However, if encryption technology is made freely available worldwide, it would no doubt be usod extensively by terrorists, drug dealers, and other criminals to harm Americans both in the U.S. and abroad. For this reason, the Administration will continue to restrict export of the most sophisticated encryption devices, both to preserve our own foreign intelligence gathering capability and because of the concerns of our allies who fear that strong encryption technology would inhibit their law enforcement capabilities.

At the same time, the Administration understands the benefits that encryption and related technologies can provide to users of computers and telecommunications networks. Indeed, many of the applications of the evolving National Information Infrastructure will require some form of encryption. That is why the Administration plans to work more closely with the private sector to develop new forms of encryption that can protect privacy and corporate secrets without undermining the ability of law-enforcement agencies to conduct legally authorized wiretaps. That is also why the Administration is committed to make available free of charge a Digital Signature Standard.

The Administration believes that the steps being announced today will help provide Americans with the telecommunications security they need without compromising the capability of law enforcement agencies and national intelligence agencies. Today, any American can purchase and use any type of encryption product. The Administration does not intend to change that policy. Nor do we have any intention of restrictiog domestic encryption or mandating the use of a particular technology. 